\title{
Open Innovation: a dynamic capabilities perspective
}

Citation for published version (APA):

Zobel, A. K. (2013). Open Innovation: a dynamic capabilities perspective. [Doctoral Thesis, Maastricht University]. Datawyse / Universitaire Pers Maastricht. https://doi.org/10.26481/dis.20131212az

Document status and date:

Published: 01/01/2013

DOI:

10.26481/dis.20131212az

Document Version:

Publisher's PDF, also known as Version of record

\section{Please check the document version of this publication:}

- A submitted manuscript is the version of the article upon submission and before peer-review. There can be important differences between the submitted version and the official published version of record.

People interested in the research are advised to contact the author for the final version of the publication, or visit the DOI to the publisher's website.

- The final author version and the galley proof are versions of the publication after peer review.

- The final published version features the final layout of the paper including the volume, issue and page numbers.

Link to publication

\footnotetext{
General rights rights.

- You may freely distribute the URL identifying the publication in the public portal. please follow below link for the End User Agreement:

www.umlib.nl/taverne-license

Take down policy

If you believe that this document breaches copyright please contact us at:

repository@maastrichtuniversity.nl

providing details and we will investigate your claim.
}

Copyright and moral rights for the publications made accessible in the public portal are retained by the authors and/or other copyright owners and it is a condition of accessing publications that users recognise and abide by the legal requirements associated with these

- Users may download and print one copy of any publication from the public portal for the purpose of private study or research.

- You may not further distribute the material or use it for any profit-making activity or commercial gain

If the publication is distributed under the terms of Article $25 \mathrm{fa}$ of the Dutch Copyright Act, indicated by the "Taverne" license above, 


\section{Open Innovation:}

A Dynamic Capabilities Perspective 
(C) Ann-Kristin Zobel, Maastricht 2013

All rights reserved. No part of this publication may be reproduced in any form or by any means without prior written consent by the author.

ISBN 9789461592828

Cover Design: Bea Ridder

Printed by: Datawyse 


\title{
Open Innovation:
}

\section{A Dynamic Capabilities Perspective}

\author{
DISSERTATION \\ to obtain the degree of Doctor at \\ Maastricht University, \\ on the authority of the Rector Magnificus, Prof. dr. L.L.G. Soete \\ in accordance with the decision of the Board of Deans, \\ to be defended in public \\ on Thursday 12 December 2013, at 10.00 hours
}

by

Ann-Kristin Zobel

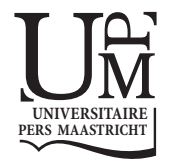




\section{Supervisor:}

Prof. dr. J. Hagedoorn

\section{Assessment Committee:}

Prof. dr. M. Wetzels (voorzitter)

Prof. dr. H.W. Chesbrough, University of California Berkeley, USA

Prof. dr. P. Mohnen 


\section{CONTENTS}

Chapter 1: Dynamic Capabilities for Open Innovation - An Introduc- 1 tion

Introduction 2

An Introduction to Research in Open Innovation 5

Dynamic Capabilities as a Theoretical Perspective 9

Research Questions $\quad 11$

$\begin{array}{ll}\text { Research Design } & 17\end{array}$

$\begin{array}{ll}\text { Dissertation Outline } & 20\end{array}$

Chapter 2: $\quad$ The Fuzzy Front End of Open Innovation - How Firms 21 Identify Opportunities for Open Innovation

Introduction $\quad 22$

$\begin{array}{ll}\text { Theoretical Background } & 24\end{array}$

Methodology 27

Results Section 1: Patterns of Open Innovation Opportunity 32

Identification

Results Section 2: Implications of Patterns of Open Innova- 40

tion Opportunity Identification

Results Section 3: Dynamics of Open Innovation Opportunity 46

Identification

Discussion and Conclusion $\quad 56$

Chapter 3: Conditions of Open Innovation Effectiveness - Internal $\quad 61$ Integrative Capability and External Environmental Factors

Introduction $\quad 62$

Theoretical Background $\quad 64$

Hypotheses $\quad 68$

$\begin{array}{ll}\text { Methodology } & 75\end{array}$ 
$\begin{array}{ll}\text { Results } & 82\end{array}$

$\begin{array}{ll}\text { Discussion } & 88\end{array}$

Limitations and Future Research $\quad 92$

Chapter 4: $\quad$ External Dynamic Capabilities - Creating Competitive 95 Advantage in Innovation via External Resource Renewal

Introduction 96

Conceptualizing External Dynamic Capabilities $\quad 97$

Structural Relationships: External Resource Renewal 109

$\begin{array}{ll}\text { Methodology } & 115\end{array}$

Data Analysis and Results 121

$\begin{array}{ll}\text { Discussion } & 131\end{array}$

$\begin{array}{lll}\text { Chapter 5: } & \text { Discussion and Conclusion } & 137\end{array}$

$\begin{array}{ll}\text { Introduction } & 138\end{array}$

Summary of Main findings $\quad 139$

Implications and Contributions 142

Limitations and Suggestions for Future Research 149

$\begin{array}{ll}\text { Conclusion } & 150\end{array}$

$\begin{array}{ll}\text { References } & 151\end{array}$

$\begin{array}{ll}\text { Summary } & 163\end{array}$

Samenvatting 166

$\begin{array}{ll}\text { Acknowledgements } & 169\end{array}$

$\begin{array}{ll}\text { Biographical Sketch } & 170\end{array}$ 


\section{TABLES}

Table 1.1 Overview of three empirical studies of dynamic capabilities for open innovation

Table 2.1 Case descriptions 30

Table 2.2 External discovery and internal creation of open innovation 33 opportunities

Table 2.3 Dynamics of the open innovation framework 47

$\begin{array}{lll}\text { Table } 3.1 & \text { Survey measurement scales } & 77\end{array}$

Table 3.2 Descriptive statistics and correlation coefficients 83

$\begin{array}{lll}\text { Table } 3.3 & \text { OLS regression results } & 84\end{array}$

Table 4.1 Categorization of existing literature into modes of resource 99 renewal and classes of dynamic capabilities

Table 4.2 Conceptualization of external dynamic capabilities in terms of 104 underlying processes

$\begin{array}{lll}\text { Table 4.3 Survey measurement scales } & 117\end{array}$

Table 4.4 Correlation matrix and reliability of reflective constructs 123

Table 5.1 Contributions to an emerging theory of open innovation 143 



\section{FIGURES}

Figure 2.1 An open innovation framework 43

Figure 2.2 A dynamic open innovation framework 55

$\begin{array}{lll}\text { Figure 3.1 Theoretical framework - internal organizational and external } & 67\end{array}$ environmental conditions of open innovation

$\begin{array}{lll}\text { Figure } 3.2 & \text { a) The moderating effect of transfer capability } & 87\end{array}$

b) The moderating effect of translation capability

c) The moderating effect of technological turbulence

Figure 4.1 Conceptualization of external dynamic capabilities in terms of 109 second-order models

Figure 4.2 Validation of higher order models of external DCs with reflec- 125 tive indicators

Figure 4.3 Structural model of external resource renewal 126

Figure 4.4 Two-groups mediation analysis: high versus low external 129 seizing dynamic capabilities 



\section{CHAPTER 1}

Dynamic Capabilities for Open Innovation

- An Introduction 


\section{INTRODUCTION}

Innovation can be considered as the main mechanism for companies to grow and to create and sustain long-term competitive advantage (e.g. Teece, Pisano, \& Shuen, 1997; Danneels, 2002; Katila \& Ahuja, 2002; Verona \& Ravasi, 2003; Wang \& Ahmed, 2007). Therefore, firms are constantly searching for ways to transform and advance their innovation strategies in order to generate and maintain superior firm performance. Traditionally, firms operated predominantly according to a closed innovation model, which emphasizes internal focus and control of the innovation process. Closed innovation refers to the notion that firms rely mostly on their internal research and development (R\&D) function for launching new research projects and that they employ their own product and process development facilities to bring new innovations to the market (Chesbrough, Vanhaverbeke, \& West, 2006). This implies that the corporate R\&D laboratory constitutes the locus of innovation in which firms explore and exploit their internal technology base (Mowery, 1983).

However, the globalization, volatility and velocity of market and technological developments have recently called for a transformation of the traditional model of closed innovation. More specifically, resources for innovation are becoming increasingly distributed and are changing more frequently (Gassmann \& Enkel, 2004; Davis \& Eisenhardt, 2011), R\&D costs are accelerating while at the same time product life cycles are becoming shorter (Chesbrough, 2007; Drechsler \& Natter, 2012), and improved market institutions such as intellectual property rights, venture capital and technology standards enable organizations to trade their knowledge and ideas (Dahlander \& Gann, 2010). Such economic and technological changes and trends suggest that single firms cannot anymore innovate in isolation (Davis \& Eisenhardt, 2011). Therefore, an alternative approach to managing innovation proposes that firms respond to these developments by opening up their boundaries (Chesbrough, 2003; Chesbrough, Vanhaverbeke, \& West, 2006), combining internally and externally developed knowledge in their innovation processes (Almirall \& Casadesus-Masanell, 2010; Foss, Laursen, \& Pedersen, 2011), and bringing in-house inventions to markets via external paths (Dahlander \& Gann, 2010; Huizingh, 2011). In that context, open innovation can be defined as "the use of purposive inflows and outflows of knowledge to accelerate internal innovation, and expand the markets for external use of innovation, respectively" (Chesbrough, Vanhaverbeke, \& West, 2006, p.1). Hence, by definition, the concept of open innovation includes both outside-in processes to source external knowledge, as well as inside-out processes to leverage external paths to markets.

The idea that firms include external sources of knowledge into their innovation process is, of course, not entirely new. Instead, the concept of innovation can be considered as a continuum between closed forms and more open forms of innovation. Along this continuum of innovation, prior studies can be related to different degrees of openness. For instance, previous literature has studied firms' 
use of strategic alliances (e.g. Mowery, Oxley, \& Silverman, 1996; Powell, Kogut, \& Smith-Doerr, 1996; Hagedoorn \& Duysters, 2002), the co-creation processes between firms and users (e.g. von Hippel, 1976; von Hippel \& Katz, 2002; Bogers, Afuah, \& Bastian, 2010), or the rise of intermediate markets (Arora, Fosfuri, \& Gambardella, 2001). While prior theorizing suggests that firms use some forms of accessing external knowledge, the model of open innovation proposes that the role of this external knowledge has shifted from being supplemental to obtaining a more equal role in a firm's innovation process (Chesbrough, Vanhaverbeke, \& West, 2006). This supports the notion that, instead of speaking of a dichotomy of closed versus open innovation, the idea of open innovation needs to be placed on a continuum, ranging from closed to open, covering different degrees of openness (Dahlander \& Gann, 2010; Huizingh, 2011).

While the traditional model of innovation is based on the logic of internal focus and control and can, therefore, be found at the lower end of the continuum, companies that are adopting an open innovation model embrace a mentality of outside-in and inside-out thinking that builds extensively on external sources of innovation and commercialization (Chesbrough, 2003; Gassmann \& Enkel, 2004; Chesbrough, Vanhaverbeke, \& West, 2006). The core idea is the involvement of diverse actors (e.g. customers, suppliers, universities, competitors, individual inventors, start-up firms, etc) in various flexible ways (e.g. collaborative agreements, crowdsourcing, co-creation, external corporate venturing, out-licensing, technology sales, etc) that transcend beyond the traditional notion of innovation alliances and contract research (Keupp \& Gassmann, 2009). Technical and scientific knowledge and competences that were traditionally developed internally are now accessed from a broad set of external parties, which are flexibly chosen and recombined over time (Almirall \& Casadesus-Masanell, 2010; Chiaroni, Chiesa, \& Frattini, 2011). Likewise, internal knowledge and technology are increasingly commercialized via external paths to markets (Gassmann \& Enkel, 2004; Bianchi et al., 2011; Huizingh 2011). Therefore, firms have relocated to the upper end on the continuum between being closed and open. As a result, the locus of innovation has shifted, since open forms of innovation increasingly crowd out more traditional intra-firm innovation (Elmquist, Fredberg, \& Ollila, 2009; Lakhani \& Tushman, 2012).

By now there is a fair body of research addressing a range of factors deemed crucial in opening up the firm's innovation process. For example, some studies have investigated factors that operate as antecedents of open innovation, such as scarcity of internal resources or characteristics of the firm's product markets (Gassmann \& Enkel, 2004; Keupp \& Gassmann, 2009; Drechsler \& Natter, 2012; Garriga, von Krogh, \& Spaet, 2013). Furthermore, there is a small number of empirical studies researching the extent to which openness leads to increased R\&D and innovation outcomes (Fey \& Birkinshaw, 2005; Laursen \& Salter, 2006; Leiponen \& Helfat, 2010; Knudsen \& Mortensen, 2011; Garriga, von Krogh, \& Spaet, 
2013). Nevertheless, open innovation is still a relatively new phenomenon and, so far, lacks theoretical foundations. Constructs and relationships that help to explain such antecedents and outcomes of open innovation are not yet clearly established. In particular, while a first understanding of antecedents and outcomes of open innovation has been developed, it is less clear how firms create and capture value from open innovation and why they differ in the extent to which they are successful in doing so. Hence, explanatory factors of open innovation are, so far, missing.

This begs the question of how firms develop strategies that enable them to benefit from open innovation approaches, what mechanisms are implemented and how resources are being deployed to support these mechanisms. One approach particularly useful for developing a better understanding of the phenomenon of open innovation and its outcomes is to adopt a capability perspective. Such a perspective deals with the organizational capabilities and processes firms need to develop and deploy in order to create innovations (e.g. Amit \& Schoemaker, 1993; Helfat, 2000; Danneels, 2002; Marsh \& Stock, 2006; Bingham, Eisenhardt \& Furr, 2007). The capabilities required to recombine resources from outside and inside the firm are likely to be different from those found in traditional R\&D settings (Dahlander \& Gann, 2010). These firm-level capabilities may help to explain how and why firms differ in the extent to which they implement open innovation and translate it into positive outcomes. Hence, it is of interest how firms implement open innovation strategies to benefit from external knowledge sources and paths to market and what kinds of capabilities support these strategies. A crucial question refers to how such capabilities create a competitive advantage in innovation in a world in which sources of innovation are increasingly distributed and cannot anymore be kept secret and protected within the firm's boundaries.

In this context, this dissertation adopts a capability perspective in order to develop a better understanding of these aspects of open innovation. In doing so, I marry insights from open innovation research with theories of dynamic capabilities to shed light on relevant capabilities and processes for creating and capturing value from open innovation. In the following four chapters, dynamic capabilities are discussed as crucial mechanisms for adding, shedding, transforming and renewing resources and capabilities in order to be at the forefront of (open) innovation (e.g. Teece, Pisano, \& Shuen, 1997; Eisenhardt \& Martin, 2000). While acknowledging the relevance of purposive inside-out flows, I mostly (with the exception of study one) focus on open innovation in terms of the embracement of external ideas, knowledge, and technologies to accelerate internal innovation processes (Chesbrough, 2003; Almirall \& Casadesus-Masanell, 2010). In the following, I shortly outline the emerging literature stream on open innovation, with a particular focus on outside-in aspects. The discussion of prior open innovation research will reveal some of the gaps in the existing literature, especially with regard to the organizational capabilities that are required for becoming effective at leveraging external sources of innovation and commercialization. I then elucidate how and 
why the dynamic capability perspective can help to shed light on these gaps in the existing open innovation literature. The discussion of theories of dynamic capabilities enables the development of research questions that address these gaps and provide a focus for developing a better understanding of capabilities for open innovation. Finally, I discuss the methodological approach of this dissertation and its unique combination of quantitative and qualitative research in contributing to an emerging theory of open innovation.

\section{AN INTRODUCTION TO RESEARCH IN OPEN INNOVATION}

The emerging conceptual and empirical literature on open innovation can be sketched in terms of four different themes or topics. A first set of studies provides some empirical evidence of firms opening up their boundaries to capture outward and inward knowledge flows. A second topic refers to the conceptualization of openness in terms of firms' breadth and depth in external knowledge search. A similar set of studies discusses to what extent these degrees of openness lead to different performance and innovation outcomes. Finally, a small collection of prior work deals with organizational and managerial challenges that arise due to increasing permeability and openness in the firm's boundaries. Despite these emerging themes and topics and increasing empirical studies, the relatively young literature on open innovation leaves many questions and gaps yet unaddressed.

Recently, empirical evidence and in-depth case studies on the phenomenon of open innovation have started to accumulate. A first, more practice-oriented literature stream reveals that firms across industries are increasingly opening up their innovation processes (Kirschbaum, 2005; Chesbrough \& Crowther, 2006; Dodgson, Gann, \& Salter, 2006; Huston \& Sakkab, 2006; Rohrbeck, Hölzle, \& Gemünden, 2009). Internal and external conditions, such as internal impediments to innovation (Keupp \& Gassmann, 2009) and product and industry characteristics (Gassmann \& Enkel, 2004) were found to influence a firm's decision to open up its boundaries. Most importantly, scarcity of internal resources and constraints in the application of these resources shape the firm's need to search more broadly for knowledge in the external environment (Keupp \& Gassmann, 2009; Drechsler \& Natter 2012; Garriga, von Krogh, \& Spaet, 2013). These antecedents to open innovation suggest that firms differ in the extent to which they open up their boundaries to become more permeable for inflows and outflows of knowledge and technology (Dahlander \& Gann, 2010; Huizingh, 2011).

Differences in firms' degrees of openness indicate that they face strategic choices regarding the extent to which they open up their innovation process and adopt different open innovation practices (Drechsler \& Natter, 2012; Lakhani \& Tushman, 2012). Prior work suggests that the degree of a firm's openness is determined by two aspects. First, the breadth of openness specifies to what extent firms 
access different external knowledge sources, including customers, suppliers, competitors, universities, start-up companies, innovation intermediaries, individual inventors, and other firms (Laursen \& Salter, 2006; Bahemia \& Squire, 2010; Leiponen \& Helfat, 2010). Second, the depth of openness refers to how deeply or intensively firms draw from these different external knowledge sources (Laursen \& Salter, 2006, Drechsler \& Natter, 2012). Hence, depth refers to the importance of external knowledge sources for the focal firm's innovative activities. These two dimensions describe a firm's effort to search beyond its organizational boundaries for external knowledge required to innovate (Garriga, von Krogh, \& Spaet, 2013). Jointly, breadth and depth can be characterized as a firm's degree of openness and both are likely to have an effect on the extent to which the firm's overall open innovation strategy leads to positive innovation outcomes.

A few studies have addressed performance implications of open innovation and yielded interesting findings. For instance, while it was shown that large networks of flexible partnerships can be highly beneficial for the firm (Almirall \& Casadesus-Masanell, 2010) and that collaboration constitutes a crucial determinant of high innovation performance (Herstad et al., 2008), empirical studies also indicate that the breadth and depth of a firm's external search strategies are not linearly related to innovative performance (Laursen \& Salter, 2006; Huang, Rice, \& Galvin, 2009). Instead, curve-linear relationships were established which demonstrate that openness does not always automatically accelerate a firm's internal innovation capacity. In addition, both the type and the overall quantity of modes of openness can create positive, negative and insignificant outcomes (Huang, Rice, \& Galvin, 2009; Knudsen \& Mortensen, 2011). Furthermore, numerous managementoriented case studies have discussed firms that excel at implementing open innovation (e.g. Huston \& Sakkab, 2006; Rohrbeck, Hölzle, \& Gemünden, 2009; Kirschbaum, 2005) and firms that are less successful in capitalizing on open innovation strategies (Chesbrough, 2003). These differential performance outcomes are striking and raise questions regarding where these differences stem from.

One root cause of these differences lies in the challenges that firms, relying on external sources of innovation, experience when they try to identify the most valuable innovations in the external environment (West \& Bogers, 2013). Firms need to put effort into finding appropriate external knowledge sources and broadening the scope of partners (Birkinshaw \& Monteiro, 2007; Elmquist, Fredberg, \& Ollili, 2009; Chiaroni, Chiesa, \& Frattini, 2011). They differ in their abilities to identify, screen, and evaluate external inputs and outputs of the innovation process, as they face substantial barriers in their search processes. On the one hand, search and decision processes are likely to become subject to consistent patterns of collaboration over time due to socialization (Dahlander \& Gann, 2010). On the other hand, firms may engage in 'over-search', managing too many external relations that are not anymore relevant for the organizational context (Laursen \& Salter, 2006; Katila \& Ahuja, 2002). Hence, search strategies and the identification and recogni- 
tion of relevant and valuable external knowledge sources represent a significant organizational challenge in the open innovation process.

In addition, the identification and acquisition of external resources does not necessarily mean that firms can integrate them into their existing innovation processes (Huang, Rice, \& Galvin, 2009). As a result, a further challenge in the open innovation context refers to the actual integration of external knowledge or technology (Huang, Rice, \& Galvin, 2009; Birkinshaw, Bessant, \& Delbridge, 2007). Firms need to be able to absorb the knowledge contained in external sources and integrate it into their own internal innovation processes (Wang \& Ahmed, 2007; Zahra \& George, 2002). To achieve this, firms need to overcome implementation stickiness, which refers to difficulties experienced between the decision to source external knowledge and the start of actual use (Szulanski, 2000). External elements may be documented in a way that makes them inappropriate for internal use (Marsh \& Stock, 2006) or difficult to harmonize and align with internal knowledge sources. Furthermore, negative behavioral responses to external elements may need to be overcome, which is referred to as the 'Not-Invented-Here' syndrome (Katz \& Allen, 1982; Sieg, Wallin, \& von Krogh, 2009; Chesbrough \& Crowther, 2006; West \& Gallagher, 2006). In sum, organizational challenges of open innovation are particularly related to the identification and integration of external knowledge sources.

Despite the importance of these organizational challenges, only few studies discuss how firms can tackle the demanding tasks of implementing open innovation and managing collaborative innovation efforts. For instance, Davis and Eisenhardt (2011) study the processes by which some technology collaborations generate innovations while others do not. However, this study adopts the partnership as the unit of analysis and, therefore, has little implications for how an individual firm can benefit from increasing collaborative innovation processes. At the firm level Foss, Laursen and Pedersen (2011) examine internal organizational practices that support firms in leveraging user and customer knowledge in the context of open innovation. They find that delegation of decision rights increases the likelihood that external knowledge is brought into the firm, while communication and incentive systems help to ensure that this knowledge is disseminated and utilized inside the firm. Yet, this study focuses exclusively on user and customer knowledge and does not investigate a firm's broader open innovation strategy that incorporates a much more diverse set of external knowledge sources. In general, prior work in related literature streams typically studies capabilities and practices for isolated collaborative innovation activities, such as alliances and acquisition, but does not consider a broader portfolio of activities that characterize an open innovation strategy (e.g. Karim \& Mitchell, 2000; Capron, Mitchell, and Swaminathan, 2001; Capron \& Anand, 2007; Dyer \& Kale, 2007; Sarkar, Aulakh, \& Madhok, 2009). Finally, Petroni, Venturini and Verbano (2012) provide some anecdotal evidence that the adoption of open innovation influences the organizational structures of $R \& D$ and the ways 
firms manage their R\&D personnel. In particular, they find that matrix and network organizational models, as well as central personnel that are able to select and integrate external knowledge and expertise, are becoming increasingly important in an open innovation context.

Despite these important insights, these studies shed only little light on the organizational challenges of identification and integration of external knowledge sources in an open innovation context. An explanation of how and why firms differ in overcoming these challenges and becoming effective at open innovation is still lacking. There is a gap in understanding how firms can identify valuable opportunities for open innovation and how they translate the open innovation concept into positive innovation outcomes. In particular, it is unclear how these opportunities and outcomes can be achieved by means of organizational capabilities. Little is known about the capabilities and processes that enable external resources to flow into and out of the organization and facilitate the effective utilization of these resources across the firm's boundaries. Furthermore, as resources are externally available and transferable in an open innovation context, it remains questionable how open innovators, leveraging such external resources, can create an innovationbased competitive advantage. If resources are widely accessible, how can a firm differentiate its innovative performance from relevant competitors?

To shed light on this issue, this dissertation looks into the underlying capabilities that firms develop and deploy in order to effectively tap into diverse external knowledge sources and leverage them to create a competitive advantage in innovation. The three empirical studies in this dissertation are based on the fundamental assumption that the dynamic capabilities view serves as an appropriate theoretical foundation for addressing these issues. As open innovation deals with the transfer of resources and the acceleration of innovation capabilities, the dynamic capabilities view can help to explain how such resource transfer and change in capabilities can be achieved. The dynamic capabilities view focuses on the capacity of organizations to address rapidly changing environments and to create, integrate, and reconfigure resources and capabilities (e.g. Teece, Pisano, \& Shuen, 1997; Eisenhardt \& Martin, 2000; Helfat et al., 2007; Teece, 2007). Therefore, I argue that in dynamic markets in which companies may be forced to open up their boundaries, the dynamic capabilities by which firms access, transfer, combine, and integrate external resources, become the main source of open innovation performance. These dynamic capabilities are driven by organizational processes that are firm-specific and can, therefore, contribute to an explanation of how firms obtain an innovationbased competitive advantage in a more open environment where resources are widely available and transferable. In the following, I will shortly outline the dynamic capabilities realm, which serves as a theoretical foundation of this dissertation. 


\section{DYNAMIC CAPABILITIES AS A THEORETICAL PERSPECTIVE}

The dynamic capabilities perspective represents a recent extension to the resourcebased view (RBV) of the firm to address the constant pursuit of adding, shedding, renewing and reconfiguring resources and capabilities in rapidly changing environments (e.g. Teece, Pisano, \& Shuen, 1997; Eisenhardt \& Martin, 2000; Helfat et al., 2007; Teece, 2007). According to the RBV, firms can be conceptualized as bundles of resources and operational capabilities (Barney, 1991). Resources are any firm-specific assets that are owned or controlled, while operational capabilities are used by the firm to deploy these resources on a day-to-day basis (Amit and Schoemaker, 1993). More recently, the concept of dynamic capabilities was introduced to address the static nature of the RBV and to extend its applicability to the context of turbulent and dynamic environments (Teece, Pisano, \& Shuen, 1997). While the RBV fails to explain how firms can adapt to and remain competitive in changing environments, dynamic capabilities deal with the continuous upgrading of the firm's knowledge-based assets and other resources. They refer to "the capacity of an organization to purposefully create, extend, or modify its resource base." (Helfat et al., 2007, p.1) Thereby, they aim at integrating, building, and reconfiguring internal and external resources and competencies in order to adapt to changing environments and to remain competitive in the long term (Montealegre, 2002).

Dynamic capabilities are enabled by path dependent processes that are built and embedded in firms to change the existing resource base (e.g. Zahra, Sapienza, \& Davidsson, 2006; Ambrosini \& Bowman, 2009). While dynamic capabilities have certain commonalities (Eisenhardt \& Martin, 2000; Wang \& Ahmed, 2007) they are still heterogeneously distributed across firms (Galunic \& Eisenhardt, 2001) and their complex and intangible nature makes them difficult to transfer or imitate (Collis, 1994; Pitelis \& Teece, 2010). Hence, dynamic capabilities can be assumed to constitute a source of competitive advantage, if they adequately change the resource base, particularly in turbulent and high-velocity environments (Zollo \& Winter, 2002; Zott, 2003; Helfat et al., 2007).

Existing literature offers different definitions, classifications and conceptualizations of dynamic capabilities. Eisenhardt and Martin (2000), for instance, suggest that dynamic capabilities (1) acquire and shed resources, (2) integrate, and (3) recombine them. Similarly, Verona and Ravasi (2003) differentiate between knowledge creation/absorption, knowledge integration, and knowledge reconfiguration as underlying mechanisms of dynamic capabilities. Wang and Ahmed (2007) define three components of dynamic capabilities, including adaptive, absorptive and innovative capability. Similarly to the components-approach, Barreto (2010) proposes different dimensions of dynamic capabilities that entail sensing opportunities and threats, making timely and market-oriented decisions and changing the resource base. Finally, Teece (2007) conceptualized three classes of dynamic capabilities at the most aggregate and comprehensive level. Firms exhibiting 
dynamic capabilities effectively sense and shape opportunities, address these opportunities by seizing them, and continuously reconfigure themselves as markets and technologies change (Teece, 2007). While these disaggregrations, classes, and components demonstrate fine-grained differences in the definition and conceptualization of dynamic capabilities, they can be summarized in terms of Teece's terminology as the abilities to (1) sense and shape opportunities, (2) to seize these opportunities, and (3) to maintain competitiveness through enhancing, combining, and reconfiguring intangible and tangible assets. I use this classification as a definition of dynamic capabilities throughout this dissertation.

First, sensing dynamic capability refers to the mobilization of requisite resources and organizational infrastructure to generate opportunities for creating, acquiring, or shedding resources (Katkalo, Pitelis, \& Teece, 2010). Second, seizing dynamic capability refers to how firms capture value from these opportunities by means of appropriate integration, and absorption. Finally, reconfiguring dynamic capability describes how resources are continuously recombined as markets and technologies change. Recent research suggests that firms can sense, seize and reconfigure opportunities for resource alterations internally or externally (Di Stefano, Peteraf, \& Verona, 2010). Internally, new resources or capabilities can be created or built by means of entrepreneurial efforts (Helfat \& Peteraf, 2003; Zahra, Sapienza, \& Davidsson, 2006; Helfat et al., 2007) or existing resources can be leveraged and recombined for new applications or product categories (Kogut \& Zander, 1996; Danneels, 2010). Externally, resources can be accessed by sensing opportunities in the outside environment (Zahra \& George, 2002; Teece, 2007; Barreto, 2010), acquiring and integrating external resources (Eisenhardt \& Martin, 2000; Verona \& Ravasi, 2003), and absorbing external information (Wang \& Ahmed, 2007).

Adopting an external perspective, dynamic capabilities can be applied to the context of open innovation and explain how firms sense, seize and reconfigure external sources of innovation and commercialization to create a competitive advantage in innovation. Both open innovation and dynamic capabilities concern strategic responses to rapidly changing environments and a transformation of resources and capabilities. Their interface lies in their focus on the acquisition of external resources in order to alter and transform the firm's internal resources and be at the forefront of innovation. Both approaches emphasize the significance of knowledge resources and discuss interorganizational knowledge transactions as an important means to extend a firm's internal knowledge base. As a consequence, this dissertation starts with the basic assumption that specific dynamic capabilities constitute the underlying mechanisms of how companies can adapt and change their innovation model into a more open form. In order to investigate the role of dynamic capabilities in the context of open innovation, I examine how they can be disaggregated and what specific types, parts, or components of dynamic capabilities can help to explain how firms create and capture value from openness in innova- 
tion. The following section introduces the overall research question of this dissertation and explains the different sub-questions and foci of the respective chapters.

\section{RESEARCH QUESTIONS}

The objective of this dissertation is to provide a better understanding of the dynamic capabilities firms develop and deploy in order to become effective at open innovation. To structure this dissertation I use some organizing mechanisms that are illustrated in table 1.1. First, in order to address the overall objective of this dissertation, I examine two different stages of the open innovation process. One the one hand, I investigate the dynamic capabilities that support value creation in an open innovation context. Value creation refers to the extent to which firms create and shape opportunities for open innovation and enlarge their own resource base by gaining access to external sources of innovation and commercialization. As firms develop dynamic capabilities for identifying and recognizing appropriate opportunities for accessing and shedding resources, value creation will also increase. On the other hand, I examine how firms can capture value from open innovation. In this context, I understand value capture as firms' efforts to nurture externally accessed resources and disseminate and utilize them within their own firm boundaries. Furthermore, value capture deals with the extent to which firms apply isolating mechanisms in order to preserve the value of these resources. Hence, with respect to this second phase of the open innovation process, this dissertation aims at investigating dynamic capabilities that determine to what extent firms can capture value from their openness in innovation and how they can translate openness into positive innovation outcomes. Combining the notion of value creation and value capture, the overarching research question of this dissertation is as follows:

How and why do dynamic capabilities explain how firms create and capture value from open innovation?

In addressing this overarching research question, I implemented three separate empirical studies that address various facets of value creation and value capture from open innovation by means of dynamic capabilities. Table 1.1 displays the different foci of these studies. As discussed above and outlined in the overarching research question, one structural mechanism for this dissertation is constituted in 


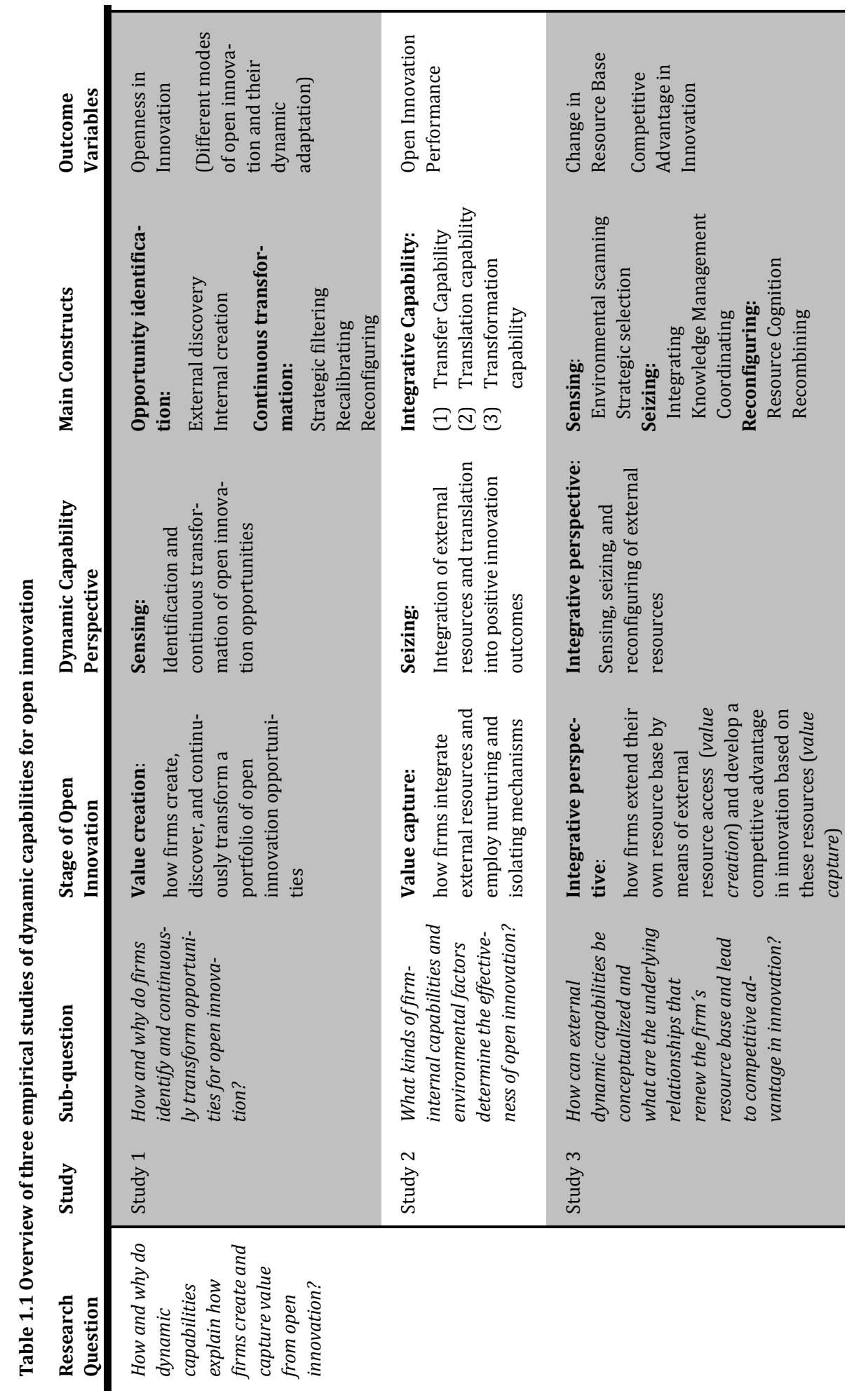


the differentiation between value creation and value capture in the open innovation process. The second structural or organizing mechanism refers to the disaggregation of dynamic capabilities in terms of sensing, seizing, and reconfiguring. On the one hand, sensing dynamic capabilities deal with how firms identify and shape opportunities for open innovation and thereby, concern value creation. On the other hand, seizing and reconfiguring dynamic capabilities shed light on how firms address these opportunities by integrating and recombining externally accessed resources in the context of open innovation. Thereby, they concern value capture rather than value creation. As revealed in table 1.1 the three studies place a different emphasis on these classes of dynamic capabilities in accordance to their focus on value creation and value capture. In the following, the three studies are introduced in more detail.

\section{Study 1 - The Fuzzy Front End of Open Innovation: How Firms Identify Oppor- tunities for Open Innovation}

The first chapter deals with antecedents of open innovation and investigates the generative mechanisms by which firms create open innovation initiatives and put them into practice. So far, little is known about how firms organize search for external knowledge and commercialization and how opportunities for open innovation are identified and recognized, in the first place. This gap in the open innovation literature is significant, since firms seem to differ substantially in their abilities to identify external knowledge sources (Laursen \& Salter, 2006). As discussed above, a major challenge for firms relying on external sources of innovation is to effectively identify the most valuable innovations (Birkinshaw \& Monteiro, 2007; Elmquist, Fredberg, \& Ollili, 2009; Chiaroni, Chiesa, \& Frattini, 2011; West \& Bogers, 2013). Due to these challenges firms are likely to have heterogeneous abilities for identifying, screening, and evaluating external inputs and outputs of the innovation process. If most firms differ in the extent to which they identify and adjust opportunities for open innovation, the question arises where do these capabilities come from? To address this gap, this study explores the process of opportunity identification for open innovation. More specifically, it addresses the following research question:

How and why do firms identify and continuously transform opportunities for open innovation?

This exploratory study deals with how firms create and shape opportunities for open innovation. On the one hand, this corresponds to value creation in the open innovation process, as demonstrated in table 1.1. This study aims at providing insights into the origins of open innovation strategies and at shedding light on how firms carry out search and identify opportunities in an open innovation context. The purpose of this paper, therefore, is to develop a better understanding of the 
fuzzy front end of the open innovation process that deals with value creation. On the other hand, this study shows that firms require dynamic capabilities in order to become effective in this search process. According to table 1.1, this corresponds to the dynamic capability to 'sense' opportunities for gaining access to new resources or shedding resources via external paths to markets. In addition to the dynamic capabilities perspective, this study draws from theories of strategic entrepreneurship, as they provide an additional valuable perspective on the concept of opportunity identification. By drawing on the dynamic capabilities and strategic entrepreneurship literatures and implementing a case study research design, this study (1) disentangles patterns of opportunity identification through which firms shape their open innovation strategies, (2) examines the implications of such opportunity identification patterns for a portfolio of open innovation activities, and (3) sheds light on how opportunities for open innovation are continuously transformed. As table 1.1 shows, it develops new theoretical constructs of open innovation opportunity identification (external discovery and internal creation) and the continuous transformation (strategic filtering, recalibrating, reconfiguring) of these opportunities. In addition, new relationships are developed that explain how these new constructs of opportunity identification generate different modes of openness and how these modes are being continuously transformed.

The main contribution of this study is a better understanding of how and why firms differ in identifying and recognizing opportunities for open innovation. By identifying patterns of opportunity identification and a set of dynamic capabilities firms employ to continuously transform their open innovation opportunities, this study sheds some light on the variations in the degree to which firms effectively identify and refresh a portfolio of external sources of innovation.

\section{Study 2 - Conditions of Open Innovation Effectiveness: Internal Integrative Capability and External Environmental Factors}

As table 1.1 displays, study two investigates the conditions under which openness in innovation is most effective. While differential outcomes of open innovation have been established in the literature (e.g. Laursen \& Salter, 2006; Almirall \& Casadesus-Masanell, 2010; Knudsen \& Mortensen, 2011), it is currently lacking explanations for such diverse effects. In other words, it is less clear why firms differ in capturing value from openness in innovation and which conditions facilitate such value capture. In order to shed light on this issue, I study internal organizational and external environmental characteristics that support the effectiveness of openness in innovation. Therefore, the research question of this study is as follows:

What kinds of firm-internal capabilities and environmental factors determine the effectiveness of open innovation? 
This study focuses on value capture rather than value creation, since it deals with the extent to which firms can reap benefits from their openness in innovation (see table 1.1). Hence, it adopts a value capture perspective of open innovation to develop a better understanding concerning how firms can translate their open innovation strategies into positive innovation outcomes. To shed light on why firms differ in their abilities to capture benefits from openness in innovation, I investigate how open innovation can be facilitated and supported by various internal and external conditions.

In terms of dynamic capabilities, this study deals with how firms 'seize' opportunities arising from openness in innovation. As demonstrated in table 1.1, I investigate how firms address opportunities from open innovation and translate them into positive outcomes. In particular, this study proposes that resource integration, in addition to resource access is critical. Hence, a fundamental dynamic capability to seize opportunities from open innovation is constituted in the firm's integrative capability. This integrative capability is reflected in terms of three dimensions that deal with knowledge transfer, knowledge translation and knowledge transformation. These underlying dimensions of a firm's integrative capability partly determine how productively it can manage knowledge resources across boundaries.

However, integrative capability cannot be treated in isolation but has to be considered jointly with the external environment that the firm is operating in. Prior work has shown that firms are more likely to innovate when they face specific environmental conditions (Brown \& Eisenhardt, 1997). Hence, in order to complement the capability perspective and avoid treating the firm in isolation, this study also takes external environmental factors into account. Jointly, internal integrative capability and external environmental factors are suggested to influence to what extent openness in innovation leads to increased open innovation performance, which constitutes the outcome variable of interest in this study.

This study contributes to an emerging theory of open innovation by providing a more differentiated picture concerning the conditions that make openness in innovation effective. The main findings reveal that increasing access to external knowledge sources leads to enhanced open innovation performance, particularly when firms possess strong integrative capabilities and operate under environmental circumstances of high technological turbulence. The findings shed some light on why some firms are benefiting more from open innovation than others. 


\section{Study 3 - External Dynamic Capabilities: Creating Competitive Advantage in Innovation via External Resource Renewal}

In light of the shift towards open innovation, a crucial question refers to how firms can renew their resource base and create a competitive advantage in innovation by tapping into these external sources. This requires a more holistic perspective of dynamic capabilities for open innovation that studies the entire process from resource access to resource integration and recombination. To shed light on this process of external resource renewal, two specific objectives are addressed in the third study. First, this study aims at developing the theory of dynamic capabilities by further conceptualizing and operationalizing dynamic capabilities for sensing, seizing, and reconfiguring external resources. Second, this paper aims at developing a more fine-grained understanding of the underlying relationship that explain how external dynamic capabilities enable resource renewal and lead to competitive advantage in innovation. Hence, the research question of this study can be phrased as follows:

How can external dynamic capabilities be conceptualized and what are the underly-

ing relationships that renew the firm's resource base and lead to competitive advantage in innovation?

As table 1.1 illustrates, study three adopts an integrative perspective of value creation and value capture by examining the process of external resource renewal. On the one hand, external resource renewal refers to how firms gain access to new external resources and, thereby create value by enlarging their own internal resource base. On the other hand, external renewal deals with how firms translate this external resource access into superior internal operational capabilities and competitive advantage in innovation. This latter aspect deals with the extent to which firms capture value from external resource access. In line with this integrative perspective, this study also adopts a more holistic dynamic capabilities perspective. In particular, in study three I simultaneously consider all three classes of dynamic capabilities, including sensing dynamic capability (in terms of environmental scanning and strategic selection), seizing dynamic capability (in terms of integrating, coordinating, and knowledge management), and reconfiguring dynamic capability (in terms of resource cognition and recombining). Compared to studies 1 and 2 that investigate antecedents of openness and moderators of open innovation performance, this study examines changes in the firm's resource base and investigates competitive advantage in innovation as the main outcome variables of interest.

The main contribution of this study is that it develops and empirically explores new constructs of external sensing, seizing, and reconfiguring dynamic capabilities, and the relationships between these constructs, the resource base, and competitive advantage in innovation. The analysis shows that a more complex chain of relationships explains how these external dynamic capabilities renew 
specific components of the resource base and create competitive advantage in innovation. These findings further reveal that competitive advantages rests to a large extent on these three classes of external dynamic capabilities, which enable firms to sense opportunities for accessing new external resources, seize these resources, and reconfigure them internally. Surprisingly, the results show that external resource renewal is detrimental unless firms deploy external seizing dynamic capabilities. Therefore, this study adds to an explanation why firms differ in creating value from external resources or, in other words, why some firms are more effective at open innovation than others. As a consequence, this study adds to the dynamic capabilities view and contributes to an emerging theory of open innovation by providing more refined constructs and relationships.

\section{RESEARCH DESIGN}

In the following, I explain the multi-strategy research design of this dissertation and discuss to what extent the empirical studies in this dissertation incorporate both exploratory and confirmatory research designs. This combination allows the generation and development of new constructs and relationships, as well as first empirical tests of some theoretical conjectures. Multi-strategy research nearly always entails the collection and analysis of both quantitative and qualitative data (Bryman, 2006). I will show how qualitative and quantitative data collection and analysis complement each other in this dissertation and lead to a more complete investigation of the phenomenon of open innovation.

Since open innovation is a relatively new phenomenon, a clear set of constructs and relationships is just starting to emerge. This immature stage of theory may require an 'in-depth' description and examination of the phenomenon (Yin, 2009). This calls for exploratory research designs that aim at generating and refining new constructs and relationships and, thereby, allow theory building. At the same time, however, there are various theoretical antecedents to open innovation that can partly inform this new phenomenon. Since open innovation is understood as various forms of relationships with external actors, it is closely related to a broader discussion of the boundaries of the firm and external technology sourcing (e.g. Nelson \& Winter, 1982; Cohen \& Levinthal, 1990; Dahlander \& Gann, 2010), the alliance literature (e.g. Powell, Kogut, \& Smith-Doerr, 1996; Hagedoorn \& Duysters, 2002), or the literature on dynamic capabilities that deals with the acquisition, integration, and reconfiguration of knowledge inside or outside the firm's boundaries (e.g. Teece, Pisano, \& Shuen, 1997; Eisenhardt \& Martin, 2000; Helfat et al., 2007). The dynamic capabilities literature, in particular, provides some preliminary constructs relevant for open innovation, such as the classification of sensing, seizing and reconfiguring. Additionally, it suggests some tentative relationships between these constructs, the firm's resource base and innovation outcomes. These tentative constructs and relationships from related literature can be used for 
conducting more confirmatory investigations of the phenomenon of open innovation that test preliminary theoretical conjectures. Therefore, the research field of open innovation may benefit from both exploratory as well as more confirmatory research designs.

The choice between exploratory versus confirmatory research designs is largely dependent on the research question(s) of the underlying study (Yin, 2009). Different research questions need to be answered in terms of different research designs. Exploratory research designs are most applicable for questions that deal with 'how and why' questions; they are appropriate for questions that aim at generating new constructs and relationships. Study one deals with such a question as it aims at investigating how and why firms identify and continuously transform opportunities for open innovation. So far, research on open innovation has mainly evolved around how openness influences a firm's ability to innovate (Dahlander \& Gann, 2010), while the antecedents to these open innovation activities have remained underexplored. Given limited prior theory and empirical research on the opportunity identification stage of open innovation, an exploratory research design is most suitable for this kind of question. Hence, study one is exploratory and focuses on theory building by introducing new constructs and exploring previously unaddressed relationships (Colquitt \& Zapata-Phelan, 2007; Edmondson \& McManus, 2007).

Confirmatory research, in contrast, tests a priori hypotheses derived from prior theory. In other words, existing theory is applied in an empirical study as a means of grounding a specific set of a priori hypotheses (Punch, 2005). Study two is most heavily based on prior constructs and relationships. It develops the research question of what kinds of firm-internal capabilities and environmental factors determine the effectiveness of open innovation. In addressing this research question, this study draws heavily from prior constructs and relationships in the dynamic capabilities realm, with a particular focus on integrative capabilities. Furthermore, it aims at accounting for variance in open innovation effectiveness by systematically examining the influence of conditional factors. Therefore, it is to be seen more as a confirmatory study. Study three presents some conceptual work that qualifies previous constructs and relationships, but also engages in some first empirical investigation and testing of these constructs and relationships. It deals with the conceptualization of external dynamic capabilities and the underlying relationships that renew the firm's resource base and lead to competitive advantage in innovation. Hence, in studies two and three I use confirmatory research designs to test theoretical propositions that are grounded in conceptual arguments from related literatures. The emphasis on confirmatory research helps to sketch the contours or dimensions of the phenomenon of open innovation (Punch, 2005).

To implement these exploratory and confirmatory research designs, I employ both quantitative and qualitative data collection and analysis methods. Even 
though exploratory research should not be equated with qualitative research and confirmatory does not necessarily need to be conducted in terms of quantitative research, qualitative data is typically used for theory building, while quantitative analysis is more suitable for theory testing. Quantitative and qualitative approaches to empirical research reveal important differences in data collection and analysis, but they also share some similarities in the underlying logic that drives both types of empirical inquiry (Punch 2005). Furthermore, neither approach is always superior to the other and both approaches are needed in strategic management research. Two important reasons for combining quantitative and qualitative research in this dissertation refer to complementarity and completeness, which will be explained next.

First of all, the two approaches complement each other, since qualitative research is typically case-oriented, whereas quantitative research is first and foremost variable-oriented (Miles \& Huberman, 1994). On the one hand, qualitative approaches deal with cases and are, therefore, more sensitive to context and process (Punch 2005). Qualitative research aims at in-depth and holistic understanding and is well able to deal with the complexities of the phenomenon of open innovation. In study one of this dissertation open innovation is studied holistically and in its context by collecting rich qualitative data on the basis of a multiple case study research design. Furthermore, systematic analysis of qualitative data is particularly helpful for creating new constructs and patterns for a relatively new phenomenon of interest (Edmondson \& McManus, 2007). Based on qualitative data analysis I develop new constructs and relationships for the phenomenon of open innovation, with a specific focus on the opportunity identification process.

The quantitative approach, on the other hand, conceptualizes reality in terms of variables and relationships between these variables (Miles \& Huberman, 1994). Since quantitative analysis rests on measurement, it requires the prestructuring of data, and usually research questions, conceptual frameworks and design as well (Punch, 2005). Studies two and three are based on such prestructured conceptual frameworks and develop a priori hypotheses. These studies aim at explaining variance and finding probabilistic relationships amongst variables of open innovation and dynamic capabilities. Quantitative data analysis enables me to make standardized comparisons and permits overall descriptions of the phenomenon of open innovation in a more systematic and comparable way. In studies two and three I conduct quantitative data analysis, based on survey research, in order to provide such a systematic analysis of the phenomenon of open innovation.

A further benefit of combining quantitative and qualitative research approaches refers to obtaining completeness in researching a certain phenomenon. Completeness refers to the notion that the researcher can bring together a more comprehensive account of the area of enquiry - open innovation - if both quantita- 
tive and qualitative research are employed (Bryman, 2006). Qualitative research provides better contextual understanding, while quantitative research leads to higher generalizability and external validity of findings and can demonstrate broad and systematic relationships among variables. Hence, by combining quantitative and qualitative research I aim at achieving greater completeness in researching the phenomenon of open innovation.

\section{DISSERTATION OUTLINE}

The remainder of this dissertation is structured as follows. Chapters 2,3 , and 4 deal with one of the three research questions respectively. Chapter 2 explains the exploratory empirical study that deals with the generative mechanisms of open innovation that lead to opportunity identification and transformation. Chapter 3 deals with the conditional perspective of open innovation that explicates when openness in innovation is most effective. Chapter 4 presents the integrative or holistic perspective of external resource renewal. All three empirical chapters are fully self-contained and so all information relevant to individual chapters is included in each of these chapters. Chapter 5 revisits the overall research question; it summarizes the main findings of these three studies and discusses their implications in terms of theory and practice. Finally, some limitations of this dissertation are laid out and directions for future research are given. 


\section{CHAPTER 2}

\section{The Fuzzy Front End of Open Innovation \\ - How Firms Identify Opportunities for Open Innovation ${ }^{1}$}

While recent research discusses the management and outcomes of various open and collaborative forms of innovation, little is known about how firms identify opportunities for open innovation. Based on an exploratory empirical study this chapter sheds some light on this fuzzy front end of open innovation. Iterating between multiple case study analysis and the dynamic capabilities and strategic entrepreneurship literature, new theoretical constructs and relationships are developed that help to explain how firms identify and refresh opportunities for open innovation. First, this study identifies two key dimensions (external discovery and internal creation) that describe the opportunity identification process for open innovation. Second, based on these dimensions, four distinct modes of open innovation (complementary, entrepreneurial, exploratory and strategic) are derived that capture some of the variance that exists when firms create and discover opportunities for open innovation. Third, this study introduces three dynamic patterns (strategic filtering, recalibration, and reconfiguration) that explain how firms continuously adapt their open innovation opportunity set in order to increase external and internal fit. This study contributes to the open innovation literature by discussing an emerging framework that provides rich insights into how firms create, discover, and refresh a portfolio of open innovation opportunities.

\footnotetext{
${ }^{1}$ I would like to thank John Hagedoorn for his helpful comments and useful suggestions. I also appreciate the helpful comments by Keld Laursen and conference participants at the DRUID-DIME Winter Conference 2011, as well as seminar participants at Maastricht University, on earlier versions of this paper. I am also grateful to the managers in the four case firms who agreed to participate in this study as key informants and who provided valuable insights.
} 


\section{INTRODUCTION}

A view of corporate innovation that emphasizes inflows and outflows of knowledge and the creation of value across organizational boundaries is emerging (Chesbrough, 2003; Chesbrough, Vahanverbeke, \& West, 2006). In increasingly dynamic business environments in which resources are highly distributed across multiple institutions and are frequently changing it is unlikely that single firms can consistently innovate (Davis \& Eisenhardt, 2011; Dahlander \& Gann, 2010). While internal $R \& D$ remains important, the spotlight in this changing innovative landscape swings to open models of innovation. Firms increasingly attempt to improve their innovation capacity by tapping into sources of external knowledge and utilizing external paths to commercialization (e.g. Chesbrough, 2003; Laursen \& Salter, 2006; Foss, Laursen, \& Pedersen, 2011; Garriga, von Krogh, \& Spaeth, 2013). As opposed to the closed innovation model that relies predominantly on the firm's internal $R \& D$ and product or process development facilities, the central notion of the open innovation view is the combination of diverse external innovation sources (e.g. customers, suppliers, universities, individual inventors, etc.) in various flexible ways (e.g. collaborative agreements, crowdsourcing, co-creation, external corporate venturing, etc.). Broadly defined, open innovation refers to outside-in flows of knowledge to accelerate internal innovation processes, as well as inside-out flows of knowledge and technology via alternative paths to commercialization, such as out-licensing, spin-offs, or technology sales (Chesbrough, Vanhaverbeke, \& West, 2006).

A growing number of empirical studies has examined the phenomenon of open innovation. These studies mainly analyze explanatory factors that lead to different outcomes of open innovation, including positive effects of open business models on investor perceptions (Alexy \& George, 2012), the influence of different governance modes for external $\mathrm{R} \& \mathrm{D}$, along with openness to new ideas and codifiability of knowledge on R\&D performance (Fey \& Birkinshaw, 2005), and the optimal degree of openness in terms of radical and incremental innovation (Laursen \& Salter, 2006). While these studies have investigated performancerelated outcomes of openness, a small number of contributions has looked into the organization of collaborative innovation activities itself. These studies investigate processes by which some technology collaborations generate innovations while others do not (Davis \& Eisenhardt, 2011), delineate internal organizational practices that support firms in leveraging user and customer knowledge (Foss, Laursen, \& Pedersen, 2011), and shed light on organizational structures of R\&D in the context of OI (Petroni, Venturini, \& Verbano, 2012). This research provides exciting insights into OI but important issues remain unresolved.

One of these issues refers to the fuzzy front end of open innovation that deals with the territory leading up to the adoption of different OI activities (Cohen \& Levinthal, 1990). A major challenge for firms relying on OI is to effectively identi- 
fy the most valuable external sources of innovation, in the first place (West \& Bogers, 2013). Firms typically face substantial barriers in their external search processes for innovation. On the one hand, search and decision processes are likely to become subject to consistent patterns of collaboration over time due to socialization (Dahlander \& Gann, 2010). Inertia in search processes results in continuation of relations that are not meeting expectations, thereby producing overembeddedness (Uzzi 1987), with too little diversity in terms of partners. On the other hand, firms may engage in 'over-search', managing too many external relations that are not anymore relevant for the organizational context (Laursen \& Salter, 2006; Katila \& Ahuja, 2002). In addition to these search barriers, organizations often face changing demands from an evolving internal and external task environment (Maurer \& Ebers, 2006), requiring them to continuously adapt their search processes. However, due to path dependency, firms often fail to adequately refresh their opportunity landscape as selected opportunities will be close to previous activities and will narrow the firm's locus of search for new technologies (Teece, Pisano, \& Shuen, 1997; Rosenkopf \& Nerkar, 2001; Ambrosini, Bowman, \& Collier, 2009). Despite these important challenges, literature currently lacks an indepth account of how firms search for and identify relevant OI opportunities.

So far, research on OI has focused on the management and outcomes of collaborative and open forms of innovation, while the generative mechanisms and origins of these OI activities have remained underexplored. While prior work provides some insights into antecedents of OI in terms of firm and industry characteristics (Keupp \& Gassmann, 2009; Drechsler \& Natter, 2012; Garriga, von Krogh, \& Spaeth, 2013), it lacks an explanation of the processes by which firms organize search for external knowledge and commercialization. To this point, it is less clear how firms overcome tensions between inertia and over-search and how they effectively identify and adjust opportunities for OI. This is a striking feature of the OI literature; since firms are expected to differ in their abilities to identify, screen, and evaluate external inputs and outputs of the innovation process (Laursen \& Salter, 2006), it is of interest where these differences stem from. To address this gap, the purpose of this study is to better understand the processes by which firms search for and identify opportunities for OI. In this context, I understand opportunities for OI as chances to meet a market need through a creative combination of external and internal resources to deliver new innovations.

In this study, I examine the process of opportunity identification directly and aim to uncover patterns of search in an OI context. Given limited prior theory and empirical research, I use theory building (Eisenhardt, 1989) based on comparative case methods. The empirical setting is four firms, considered as OI leaders, with headquarters in the Netherlands, France, and Germany. Theory building from these cases allows me to create and develop new theoretical constructs and relationships for opportunity identification for OI. The major findings from this multiple case study were theoretical insights concerning processes that characterize 
opportunity identification and transformation for OI. More specifically, I identify two key dimensions of the OI opportunity identification process - external discovery and internal creation - as well as dynamic patterns that describe how firms strategically filter external search, recalibrate internal requirements, and reconfigure opportunities between different OI modes.

This study contributes to the emerging OI literature by developing a theoretical framework that opens the black box of opportunity identification in OI. This framework reveals how firms identify and continuously transform opportunities of OI and, thereby, sheds some light on the fuzzy front end of OI. Hence, it helps to clarify the nature of the processes that foster OI at the organizational level and unravel the origins of OI. Another core contribution refers to the classification of the broad concept of OI into different modes, which are shaped and determined by differences in the firm's opportunity identification processes.

\section{THEORETICAL BACKGROUND}

The notion of opportunity identification in an innovation context has been discussed extensively in two separate, yet related literature streams. First, opportunity identification constitutes an essential element of the dynamic capabilities view. The dynamic capabilities view focuses on the capacity an organization facing a rapidly changing environment has to create new resources, to renew or alter its resource base (e.g. Teece, Pisano, \& Shuen, 1997; Eisenhardt \& Martin, 2000; Helfat et al., 2007). In terms of its specific role, early research has mainly considered dynamic capabilities as concerning changes in resources, capabilities, operating routines, or one combination of these. More recently, other specific roles have been added, such as decision-making (Pandza \& Thorpe, 2009), the ability to monitor capabilities and environmental changes (Schreyögg \& Kliesch-Eberl, 2007) and the ability to sense opportunities (Barreto, 2010). In order to change their resource base firms need to identify, prioritize, and select opportunities and new projects (Teece, 2012). Hence, opportunity identification is an essential element of such dynamic capabilities (Augier \& Teece, 2009).

In order to effectively identify opportunities for OI, firms need to develop the capacity to perceive opportunities for changing existing routines or resource configurations. Since OI deals with inflows and outflows of resources and the renewal of innovation and commercialization capabilities, the dynamic capabilities view helps to explain how such transfer and change in capabilities can be initiated. While dynamic capabilities have certain commonalities (Eisenhardt \& Martin, 2000; Wang \& Ahmed, 2007) they are still heterogeneously distributed across firms (Galunic \& Eisenhardt, 2001) and their complex and intangible nature makes them difficult to transfer or imitate (Collis, 1994; Pitelis \& Teece, 2010). Therefore, dynamic capabilities can help to explain how and why firms differ in identifying and 
recognizing opportunities for OI. Following Teece's (2007) terminology, this study focuses on the dynamic capability to 'sense' opportunities for gaining access to new resources or shedding resources via external paths to markets. These sensing dynamic capabilities involve conducting search and sense-making activities in a mindful way (Pandza \& Thorpe, 2009).

The second literature stream that provides particular insights into OI opportunity identification is strategic entrepreneurship. Strategic entrepreneurship can be defined as the ability of firms to create, define, discover, and exploit opportunities (e.g. Ireland, Hitt, \& Sirmon, 2003; Zahra, Sapienza, \& Davidsson, 2006; Zahra, 2008; Alvarez, Barney, \& Anderson, 2013). It is a term used to capture firms' efforts to simultaneously exploit today's competitive advantages while exploring for the innovations that will be the foundation for tomorrow's competitive advantages (Ireland \& Webb, 2007). Ketchen, Ireland, and Snow (2007) refer to this dual objective as incorporating advantage-seeking, as well as opportunity-seeking activities (Ketchen, Ireland, \& Snow, 2007). While the literature on entrepreneurship deals with judgment and alertness in order to capture more general profit opportunities, it also deals with the more specific function of innovation (Klein, 2008). In this context, strategic entrepreneurship and OI are interrelated and can inform each other. Ketchen, Ireland and Snow (2007), for instance, show how collaborative innovation can bridge the gap between internal innovation and the continuous innovation required by strategic entrepreneurship. Furthermore, external networks can serve as sources of information that help entrepreneurial firms identify potential opportunities (Ireland, Hitt, \& Sirmon, 2003). Hence, the strategic entrepreneurship literature is expected to provide meaningful insights into the opportunity identification process for OI.

Both the dynamic capabilities view as well as the strategic entrepreneurship perspective acknowledge that firms identify new opportunities for innovation internally or externally of their corporate boundaries. Prior work has demonstrated the relevance of these dimensions of opportunity identification. For instance, the acquisitions and alliances literature has shed some light on how firms externally identify new opportunities for innovation and search for partners with complementary capabilities (Rothaermel, 2001;Capron \& Anand, 2010; Capron \& Mitchell, 2010). More generally, prior work has shown how firms scan across external markets and technologies in order to discover new opportunities for innovation (e.g. Pavlou \& El Sawy, 2006; Teece, 2007; Danneels, 2008) and engage in external imitative search to capture aspects of a rival's resource configuration (Zott, 2003). Overall, prior studies have shown that firms search externally of their corporate boundaries to find new innovation opportunities.

With regard to internal opportunity identification, it has been shown how active internal search can lead to new opportunities for innovation (Winter, 2000; Zott, 2003). The origins of dynamic capabilities are often represented in internal 
entrepreneurial acts (Augier \& Teece, 2006). For instance, firms look inside the organization, searching for local abilities or competencies that could form the basis of continual improvement strategies (Pablo et al., 2007). Alternatively, improvisation, trial and error and experimentation can generate new opportunities for innovation (Zollo \& Winter, 2002; Zahra, Sapienza, \& Davidsson, 2006). By experimenting with novel and emerging technologies firm can overcome learning traps and create new opportunities (Ahuja \& Lampert, 2001). These entrepreneurial activities are often driven by internal strategy-making and strategic intent (Salvato, 2003; Moliterno \& Wiersema, 2007; Kay, 2010). In sum, prior research has shown how internal entrepreneurial and strategic processes support opportunity identification.

Together, external and internal search form the basis of a firm's capability to create new opportunities for innovation (Teece, Pisano, \& Shuen, 1997; Zott, 2003). However, in addition to external and internal search, the dynamic capabilities literature, in particular, discusses the continuous transformation of opportunities. Since no successful firm remains static, it must continuously learn to adapt its opportunity set (Teece, 2007). For instance, Rindova and Kotha (2001) show how firms increase the flexibility of their overall asset stock as well as the match between the assets of the firm and its shifting strategic needs. Furthermore, the dynamic capabilities literature discusses how resources and capabilities can be transferred into new domains and contexts of application in order to leverage an existing opportunity set (Bowman \& Ambrosini, 2003; Ireland, Hitt, \& Sirmon, 2003). Thus, in addition to opportunity identification, prior research highlights the need for continuous transformation in order to refresh a firm's opportunity set (e.g. Rindova \& Kotha, 2001; Teece, 2007).

In sum, the dynamic capabilities and strategic entrepreneurship literatures offer insights into how opportunities for innovation are identified. These literature streams indicate that: (1) firms can use external and internal opportunity identification, and that (2) a firm's opportunity set needs to be continuously transformed in order to adapt to changing environments. However, it is not clear to what extent these concepts are also useful in the context of OI. In addition, previous work has mostly considered isolated practices of identifying opportunities for innovation, such as experimentation, alliances, or acquisitions. However, given pressures for remaining competitive in an increasingly turbulent and global environment, firms are exploring many different OI activities and utilize a variety of approaches to engage with external parties to jointly develop new innovations. Hence, a broader context is required that takes into account that opportunity identification for $\mathrm{OI}$ is not based on single decisions to partner, but involves portfolio considerations of engaging with various external partners via diverse interactive mechanisms. Furthermore, it is of interest how firms increase the flexibility of such a portfolio of OI opportunities and continuously transform identified opportunities with changing conditions. This requires a joint consideration of opportunity identification, 
which is grounded more in the strategic entrepreneurship literature, and the notion of continuous transformation, which shares more characteristics with the dynamic capabilities realm. These considerations lead to the following research questions: 1) If there are discernible patterns of opportunity identification through which firms shape their OI strategies, what do they look like? 2) What are the implications of such opportunity identification patterns for a portfolio of OI activities? 3) How are opportunities for OI continuously transformed?

\section{METHODOLOGY}

\section{Research Design}

As $\mathrm{OI}$ is a relatively new phenomenon, it is not surprising that it still lacks plausible existing theory, particularly with regard to the opportunity identification stage. While research on dynamic capabilities and strategic entrepreneurship may provide some insights into opportunity identification and transformation, it is not clear how exactly these two research streams can be combined and to what extent their underlying concepts can help to gain a better understanding of the phenomenon of OI. Hence, the aim of this study is theory building rather than theory testing (Eisenhardt, 1989). Theory building aims at introducing new constructs and exploring previously unaddressed relationships (Colquitt \& Zapata-Phelan, 2007). I chose multiple case studies as the research design for theory building (Eisenhardt, 1989). A multiple case study allows replication logic, with each case confirming or not the inferences drawn from others (Yin, 2009). Theory building research using the case study method is particularly suitable for answering questions in unexplored research areas (Edmondson \& McManus, 2007). Furthermore, emergent theory from multiple-case research is more generalizable and better grounded than theory from single-case studies, making it more suitable to validation with other methods (Eisenhardt \& Graebner, 2007). Therefore, I selected four firms, active in the field of OI, in order to shed light on my research questions. Rich qualitative data collected in these four cases and triangulated by means of multiple in-depth interviews, documents, and observations, helps to explicate the complex processes involved in OI opportunity identification. Furthermore, systematic analysis of qualitative data is particularly helpful for creating new constructs and patterns for a relatively new phenomenon of interest (Edmondson \& McManus, 2007). The theory-building process occurs via recursive cycling among the case data, emerging theory, and extant literature on dynamic capabilities and strategic entrepreneurship. Throughout the design and implementation of the case study method, I developed a case study protocol, a report specifying how the case study has been conducted, and constructed a case study database, which puts all material collected and created during the study together. These techniques help to enhance the reliability of the case study (Gibbert, Ruigrok, \& Wicki, 2008). 


\section{Sampling and Data Collection}

I conducted case studies in four international firms. These cases were selected purposefully on the basis of a theoretical sampling procedure in order to increase the chances of observing the phenomenon of interest - open innovation (Eisenhardt, 1989). In a first step, I screened websites of leading OI practitioner conferences held in 2010 (including NineSigma Open Innovation Leadership Summit, Open Innovation Conference in Frankfurt, European Innovation Conference [Open Innovation and New Business Creation Track], Marcus Evans Annual Innovation Excellence, and the Co-Development and Open Innovation Conference). Based on this screening, I generated a list of firms that participated in several of these conferences. I contacted a number of firms from this list that are located within my geographical proximity to allow traveling and rich qualitative data collection. In addition, potential cases had to qualify as 'large' firms. I was particularly interested in large firms, as these are more likely to engage in a larger variety of OI activities and therefore, increase the chance to observe the opportunity identification process for a portfolio of OI opportunities. Furthermore, I decided to focus on medium-to high-tech firms to ensure that they have a similar understanding of the term 'innovation'. At the same time, I was looking for firms from different industries in order to enhance the external validity of the study.

Amongst the firms that qualified for these characteristics, four agreed to participate in this study. In a second step, prior to the actual data collection, I ensured that these firms can be classified as 'open innovators', by applying the following criteria. First, I analyzed their annual reports; four firms explicate in their annual reports that they rely on OI as a strategic approach to managing their innovation processes. Second, all four firms state on their corporate websites that they implement OI strategies, processes, and tools. Finally, all four firms have had articles on the topic of OI published in trade journals and are classified as OI firms in academic papers. In sum, based on these criteria, I can be confident that the selected firms engage extensively in OI and are therefore relevant for my research question.

Data collection took place throughout May 2010 to September 2012. I followed Yin's (2009) call for multiple sources of evidence by collecting data through interviews, site visits, internal documents, and extensive archival search that included annual reports, industry publications, and other written material on the company (such as the media articles, trade journals and websites). The triangulation of multiple data sources helps to provide stronger substantiation of newly developed constructs and relationships (Eisenhardt, 1989; Yin, 2009). The primary sources were 23 semi-structure interviews, each lasting approximately between an hour and a half and three hours. The semi-structured interview guidelines were developed on the basis of the literature analysis and a priori constructs, but also maintained enough flexibility and openness to allow for emerging issues and 
concepts throughout the interviews. Each interview was taped and transcribed to ensure reliability, resulting in 420 pages of primary source material. Interviewees were key informants on the topic of OI, including OI directors, innovation directors, venturing directors, etc. In addition to high-level corporate executives, I also interviewed some business unit general managers. Interviewing multiple key informants at multiple levels and different times leads to richer and more reliable emergent theory, as it mitigates data biases, such as retrospective sensemaking and/or impression management (Eisenhardt \& Graebner, 2007). Details on the case study firms, key informants, and other data can be found in table 2.1.

\section{Data Analysis}

Data analysis followed procedures recommended by Miles and Huberman (1994), Eisenhardt (1989), and Eisenhardt and Graebner (2007). From the interview data and documents, I first compiled individual case descriptions for each firm with regard to how firms organize for innovation in general and for OI in particular. This resulted in thick descriptions of each firm's OI opportunity identification process, in the form of about 80 pages of case study description. Once I had developed the individual case descriptions, I used them for two types of analysis: within-case and cross-case analysis. Within-case analysis focused on describing the processes and activities firms employed to initiate OI. The aim was to develop generalizable constructs about the OI opportunity identification process. I was aware of the prior literatures on strategic entrepreneurship and dynamic capabilities and their conceptualization of external/internal opportunity identification and continuous transformation, so I examined the data for the emergence of these construct categories. But I also looked for unexpected types of opportunity identification. At this stage of the analysis I implemented data analysis techniques by Miles and Huberman (1994). In a first step I relied particularly on data display in terms of construct tables in order to organize the large amounts of data and develop preliminary categories. In a second step, I implemented data reduction and transformation techniques (Miles \& Huberman, 1994) in order to condense the data at hand. I particularly looked for patterns and components that enabled me to aggregate the data into higher conceptual characteristics. These analytical steps are analogous to an exploratory factor analysis in which large amounts of data are reviewed, reduced, and transformed into major themes and categories that result in a better understanding of the initial data (Lee, 1999). 
CHAPTER 2 - The Fuzzy Front End of Open Innovation

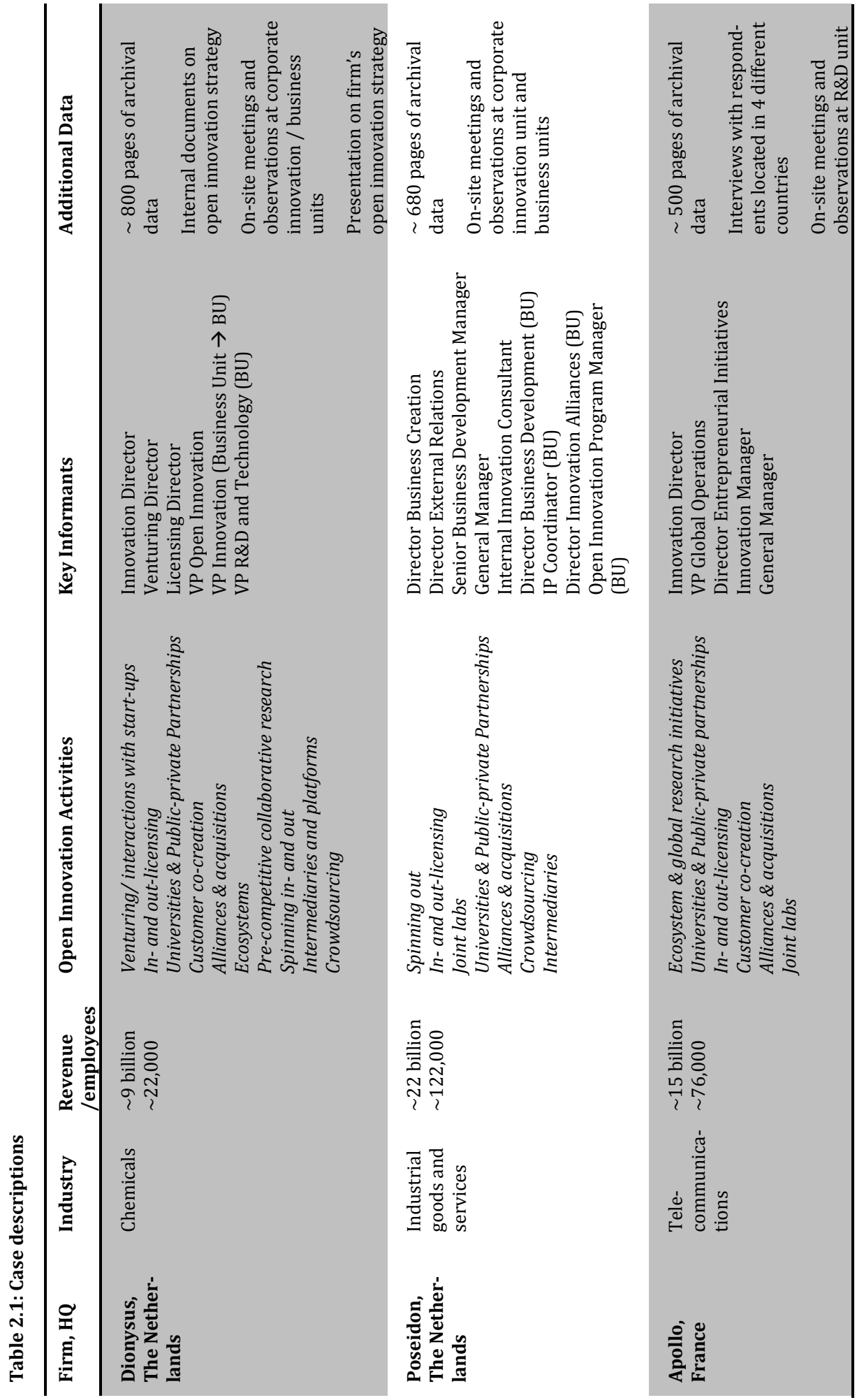


CHAPTER 2 - The Fuzzy Front End of Open Innovation

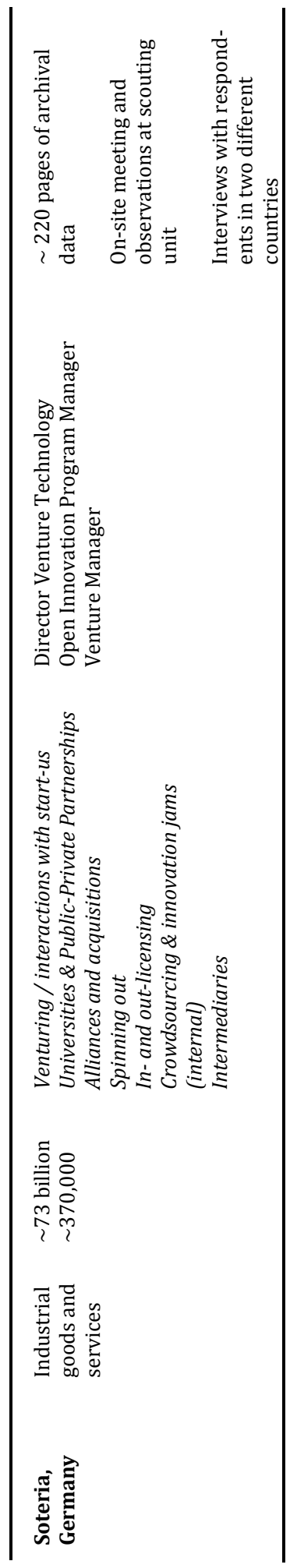


After I had a good understanding of each case and had organized the data into preliminary categories, I then began cross-case analysis. At this stage I refined emerging patterns through replication logic, frequently revisiting the data to compare and verify systematically the occurrence of specific themes and categories within each case (Yin, 2009). Again, I relied on techniques by Miles and Huberman (1994) for cross-case analysis. These include meta-matrices to assemble descriptive data from each case in a standard format. I then ordered these meta-matrices by partitioning and clustering them according to the emerging key categories. Cross-case analysis helps to generalize the emerging patterns and deepen understanding and explanations of the emerging constructs and relationships. Finally, I drew conclusions from the matrix data using various techniques, including noting patterns, contrasting, comparing and clustering (Miles \& Huberman, 1994). In addition, I iterated between theories and concepts in the dynamic capabilities and strategic entrepreneurship fields and the data to clarify my findings and theoretical arguments.

\section{RESULTS SECTION 1: PATTERNS OF OPEN INNOVATION OPPORTUNITY IDEN- TIFICATION}

Two distinct dimensions of identifying opportunities for OI emerged from the data. More specifically, I find that firms differentiate between external and internal search. In addition, in the iterative probing of checking the emerging constructs against categories used in extant research on strategic entrepreneurship and dynamic capabilities (Eisenhardt, 1989), I found that the two dimensions of opportunity identification for OI had similarities to two existing concepts in the strategic entrepreneurship literature, namely the discovery and the creation approaches to opportunity identification (e.g. Ardichvili, Cardozo, \& Ray, 2003; Alvarez \& Barney, 2007; Alvarez, Barney, \& Anderson, 2013). External discovery and internal creation represent different dimensions of search for opportunities in an OI framework. Table 2.2 presents illustrative activities and quotes from the cases that characterize these two types of opportunity identification. While previous literature on strategic entrepreneurship predominantly suggests that opportunity creation and opportunity are incommensurable (e.g. Alvarez \& Barney, 2007; Alvarez, Barney, \& Anderson, 2013), the case study data at hand suggests an alternate view for the context of $\mathrm{OI}$, as the next sections will show. 


\begin{tabular}{|c|c|c|c|}
\hline 苞 & 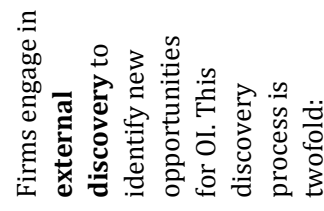 & 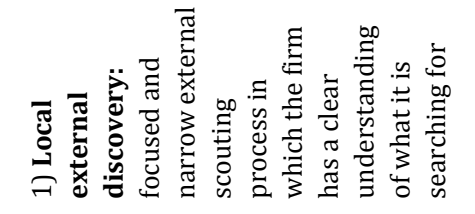 & 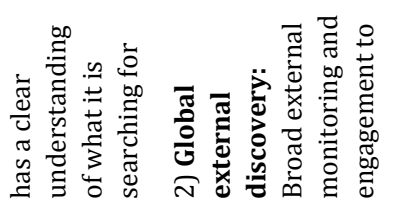 \\
\hline 离 & 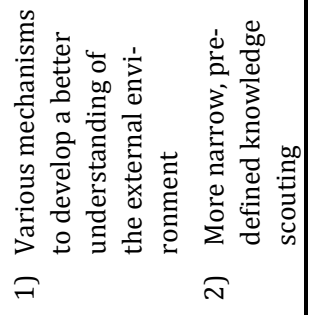 & 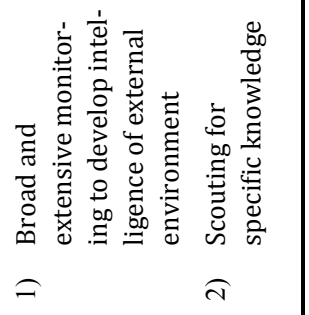 & 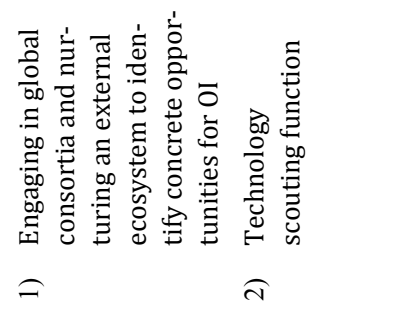 \\
\hline 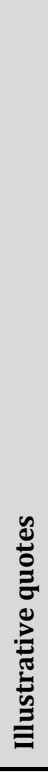 & 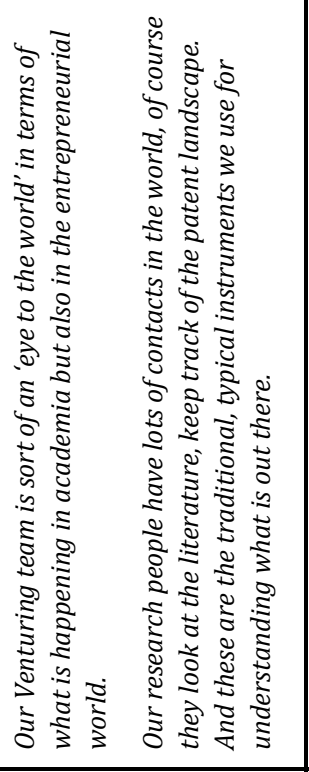 & 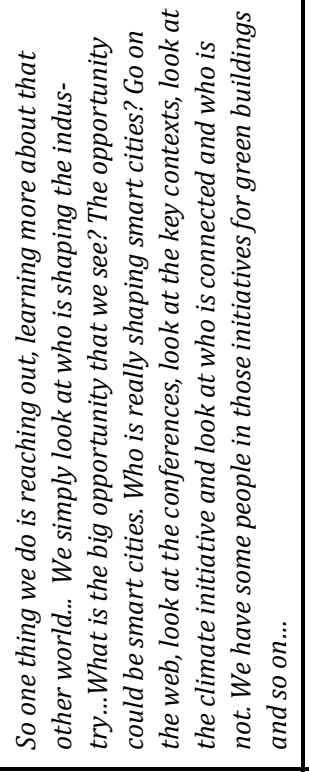 & 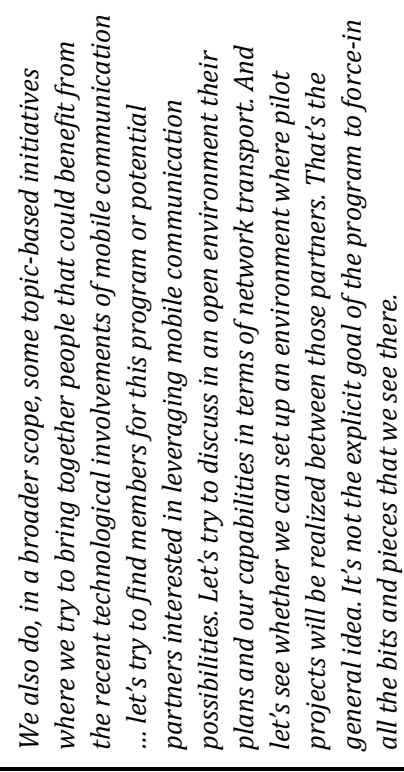 \\
\hline 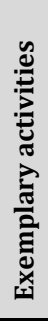 & 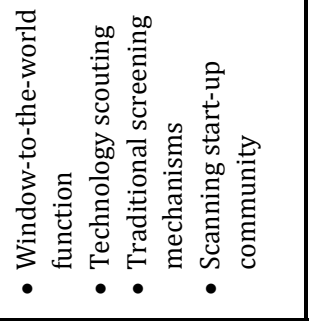 & 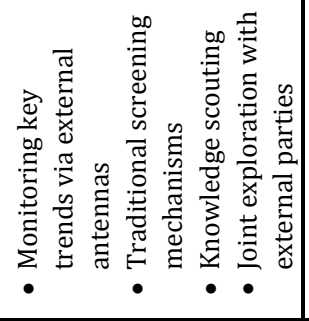 & 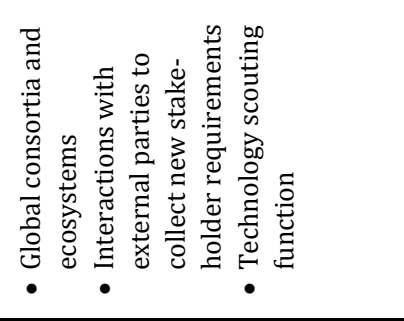 \\
\hline 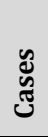 & 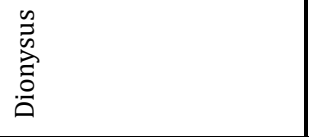 & 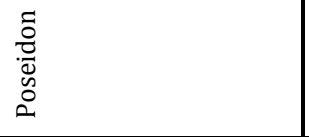 & $\begin{array}{l}\stackrel{0}{\overline{0}} \\
\frac{2}{2}\end{array}$ \\
\hline 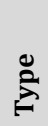 & 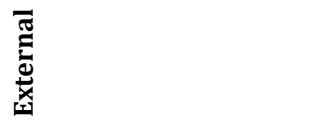 & & \\
\hline
\end{tabular}




\begin{tabular}{|c|c|c|c|}
\hline 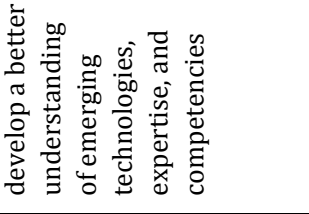 & 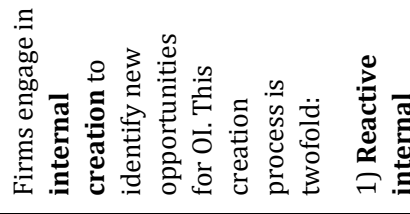 & 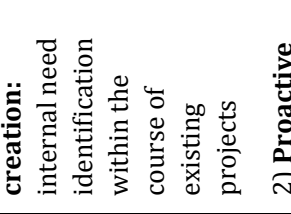 & 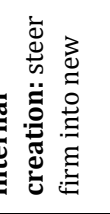 \\
\hline 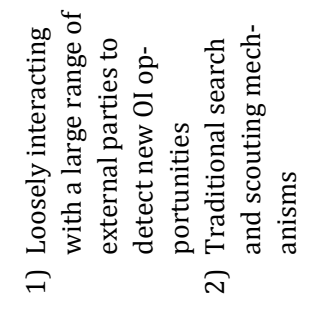 & 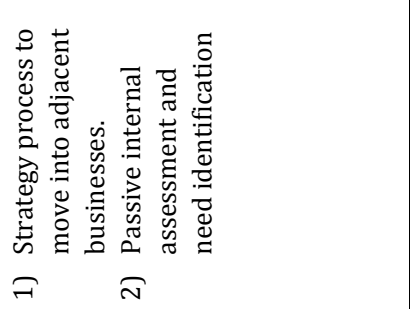 & 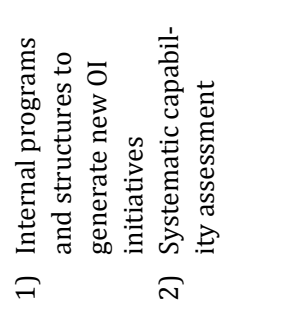 & 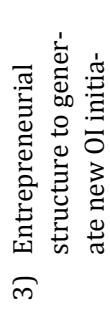 \\
\hline 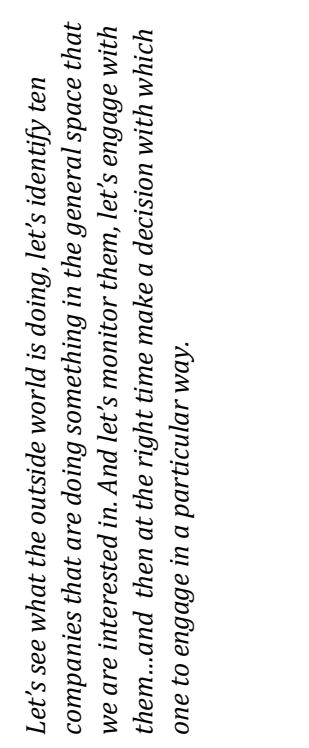 & 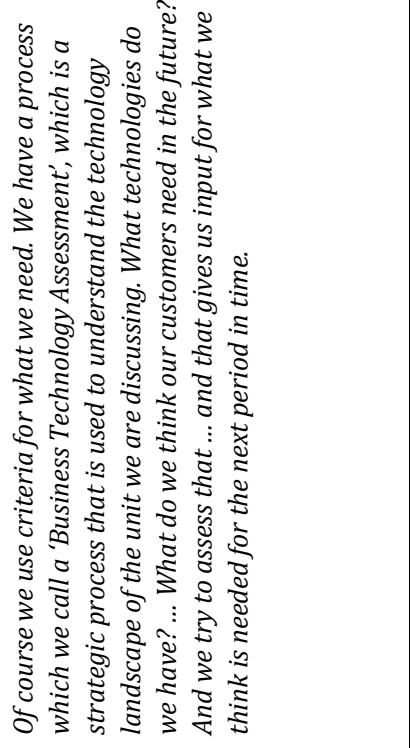 & 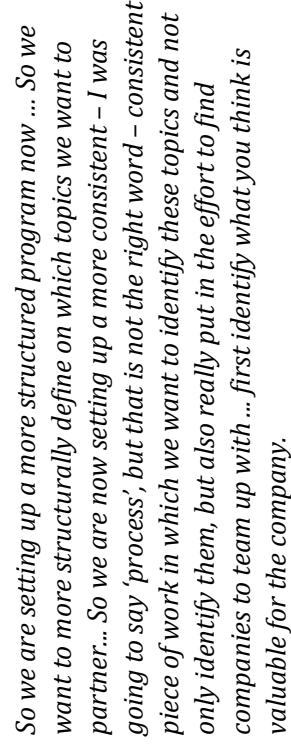 & 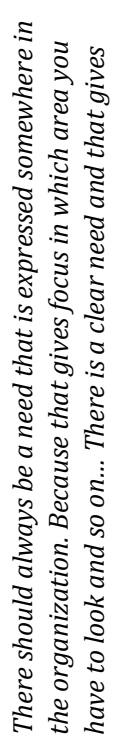 \\
\hline 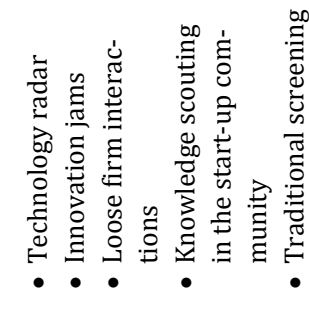 & 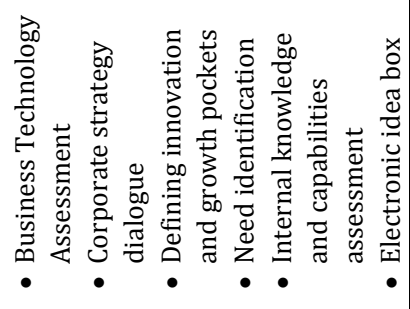 & 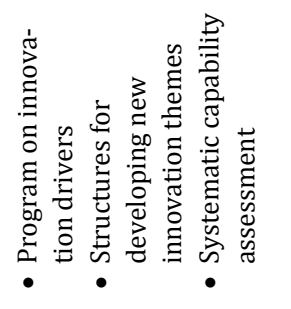 & 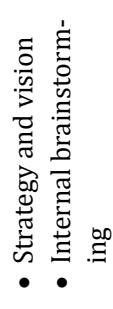 \\
\hline \multirow[t]{2}{*}{$\begin{array}{l}\frac{\pi}{\vec{D}} \\
\stackrel{0}{0} \\
\stackrel{0}{0}\end{array}$} & 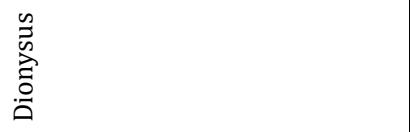 & 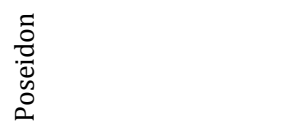 & $\begin{array}{l}\stackrel{\circ}{\overline{7}} \\
\stackrel{2}{<}\end{array}$ \\
\hline & \multicolumn{3}{|l|}{ 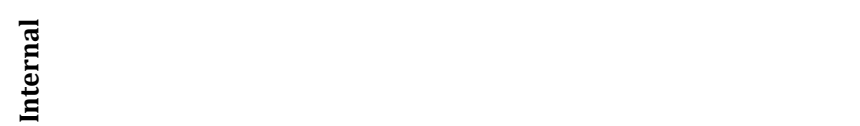 } \\
\hline
\end{tabular}




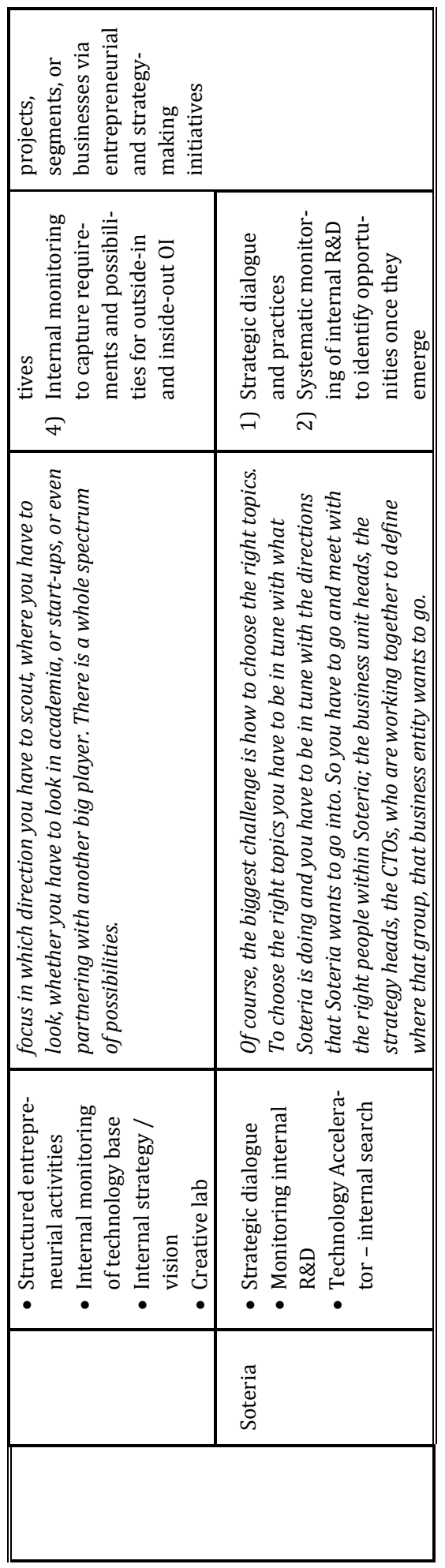




\section{How Firms Externally Discover Opportunities for Open Innovation}

The data (see table 2.2 for an excerpt) suggests that firms implement systematic monitoring efforts in order to capture emerging external technological trends. OI managers refer to these activities as developing 'a technology radar', setting up 'external antennas' or establishing a 'window-to-the-world' function. This enables firms to become more receptive for new opportunities to combine external and internal resources in the innovation process. In addition, firms aim at obtaining a better understanding of emerging stakeholder requirements, which, in turn initiates new opportunities for OI. A good example is Soteria's 'innovation jam' that aims at collecting new customer requirements, as explained by Soteria's OI program manager "... we carried out a jam with customers in China and virtually constructed a wish-list for two of the Soteria divisions. And we asked all our customers to define product features ... which they wished Soteria products had." These stakeholder requirements build the grounds for new OI projects, in collaboration with these specific customers or other external parties.

External opportunity identification often occurs in a joint effort with external parties. Loose interactions with a wide range of external parties enables the firm to broadly scan the technology landscape and discover more concrete options for collaborative innovative efforts. A good example is Apollo's effort to identify opportunities in the context of a large ecosystem of external parties, as explained by the VP of global operations: "We set up consortia that really bring the stakeholders together to identify opportunities. When you want to reach a goal it is about 'how can you get there?' And when you bring partners together, you identify opportunities in order to get there." Moreover, firms discover opportunities by scouting for new knowledge and technologies. Traditional screening mechanisms, such as networking, participating in conferences, patent analysis, or the screening of other databases are employed to identify valuable knowledge and technology and thereby, define new opportunities for OI. A good example is Apollo's technology scouting function, as illustrated by Apollo's director of entrepreneurial initiatives: "We have various functions where people scout technologies. They scout start-ups to see whether any of those technologies could be interesting for our business ... but you can also scout technologies in Universities and Academia ... that is also a way to get new technologies on board."

This pattern of external opportunity identification shares some similarities with the concept of 'discovery' in the strategic entrepreneurship literature. Discovery theory concerns how firms scan the external environment to discover opportunities for producing new products and services (Alvarez \& Barney, 2007). New opportunities for innovation are initiated by exogenous shocks to markets or technologies and are further shaped by external stimuli and changes in the environment (e.g. Zollo \& Winter, 2002; Shane, 2003; Alvarez, Barney, \& Anderson, 2013). In order to capture these changes in the environment and identify new 
opportunities, firms search and scan across external markets and technologies (e.g. Zott, 2003; Danneels, 2008). In line with this literature, I find that one way firms try to identify opportunities for OI is to become very externally oriented and engage into an 'external discovery' process. The emphasis is on 'discovery' rather than 'identification', since a firm's fundamental assumption of this process is that opportunities for OI reside outside the firm's boundaries in terms of new technological and market trends, which simply need to be recognized. Overall, I define external discovery as the capacity to recognize new trends and technologies by engaging with external parties and scouting external technologies.

As illustrated in table 2.2, the data further reveals that external discovery entails two rather distinct patterns of external search processes. On the one hand, firms engage in a local external discovery process. Local external discovery refers to a more focused and narrow scouting process, in which the firm has a clear understanding of what it is looking for in the external environment. As Soteria's director of venture technology explained: "Once a strategic direction is established within Soteria, some business units ... may have a very specific need; they communicate it to us, we go and look for it." On the other hand, firms engage in a more global external discovery process in order to develop a better understand of emerging technologies, expertise, and competencies without necessarily pre-filtering them with regard to specific internal needs. In such cases, firms aim at understanding emerging patterns and trends in the environment, with little or no direction from the organization. This objective is illustrated by Poseidon's director of external relations: "Here you have a potential future technology and ... you want to extract knowledge, for example from suppliers, on that potential future technology. And you want to - let's say - get a better picture on the world."

This differentiation into local and global external discovery is reflected in the strategic entrepreneurship literature, which distinguishes between 'opportunity seeking' and 'advantage seeking' (e.g. Hitt et al., 2001; Ireland, Hitt, \& Sirmon, 2003; Ireland \& Webb, 2007). First, 'opportunity seeking' involves an inherent learning process that aims at building a diverse knowledge base to expand the firm's repertoire (Ketchen, Ireland, \& Snow, 2007). Opportunity seeking involves sorting through potential opportunities to identify areas of future activity for the firm. Second, advantage seeking focuses more on the implementation of a chosen strategy and aims at finding the best ways to profitably deliver new products (Ketchen, Ireland, \& Snow, 2007). I find that external discovery can entail both advantage-seeking as well as opportunity-seeking elements. Advantage-seeking is reflected in local external discovery that aims at filling internal knowledge gaps, while opportunity-seeking is reflected in global external discovery that pursues the recognition of emerging technologies and trends. However, in this case, I avoided the terms from the literature, both because they did not capture all data and because they implied that search for OI opportunities consists of a dichotomy of 
opportunity-seeking and advantage-seeking. The following section, however, will show that search for OI opportunities entails more than these two categories.

\section{How Firms Internally Create Opportunities for Open Innovation}

As shown in table 2.2, internal identification of OI opportunities is guided by a strategic process and dialogue. Firms define future innovation and growth areas to construct new opportunities for open forms of innovation. This strategic process relies on a formal and structured process to define topics that are strategically relevant and suitable for OI. A good example is Poseidon's program on innovation drivers, which aims at defining new growth areas that build the grounds for OI: "Part of our program is called innovation drivers in which we spend quite a bit of energy to find out what will drive people in the near future... If you are doing that type of work, then you will also find out that there is a probability for Poseidon to grow into a certain area. Then there is a certain body of knowledge that goes with that or a certain capability that we need to have - either in-house or externally." An important element in this opportunity identification process is a strategic dialogue, which helps firms to choose suitable themes for OI. Strategic dialogue and vision guide the firm in this process, as further explained by Apollo's VP of global operations: "We have a vision of the company and we have a strategy in order to get to that vision. But even as a big company we cannot do it all ourselves. So what we typically do is in order to realize that vision we look around us and see whether there are partners that could help us in order to reach that goal."

Table 2.2 further illustrates that firms also intensively monitor internal innovation projects to gain a better understanding of their existing competences and to assess current knowledge and capability gaps. In addition to scanning external developments and trends, it is equally important to get a clear picture of the knowledge that has been built in-house and of specific goals and requirements that need to be addressed. Such need identification builds grounds for future OI opportunities, as explained by Apollo's innovation director: "In a really systemized way you start thinking internally and at a certain point in time you know what you can do on your own and where you need partners. And then we are actively going to search for those partners." Furthermore, internal monitoring enables opportunities for inside-out OI activities. More specifically, firms intensively monitor internal intellectual property in the attempt to identify alternative paths for commercialization. A good example is Soteria's 'Technology Accelerator' which conducts internal search in order to identify opportunities for knowledge outflows: "The spin-off activity department is searching actively - but they search within Soteria. And they also do promotion and they look for [internal] business cases." Similarly, Apollo has established an 'IP Transformation Process' which aims at identifying IP that is not being used internally and that can be out-licensed in an OI framework. 
In addition to strategic dialogue and internal monitoring, firms engage in internal idea generation and entrepreneurial activities. Opportunity creation for OI is supported by systematically collecting new ideas, particularly from the bottom of the organization. Dionysus, for instance, uses an 'Electronic Idea Box' to articulate potential challenges for an OI environment, as explained by the VP of R\&D and Technology: "We have an automated tool for idea generation that is called electronic idea box. There we do make our needs explicit, but that's used internally - so that we know what kind of ideas we want." Apollo, on the other hand, relies on a "Creative $L a b$ ' in order to generate new ideas and address new challenges: "We also have a 'creative lab', which is actually a tool to instantiate something around open innovation, which includes brainstorming and quick prototyping." Poseidon has implemented an internal crowdsourcing initiative in order to generate new ideas and opportunities from the bottom of the organization. The aim of this crowdsourcing activity is to provide a structure for employees to develop challenges that are suitable for an OI context, as explained Poseidon's OI manager: "We have developed a processstructure behind it in order to structure opportunities and to get that more bottom-up from the organization than top-down." The generation of new ideas relies heavily on frequent interactions between various parts of the organization. Firms implement 'internal open innovation' to define what will be needed to support current and future products and to try to capture ideas from various parts of the organization. Internal OI then builds the grounds for more external OI, as explained by Soteria's OI program manager: "And I strongly believe that these initiatives - these kinds of internal initiatives - prepare the grounds for more open innovation."

In sum, the data reveals that next to external discovery firms also engage in an internal opportunity identification process. Therefore, in line with prior work that has suggested both internal and external paths to opportunity identification (e.g. Zollo \& Winter, 2002; Zott, 2003; Augier \& Teece, 2006; Pavlou \& El Sawy, 2006; Teece, 2007; Capron \& Mitchell, 2010), I find that firms search for OI opportunities both inside, as well as outside their corporate boundaries. The internal search process, however, shares more characteristics with the concept of opportunity creation. Unlike research on the discovery process, which assumes that opportunities are 'out there', just waiting to be discovered, research on the creation process assumes that opportunities are constructed and created by the firm itself (e.g. Alvarez \& Barney, 2007; Miller, 2007; Alvarez, Barney, \& Anderson, 2013). This means that opportunities can be endogenously formed and created by entrepreneurs within the organization's boundaries (Alvarez, Barney, \& Anderson, 2013). The opportunity creation process goes beyond discovery, as it requires active sensing, development, evaluation and reframing of internally emerging opportunities (Zahra, 2008). In line with this literature, the data analysis reveals that OI firms engage in internal creation to construct and shape opportunities for combining internal and external resources. In this context, opportunities are enacted, since firms rely on a corporate strategy dialogue and internal interactive 
processes. I define internal creation as the capacity to actively search inside the company for current business needs and opportunities to move into business adjacencies.

Two distinctive processes of internal creation emerge more inductively from the data (see table 2.2). On the one hand, opportunities for OI can be created in a more reactive manner. This process is predominantly based on internal need identification. Firms create opportunities for OI as they engage in projects within the firm's existing businesses. In the course of these projects certain pieces of knowledge and technology may be recognized as missing, thereby, forcing managers to engage in OI as a problem-solving mechanism. As Soteria's OI program manager explains: "So this is within the innovation process; if you have the development of a new product and you lack of a very certain technology, then for example, we try to recommend NineSigma as a provider for this missing piece to complement the development process." On the other hand, opportunities are also more proactively created. In these cases, firms do not react to current problems and needs, but actively steer the firm into new strategic directions. Here, opportunities for OI are created in a more entrepreneurial manner in order to generate new projects, segments, or businesses. Dionysus' VP of OI explains how strategic steering is relevant for this proactive opportunity creation: "It really depends on the strategy the company takes. We have annual strategy meetings, looking at where we want to go, and how we want to get there. Given this changing landscape, strategy is adapted here and there and we look at new opportunities as well. And if we find a new opportunity, then definitely one of the ways is to partner in order to get that knowledge."

This categorization into reactive and proactive opportunity creation is reflected in the understanding that opportunity creation includes problem solving, but is not reducible solely to such. The reactive form of opportunity creation is in line with a problemistic view of search for opportunities (e.g. Nelson \& Winter, 1982). Accordingly, search for opportunities is triggered by the problems the firm encounters and usually has a satisficing character (Rosenkopf \& Nerkar, 2001). Reactive creation is more related to advantage seeking than to opportunity seeking since it involves the implementation of existing strategies and products. In addition to problem solving, opportunity creation can also be more generative or pro-active (Miller, 2007). This pro-active creation process addresses opportunity-seeking rather than advantage-seeking objectives, as it aims at generating novel alternatives that are not so much pre-determined by prior experiences and existing needs.

\section{RESULTS SECTION 2: IMPLICATIONS OF PATTERNS OF OPEN INNOVATION OPPORTUNITY IDENTIFICATION}

The previous section identified two dimensions of the OI opportunity identification process - external discovery and internal creation. These dimensions were further 
disaggregated into more fine-grained categories of local and global external discovery and reactive and proactive internal creation. Similarities with the concepts of discovery versus creation and opportunity-seeking versus advantage-seeking were discussed. Furthermore, it was shown that opportunity seeking and advantage seeking can take place both inside as well as outside the firm's boundaries. Global external discovery and proactive internal creation pursue opportunity-seeking, while local external discover and reactive internal creation address advantageseeking objectives. The strategic entrepreneurship literature calls for studying the interactions and relationships between these different forms of opportunity identification. For instance, Ketchen, Ireland, and Snow (2007) call for studying the interactions between internal and external advantage-seeking and opportunityseeking. Zahra (2008) suggests that firms can combine opportunity discovery and opportunity creation by means of implementing both formal and informal mechanisms. This notion of combining different dimensions of opportunity identification is confirmed by the case data at hand. More specifically, the data shows that in the context of identifying opportunities for OI, firms balance discovery and creation by combining external and internal search.

Surprisingly, the data reveals that external discovery, which would be the most obvious route to identifying external sources of innovation and commercialization, is insufficient. Instead, it is equally if not more important to internally create opportunities that are driven by firm-specific needs and strategies, as illustrated by Poseidon's director of business creation: "I mean, finding the partners - you can set up systems for that. But I don't think that the trick is there. I think the trick is in deciding where you see the value in the near future for your company." While external discovery assumes that opportunities exist in the external environment, independently of the focal firm, and can therefore be equally well discovered by competitors, internal creation may contribute to more valuable and rare OI opportunities that are firm-specific and can lead to competitive advantage.

As opposed to the strategic entrepreneurship literature in which opportunity creation and discovery are mostly treated as incompatible processes (e.g. Alvarez \& Barney, 2007; Alvarez, Barney, \& Anderson, 2013), I find that in an OI context firms combine opportunity creation and discovery by implementing them inside and outside the firm's boundaries, respectively. Internal creation and external discovery of OI opportunities are complementary and equally considered, as illustrated by Poseidon's director of external relations: "First you need to decide what you want to achieve, where you want to be as a company. And then - based on that vision - decide to what extent collaborating with others will bring that goal closer... Of course, once you have become a well-established player in that new, more stable environment, then you can start exploring and opening up and see whether you can expand into adjacencies." Hence, external discovery and internal creation are not treated in isolation, but represent two inherently interrelated dimensions of the opportunity identification process. 
Nevertheless, in line with notions from the strategic entrepreneurship literature, the data confirms the inherent tensions between opportunity creation and opportunity discovery. Moreover, tensions are not only experienced across these dimensions but also within the dimensions. For instance, reactive internal opportunity creation is not easily accommodated with proactive opportunity creation. I find that firms address these tensions by combining internal opportunity creation and external opportunity discovery into alternative, yet supplementary OI modes. External discovery influences the mode of OI the firm will pursue. Likewise, the data shows that internal creation determines what mode of OI is implemented.

Figure 2.1 illustrates how the joint consideration of external discovery and internal creation can be translated into a framework of OI. This framework consists of four different modes of $\mathrm{OI}$ that result from different combinations of external discovery and internal creation. In the following, I present the four OI modes and discuss their respective characteristics.

\section{Mode 1: Complementary Open Innovation}

Complementary OI combines reactive internal creation and local external discovery (see figure 2.1). In this mode, OI opportunities are integrated into projects that already exist internally. It usually involves an established business that develops a concrete idea concerning how to improve a specific product line by accessing external knowledge. The applications of the OI opportunity are known in advance, as needs get identified within the course of an existing project. Since needs and requirements are well understood by the firm, proactive opportunity creation is not required. Instead, opportunity identification occurs more reactively, along the way of a new product development process. Likewise, complementary OI involves local external discovery as firms know what they are looking for and like to limit the number of partners in order to maintain control over outcomes and solutions. Furthermore, external search is local since the firm follows a satisficing principle to quickly address their internal problems and gaps. Poseidon's IP coordinator refers to this OI mode as 'active open innovation', and explains it as follows:

"You cannot do active open innovation if there is no project that actually absorbs the knowledge that we gain. ...before we even start active open innovation, we speak to all the segments: ... What are you looking for? ... And at that point we have scouts in the US, in Europe, in Asia, that really go out to all the small companies and big companies and ask the questions that we have. So really specific questions..." 
Figure 2.1: An open innovation framework

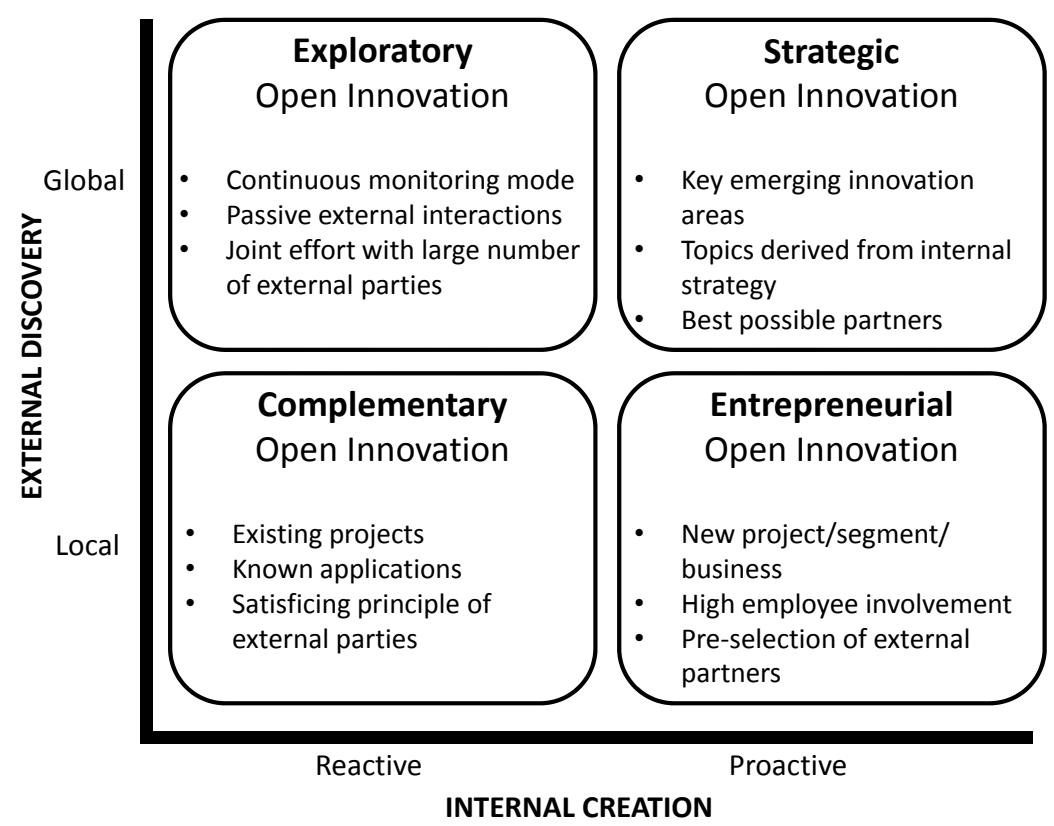

\section{Mode 2: Entrepreneurial Open Innovation}

Entrepreneurial OI combines proactive internal creation and local external discovery (see figure 2.1). In the entrepreneurial mode, new opportunities are typically created via internal entrepreneurial processes which are then supplemented by external inputs. Typically there is no existing internal project that can readily absorb externally sourced knowledge. Instead a new project, segment, or even a new business is initiated. As entrepreneurial OI aims at generating completely new ideas, the opportunity identification often emerges from the bottom-up of the organization rather than top-down. Usually, employees are heavily involved in the opportunity identification process for entrepreneurial OI. External opportunity discovery is typically focused, since partners or external knowledge sources are pre-selected in the initiation of the project. For example, Apollo has set up an internal employee program in the form of an 'Entrepreneurial Bootcamp' in order to stimulate entrepreneurial engagement with external parties. Apollo's director of entrepreneurial initiatives explains the underlying ideas of this 'bootcamp' as follows: 
"I am driving an internal employee innovation program, which also tries to leverage external knowledge in a certain way... it is going into the direction of getting some entrepreneurs in the company with their ideas to start new businesses... And we are also trying to set up some external partnerships in the early phases of the program... already there we are trying to find partners that could not only build the technology, but also try to conclude about a business model with potential partners."

\section{Mode 3: Exploratory Open Innovation}

In the top left-hand corner of figure 2.1, we find exploratory OI, which combines reactive internal creation and global external discovery. It includes more passive external interactions that are only loosely defined by internally pre-defined needs and requirements. In the exploratory OI mode, it is not necessarily the objective to force in all bits and pieces that are discovered in the external environment - instead it pursues the objective of learning about new technological trends and needs of stakeholders. In a joint effort with external parties, exploratory OI aims at developing a better understanding concerning future innovations. Often this joint exploration takes place with partners that are not active in the same markets. Hence, the focus is on non-competitive or pre-competitive interactions. The aim is to generally explore opportunities for more concrete collaborative projects. This is achieved by means of discussion and brainstorming within the scope of a certain theme or topic. The exploratory mode of OI is very extensive on external discovery as typically 'everybody' is allowed to participate. Exploratory OI is considered as a background process and continuous monitoring mode. Hence, it is less active from an internal opportunity creation perspective. Any concrete implementations and applications of these OI opportunities are not known in advance and outcomes of the exploratory OI mode do not directly fit into any existing business unit or segment. For instance, Apollo engages in global initiatives and ecosystems in order to enhance their exploratory OI, as explained by the VP of global operations:

"We have these ecosystems which are almost like a continuous monitoring mode as to what is happening. And then we see: how does that make sense? How does it fit into our strategy? Would it be helpful to have a collaboration with that party in order to gain some knowledge about opportunities in that field? So that is happening more as a background process."

\section{Mode 4: Strategic Open Innovation}

Strategic OI combines proactive internal creation and global external discovery (see top right-hand corner of figure 2.1). It focuses on key emerging innovation areas and topics that are derived from the firm's internal strategy. Within the boundaries of these emerging strategic areas, firms then look for outside opportunities and set 
up collaborations. By definition, strategic OI starts with a strategy. The main focus is on identifying future-oriented topics of strategic importance to the firm and then put some effort in finding external parties to team up with on these topics. External discovery is then typically extensive as firm aim at setting up the best possible collaboration for achieving this strategic goal. For instance, Poseidon has implemented an internal crowdsourcing campaign, while stimulates employees to generate strategically relevant opportunities, while simultaneously identifying potential external partners who can provide input on these strategic opportunities. Poseidon's director of business creation explains this strategic crowdsourcing campaign, as follows:

"We have set up a very specific crowdsourcing campaign in the organization, where we have developed a process in order to structure opportunities and to get that more bottom-up from the organization rather than top-down. The result is a very valid portfolio of opportunities in a very structured way and processed way where all the basic questions are laid down into quite some detail ...But we only want opportunities in there, where people not only specify the need, but have already found themselves a viable solution in the external world."

\section{An Open Innovation Framework}

A major conclusion from this first analytical step is that differences in the external discovery and internal creation processes of firms lead to different modes of OI. The data reveals that in the context of OI the discussion of opportunity creation and discovery should not be reduced to an 'either/or' distinction. In reality, firms utilize a variety of approaches to initiate OI. In other words, firms discover and create opportunities for OI. Applying this framework to the data, I identified four modes of OI that capture the variances in firms' opportunity discovery and creation processes (see figure 2.1). The data further shows that these modes are not mutually exclusive, but that there may be different OI modes within a single organization hence, firms consider a portfolio of OI opportunities. In summary, processes of external discovery and internal creation function as strategic determinants of OI. Juxtaposing these two dimensions, we can derive a framework of OI that reveals four distinct modes. This framework illustrates the diversity of OI modes as reflected in the case data. In the following, I will consider the dynamic properties of this framework and show that it goes beyond the two rather static dimensions of opportunity identification and the individual modes that result from these dimensions. 


\section{RESULTS SECTION 3: DYNAMICS OF OPEN INNOVATION OPPORTUNITY IDEN- TIFICATION}

Opportunity creation and discovery processes are path dependent, emergent, and myopic (e.g. Teece, Pisano, \& Shuen, 1997; Rosenkopf \& Nerkar, 2001). Firms tend to engage in activities that are consistent with prior beliefs about the nature of the opportunities they might face (Alvarez, Barney, \& Anderson, 2013) and deep investments may make an actor resistant to new ways of doing something (Levitt \& March, 1988). However, technologies, markets, and strategies are dynamic and evolve over time (e.g. Schreyoegg \& Kliesch-Eberl, 2007; Wang \& Ahmed, 2007; Teece, 2012). As a consequence, opportunities may become easily obsolete and may not fit the firm's internal strategy and/or external environmental developments (Hitt et al., 2001). The case data at hand also highlights the need for continuous adaptation of the processes of OI opportunity identification. More specifically, the data analysis suggests that firms adjust the two dimensions of opportunity identification - external discovery and internal creation - as well as continuously transform the individual modes of OI. Table 2.3 illustrates these dynamic patterns and provides some exemplary activities and illustrative quotes.

\section{Transforming the Dimensions of the Open Innovation Framework: Strategic Filtering \& Recalibrating}

In the process of OI opportunity identification firms attempt to continuously match shifting internal strategic posture with external environmental changes. More specifically, firms implement two separate mechanisms to dynamically update the two dimensions of the OI framework in terms of external discovery and internal creation. As demonstrated in table 2.3, firms employ a process to break the path dependency of external search and continuously transform external discovery. Over time the external discovery process becomes myopic, since firms would like to continue partnering with external parties that they have built up positive experiences with. This problem is explained by Poseidon's director of innovation alliances: "The typical way of working is that you build a consortium; people love working together and then people start repeating themselves. Of course, there are always issues still to be addressed and after project $A$ comes project B, comes project $C$, without having a clear goal in mind. So it becomes an exercise for the sake of new research and not an exercise for the sake of delivering marketable solutions." Therefore, firms attempt not to become locked into their external discovery routines, by continuously refining their external 'window-to-the-world'. However, at the same time, firms easily become subject to over-search and scan and discover too broadly in the external environment. Hence, external discovery needs to maintain a specific direction that needs to be continuously updated with regard to the firm's internal strategy. The need for this strategic focus in the external discovery process is 


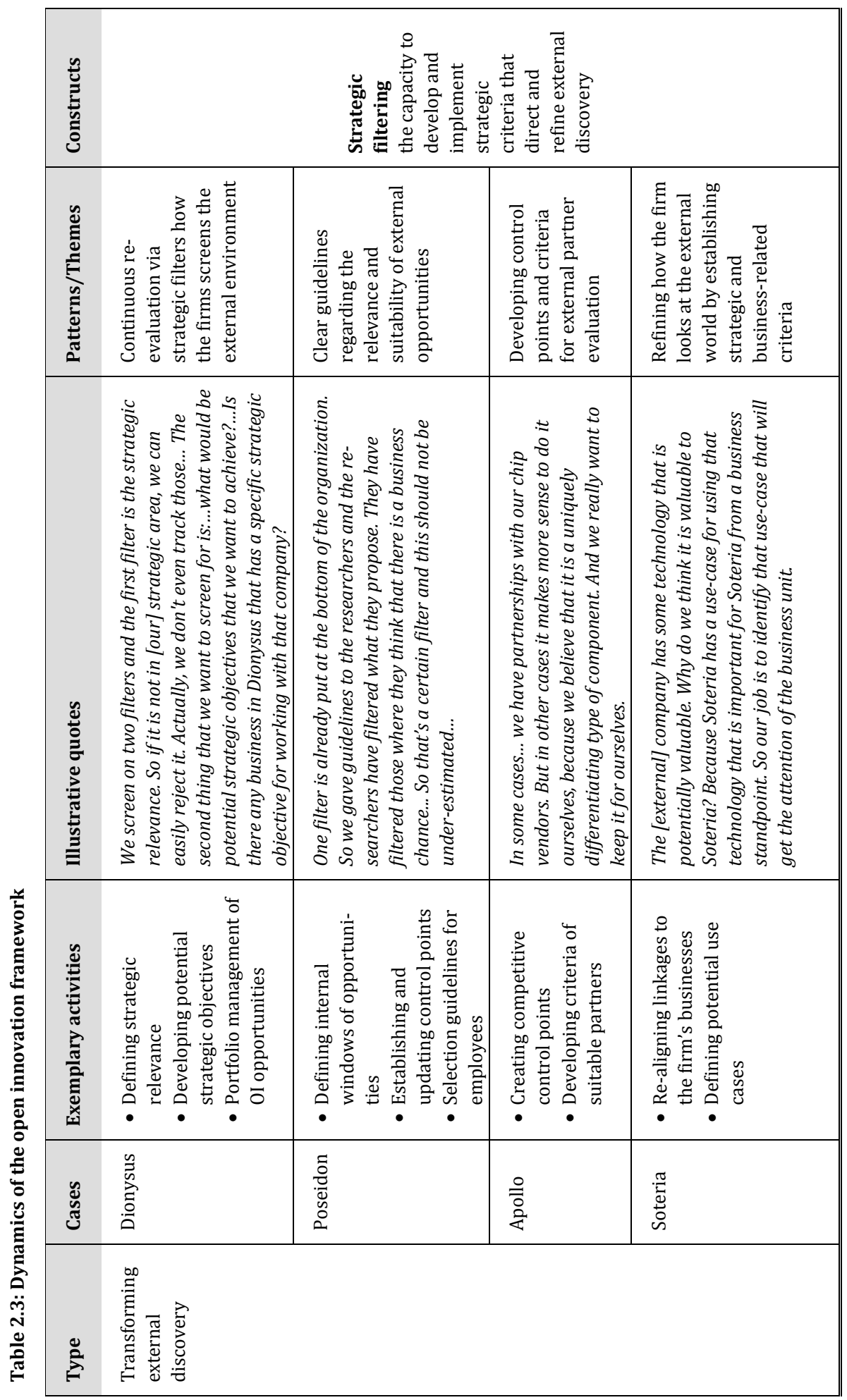




\begin{tabular}{|c|c|c|c|}
\hline \multicolumn{4}{|c|}{ 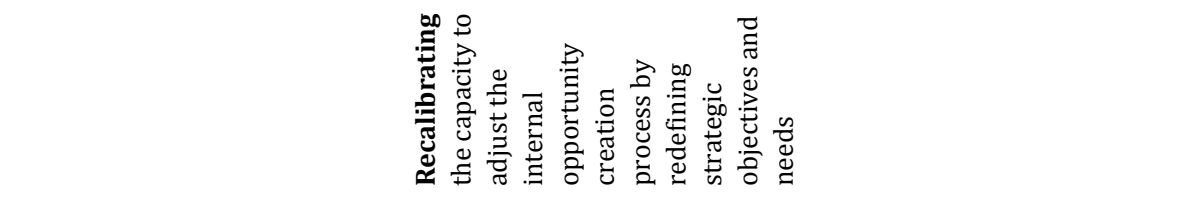 } \\
\hline 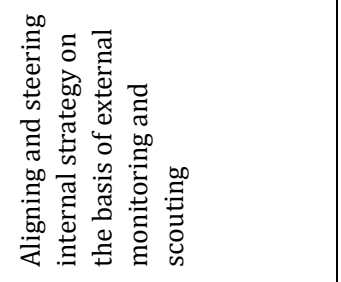 & 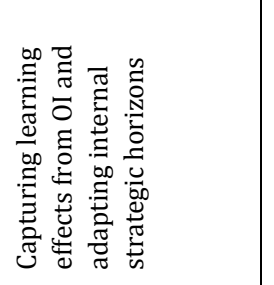 & 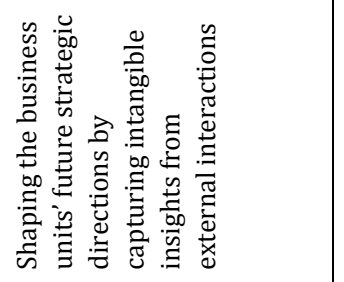 & 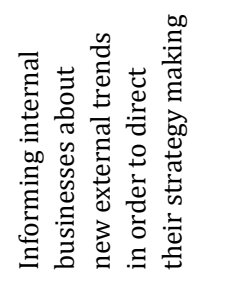 \\
\hline 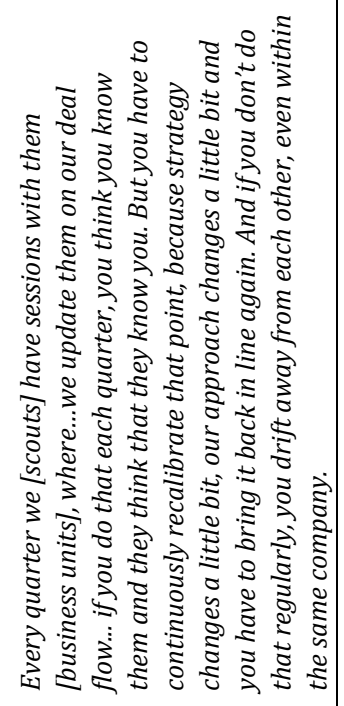 & 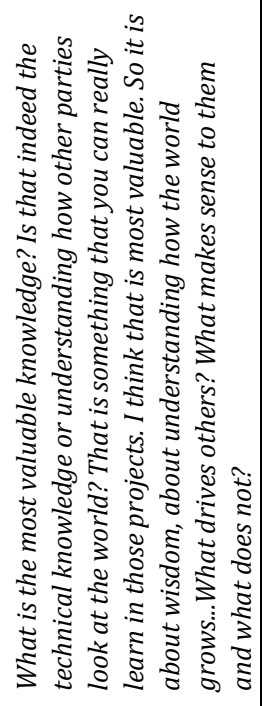 & 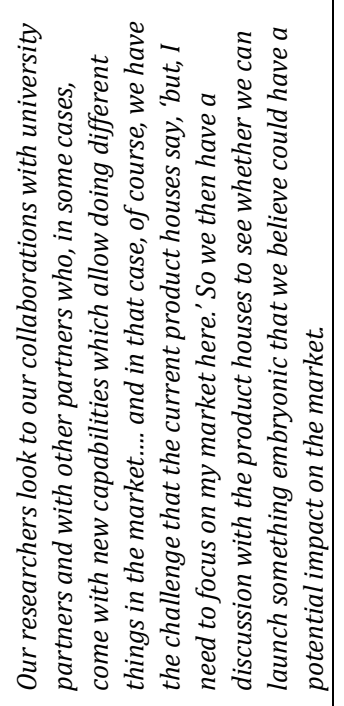 & 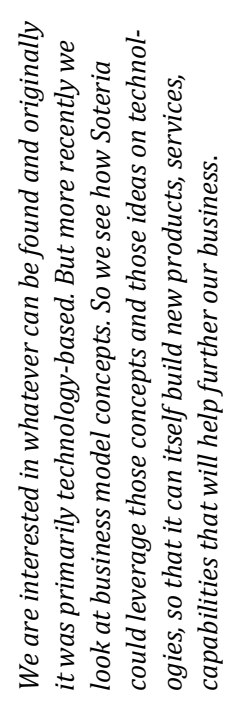 \\
\hline 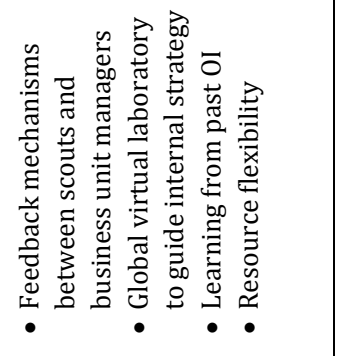 & 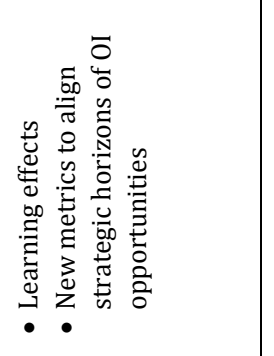 & 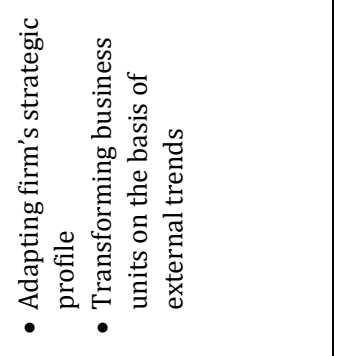 & 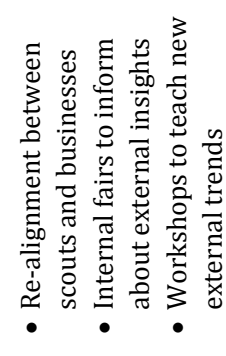 \\
\hline 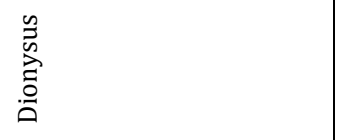 & 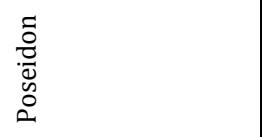 & $\begin{array}{l}\stackrel{\circ}{\circ} \\
\text { 衣 }\end{array}$ & $\begin{array}{l}\stackrel{\pi}{\tilde{d}} \\
\stackrel{\tilde{D}}{0}\end{array}$ \\
\hline 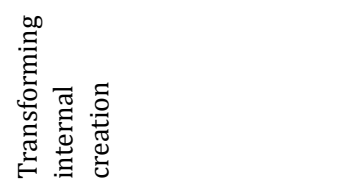 & & & \\
\hline
\end{tabular}




\begin{tabular}{|c|c|c|c|}
\hline \multicolumn{4}{|c|}{ 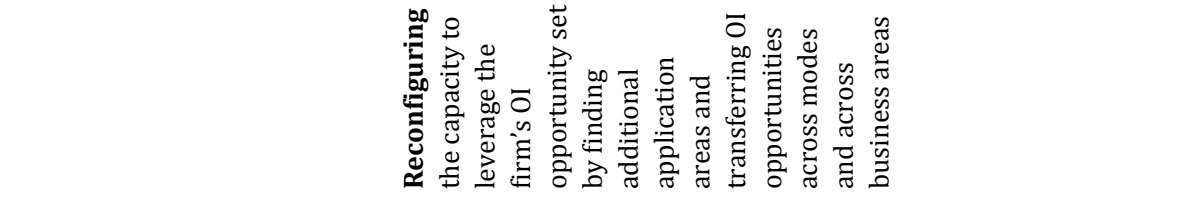 } \\
\hline 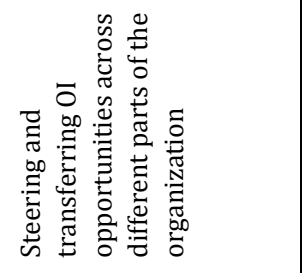 & 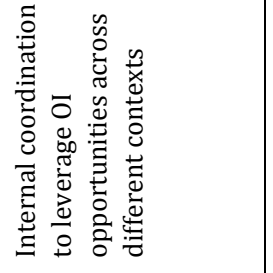 & 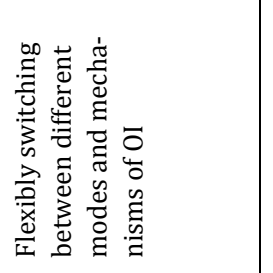 & 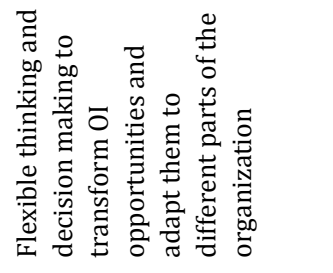 \\
\hline 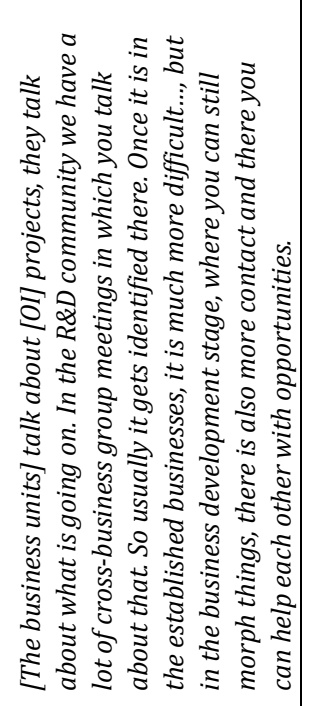 & 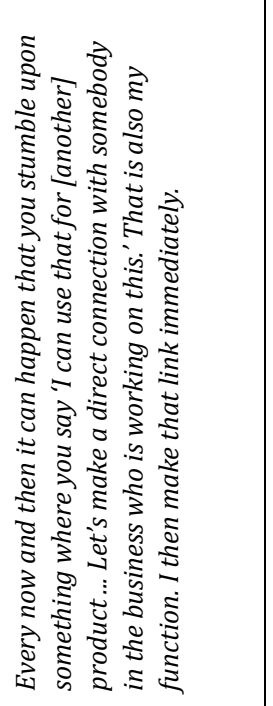 & 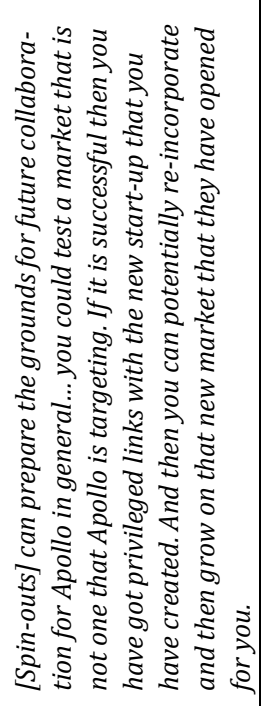 & 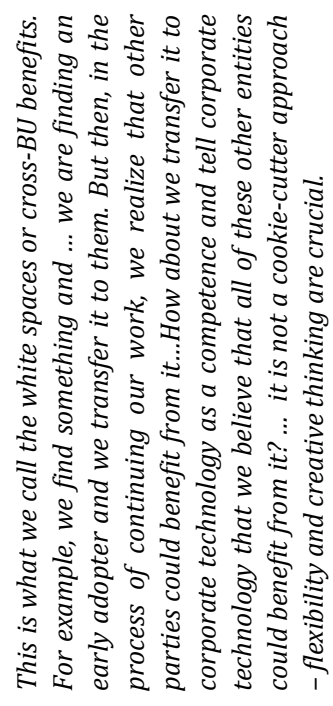 \\
\hline 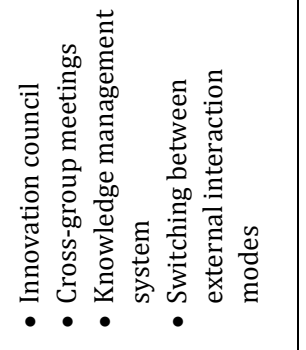 & 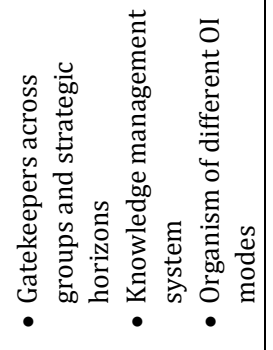 & 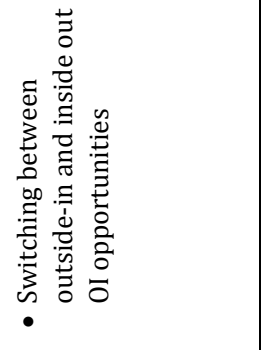 & 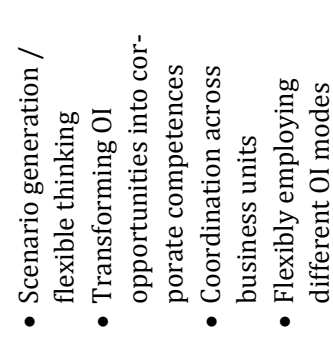 \\
\hline 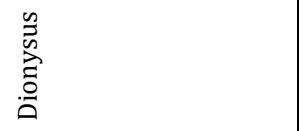 & $\begin{array}{l}\tilde{0} \\
\stackrel{0}{0} \\
\dot{0} \\
0 \\
0\end{array}$ & $\begin{array}{l}\stackrel{\circ}{\overline{8}} \\
\stackrel{\circ}{4}\end{array}$ & 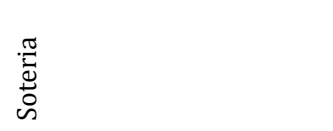 \\
\hline 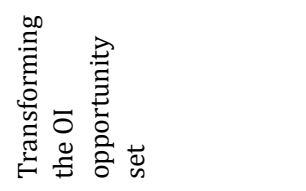 & & & \\
\hline
\end{tabular}


illustrated by Dionysus' VP of innovation: "You have to make a choice and then within those borders find the nice open innovation opportunities."

In order to refresh external discovery and provide strategic direction, firms develop and implement a number of filters that steer external search. Strategic filtering aims at establishing fit between external discovery and the firm's internal strategic posture in order to avoid over-search and monitor only those external institutions that are related to the strategic space of the focal firm. In order to achieve this fit, firms must understand their current and future strategic positions. This enables them to develop various filters with respect to what is relevant to the focal company amongst all opportunities and options in the external world. A first strategic filter involves transparency of existing innovation projects such that the firm has a good understanding of its strategic scope. This enables the firm to continuously refresh portfolio considerations such that discovered OI opportunities optimally contribute to the strategic targets of the focal firm. External discovery should be organized in such a way that OI opportunities reflect the entire portfolio of the firm. These portfolio considerations are explained by Dionysus' venturing director: "Our [OI] portfolio should basically reflect the portfolio of Dionysus. So if you would only have nutrition opportunities and we would forget about 'material' opportunities, then that's not good. It should be a reflection of what we do... So there are all sorts of portfolio considerations that I want to see."

A second filtering mechanism refers to timing of externally discovered opportunities for OI. It is crucial to develop an understanding at what point in time the focal firm is capable of absorbing externally discovered OI opportunities. In other words, when does the window to create substantial synergies between internal and external resources materialize? Poseidon's IP coordinator explains: "When the project is in a technology function creation process, then they are open for open innovation. Then they can absorb ideas from third parties. But when a specific project starts in the product development phase, then they have made their decision." If opportunities are discovered at the wrong point of time, they will not be absorbed by the business units of the firm. Hence, external discovery needs to be continuously updated with regard to internal timing considerations.

A third filtering mechanism refers to continuously refining external discovery in such a way that is maintains a clear link with the focal firm's businesses. This involves understanding the business cases of the focal firm so that this can be incorporated in the screening process of external discovery. The data suggests that firms are only able to discover valuable opportunities for OI if they have a good understanding of current and future use cases of these opportunities. This ensures a clear link of OI opportunities to the firm's innovation pipeline and, thereby enables the subsequent exploitation and absorption of the OI opportunities, as illustrated by Soteria's director of venture technology: "Ultimately we still want the 
[external] company to work with the business units and we want some transfer to take place".

Finally, I find that firms dynamically filter with respect to competitive considerations. Such competitive filtering mechanisms particularly apply to inside-out OI. It deals with deciding which internal technologies are 'free' for external commercialization and with ensuring that competitors cannot capture a competitive advantage from these technologies. Poseidon's director of external relations explains how they establish and update control points for critical technologies. "The essence of the strategy is finding out how you need to manage that mix: what parts of your innovation can you share with others and what parts should you do on your own." Based on inductive analysis (see table 2.3) I coin the term 'strategic filtering' to address the continuous transformation of external discovery. Overall, I define strategic filtering as the capacity to develop and implement strategic criteria that direct and refine external discovery.

In addition to applying strategic filters to external discovery, my data reveals that in order to avoid strategic lock-in, firms continuously recalibrate their internal creation process and re-align their strategic focus (see table 2.3). As such, firms can ensure that they create opportunities for OI that are in line with recent external developments and trends. This includes systematic feedback mechanisms between scouts who are responsible for discovering external opportunities and the business units which usually focus on internal opportunity creation. This requires frequent meetings and communication between the two parties in order to ensure continuous re-alignment: "We tell them about what it is that we see out there." Moreover, when scouts find potentially interesting technologies that do not immediately fit into the business units, then they are sometimes pushed into the R\&D community in order to bring them to the right level of discussion. Soteria, for instance, frequently hosts internal fairs and shows at which scouts can present new external trends and technologies. This is to ensure that the internal businesses remain receptive to external ideas and that the internal creation process is continuously adjusted. Furthermore, it helps to create greater internal awareness of the diversity of OI opportunities. Related to this is the continuous adjustment of the strategic scope of the business units. For instance, Dionysus has established a global virtual laboratory, which steers the internal creation process and guides strategic decision making, as explained by the vice president of OI: "A science network which allows us to take the right decisions and make the right evaluations."

Another important aspect refers to learning from past experiences and adjusting the internal creation process accordingly. One example is Dionysus' learning experience when it engaged in an OI project by investing into a start-up firm that had developed a specific enzyme technology. While this initiative did not lead to a new product being introduced into the market and, hence, was considered a failure, Dionysus managed to revise the strategic direction of the business unit and free up 
resources for more promising OI opportunities. Similarly, Poseidon's director of external relations emphasizes the importance of capturing such learning effects: " $I$ think it is more about finding out that a given path is not the right way to go... and then also to decide to stop it or continue with it, or whatever." Both Apollo and Soteria continuously monitor to what extent they are discovering and capturing external trends and technologies and adjust their internal creation process accordingly. Apollo's innovation manager explains that it is crucial to adapt the profile of the firm in accordance to external discovery: "If you monitor over the years certain research areas..., then you can conclude with a group of people that works in technology where something should be going." This implies that beyond technology acquisition, these firms attempt to translate externally acquired knowledge into value via learning experiences for future internal creation. Soteria, for instance, disseminates these learning experiences internally via seminars or workshops that help to explain what has been discovered in the external world.

Adjustment of the internal creation process requires a constant revision and evolution of the firm's research roadmap. In this context, insights from external discovery can be used to inform and revise the firm's research roadmap and adjust it to emerging external trends. In a next step, this requires the firm to shift internal resources from existing projects to new opportunities. As firm resources are typically tied up, this means that resources need to be freed for new, potentially more valuable, OI opportunities. This involves balancing the strategic horizons of the businesses to compromise fire-fighting at the business unit level and more longterm projects that capture future trends at the corporate level. Poseidon, for instance, is currently implementing new metrics that better align with the strategic horizons of OI opportunities and allow firms to capture and react to emerging trends in the external environment. In sum, firms continuously adapt their internal creation processes, based on insights captured from the external environment.

Dynamic capabilities research has highlighted the concepts of strategic flexibility and continuous transformation as important aspects (Rindova \& Kotha, 2001). Firms continuously re-align their internal strategic posture and shift strategic needs (Wang \& Ahmed, 2007). Rindova and Kotha (2001), for instance show how firms increase the flexibility of their overall asset stock as well as the match between the assets of the firm and its shifting strategic needs in transient conditions. Protogerou, Caloghirou and Lioukas (2011) refer to strategic competitive response to address how firms aim at understanding and adapting to environmental trends. In keeping with prior research, the data analysis suggests that firms continuously transform their strategic posture and adapt their internal creation processes. I refer to this process as recalibrating, which can be defined as the capacity to adjust the internal opportunity creation process by redefining strategic objectives and needs. 


\section{Transforming Modes of the Open Innovation Framework: Reconfiguring}

The data analysis reveals that it is not only the dimensions of the OI framework that are continuously transformed via strategic filtering and recalibration (see table 2.3). In addition, the OI opportunity set itself and the different OI modes constituting this opportunity set also require continuous adaptation. Poseidon's director of external relations, for instance, highlights the need for transforming OI opportunities across different business units: "Two weeks ago we had a meeting to stop one of those projects seen as very successful. What was the fight about? The major items on the table were, (a) is this still a priority on our roadmaps? That ultimately was the case, so that was the good news. (b) What [organizational] department? And then the chances that you - years in advance - pinpoint the right ones, is rather limited, to be honest." Hence, continuous transformation is required in order to optimally leverage the OI opportunity portfolio in the most suitable parts of the organization. The data suggests that new applications of OI opportunities can be discovered by 'morphing' these opportunities across business units. I have come across several examples in which OI was leveraged into other strategic areas than initially planned. For instance, in one case Poseidon transferred an opportunity from a more future-oriented, strategic OI initiative to a business unit working on a short-term project which could incorporate the OI initiative in a more complementary manner. Similarly, Soteria frequently engages in scenario generation and flexible thinking in order to capture white spaces and cross-business benefits. Furthermore, when Soteria believes that cross-business benefits are involved it translates the OI opportunity into a more general competence. The corporate technology department can then promote this new competence to other parts of the organization, creating additional opportunities from OI. Similar cross-business transfer mechanisms may apply for inside-out OI. Firms can engage in identifying alternative options as to how to commercialize an internal technology and generate scenarios for applications in different environments. For example, Soteria's venturing manager explained how they licensed an internal technology that was developed in the automotive segment into an external medical environment: "Sometimes it's obvious and the purpose and the market are clear, but in this case it was all but obvious."

In order to identify such transfer opportunities, frequent cross-business group meetings are held. In addition, Dionysus has established an 'Innovation Council' in which directors of all business groups are represented. The council discusses potential transfer opportunities of current projects and opportunities and steers anything that goes beyond the regular business, as explained by Dionysus' innovation director: "The responsibility lies, in principle, with any business group. So if they have their own portfolio of technologies and projects and decide: this does not fit our strategy anymore, then it goes up to the council. Ok, can anybody else use this technology?" 
Another transfer mechanism refers to knowledge management and systems. Poseidon, for instance, has implemented a new knowledge management system that collects external insights and spreads them within the organization. This might initiate new possibilities for applying OI opportunities. Similarly, Dionysus has implemented a knowledge management system in which all information captured from the outside is collected. This will help employees "to discover what their colleagues have discovered", which in turn enables leveraging of OI opportunities. Moreover, these knowledge management systems go beyond the individual business unit, enabling cross-business transfer. As Dionysus' innovation director summarizes: "There are lots of opportunities for us to share internally, what has been discovered and what can be used."

Finally, in addition to transferring OI opportunities across business units, firms also flexibly switch between the four identified modes of OI. This is to ensure continuous strategic fit between the firm's requirements and the OI initiative. A good example is Dionysus which switched from licensing a technology from a startup firm in the complementary OI mode to a strategic acquisition of that specific start-up. Apollo, for instance, re-incorporated a firm that was previously spun out from the organization. Similarly, Soteria attempts to remain flexibility across its different OI modes. For instance, spin-outs may serve as future access to complement internal technologies. Finally, Poseidon attempts to create an 'organism' of OI, in which different modes can inform each other. For instance, Poseidon frequently interacts with its own spin-outs to identify future OI opportunities. As Dionysus' venturing director summarizes: "The objective is to get the outside opportunity into Dionysus. It doesn't matter which way. It should be the most effective, efficient, economically attractive way."

An important aspect of continuous transformation in the dynamic capabilities literature is the notion of fungibility (Teece, 1982; Danneels, 2002; 2010; Miller, 2003). Fungibility refers to the extent to which firms can draw on existing resources and apply them to new uses such as new product categories. Hence, it deals with the extendability of a resource and suggests that knowledge resources can be used repeatedly and leveraged into different areas (Eisenhardt \& Martin, 2000; Ambrosini, 2003; Danneels, 2010). Galunic and Eisenhardt (2001) refer to this mechanism as 'reconfiguring'. In their study of modular corporate forms, they focus on the modularity of corporate resources and investigate the processes by which these resources are dynamically reconfigured between divisions as markets and corporate players co-evolve. Interestingly, my data suggests a similar mechanism at the opportunity stage of OI. In this context, reconfiguration aims at leveraging the firm's OI opportunity set by finding additional applications across business areas and across different modes. It involves the restructuring of opportunities in order to optimize value creation. Overall, I define reconfiguring as the capacity to leverage the firm's OI opportunity set by finding additional application areas and transferring OI opportunities across modes and across business areas. 


\section{A Dynamic OI Framework}

A next step refers to integrating these dynamic patterns into the OI framework. Figure 2.2 illustrates a dynamic version of the OI framework, by introducing 'time' as a third dimension of opportunity identification. As argued above, as the firm's environment and its internal posture change over time, firms dynamically transform their processes of OI opportunity identification and their OI opportunity set. Adding to prior literature on continuous transformation, this study suggests three separate dynamic processes. As discussed in the previous sections, strategic filtering and recalibrating refer to the continuous transformation of the framework's dimensions (external discovery and internal creation), while reconfiguring refers to the continuous transformation of the OI opportunity set.

Figure 2.2: A dynamic open innovation framework

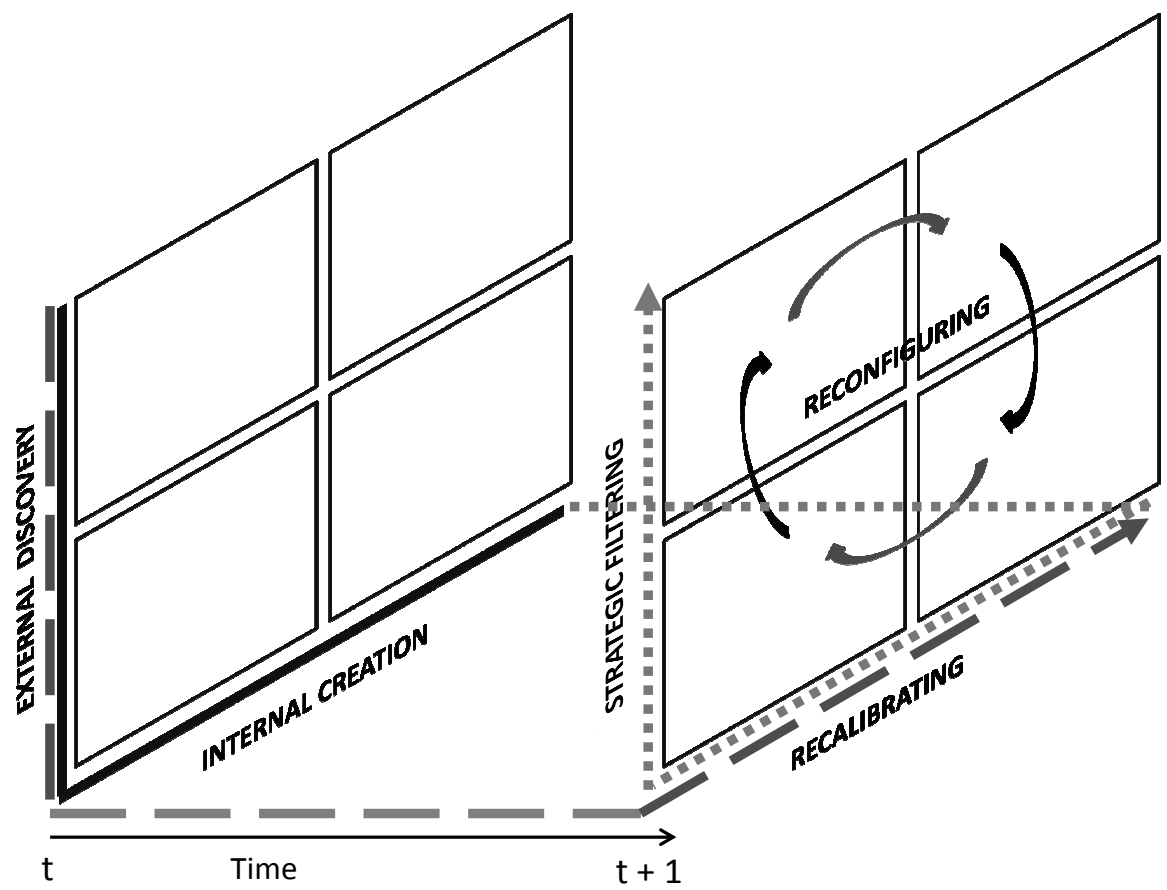

As indicated in figure 2.2, internal creation informs and refines external discovery, via strategic filtering. By engaging in internal opportunity creation firms develop a better understanding of current internal needs/gaps and of new strategic areas. This understanding helps firms to refine their external discovery process over time via strategic filtering, "...because only if you know what you already know, you can define what further information you really need." (Soteria's OI program manager). This is visualized in figure 2.2 in terms of an arrow reaching from the 
dimension of internal creation at time $t$ to the dimension of external discovery at time $t+1$. Hence, over time, internal creation leads to enhanced external discovery via strategic filtering.

Furthermore, figure 2.2 illustrates that external opportunity discovery informs and updates internal creation, via recalibrating. By capturing emerging environmental trends and new technologies via local and global discovery, firms can continuously adjust and align their internal creation process. Again, this is visualized in figure 2.2 in terms of an arrow reaching from the dimension of external discovery at time $t$ to the dimension of internal creation at time $t+1$. Poseidon's director of business creation highlights the importance of capturing insights from external discovery for re-aligning internal strategic frameworks: "Are we receptive enough to new ideas from the outside that don't fit our fixed businesses and our nice internal framework of how things should work...? And when there is something new coming in? I think now we start to realize that it will be the next step to open that up again." Therefore, external discovery leads to enhanced internal creation by means of recalibration. These findings are in line with Zahra's (2008) suggestion that opportunity discovery and creation can form a virtuous and dynamic cycle where discovery enriches creation which, in turn, fosters the discovery of new opportunities. This study adds to these insights by suggesting distinctive mechanisms that explain how discovery enriches creation (via recalibration) and how creation fosters discovery (via strategic filtering).

Finally, this study adds another dynamic pattern that explains how firms reconfigure their OI opportunity set and, thereby, leverage OI opportunities across business units and modes. Figure 2.2 depicts how the OI opportunity set, as determined by external discovery and internal creation, is reconfigured and leveraged over time. An example at Poseidon can illustrate how OI modes are reconfigured over time, when Poseidon transferred an OI opportunity from the exploratory mode to the complementary mode "There is a company that we are already in talks with for half a year to find out how can we work together. And then suddenly something came out of their labs, where somebody said 'we could actually use this.' And it just came through that channel to me and this Friday I put the responsible people in Poseidon for that specific part of the business together. And I will bring this in and we will find out within the hour whether we would like to take this further." Hence, reconfiguring reflects the continuous transformation of OI opportunities across different business units and modes.

\section{DISCUSSION AND CONCLUSION}

I have argued in this study that $\mathrm{OI}$ is an important phenomenon and that the generative mechanisms through which it occurs are theoretically interesting in their own right, and also relatively poorly understood. This study adds to the emerging 
literature stream of OI by providing in-depth insights into this phenomenon and it clarifies how firms identify and continuously transform opportunities for OI. While prior research has discussed the management and outcomes of OI activities (e.g. Fey \& Birkinshaw, 2005; Laursen \& Salter, 2006; Almirall \& Casadesus-Masanell, 2010; Foss, Laursen, \& Pedersen, 2011; Petroni, Venturini, \& Verbano, 2012), the fuzzy front end in terms of how OI activities come about was left unaddressed. To address these generative mechanisms I explored the OI opportunity identification process by means of a theory building approach. To guide the theory building process I used concepts and theories stemming from the strategic entrepreneurship and dynamic capabilities literatures that help to shed light on this first stage of OI. Using multiple case study methods, I then investigated the OI opportunity identification process in a selected sample of leading OI firms. A core contribution is an emergent theoretical framework of how firms identify and continuously transform opportunities for OI. This framework enables a better understanding of the origins and processes of OI. Several aspects can be highlighted that outline a theory for OI.

First, my research generates two main dimensions of opportunity identification for OI. On the one hand, firms engage in an external discovery process that aims at locally scouting required technologies and globally exploring emerging technological trends. On the other hand, firms implement an internal creation process that aims at reactively identifying internal needs and proactively generating new strategic themes and topics. Hence, external discovery and internal creation represent different dimensions of search for opportunities in an OI framework. Prior research suggests that there are substantial variations in the degrees to which firms identify external knowledge and commercialization sources (Laursen \& Salter, 2006; West \& Bogers, 2013). This study proposes that this is reflected in the different ways firms process external discovery and internal creation. Firms employ different search strategies by implementing various combinations of reactive internal creation, proactive internal creation, local external discovery, and global external discovery. While external discovery would represent the most obvious route to OI, this study reveals that it is equally important to focus on internal creation in order to identify OI opportunities that are driven by firm-specific strategies and needs.

These dimensions of opportunity identification for OI are mirrored in theoretical concepts of the strategic entrepreneurship literature (e.g. Ireland \& Webb, 2007; Ketchen, Ireland, \& Snow, 2007). They reflect firms' attempts to create wealth by exploiting current competitive advantages (via reactive internal creation and local external discovery) and by setting the stage for future performance through identifying OI opportunities that will create subsequent advantages (via proactive internal creation and global external discovery). Furthermore some similarities with the theoretical concepts of discovery and creation were uncovered. Contrasting the incompatibility of these concepts in the entrepreneurship 
literature (e.g. Alvarez, Barney, \& Anderson, 2013), the framework at hand suggests that in the context of OI firms can balance discovery and creation by combining external and internal search.

Second, based on these dimensions I developed an OI framework highlighting the important roles of external discovery and internal creation and the ways these two processes interact with one another. This framework suggests a number of important insights. It demonstrates that external discovery and internal creation are strategic determinants of different modes of OI. Juxtaposing these dimensions of opportunity identification reveals a matrix structure of four different modes of OI that capture the variance that exists when firms discover and create opportunities for OI. Hence, patterns of opportunity identification have direct implications for the firm's types of OI. More specifically, four distinct modes can be created by jointly considering external discovery and internal creation: complementary-, entrepreneurial-, exploratory-, and strategic OI. Firms use these modes to pursue different objectives, including complementing their internal innovation projects, creating new projects or segments, capturing external trends and technologies, and moving into adjacent strategic areas in collaboration with external partners.

So far, OI has come in many forms and tastes, which adds to the richness of the concept but hinders theory development (Dahlander \& Gann, 2010; Huizingh, 2011). This calls for the development of OI frameworks in order to contribute to a better understanding of the encompassing phenomenon. As Huizingh (2011) suggests, different sets of OI practices can be contrasted to develop matrices distinguishing various forms of OI. This study addresses this call by proposing such a matrix of different OI modes. The diversity of these modes shows that OI is not only used as a defensive mechanism to complement the new product development process and address a lack of knowledge and competences (Keupp \& Gassmann, 2009; Drechsler \& Natter, 2010; Garriga, von Krogh, \& Spaeth, 2013). In contrast, OI firms also engage in joint exploration, learn about new trends, and grow into business adjacencies. Hence, firms pursue both defensive as well as more offensive motives in their OI portfolio (Chesbrough \& Crowther, 2006). Moreover, instead of making individual decisions concerning single interactions with external partners, firms consider a portfolio of different modes of OI opportunities.

Third, this framework demonstrates the dynamic nature of OI opportunity identification. Prior research has shown that opportunities may become easily obsolete and firms may become subject to path dependency, inertia, and oversearch (e.g. Uzzi, 1987; Teece, Pisano, \& Shuen, 1997; Katila \& Ahuja, 2002; Laursen \& Salter, 2006; Ambrosini, Bowman, \& Collier, 2009). In line with this notion, this study shows how firms continuously transform their OI opportunities and the ways these opportunities are identified. The data analysis generates three dynamic patterns that explain how firms adapt and re-align their OI portfolio in order to avoid that opportunities become obsolete. These dynamic patterns illustrate how 
firms attempt to overcome tensions between inertia on the one hand, and oversearch on the other hand. First, the dynamic process of recalibrating addresses risks of strategic lock-in and path-dependency (Teece, Pisano, \& Shuen, 1997) by continuously redefining internal strategic objectives and needs. Second, firms apply strategic filters to their external discovery process to avoid over-search (Katila \& Ahuja, 2002; Laursen \& Salter, 2006) and reconsider repeated patterns in external partner selection (Dahlander \& Gann, 2010). Third, reconfiguring OI opportunities between different parts of the organization and different modes of interactions enables firms to re-establish fit when internal requirements change and to optimally leverage the OI opportunity portfolio.

These processes are most anchored within the dynamic capabilities literature (e.g. Zahra, Sapienza, \& Davidsson, 2006; Helfat et al., 2007; Teece, 2007; Wang \& Ahmed, 2007). They reflect how firms align their OI opportunity portfolio with changing environmental developments and with shifting strategic requirements. Hence, this study suggests that firms develop a set of dynamic capabilities - strategic filtering, recalibrating, and reconfiguring - to continuously realign and refresh OI opportunity identification. A dynamic capability for OI is then concerned with finding the right balance between the relevant contingencies in the business environment (external fit) and the firm's internal strategies and resources (internal fit). The ability to dynamically manage the OI framework may actually become a core dynamic capability that other firms find difficult to replicate. Hence, the combination of external discovery and internal creation and the continuous transformation of the OI opportunity identification process via strategic filtering, recalibrating, and reconfiguring may contribute to more valuable and rare OI opportunities that are firm-specific and lead to competitive advantage.

In sum, this research contributes to the emerging research field of OI by developing a theoretical framework of OI based on the opportunity identification process. This framework provides some insights into the origins of OI strategies. In addition, it opens the black box of OI and provides a means for studying alternative OI modes. It further highlights the importance of dynamically managing an OI framework. It illustrates how firms must balance external discovery and internal creation and how they continuously transform their OI opportunity landscape. Together, these features of the developed framework suggest an outline of a theory of $\mathrm{OI}$ and provide various possibilities for future research. For instance, the suggested framework of OI does not incorporate any normative implications. In other words, so far, little can be said concerning which modes or which combination of OI modes is most successful for different firms. An avenue for future research is to link the four identified modes of OI to different innovation outcomes. For instance, one would assume that complementary OI positively contributes to incremental innovation, whereas strategic OI may lead to new business creation. In addition, it would be of interest to study contextual factors of this OI framework. Under which external and internal conditions are individual modes of OI most appropriate? Thereby, 
CHAPTER 2 - The Fuzzy Front End of Open Innovation

future work can add to this study and shed more light on the fuzzy front end of OI by providing a better understanding of the territory leading up to the adoption of various OI activities. 


\section{CHAPTER 3}

\section{Conditions of Open Innovation Effectiveness - Internal Integrative Capability and External Environmental Factors ${ }^{2}$}

While firms increasingly open up their boundaries to access external sources of innovation, they often struggle to translate this openness in innovation into positive outcomes. At the center of this study is a theoretical and empirical examination of the conditions that determine to what extent firms benefit from their openness in innovation. Drawing from a dynamic capabilities perspective this study investigates conditional factors in the internal organization and external environment of firms that influence the relationship between openness in innovation and open innovation performance. The empirical analysis reveals a positive effect of the degree of openness on open innovation performance, which is stronger under firm conditions that are characterized by strong integrative capabilities, particularly by the underlying dimensions of knowledge transfer and knowledge translation capability. Furthermore, the effect is stronger under environmental conditions of high technological turbulence. As a result, this study contributes to an explanation of inter-firm heterogeneity in capturing value from openness in innovation.

\footnotetext{
2 I am grateful to John Hagedoorn for his valuable feedback. I would also like to thank Wim Vanhaverbeke for supporting the data collection via Exnovate. Many thanks also go to Valérie Duplat, Lisa Brüggen, and Dominik Mahr for their feedback and help in the survey design and to Désirée Schumacher and Hannes Günther for sharing their insights on data analysis.
} 


\section{INTRODUCTION}

Firms are increasingly opening up their innovation processes by combining internally and externally developed knowledge (Foss, Laursen, \& Pedersen, 2011) and bringing in-house inventions to markets via external paths (Dahlander \& Gann, 2010). While traditionally, innovation was based on strong internal and exclusive R\&D, firms that are adopting an open innovation (OI) model embrace a mentality of outside-in and inside-out thinking that builds extensively on external sources of innovation and commercialization (Chesbrough, 2003). While acknowledging the inside-out dimension of OI, this study focuses on the deployment of external ideas, knowledge, and technologies to accelerate internal innovation processes (Almirall $\&$ Casadesus-Masanell, 2010). The core idea of this outside-in mode of OI is the involvement of different external parties (e.g. customers, suppliers, universities, competitors) in various flexible ways that transcend beyond the traditional notion of innovation alliances and contract research (Keupp \& Gassmann, 2009). Knowledge and competences that were traditionally developed internally are now increasingly accessed from a broad set of external parties, which are flexibly chosen and recombined over time (Chiaroni, Chiesa, \& Frattini, 2011).

While the OI model is becoming increasingly popular, first empirical evidence reveals that openness is not necessarily beneficial and that returns from OI vary substantially between firms (Laursen \& Salter, 2006; Knudsen \& Mortensen, 2011). Recent studies suggest diminishing returns to performance when firms open their innovation process to external sources of knowledge too broadly (Laursen \& Salter, 2006). Furthermore, while inter-organizational knowledge and technology transactions are increasing, many firms face organizational and managerial difficulties in realizing these transactions (Huizingh, 2011; Knudsen \& Mortensen, 2011). While differential outcomes of OI have been established in the literature, it is currently lacking explanations for such diverse effects. There is a gap in understanding how firms can translate their OI strategies into positive innovation outcomes. To shed light on why firms differ in their abilities to capture benefits from openness in innovation, it needs to be investigated how OI can be facilitated and supported by various conditions.

There seems to be a consensus in the literature that the context dependency of OI is one of the least understood topics (Bahemia \& Squire, 2010; Dahlander \& Gann, 2010; Di Benedetto, 2010; Huizingh, 2011). Literature on the strategic, behavioral, and decision making aspects of OI highlights both internal and external context characteristics (Fey \& Birkinshaw, 2005; Almirall \& CasadesusMasanell, 2010). An optimal approach to a strategy, such as OI should be one that explicitly accounts for both internal organizational and external environmental attributes (Ginsberg \& Venkatraman, 1985; Venkatraman, 1990). Hence, it is of interest under what firm-specific internal conditions and environmental contingencies openness in innovation becomes effective. Internal conditions can relate to 
firm demographics and strategies (Huizingh, 2011), but also concern how firms organize internally for OI. In addition, openness in innovation may be more effective in an environment displaying certain characteristics, such as technological turbulence (Almirall \& Casadesus-Masanell, 2010). The core idea of this logic is that 'fit' between the firm's degree of openness and specific firm-internal and external factors should lead to superior OI performance.

Although there seems to be a consensus that OI depends strongly on interorganizational knowledge transactions (Fey \& Birkinshaw, 2005; Chiaroni, Chiesa, \& Frattini, 2001; Foss, Laursen, \& Pedersen, 2011; Petroni, Venturini, \& Verbano, 2011), little is known about the internal organizational processes that enable external knowledge resources to flow into the firm. So far, knowledge management research is often restricted to internal knowledge creation and exploitation processes (Nonaka, 1994; Grant, 1996). However, organizational capabilities for dynamic knowledge management are also vital for the effective integration of external knowledge resources (Foss, Laursen, \& Pedersen, 2011). The transformation towards OI is largely an internal organizational innovation (Christensen, Olesen, \& Kjaer, 2005) that changes the ways firms acquire and integrate knowledge resources. This means that knowledge management capacity may serve as an important theoretical foundation for OI. Hence, the firm's internal organizational capabilities for managing external knowledge resources are likely to represent an important factor in determining the effectiveness of openness in innovation.

Likewise, while the impact of external environmental conditions, such as technological opportunities and competitiveness, on firm innovativeness and performance has been widely acknowledged (e.g. Zahra, 1996; Zahra \& Bogner, 2000), the impact of external factors on the effectiveness of OI is less clear. Nevertheless, the OI literature suggests that the effective usage of different external knowledge sources by an individual firm is partly contingent upon its external environment (Laursen \& Salter, 2006). In particular, industry effects, competitive intensity and the degree of market and technological turbulence have been highlighted (Huizingh, 2011). The external environment builds an innovation ecosystem (Teece, 2007), which has major effects on the benefits and risk of adopting an OI approach. This paper focuses on two elements of the external ecosystem - technological turbulence and competitive dynamics - which may alter the relationship between the degree of openness and OI performance.

The aim of this paper is to study internal and external characteristics that support the effectiveness of openness in innovation. It aims at providing a more differentiated picture concerning the conditions that make openness in innovation effective. Using survey data from 119 firms, I find strong support for both internal and external factors that moderate the relationship between openness and $\mathrm{OI}$ performance. These findings help to develop a better understanding of the organizational and environmental conditions that allow firms to effectively exploit exter- 
nal knowledge and harness the benefits of OI. This understanding sheds some light on why some firms are benefiting more from OI than others.

The paper proceeds as follows. The first section provides the theoretical background for studying the effectiveness of OI. An integrative framework of internal and external conditional factors of openness in innovation is suggested. In the second part, hypotheses concerning these factors are developed. Section three explains the data collection and applied methods. Section four presents the findings with regard to the interactions between organizational and environmental facets and the firm's openness in innovation. The final section contains the discussion of the results, together with conclusions and implications for future research.

\section{THEORETICAL BACKGROUND}

This study adopts a dynamic capabilities perspective to account for interdependencies of openness in innovation and internal organizational capabilities. The theory of dynamic capabilities builds on the resource-based view (RBV) and the knowledge-based view (KBV) of the firm. According to the RBV, firms can be conceptualized as bundles of resources and operational capabilities (Barney, 1991). Resources are any firm-specific assets that are owned or controlled, while operational capabilities are used by the firm to deploy these resources on a day-to-day basis (Amit \& Schoemaker, 1993). A single key resource - knowledge - has been highlighted for creating innovative and performance benefits in dynamicallycompetitive environments. According to the KBV the firm can be conceptualized as an institution for developing and integrating knowledge resources (e.g. Kogut \& Zander, 1992; Grant, 1996). Knowledge has been considered the most important strategic resource of the firm and, therefore, the KBV can be seen as the most essential subset of the RBV (Kogut \& Zander, 1992). Considering the strategic relevance of knowledge resources in the innovation process, external knowledge integration can also be considered as the essence of OI.

More recently, the concept of dynamic capabilities was introduced to address the static nature of the resource- or knowledge-based views and to extend their applicability to the context of turbulent environments (Teece, Pisano, \& Shuen, 1997). While the RBV and KBV fail to explain how firms can adapt to and remain competitive in changing environments, dynamic capabilities deal with the continuous upgrading of the firm's knowledge-based assets and other resources. They aim at integrating, building, and reconfiguring internal and external (knowledge) resources and competencies in order to adapt to changing environments and to remain competitive in the long term (Montealegre, 2002).

Within the RBV, KBV and dynamic capabilities debate, a central issue of attention refers to the question of where knowledge resources come from (Maritan \& Peteraf, 2011). Originally, the RBV assumes asset immobility (Barney, 1991), which 
means that resources are firm-specific and cannot be easily traded and transferred across organizations. As a result, the origin of valuable knowledge-based resources was assumed to lie within the firm itself. Likewise, numerous studies on dynamic capabilities describe entrepreneurial and integrative processes for internally developing new knowledge positions (e.g. Zahra, Sapienza, \& Davidsson, 2006; Cepeda \& Vera, 2007). However, in the context of OI, knowledge resources are no longer restricted to the firm's boundaries. A multitude of environmental and market factors, such as increased technological complexity and accelerated product life cycles, force firms to extend and combine their own resource base with those of external parties (Chesbrough, 2003; Dahlander \& Gann, 2010). This means that firms may access and utilize resources that are not independently 'owned' by the individual firm, (Zander \& Zander, 2005). This suggests that the RBV and KBV need to be extended to incorporate access to resources that lie outside the firm's boundaries and that are not entirely owned or controlled by the firm (Lavie, 2006).

However, firms cannot expect that mere access or 'rights' to utilize external knowledge resources leads to increased innovative performance (Kraaijenbrink, Spender, \& Groen, 2010). Instead, firms need to be capable of developing and deploying external knowledge resources internally in a rent-generating manner (Montealegre, 2002). Hence, knowledge integration rather than access to knowledge resources themselves is critical (Grant, 1996). The firm's integrative capability determines how efficiently it can manage knowledge across boundaries and how productively new knowledge resources are utilized (Kogut \& Zander, 1992; Grant, 1996; Carlile, 2004). In previous studies, integrative capability has been discussed predominantly within the context of intra-organizational boundaries, such as across departments or disciplines (Iansiti \& Clark, 1994; Henderson \& Cockburn, 1994). In the context of OI, the applicability of integrative capability with regard to inter-organizational boundaries becomes increasingly relevant, as firms are becoming more permeable with respect to external sources of knowledge. The ability to integrate external knowledge resources can be considered a dynamic capability as it aims at upgrading the firm's knowledge-based resources in order to advance and accelerate the firm's innovation process.

When external knowledge resources flow into the firm then, over time, those assets can become more distinctive and valuable, if applied appropriately within the new environment (Fey \& Birkinshaw, 2005). In this context, integrative capabilities are essential for deploying the transformational characteristics of external resources. Transformational characteristics are those aspects of knowledge resources that are specific to a firm and/or to a particular industry at a given point in time (Amit \& Schoemaker, 1993). These transformational characteristics are essential as they attach idiosyncrasies to external knowledge resources that make them difficult to imitate (Amit \& Schoemaker, 1993) and are, therefore, crucial for driving superior innovative performance. 
Integrative capability has been associated with different dimensions, such as organizational and managerial processes (Teece, Pisano, \& Shuen, 1997), information and managerial systems (Henderson \& Clark, 1990), or organizational culture (Kogut \& Zander, 1996). Hence, a crucial question refers to the nature of the elements of integrative capability that allow some firms to be more efficacious than others in benefiting from OI. In an encompassing framework, Carlile (2004) differentiates between three facets of integrative capability that manage and integrate knowledge across boundaries. While Carlile (2004) focuses on intra-organizational knowledge transfer between functions and divisions, the suggested dimensions of integrative capability also serve as a useful framework when discussing the transfer of knowledge resources across inter-organizational boundaries.

The first dimension of Carlile's (2004) integrative capability concept knowledge transfer - describes information-processing activities for managing knowledge across boundaries, including knowledge storage, processing, and retrieval. The second dimension, knowledge translation, recognizes that knowledge often comes from different 'thought worlds'. Hence, common meaning needs to be created by translating knowledge and adapting it to the organizational context. The third dimension, knowledge transformation, refers to the creation of common interests by establishing commitment and appropriate values and norms in order to encourage usage of knowledge resources (Woiceshyn \& Daellenbach, 2005). Knowledge transfer, translation, and transformation constitute underlying dimensions of integrative capability in the context of OI. They represent a set of higherorder organizing principles (Kogut \& Zander, 1992; Grant, 1996) that enhance the productivity and efficiency of externally accumulated knowledge resources, thereby reinforcing their contribution to positive OI outcomes.

Integrative capability, however, cannot be treated in isolation. The external environment has an important impact on the potential value of acquiring and integrating new resources (Ambrosini \& Bowman, 2009). The contingency perspective suggests that relationships between strategies and performance differ across environmental conditions (e.g. Ginsberg \& Venkatraman, 1985; Venkatraman, 1990; Arora \& Nandkumar, 2012). As environments vary in their degree of uncertainty and munificence and as these conditions affect the value creation potential of new knowledge resources, the integration of external knowledge is at least partly contingent on a firm's external environment (Sirmon, Hitt, \& Ireland, 2007). This means that, in addition to investigating dimensions of internal integrative capability, it is also crucial to examine to what extent environmental conditions affect the value creation potential of OI strategies. In the OI literature, two external aspects have been highlighted as influential factors in the integration of external knowledge resources. First, prior research emphasizes the degree of turbulence in a firm's technological environment (Christensen, Olesen, \& Kjaer, 2005; Huizingh, 2011). Second, it has been suggested that potential costs and benefits of OI are highly intertwined with different levels of competition (Chesbrough, 2007; 
Dahlander \& Gann, 2010). Hence, in evaluating external contingencies of OI, I focus on different levels of technological turbulence and dynamics of competition.

The above can be summarized in a conceptual framework (see figure 3.1) that includes both internal organizational as well as external environmental intervening factors in the relationship between openness and OI performance. This framework serves as the foundation for developing hypotheses that stipulate conditional factors for OI effectiveness. In the following, I first discuss the relationship between the degree of openness the firm adopts in its innovation process and OI performance. Subsequently, I elaborate on the different dimensions of integrative capability by discussing how openness and integrative capability interact to create innovative performance. In a final set of hypotheses, the effects of external environmental contingencies on the effectiveness of OI are laid out.

Figure 3.1: Theoretical framework - internal organizational and external environmental conditions of open innovation

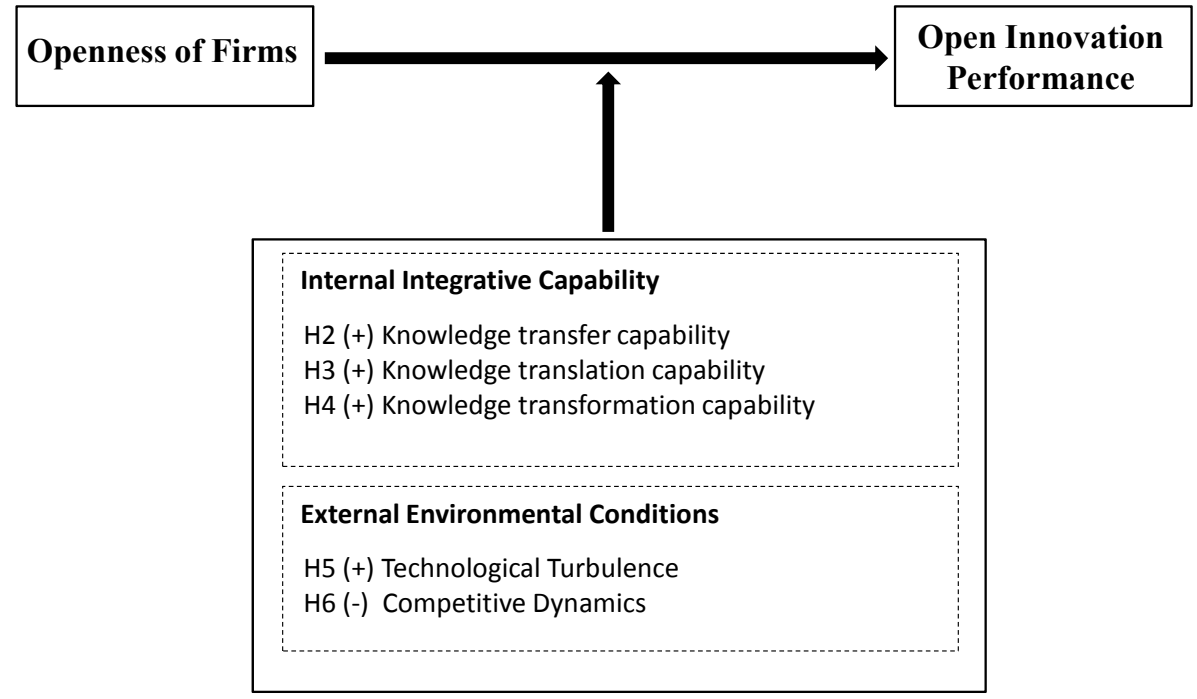




\section{HYPOTHESES}

\section{Openness and OI Performance}

Firms face strategic choices regarding whether and to what extent they adopt different OI activities (Drechsler \& Natter, 2012). Hence, OI is not characterized by a dichotomy (open versus closed), but can be described as a continuum with varying degrees of openness (Huizingh, 2011). More specifically, the degree of openness is determined by two aspects. First, the breadth of openness specifies to what extent firms access different external knowledge sources, including customers, suppliers, competitors, universities, start-up companies, innovation intermediaries, and other firms (Leiponen \& Helfat, 2010). However, openness in innovation is not just about accessing a wide number of sources, but it also involves drawing knowledge heavily from these sources (Laursen \& Salter, 2006). Therefore, the second aspect refers to the depth of openness in terms of how deeply or intensively firms draw from these different external knowledge sources (Laursen \& Salter, 2006; Drechsler \& Natter, 2012). Jointly, breadth and depth can be characterized as a firm's degree of openness and both are likely to have an effect on the performance of the firm's overall OI strategy. Performance of OI refers to the extent to which externally accessed knowledge increases the quality and speed of the firm's internal innovation and product development processes (Van de Vrande, De Jong, \& De Rochemont, 2009; Wallin \& van Krogh, 2010; Parida, Westerberg, \& Frishammar, 2012; Petroni, Venturini, \& Verbano, 2012).

The more external sources the firm accesses, the larger will be its partner opportunity set (Almirall \& Casadesus-Masanell, 2010). The breadth of knowledge sources is likely to exceed the knowledge endowment of single firms and thereby, enhances the chances of positive innovation outcomes (Chesbrough \& Appleyard, 2007; Leiponen \& Helfat, 2010). By combining efforts of a large and diverse pool of different parties, firms can enhance the scope and diversity of potential new products and achieve a better matching of products and consumer preferences (Almirall \& Casadesus-Masanell, 2010). In addition, the more external sources the firm accesses, the higher is its flexibility to recombine with the best possible partners (Almirall \& Casadesus-Masanell, 2010). Therefore, the size and diversity of external knowledge sources determines the scope and flexibility of new knowledge, which may have a positive impact on innovative outcomes (Grant, 1996).

As argued above, the depth of openness determines how extensively firms draw from specific external sources. Firms that source deeply from their external sources are likely to be more innovative, as they are better able to build valuable exchanges with external parties and to access their respective resource base. For instance, Fey and Birkinshaw (2005) show that the greater the openness to new ideas, the higher the firm's R\&D performance, as inflows of knowledge from the external environment augment the knowledge base of the firm. Furthermore, deep 
knowledge exchanges are likely to lead to superior information quality, thereby enhancing the contribution of external knowledge resources to OI performance.

Some authors suggest that the benefits of combining knowledge from different sources may diminish as the number, or breadth, of external sources increases. Laursen and Salter (2006), for instance, suggest that firms may run the risk of 'over-searching', which can have detrimental effects on overall innovation outcomes. Leiponen and Helfat (2010), however, show that such diminishing returns only set in at a very large number of sources. This means that, in general, the benefits of adopting a high degree of openness outweigh the potential costs of oversearching. Furthermore, by studying OI performance directly rather than considering broader innovation or performance outcomes, attention allocation problems associated with over-searching should be less prominent, as other 'attention pools' for managing innovation, such as internal R\&D or cross-functional integration are less relevant. Hence, I expect a positive linear relationship between openness, which can be conceptualized in terms of both breadth and depth, and OI performance:

\section{H1: The degree of openness of firms has a positive effect on OI performance.}

\section{Integrative Capability}

As demonstrated in previous studies and discussed above, firms are likely to differ in the extent to which they benefit from their breadth and depth of openness in innovation. In the following, I argue that the various dimensions of integrative capabilities help to explain these differential outcomes, as they enable the effective transfer, translation, and transformation of external knowledge resources. The interactive effects of the different dimensions of integrative capability and openness of firms on OI performance are discussed in turn.

Knowledge Transfer Capability Once the firm opens up its innovation process and gains access to external knowledge resources, it needs to develop an ability for inter- and intra-organizational knowledge transfer to allow the relocation and diffusion of these knowledge resources within the organization (EasterbySmith, Lyles, \& Tsang, 2008). This requires an information processing approach that deals with storing, diffusing and retrieving the newly accessed knowledge (Carlile, 2004). To facilitate such knowledge transfer, organizing principles need to be implemented which support the articulation and codification of new knowledge resources and make them accessible to a wider range of employees (Kogut \& Zander, 1992). For instance, Kale and Singh (1999) found that a set of knowledge management principles, including articulation, codification, sharing, and internalization, are essential elements of performance in the context of inter-organizational cooperation. 
Articulation, codification, and diffusion of external knowledge can be supported by systematic knowledge management processes and technological systems and tools. Several authors have highlighted the role of information and communication technology in supporting the shift towards OI (e.g. Dodgson, Gann, \& Salter, 2006; Chiaroni, Chiesa, \& Frattini, 2011). Furthermore, in the dynamic capabilities literature processes for articulating and codifying knowledge resources, such as collective discussions and the creation and development of knowledge management tools, have been highlighted as important mechanisms for changing the firm's knowledge base (e.g. Zollo \& Winter, 2002; Zahra, Sapienza, \& Davidsson, 2006). Together these processes and tools constitute the firm's knowledge management infrastructure (Cepeda \& Vera, 2007).

The firm's existing knowledge management infrastructure needs to be adapted in order to support the new innovation model that relies heavily on externally generated knowledge (Chiaroni, Chiesa, \& Frattini, 2011). An appropriate knowledge management infrastructure should support the transfer of external knowledge resources and the diffusion to the corresponding parties within the firm (Gold, Malhotra, \& Segars, 2001; Verona \& Ravasi, 2003). Hence, a critical element in the systematic integration of external knowledge is the existence of a knowledge management infrastructure that fosters the transfer, diffusion, and sharing of knowledge with external parties and within the firm (Cepeda \& Vera, 2007). Such a knowledge management infrastructure determines a firm's transfer capability in the context of OI.

The internal diffusion of external knowledge resources will allow employees from different organizational contexts or departmental units to access and utilize the newly acquired knowledge. This enhanced access enables new applications and rent-generating combinations of external and internal knowledge resources (Verona \& Ravasi, 2003). Thereby, an appropriate knowledge management infrastructure enhances the productive utilization of external knowledge resources and increases the chances that they get embedded within rent-generating applications. As a consequence, the firm's knowledge transfer capability, as reflected in its knowledge management infrastructure, constitutes an important aspect of external knowledge integration which helps firms to harness their OI strategies and convert them into positive innovative outcomes. This results in the following hypothesis:

H2: Knowledge transfer capability positively moderates the relationship between openness of firms and OI performance, such that the stronger a firm's knowledge transfer capability, the higher its returns from openness.

Knowledge Translation Capability External knowledge resources often derive from different 'thought worlds' with idiosyncratic meanings and interpreta- 
tions attached to it (Carlile, 2002; 2004). Particularly if external knowledge resources stem from non-firm institutions, such as universities or customers, these resources may come in certain formats that are 'alien' to the knowledge-acquiring firm. Due to the disparity of external knowledge resources and their unfamiliar forms, employees of the acquiring firms may develop divergent interpretations (Nonaka, 1994). Therefore, external knowledge resources are not easily applied in the new organizational context, even if they are accessible via an appropriate knowledge management infrastructure. This means that effective integration of external knowledge resources requires a process of translation and adaptation. Common meaning of external knowledge resources needs to be created which aligns with the new organizational context.

Common meaning can be created by designing appropriate structures and mechanisms, which allow for the coordination of external knowledge resources (Iansiti \& Clark, 1994; Garciano \& Wu, 2012). The concept of organizational structure for external knowledge integration includes, for example, the establishment of new organizational roles supporting the adoption of external knowledge resources (Petroni, Venturini, \& Verbano, 2011; Garciano \& Wu, 2012). Examples of such new roles are 'champions' who lead the process of adoption of OI, 'gatekeepers' for managing the firm's interface with the external environment, or 'integration experts' who are able to select and integrate external knowledge and manage complex structures (Chiaroni, Chiesa, \& Frattini, 2011; Petroni, Venturini, \& Verbano, 2011). Gatekeepers, for instance, are typically capable of understanding and translating externally acquired knowledge; they facilitate external communication, filter the incoming information and provide it to organizational members (Tushman \& Katz, 1980). With the help of these key individuals and other structural mechanisms, external knowledge resources can be translated according to the new organizational context.

Organizational structures devoted to the integration of external knowledge resources facilitate their translation into the firm's innovation process (Chiaroni, Chiesa, \& Frattini, 2011). They help to establish a common meaning of external knowledge resources and, thereby, establish fit with the organization's characteristics. Translation makes external knowledge resources firm-specific as they are interpreted and applied within the unique organizational context. Transformational characteristics (Amit \& Schoemaker, 1993) of external knowledge resources are activated as these new interpretations and applications develop. This means that organizational structures for external knowledge translation allow firms to capture greater benefits from their openness in innovation. This leads to the following hypothesis:

H3: Knowledge translation capability positively moderates the relationship between openness of firms and OI performance, such that the stronger a firm's knowledge translation capability, the higher its returns from openness. 
Knowledge Transformation Capability In the context of OI, different interests are likely to arise as openness reduces the frontline role of internal researchers in the innovation process (Petroni, Venturini, \& Verbano, 2011). This is likely to result in negative attitudes towards the implementation of external knowledge resources, which have been labeled as the not-invented-here syndrome (Katz \& Allen, 1982). Employees have typically invested heavily in the internal accumulation of specific knowledge and feel deeply committed to this knowledge, which they now fear to be 'at stake' (Carlile, 2002). For instance, if engineers have internally developed a new mechanical tool, they will feel their knowledge to be 'at stake' if the firm decides to acquire a similar tool outside. However, when the firm adopts OI activities, employees need to be willing to adapt their own knowledge base and integrate externally acquired knowledge. When such conflicts arise, transforming the internal knowledge base is a political and cultural process of negotiating and defining common interests (Carlile, 2004).

Knowledge transformation capability helps to create such common interests by stimulating commitment and crafting appropriate values and norms. Promoting and rewarding openness in innovation encourages employees to transform their current approaches to managing knowledge. Transforming the internal knowledge base can be achieved via different mechanisms. For example, employees can be encouraged, both formally and informally, to implement external knowledge resources. Henderson and Cockburn (1994), for instance, stress the importance of managerial systems in the form of incentives and rewards. In addition, a common language and clear communication patterns need to be established, which provide a normative sanction of how activities are to be organized and what kind of information is to be collected and evaluated (Kogut \& Zander, 1992). Such elements of transformation capability nurture an OI culture that shifts mind-sets away from 'not-invented-here' to 'proudly-found-elsewhere'.

Nurturing an OI culture also stimulates the enactment of idiosyncratic routines and interactions between employees, which further shape externally accessed knowledge resources and contribute to inimitability (Montealegre, 2002). These idiosyncratic routines and interactions are essential for activating the transformational characteristics of external knowledge resources that make these resources firm-specific. This will allow firms to capture value from their openness and translate it into positive innovation outcomes. As a consequence, transformation capability helps employees to alter their current approaches to managing knowledge and stimulates idiosyncratic routines. This results in a positive effect on the returns from openness:

H4: Knowledge transformation capability positively moderates the relationship between openness of firms and OI performance, such that the stronger a firm's knowledge transformation capability, the higher its returns from openness. 


\section{Environmental Contingencies}

Besides internal factors, external characteristics are likely to have an impact on the extent to which firms benefit from OI (Huizingh, 2011). Prior research emphasizes technological turbulence as an important contingency factor for benefiting from innovation in general (Zahra \& Bogner, 2000; Jansen, van den Bosch, \& Volberda, 2006) and from collaborative innovative activities, in particular (Hagedoorn, 1993). Technological turbulence, which can be defined as the rate of technological change (Jaworski \& Kohli, 1993), reduces the chances of profiting from internally developed technology, as current products are becoming obsolete more quickly. According to Teece (1986), firms that operate in industries that are characterized by rapid technological change are unlikely to possess the full range of knowledge requirements necessary for successful innovation. In addition, by pursuing a closed strategy to innovation in such environments, firms may not be able to cover all required costs by means of internal R\&D investments (Lambe \& Spekman, 1997). Thus, with increasing technological turbulence firms that are adopting a highly extrovert innovation strategy may be better off (Christensen, Olesen, \& Kjaer, 2005). Firms that are subject to high technological turbulence should benefit more from openness due to reduced costs of innovation and a larger range of knowledge resources that will allow them to keep abreast with rapid technological change.

In addition, high technological turbulence implies a larger opportunity set of external knowledge sources. Industrial settings that are characterized with technological turbulence and high levels of perceived technological opportunities are usually also characterized by frequent new technology introductions and high levels of R\&D spending (Zahra, 1996). Organizations that pursue OI can capitalize on these circumstances by tapping into these various technologies and R\&D investments. Therefore, firms that are operating in a highly turbulent technological environment should benefit more from openness than firms that are operating in a relative placid environment in which opportunities for external knowledge sourcing are scarce. Hence, the external condition of technological turbulence is likely to enhance the benefits from openness in innovation, leading to the following hypothesis:

H5: Technological turbulence positively moderates the relationship between openness of firms and OI performance, such that the more turbulent a firm's technological environment, the higher its returns from openness.

In addition to technological turbulence, prior research suggests that potential costs and benefits of OI are dependent on different levels and dynamics of competition that firms face in their environments (Chesbrough, 2007; Dahlander \& Gann, 2010). In this context, competitive dynamics can be characterized by the extent to which external environments are subject to accelerating degrees of competition. Acceler- 
ating competition implies that many firms seek superior performance, although they cannot all be superior at the same time (Eisenhardt \& Martin, 2000). Therefore, these competitive environments are associated with intensive pressures for higher efficiency. Such competitive pressures often lead to significantly reduced organizational slack (Zahra, 1996). However, significant amounts of resources are required for the effective sourcing and integration of external knowledge resources (Foss, Laursen, \& Pedersen, 2011). If these resources are not sufficiently available, firms are less able to translate their OI activities into positive innovation outcomes. Hence, high competitive dynamics and resulting efficiency pressures lead to resource scarcity, which constraints firms in capturing value from their openness in innovation.

Furthermore, high competitive dynamics may involve aggressive attacks from competitors that force firms to focus their attention and resources on current operations in order to remain competitive. During these periods, more attention needs to be paid to the conservation of resources and the selective pursuit of economical competitive strategies (Miller \& Friesen, 1983), instead of the acquisition and integration of new knowledge resources. Risk-taking, forceful proactiveness, and strong emphasis on novelty can be hazardous when competitive conditions and attacks become more demanding (Jansen, van den Bosch, \& Volberda, 2006). This means that firms that operate in a more competitive dynamic environment, which requires close monitoring of current resources and operations, may benefit less from openness than firms that are subject to lower competitive pressures.

Finally, OI may involve more direct costs of competition. These costs of competition emerge from the risk that one actor within the OI network could act opportunistically and behave in bad faith (Dahlander \& Gann, 2010). Chesbrough (2007) shows that there are substantial risks involved in cooperating in innovation. Indeed, OI weakens the protection of the institution's knowledge base and its core competencies, the corporate crown jewels (Kline, 2003). With increasing competitive dynamics, firms face the risk of imitation by competitors, which might jeopardize a firm's competitive advantage in innovation (Drechsler \& Natter, 2012). Hence, when a high risk exists for other firms to imitate a firm's knowledge-based resources and innovative activities, a high degree of openness might not contribute to enhanced OI performance. In sum, in the context of high competitive dynamics, the expected costs of increasing openness in innovation associated with resource scarcity, distraction from operative activities, and risks of imitation could exceed its expected benefits and therefore may not be strongly related to OI performance.

H6: Competitive dynamics negatively moderates the relationship between openness of firms and OI performance, such that the stronger the competitive dynamics in a firm's environment, the lower its returns from openness. 


\section{METHODOLOGY}

\section{Research Design and Data Collection}

To test the developed hypotheses I constructed a primary data set using a survey design. Collecting primary data with a custom-tailored questionnaire had the advantage of placing the data collection explicitly into the context of OI. The questionnaire included an introduction section on OI definitions and the survey questions were explicitly placed in the context of collaborations and external knowledge sourcing in an OI framework, thereby generating data directly on the phenomenon of interest.

The survey was addressed to members of 'Exnovate', the European Network of Excellence on Open and Collaborative Innovation. Exnovate can be considered as an OI intermediary and represents a hub of knowledge exchange on collaborative forms of innovation. It is a platform for firms that are practicing OI, thereby, making them theoretically relevant to the research question. Since this study aims at examining the relationships between openness and OI performance under different internal and external conditions, a deliberate or purposeful sampling strategy seems appropriate. In this context, it makes sense to select the sample in such a way that there is a high chance for these relationships to be observed (Punch, 2005). Therefore, I am sampling to find cases that are representative of a particular dimension of interest - that is, open innovation (Teddlie \& Yu, 2007). To achieve this, I am taking a random sample of a smaller number of units (Exnovate) from a much larger target population (OI firms). Therefore, my sampling strategy involves both purposeful as well as random elements (Collins, Onwuegbuzie, \& Jiao, 2007).

The Exnovate network includes 942 managers from international firms, while a large number of firms are situated in Belgium, Netherlands, UK, or USA. 713 of these firms are multinational corporations, while 229 are small and mediumsized firms. The support of a third-party organization helped to enhance the response rate and allowed me to directly address key informants on external knowledge sourcing and OI. Respondents mostly held the positions of OI managers, CTOs, Innovation Directors, or R\&D managers, which means that they were directly involved in the management of (open) innovation. On average, these key informants have been working for their firm for 13 years, suggesting a high level of experience and knowledge about firm strategies and processes.

The survey was designed and implemented according to Dillman's (2007) tailored design method and administered in spring 2011. Invitation e-mails were sent, explaining the study's purpose and assuring confidentiality. As an incentive, respondents were offered a customized report that summarized the results of the study. During a period of two months, five rounds of contacts were made, which yielded 165 responses (response rate $=17.5 \%$ ). Due to missing values and multiple 
responses per firm, the final sample size includes 119 completed questionnaires. A profile of the sample demonstrates a reasonable spread across industries: chemicals (32\%), electronics (12\%), other manufacturing industries (29\%), business services/communications (12\%), and others/unknown (15\%). In terms of size, large firms are overrepresented in the initial sample of Exnovate firms. This is also reflected in the distribution of firms in the final sample. Very large firms (with more than 10,000 employees) account for about $60 \%$ of the sample. About $20 \%$ of the firms can be classified as large (between 1,000 and 10,000 employees). Small and medium sized firms, those that employ less than 1,000 employees, reach a share of only about $13.5 \%$ of my sample, while for about $7 \%$ of the firms, the actual size is unknown. Hence, the sample of responding firms represents the initial firm size distribution of the Exnovate platform (about $80 \%$ large multinational firms and 20 $\%$ small and medium-sized firms) reasonably well.

\section{Measures}

The scales for the survey instrument were both borrowed from existing literature, as well as specifically developed for this study. In developing the new scales, standard guidelines were followed (Churchill, 1979; Dillmann, 2007). In order to develop an initial list of scale items, I extensively analyzed existing literature. In addition, exploratory interviews with managers in six firms that classify themselves as 'Open Innovators', were conducted. To purify and improve these items, the survey was subject to substantial pre-testing. First, the appropriateness and consistency of items was evaluated by six academics. Second, a pilot-study with eleven innovation managers was conducted for re-phrasing items and ensuring their applicability to the management world. Most measures are assessed on a sevenpoint Likert scale. The complete scales can be found in table 3.1.

OI performance Instead of studying the effect of openness of firms on innovative performance in general (Laursen \& Salter, 2006; Leiponen \& Helfat, 2010), this study assesses OI performance more directly. The three-item newly developed scale (Cronbach's alpha $=.90$ ) asks respondents to indicate to what extent external knowledge accelerates the firm's R\&D speed, enables the development of innovative products, and is incorporated in products that are successful in the market. This scale is based on existing literature which suggests that desired outcomes of OI include increased speed and quality of innovative activities (Wallin \& von Krogh, 2010; Parida, Westerberg, \& Frishammar, 2012; Petroni, Venturini, \& Verbano, 2012), and improved product development processes (Van De Vrande, De Jong, \& De Rochemont, 2009).

Openness of firms The degree of openness is reflected by the extent to which firms access external knowledge sources in their innovative activities (Laursen \& Salter, 2006). To entirely capture this multi-faceted nature, I use a 
Table 3.1 Survey Measurement Scales

Survey Items Alpha

OI Performance (7-point Likert scale from 'not at all' to 'to a very great extent')

Please indicate to what extent external knowledge...

... accelerates your firm's R\&D speed

... enables the development of innovative products in your firm

... is incorporated in your firm's products that are successful in the market

Openness (7-point Likert scale from 'not at all' to 'to a very great extent')

To what extent does your company...

Forma-

tive

... access suppliers' expertise concerning innovation activities?

... access customers' expertise concerning innovation activities?

... access competitors' expertise concerning innovation activities?

... cooperate with universities and research institutes?

... cooperate with other firms on innovation projects?

... work with innovation intermediaries (e.g. InnoCentive, NineSigma, yet2.com)?

... access external start-up companies' expertise concerning innovation activities?

Transfer Capability (7-point Likert scale from 'not at all' to 'to a very great degree')

Please indicate the degree to which the following elements are implemented in your company's external knowledge management system:

A system for the analysis and filtration of external information

Processes to inform employees of stored information and codification tools (i.e. tools to transform knowledge into written guidelines)

Tools to access the stored knowledge

Fast and easy internal search tools for external knowledge

Systems for the dissemination/allocation of external knowledge

Quality control of the acquired knowledge

Translation Capability (7-point Likert scale from 'not at all' to 'to a very great extent')

Please consider to what extent the following elements are implemented in your company:

A clear division of roles and responsibilities to implement external knowledge

Knowledge gatekeepers (i.e. central actors forming an interface between external sources

and in-house employees)

Processes to adapt external knowledge to our internal development processes

Transformation Capability (7-point Likert scale from 'strongly disagree' to 'strongly agree')

Please indicate to what extent you would agree or disagree with these statement:

Management communicates the benefits of using external knowledge throughout the firm

Our employees are encouraged to utilize external knowledge

The usage of external knowledge sources is valued in our company

Our company has standardized reward/incentive systems for using external knowledge

Our employees feel legitimized and empowered to use external knowledge

Our management promotes an open innovation culture

Technological Turbulence (7-point Likert scale from 'strongly disagree' to' strongly agree')

Please, indicate to what extent you would disagree or agree with the following statements regarding your company's technological environment:

The technology in our markets is changing rapidly

Technological changes provide big opportunities in our markets

It is difficult to forecast where the technologies in our markets will be in the next five years

Reflective Items of Openness (7-point Likert scale from 'not at all' to 'to a very great extent')

We create opportunities through acquiring knowledge / technologies from external sources

We exploit external knowledge and technologies in our company 
seven-item scale to assess the extent to which firms access various external knowledge sources, including suppliers, customers, competitors, other firms, universities/research institutes, innovation intermediaries, and start-up firms. While most items are similar to previous measures of openness (Laursen \& Salter, 2006; Leiponen \& Helfat, 2010), the scale includes two new types of external parties (innovation intermediaries and start-up firms), which have been identified as crucial in the OI literature (e.g. Christensen, Olesen, and Kjaer, 2005; Chesbrough, Vanhaverbeke, \& West, 2006; Bahemia \& Squire, 2010). By asking respondents to assess the extent to which they access diverse external knowledge sources, this scale attempts to capture aspects of both breadth and depth of openness.

As an OI strategy can have a variety of possibly uncorrelated knowledge sourcing mechanisms, a formative measurement model is appropriate (Diamantopolous \& Winklhofer, 2001). Before constructing the formative index for OI, I conducted OLS regression analyses to check for redundant items. Formative measurement raises the issue of indicator multicollinearity (Law \& Wong, 1999), but all variance inflation factors were low $(<1.7)$, and the bivariate correlations between the indicators were within an acceptable range (Diamantopolous \& Siguaw, 2006). I created the formative index as the unweighted linear sum of the measurement items (Bode et al., 2011). The formative index was then evaluated for its validity (Edwards \& Bagozzi, 2000). First, the items were correlated with a global statement ('to what extent does your company search actively for new partners for competence development?') that assesses overall openness to external parties. This step follows Diamantopoulos and Winklhofer's (2001) suggestion to correlate each indicator with "a global item that summarizes the essence of the construct that the index purports to measure" (p.272). All correlation coefficients are positive and significant. Next, a Multiple Indicators Multiple Causes (MIMIC) model was estimated in LISREL with the seven external sources as antecedents of openness and two items as reflective indicators of the construct. The two reflective items captured the effectiveness of the firm in sourcing external knowledge (see table 3.1). Estimation of the MIMIC model resulted in a nonsignificant chi-square statistic, indicating that the model-based covariance matrix and the observed covariance matrix are not significantly different. In addition the root-mean-square estimated residual suggests good model fit (RMSEA $=0.06)$. Four of the seven indicators have high loadings and are significant. When deleting the three insignificant indicators, the model performs significantly worse. Thus, all items from the MIMIC analysis were retained to create an index of OI.

Knowledge transfer capability Knowledge transfer capability in the context of $\mathrm{OI}$ is operationalized in terms of the firm's knowledge management infrastructure. This six-item reflective scale (Cronbach's alpha $=.91$ ) is adapted from a scale proposed by Cepeda and Vera (2007). While Cepeda and Vera (2007) study knowledge management infrastructure for managing internal organizational 
knowledge, items are adapted to describe formal mechanisms that firms implement for managing externally acquired knowledge. The items refer to multiple processes and tools (systems for analysis and filtration, tools for storing, accessing, searching and disseminating external knowledge, and quality control), which, together, constitute an infrastructure for transferring external knowledge resources.

Knowledge translation capability The three-item reflective scale (Cronbach's alpha $=.88$ ) addresses to what degree firms establish roles and processes to facilitate the translation of external knowledge and to adapt it to the specific context of the focal organization (Helfat \& Peteraf, 2003; Verona \& Ravasi, 2003). The scale is specifically designed for this study and captures important concepts from the literature, such as new roles and a clear division of tasks for implementing external knowledge (Chiaroni, Chiesa, \& Frattini, 2011; Petroni, Venturini, \& Verbano, 2011), the importance of knowledge gatekeepers (Tushman \& Katz, 1980), and processes for adapting external knowledge (Wallin \& von Krogh, 2010).

Knowledge transformation capability The six-item reflective scale (Cronbach's alpha $=.90$ ) addresses the extent to which firms define and align common interests for using external knowledge and establish an organizational culture of OI (Carlile, 2004). Concepts of transformation capability include the encouragement and empowerment of employees (Gold, Malhotra, \& Segars, 2001; Nonaka, 1994), communication of benefits, reward and incentive systems (Foss, Laursen, \& Pedersen 2011), values (Woiceshyn \& Daellenbach, 2005), and an overall OI culture (Dodgson, Gann, \& Salter, 2006).

Technological Turbulence This construct is based on a scale developed by Jaworski and Kohli (1993), which has been applied in many studies in the past. The three items used (Cronbach's alpha $=.84$ ) capture the pace of technological changes in the firm's market environment (technology is changing rapidly, technological changes provide big opportunities, technologies are difficult to forecast).

Competitive dynamics is captured by a single item, which asks respondents to assess to what extent they expect their competitive environment to change over the next five years. I created a dummy variable by collapsing 'less competitive' and 'similar level of competitiveness' into the category of low competitive dynamics, while the answer option 'more competitive' represents the category of high competitive dynamics.

Control Variables Various firm demographic and industry characteristics have been defined as important variables in the context of OI (Huizingh, 2011). Firm size was assessed by taking the natural logarithm of a firm's number of employees. As firm age has an impact on the innovation strategies of firms, age was included as the number of years since incorporation. Due to the international nature of the sample, I control for country-level effects by including a dummy variable that 
captures whether the firm's country of origin is the US (1) or lies outside the US (0). In addition, all firms in the sample were categorized in terms of three industry clusters: 1) processing (including chemicals and food), 2) manufacturing (e.g. electronics), and 3) others. For the last two classes I included a dummy variable ( $1=$ pertaining to this industry and $0=$ not pertaining to this industry). As a final control variable I included firms' $R \& D$ intensity, in terms of $R \& D$ expenditure divided by firm size. However, data was only available for a subset of the firms, as the data set includes private firms that do not have to reveal those numbers. Hence, in a robustness check I ran the analysis on this subset of firms in order to evaluate potential effects of internal R\&D intensity.

In order to ensure the convergent and discriminant validity of the reflective constructs, I conducted exploratory and confirmatory factor analysis. Exploratory factor analyses on all latent reflective survey scales, separately as well as jointly, revealed the anticipated factor structure, with items loading highly on the constructs they were intended to measure. No substantial cross-loadings were found and all scales were unidimensional. In addition, the measures were subjected to confirmatory factors analyses in LISREL. A satisfactory fit was achieved with a rootmean-square estimated residual (RMSEA) of 0.07 , which is below the recommended cut-off point of 0.08, and a confirmatory factor index (CFI) of 0.96, which exceeds the recommended minimum value of 0.90 (Hair et al., 2006). In addition, each loading was large and significant, evidencing convergent validity. To examine discriminant validity of the three dimensions of integrative capability I conducted chi-square difference tests on one-factor and two-factor solutions. For each pair of the different dimensions of integrative capability, the chi-square statistic for the two-factor solution was significantly lower than for the one-factor solution, which indicates that the three dimensions of the construct are rather distinct and meaningful. As a result, the above discussed items were combined in summated scales in order to assess the constructs of interest. ${ }^{3}$ To facilitate the interpretation of the results I used the average scores of the respective constructs.

\section{Addressing Nonresponse and Common Method Biases}

As this study relies on single responses for collecting firm-level data, potential common method biases need to be addressed. Several steps helped to reduce potential distortions due to common method. First, I implemented procedural remedies in designing the survey, including the improvement of items via interviews and pre-testing, ensuring that there are no right or wrong answers, and following a counterbalancing question order (Podsakoff, McKenzie, \& Podsakoff, 2003). Second, I collected data from multiple respondents per firm whenever

\footnotetext{
${ }^{3}$ As an alternative specification I created weighted factor scores to measure the focal construct. Both factor score and summated scales lead to very similar results.
} 
possible. In total, 13 matched pairs were obtained. The average correlation among these respondents is positive and significant $(0.51)$ and the average interrater reliability of 0.64 is acceptable (Bowman \& Ambrosini, 1997).

In addition, in an ex post analysis I conducted exploratory factor analysis and used Harman's one-factor test in order to verify the quality of the survey data. The principal components factor analysis extracts eight factors with an eigenvalue greater than 1, which together account for 74 percent of the total variance. Due to the fact that several distinct factors are extracted and that the first factor accounts for a relatively low amount of variance explained (34\%), it is safe to suggest that the data is not significantly affected by common method bias (Podsakoff, McKenzie, \& Podsakoff, 2003).

In addition to these procedural and statistical remedies, I ensured the validity of the subjective measure of the dependent variable (OI performance) by triangulating the information provided by the respondents with secondary objective data that was available for a subset of 79 firms. Using the Gale PROMT database, I collected data on new product announcements and analyzed how firms in the sample compare to their main competitors. ${ }^{4}$ I correlated this objective information with the subjective information on OI performance. The subjective and objective measures show a significantly positive correlation $(0.24, p<0.05)$, supporting the validity of the subjective measure. Finally, in order to test for nonresponse bias, I compared the first and last $25 \%$ of respondents on key variables and demographic characteristics (size, age, R\&D intensity). The two groups are statistically similar on all demographic and study variables. One exception is technological turbulence for which the difference in means is marginally significant (at the $10 \%$ level).

\section{Analytical Procedure}

The hypotheses were tested using OLS regression. ${ }^{5}$ To test for the hypothesized moderating effects, moderated multiple regression analyses were used. Variance

\footnotetext{
${ }^{4}$ In the Gale Group PROMT database, I counted the number of new product announcements from 20102012 for each firm. Collecting this information over a longer time period generates a number that is not likely to be affected by short-term economic or cyclical trends. Based on databases that provide investor information (e.g. Hoovers), the three most important competitors for each firm were identified. Subsequently, I calculated the respective differences of new product announcements of the firms in the dataset and the average of their main competitors. I adjusted these numbers for the total number of new product announcements made by the focal firm and its respective competitors in order to account for any industry differences. These adjusted numbers reveal how the firms in the dataset compare to their main competitors on the number of new product announcements, thereby providing an indication of their innovative performance.
}

${ }^{5}$ As the 7-point Likert scales have constant units of measurement, differences between any two adjacent points on any part of the scale are considered to be equal. Hence, the 7-point Likert scales are treated as 
inflation factors (VIFs) of all independent variables are low $(<1.8)$. Nevertheless, prior to the creation of the interaction terms, I mean-centered the independent variables to reduce multicollinearity. Because the interaction effects will still introduce multicollinearity into the model, a hierarchical regression model setup was applied in which each interaction effect was introduced sequentially into the model. The regression coefficient and the partial $\mathrm{F}$ associated with the resulting change in $\mathrm{R}^{2}$ were studied to test if a moderating effect exists or not. In addition, to understand the form of the interaction, simple slopes were analyzed and graphed at the mean and at one standard deviation below and above the mean of the independent variables (Aiken \& West, 1991; Cohen et al., 2003). This procedure allows for understanding the relationship of openness and OI performance at different levels of the conditional variables. In addition, due to the relatively small sample size, I used bootstrapping as an alternative estimation procedure, which provides more accurate estimates for small sample sizes (Brownstone \& Valletta, 2001). The bootstrap analysis generates qualitatively similar results as the OLS estimates.

\section{RESULTS}

Table 3.2 presents the means, standard deviations, and correlations between the variables used in the regression models. On average, firms are semi-open (29.7 on a range from 7 to 49). As can be seen in table 3.2, transfer-, translation-, and transformation capability are quite substantially correlated. However, this should not be surprising, as they represent different dimensions or facets of the same construct (integrative capability). It also suggests that firms tend to develop and implement the different dimensions of integrative capability in parallel. Nevertheless, as discussed above, VIFs suggest that multicollinearity is not a problem.

In the regression analyses seven models were tested (see table 3.3). ${ }^{6}$ The first model includes the control variables and the direct effects of the conditional factors on OI performance. It is notable that both transformation capability, as well as technological turbulence has a significantly positive direct effect on OI performance. The control variables, however, do not significantly influence OI performance. Model 2 includes the direct effect of the degree of openness on OI performance. As predicted in hypothesis 1, there is a significantly positive

interval data and are, therefore, applicable for OLS. As a robustness check I also conducted an ordered probit analysis, which yields qualitatively similar results as the OLS analysis.

${ }^{6}$ The data set contains a very small number of missing values on the control variables in the regression equation. Various methods of imputation (e.g. mean imputation, multiple imputation) on this small number of values lead to very similar and robust results. The results in table 2 are based on mean imputation. 


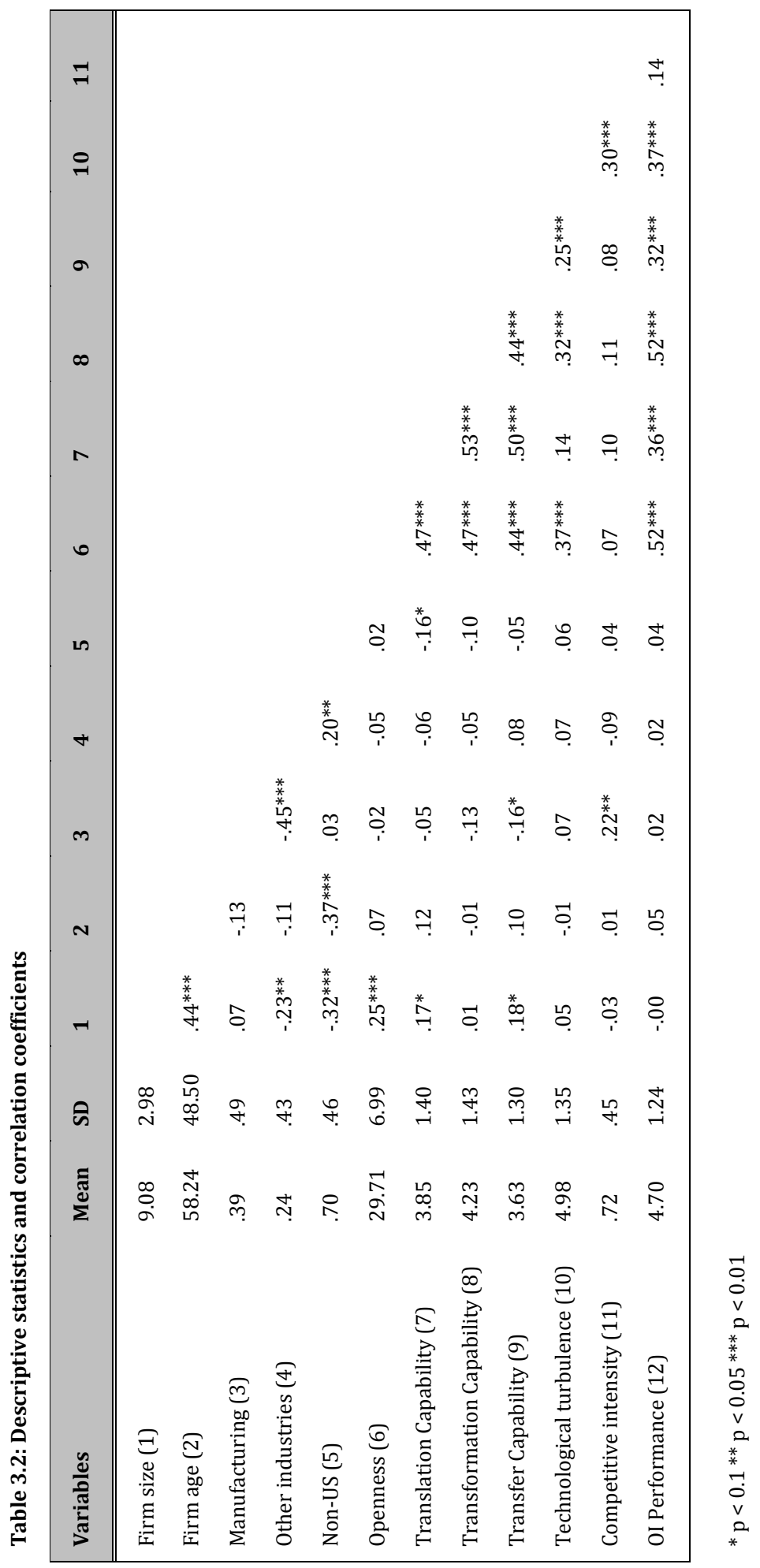




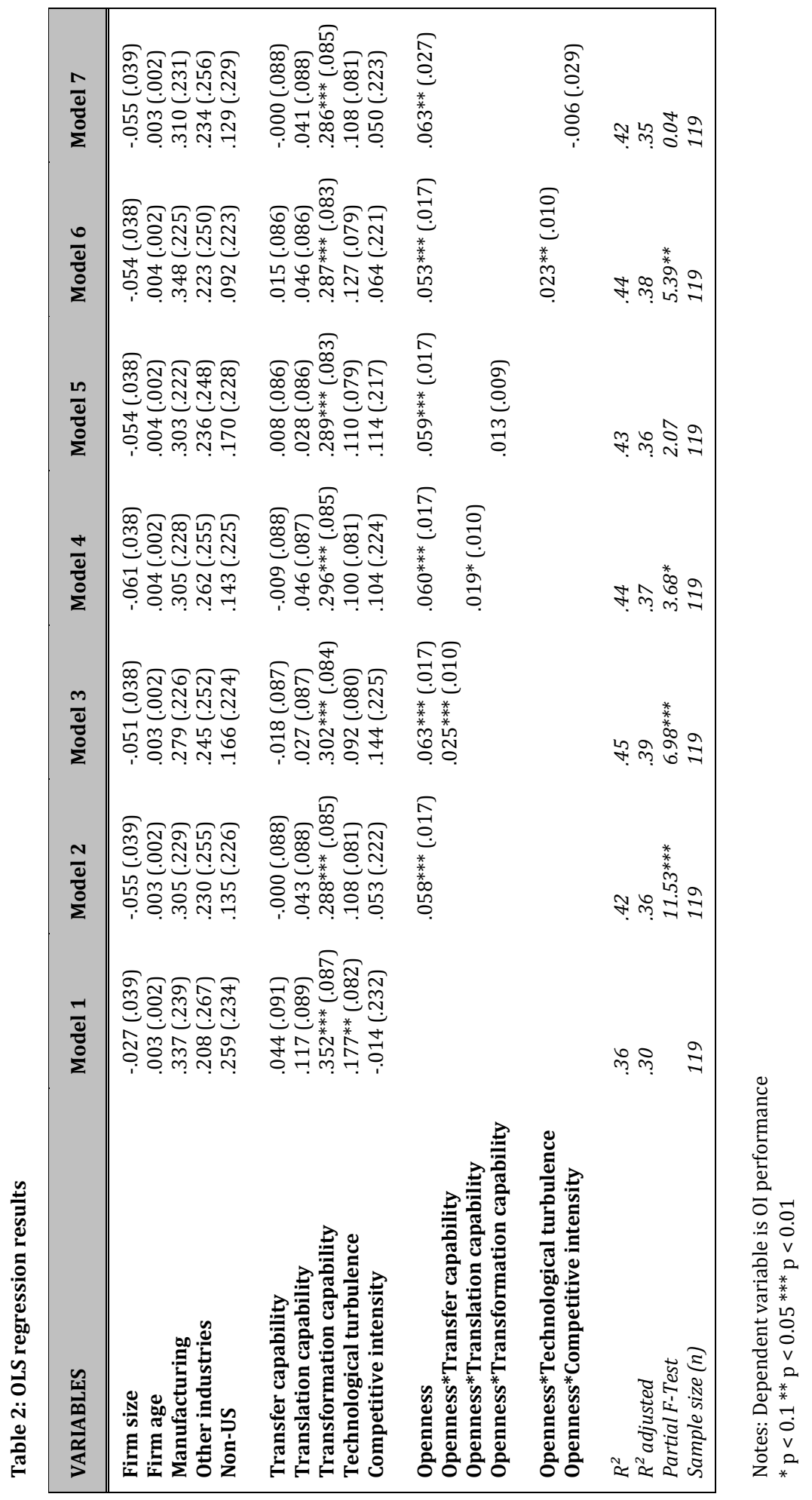


association between the degree of openness and OI performance ${ }^{7}$. Models 3 to 7 investigate the hypothesized interaction effects of openness and external and internal factors on OI performance. Model 3 tests the hypothesized moderating effect of knowledge transfer capability. The interaction effect is highly significant and positive, therefore, supporting hypothesis 2 that suggests that the stronger a firm's knowledge transfer capability the higher its returns from openness. In model 4 , the data show a marginally significant and positive interaction effect of translation capability and openness ( $\mathrm{p}=.058)$. Because of the limited significance level, the implications of this finding are somewhat tentative. Model 5 shows that the interaction effect of openness and transformation capability is insignificant. Hence, hypothesis 4 stating that the firm's knowledge transformation capability (i.e. culture) positively moderates the relationship between openness and OI performance, cannot be supported. However, transformation capability does have a significantly positive direct effect on OI performance throughout all regression models.

Regarding the hypothesized environmental contingency factors of OI performance, one out of two is supported. In model 6, the interaction effect of openness and technological turbulence is positive and significant, thereby supporting hypothesis 5 that the more turbulent a firm's technological environment, the higher its returns from openness. Model 7 reveals that the moderating effect of competitive dynamics is insignificant. As a result, hypothesis 6 cannot be supported. ${ }^{8}$

The partial F-test that evaluates changes in $\mathrm{R}^{2}$ is significant in models 2,3 , and 6 and marginally significant in model 4 . This lends further support for the hypothesized direct effect of the degree of openness on OI performance and the hypothesized moderating effects of transfer capability, translation capability, and technological turbulence. As a robustness check I reran the analysis for a subset of firms for which data on $R \& D$ intensity was available $(n=86)$. Interestingly, $R \& D$ intensity does not significantly affect OI performance. Furthermore, the results remain qualitatively similar, except that the moderating effect of knowledge transfer capability (i.e. structure) is now significant at the $1 \%$ level and the significance of the moderating effect of technological turbulence reduces to a $10 \%$ level. Hence, the results remain largely robust when accounting for internal R\&D intensity.

To better understand the nature of the interaction effects, I followed Aiken and West's (1991) recommendation to exhibit predicted values of the dependent

\footnotetext{
7 I also tested a model including a squared effect of openness to test for possible curve-linear effects as suggested by Laursen and Salter (2006). However, as expected this squared effect does not significantly predict the direct performance outcomes of OI.

${ }^{8}$ For completeness I also ran a regression model including all interaction effects. In this model, the direct effects of openness and transformation capability remain significant. Concerning the moderating effect, only technological turbulence remains significant in this fully saturated modes. However, interpreting this model is problematic due to multicollinearity issues and due to the large ratio of independent variables to the number of observations. Hence, it is not reported in table 4.3.
} 
variable at one standard deviation above and one standard deviation below the mean for the independent variables. Figures 3.2a-c show how the relationship between openness and OI performance differs depending on whether firms possess strong or weak transfer and translation capability and depending on whether firms operate in a technological environment of high or low turbulence.

Results indicate a weaker relationship between openness and OI performance when firms have weak transfer capability. In contrast, when firms possess strong transfer capability, then increasing the degree of openness enhances OI performance more substantially. Tests of the significance of the simple slopes suggest that while the simple slopes are highly significant at the mean and one standard deviation above the mean of knowledge transfer capability, the simple slope one standard deviation below the mean is insignificant. This suggests that for weak levels of transfer capability, I do not find a significant relationship between openness and OI performance. In other words, the relationship between openness and OI performance is eliminated for those firms that possess weak transfer capability. Testing the region of significance of the simple slope suggests that the relationship between openness and OI performance becomes insignificant at about half a standard deviation $(-0.89)$ below the mean of the moderator (i.e. transfer capability).

Graphing the simple slopes also seems to suggest that for low degrees of openness, firms with weak transfer capability outperform firms with strong transfer capability. Hence, in addition to the interaction effect, the graphs seem to suggest that there is a condition effect such that for higher degrees of openness, firms with strong transfer capability perform better in OI than firms with weak transfer capabilities, while for lower degrees of openness, firms with weak transfer capabilities outperform firms with strong transfer capabilities. However, t-tests reveal that the difference in OI performance between firms with strong versus weak transfer capabilities is insignificant at low degrees of openness, while it is statistically significant at higher degrees of openness. Hence, a condition effect can only be partially supported. ${ }^{9}$

The results for translation capability can be interpreted in a similar manner. For firms with strong translation capability OI performance raises more sub-

\footnotetext{
${ }^{9}$ To test whether these effects are statistically significant, I conducted two separate t-tests at high and low degrees of openness to test whether OI performance differs between firms with high (above the mean) versus low (below the mean) transfer capability. The t-test is insignificant at low levels of openness (below the mean). Hence, at low levels of openness OI performance does not significantly differ between firms with high versus low transfer capabilities However, the t-test at high levels of openness (above the mean) is significant, suggesting that firms with high-transfer capabilities do outperform firms with low transfer capabilities.
} 
Figure 3.2a: The Moderating Effect of Transfer Capability

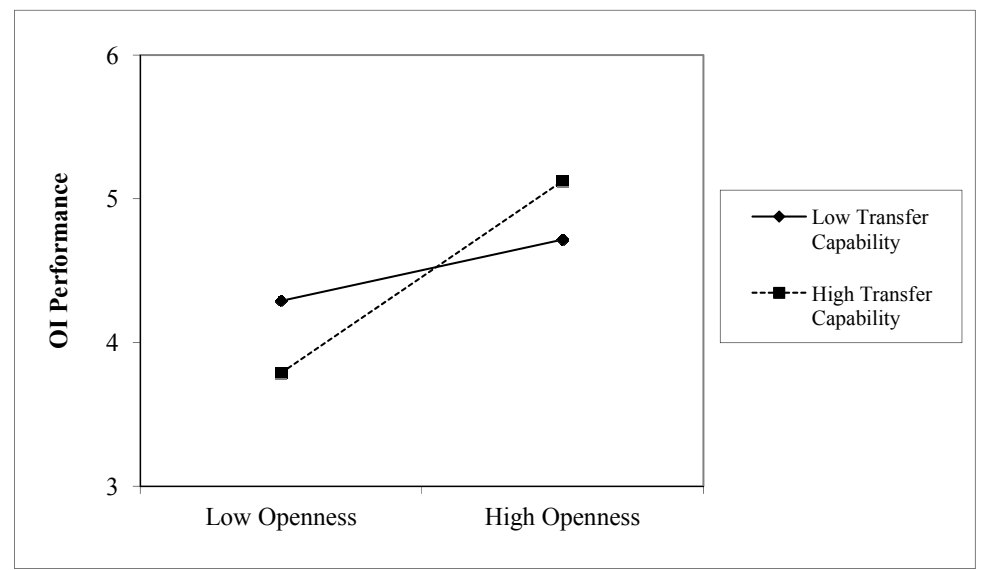

Figure 3.2b: The Moderating Effect of Translation Capability

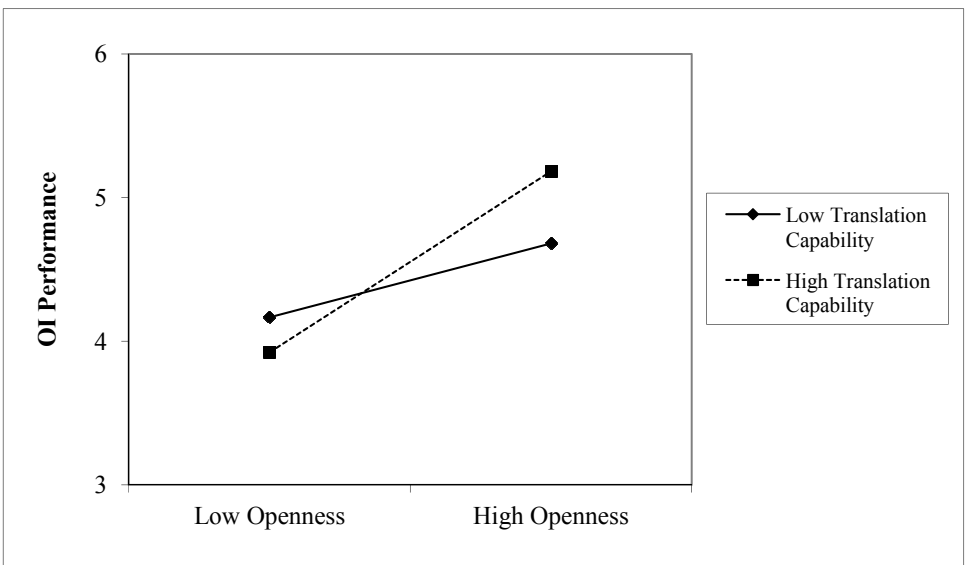

Figure 3.2c: The Moderating Effect of Technological Turbulence

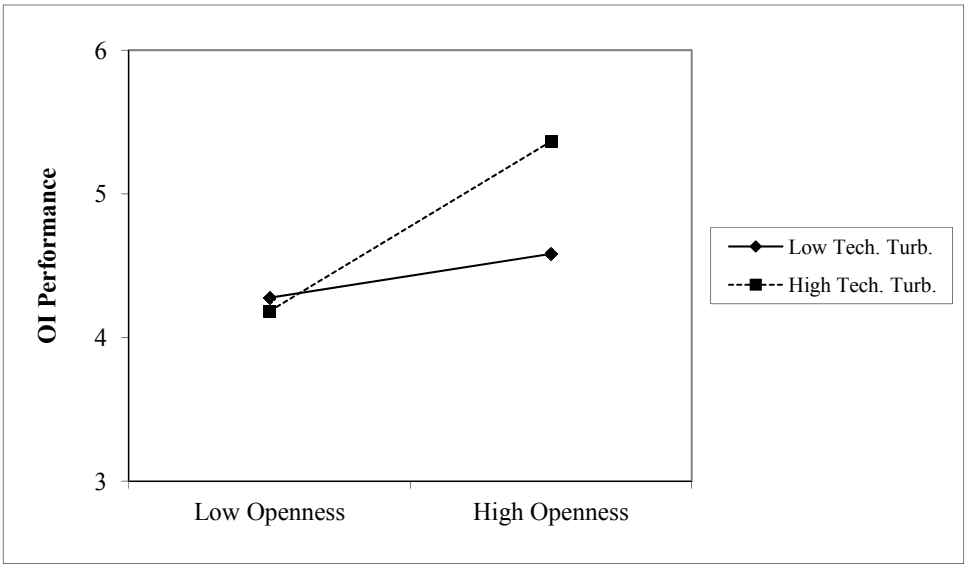


stantially with increasing openness than for firms with weak translation capability. For translation capability the simple slopes at the mean and one standard deviation above the mean are significantly different from zero, while the simple slope one standard deviation below the mean is only marginally significant (at the 10 percent level). Again the graph seems to suggest that for low degrees of openness, weak translation capabilities yield higher OI performance (and vice versa). However, at low degrees of openness, OI performance does not reveal any statistically significant differences between firms with strong translation capabilities and firms with low translation capabilities. For high degrees of openness, conversely, firms with strong translation capabilities significantly outperform firms with weak translation capabilities. ${ }^{10}$

With regard to the final significant interaction effect, firms that operate in a highly turbulent technological environment benefit more from openness than firms operating in environments with very low technological turbulence. With increasing degrees of openness, OI performance of firms that face high technological turbulence raises substantially more than OI performance of firms in relatively placid environments. The simple slopes are significant at the mean and one standard deviation above the mean, but the simple slope one standard deviation below the mean is insignificant. These results suggest that for low levels of technological turbulence, increasing openness does not lead to increased OI performance. Among firms operating in an environment characterized by low levels of technological turbulence, the positive relationship between openness and OI performances is absent. Testing the region of significance of the simple slope suggests that the relationship between openness and OI performance becomes insignificant at about half a standard deviation below the mean $(-0.65)$ of the moderator (i.e. technological turbulence).

\section{DISCUSSION}

This study examined factors that determine the effectiveness of outside-in OI. While there have been some insights into the performance effects of outside-in OI (e.g. Almirall \& Casadesus-Masanell, 2010; Leiponen \& Helfat, 2010; Laursen \& Salter, 2006; Knudsen \& Mortensen, 2011), relatively little was known about the factors that help differentiate firms that benefit from OI from firms that fail to significantly reap the benefits of OI (Huizingh, 2011). This study set out to address this gap by investigating both internal as well as external factors that moderate the relationship between openness in innovation and OI performance. This approach allowed analyzing the variation in OI performance across firms in a systematic way. The objective was to gain a better understanding of the 'fit' between the firm's degree of

\footnotetext{
${ }^{10}$ Again, I conducted two separate t-tests at high and low degrees of openness to test whether OI performance differs between firms with high versus low translation capability. The t-test is insignificant for low degrees of openness and significant for high degrees of openness.
} 
openness and specific firm-internal and firm-external factors that lead to superior OI performance. I find support for this logic, suggesting that internal integrative capability and external contingencies need to be taken into account when engaging in and capturing value from OI.

Focusing on the different dimensions of a firm's integrative capability offers valuable insights into sources of heterogeneity in OI performance. In particular, transfer and translation capabilities are found to positively moderate the relationship between openness in innovation and OI performance. This means that with increasing degrees of openness, firms that develop stronger transfer and translation capabilities benefit substantially more from this openness than firms with weaker transfer and translation capabilities. First, transfer capability, which can be developed and implemented via systematic knowledge management processes, tools, and systems facilitates the codification, storage and diffusion of external knowledge resources within the firm. Second, translation capability, which refers to organizational structures and roles to coordinate external knowledge resources and establish a common meaning, facilitates the adaptation of external knowledge resources to fit the new organizational context. With increasing degrees of openness, these information-processing and structural dimensions of integrative capability allow firms to benefit more from their openness in innovation and therefore, help to explain inter-firm heterogeneity in OI performance.

Even more so, the results show that for firms with weak transfer and translation capabilities, increasing the degree of openness does not lead to higher OI performance. This means that for weak levels of these dimensions of integrative capability, the positive relationship between openness and OI performance is absent. ${ }^{11}$ This finding emphasizes the importance of transfer and translation capabilities for capturing value from increasing degrees of openness in innovation. At the same time, however, the results seem to suggest that for low degrees of openness, it is not worthwhile to invest in these capabilities, since firms with different strengths in transfer and translation capability do not significantly differ in OI performance when they open up only to a limited extent. Thus, when firms access only a smaller number of external knowledge sources and/or do not draw deeply from these external sources, then the investment in transfer and translation capabilities does not seem to pay off. At higher degrees of openness, however, firms with strong transfer and translation capabilities are better able to capture value from this openness and their OI performance exceeds that of firms not investing in transfer and translation capabilities.

The third dimension of integrative capability - transformation capability does not constitute an important moderating factor of the relationship between openness and OI performance. The interaction effect of openness and transfor-

${ }^{11}$ For low translation capability there is still a marginally significant relationship between openness and OI performance. 
mation capability turned out to be insignificant. Nevertheless, the transformation dimension of integrative capability plays a crucial role in realizing OI performance. While there is no moderating effect, transformation capability does have a positive and significant direct effect on OI performance. This means that independent of the degree of openness, transformation capability is a direct driver of OI performance. Shaping an appropriate culture around rewarding/incentivizing, communicating, and encouraging the usage of external knowledge resources leads to higher OI performance. Therefore, as soon as firms access external knowledge sources, developing transformation capability helps to enhance OI performance. Presumably, overcoming the NIH syndrome by developing transformation capability is essential at any levels of openness. As a result, transformation capability is an important antecedent of OI performance, irrespective of the degree to which a firm opens up its innovation process.

Together, these significant effects of the different dimensions of integrative capability highlight the importance of internal dynamic capabilities for managing OI. The results show that the types of the effects of the dimensions of internal integrative capability on OI performance differ - while the effects of transfer and translation capability change with regard to the degree of openness, the effect of transformation capability is of a direct nature and independent of the firm's degree of openness. Nevertheless, all three dimensions of integrative capability are found to be important conditions or antecedents of OI performance. This shows that it is important to look inside the firm in order to better understand the effective management of outside-in OI (Foss, Laursen, \& Pedersen, 2011). There has been a call in the literature to study the internal organization of $\mathrm{OI}$ in order to better understand how firms capture value from openness in innovation (Petroni, Venturini, \& Verbano, 2012). The present study addresses this call by demonstrating that, at higher degrees of openness, firms need to develop and deploy internal integrative capabilities in order to successfully leverage external knowledge sources. Thereby, it sheds some light on how firms can adapt their internal organizational capabilities in order to benefit from OI (Chiaroni, Chiesa, \& Frattini, 2011).

In addition to internal integrative capabilities, external environmental contingencies were highlighted. Two elements of the external innovation ecosystem - technological turbulence and competitive dynamics - were suggested to affect the relationship between openness and OI performance. On the one hand, competitive dynamics, which refer to the extent to which a firm's external environment is subject to accelerating degrees of competition, shows neither direct nor moderating effects on OI performance. This means that direct and/or indirect costs of competition do not influence the extent to which firms benefit from OI. One explanation is that $\mathrm{OI}$ has become a competitive necessity, such that even in demanding and highly competitive environments, firms deliberate spend resources on their OI processes, which allows them to benefit equally well from OI as firms in less demanding environments. On the other hand, technological turbulence positively and signifi- 
cantly moderates the relationship between openness and OI performance. As the rate of technological change accelerates, firms can capture more benefits with increasing degrees of openness in innovation, while in relatively placid technological environments, the positive relationship between openness and OI performance is absent. Hence, there is evidence that in turbulent technological environments, firms can reduce costs of innovation and capitalize on a larger opportunity set of external knowledge sources as they become more open in innovation. As a result, in addition to the internal organization, external environmental factors also partly determine to what extent firms can capture value from their openness in innovation.

In terms of theory, this study contributes to the emerging research field of OI by deepening our understanding of how and when firms can successfully draw knowledge from external sources (Laursen \& Salter, 2006). This study offers a more differentiated picture regarding conditions that make outside-in innovation more effective (Bahemia \& Squire, 2010; Dahlander \& Gann, 2010) and thereby, extends our understanding of the performance effects of openness in innovation. Two aspects of internal organization (transfer and translation) and one external environmental condition (technological turbulence) are found to represent important conditions in a framework of OI. These factors help to explain why some firms benefit more from OI than others (Huizingh, 2011) and lead to a better understanding of the context-dependency of outside-in OI (Di Benedetto, 2010). Furthermore, the results demonstrate that we have to look both inside and outside the firm's boundaries to understand the effectiveness of outside-in OI.

In addition, this study develops a better theoretical foundation of OI research. The concept of OI gets sufficiently grounded into prior research, including the RBV, KBV and dynamic capabilities theories. The findings suggest that dynamic capability for external knowledge management constitutes an important theoretical underpinning of OI. More specifically, integrative capability and its underlying dimensions of knowledge transfer, translation, and transformation can help to better explain value capture processes from outside-in OI. This ability to integrate external knowledge resources into the firm's innovation process via an OI framework can be considered a dynamic capability (Teece, Pisano, \& Shuen, 1997). At the same time, this study acknowledges and demonstrates that firms' OI strategies cannot be considered in isolation, but need to be viewed within the context of the firm's external environment.

The insights from this study also have implications for the theory of dynamic capabilities and its foundations in terms of the RBV and KBV. So far, dynamic capabilities and resource- or knowledge-based research have often been restricted to internal knowledge creation and integration (Nonaka, 1994; Grant, 1996). However, this study demonstrates that the context of OI changes how firms acquire and integrate knowledge. While the RBV originally assumes that the origin 
of valuable resources lies inside the firm, this study shows that knowledge resources increasingly originate from outside the firm. Furthermore, it is illustrated how dimensions of integrative capability and specific environmental conditions explain how firms can more successfully utilize knowledge resources that are not independently owned by the individual firm (Zander \& Zander, 2005). As a result, this study extends the dynamic perspective of integrative capability by exploring how firms can manage knowledge across inter-organizational boundaries. Thereby, this study highlights the dynamic nature of knowledge assets (Fey \& Birkinshaw, 2005) and sheds light on dynamic knowledge integration across interorganizational boundaries.

\section{LIMITATIONS AND FUTURE RESEARCH}

This study is subject to a number of limitations that should be acknowledged and that also provide directions for future research. As is typical for survey research, there are some concerns as to the validity of single-source responses. While several remedies and tests were deployed, potential common method biases cannot be ruled out completely. In addition, there are some limitations regarding the sample chosen in this study. First, the sample size of this study is limited. Indeed, some of the nonsignificant or marginally significant relationships, such as translation capability, might have become (more) significant with a larger data set. Thus, it would be interesting to replicate this study and increase the sample size in order to investigate generalizability. Second, this study focuses on firms that are explicitly engaged in OI (as communicated via their membership at Exnovate). Hence, the results are likely to be representative for firms with an explicit OI strategy. It might be interesting to investigate how the results of this study compare to firms that are not formally engaged in OI. Third, firms in this sample are very heterogeneous with respect to various characteristics, such as size, industry, and R\&D intensity. Therefore, studies with less heterogeneous samples may help to develop a more nuanced understanding of internal and external context characteristics of OI.

In addition, the cross-sectional design does not allow us to observe the short- and long-term impact of internal integrative capabilities and external environmental factors. Given the dynamic nature of the constructs and relationships proposed in this study, it would benefit from a more longitudinal approach in order to understand more completely the relationships between openness, conditional factors and OI performance and assure the direction of causality. Nevertheless, this study advances the emerging discussion on OI by proposing a theoretical framework of outside-in OI and empirically examining internal and external conditional factors of OI performance.

Based on this study's findings, further research into conditional factors of OI is encouraged. For instance, it could be of interest to investigate to what extent 
the developed framework applies to alternative dependent variables, such as overall innovative performance, or firm performance in general. Furthermore, future research should look for additional internal factors and external contingencies of OI. One way to do so would be to investigate different levels of analysis, such as conditional factors at the managerial or individual level. This kind of research could complement this study's focus on organizational-level capabilities. 



\section{CHAPTER 4}

\section{External Dynamic Capabilities \\ - Creating Competitive Advantage in Innovation via External Resource Renewal ${ }^{12}$}

The core contribution of this paper is to provide a better understanding of the external resource renewal process within firms; it delivers new theoretical insights and an empirical exploration of the content and relationships of external dynamic capabilities. These external dynamic capabilities help to explain how firms leverage resources residing outside their boundaries to renew their internal resource base and create competitive advantage in innovation. Constructs of external sensing, seizing, and reconfiguring dynamic capabilities are developed and conceptualized in terms of bundles of underlying organizational processes. Firm-level survey data is used to operationalize and validate these multidimensional constructs. The empirical analysis of this data shows that a more complex chain of relationships explains how these external dynamic capabilities renew specific components of the resource base and create competitive advantage in innovation. Specifically, findings suggest that (1) external sensing dynamic capability leads to enhanced new technological resource access, (2) the relationship between new technological resource access and technological capabilities is positively moderated by external seizing dynamic capability, and (3) while technological capabilities lead to competitive advantage in innovation, external reconfiguring dynamic capability constitutes an additional direct mechanism to further increase a firm's competitive advantage in innovation.

\footnotetext{
${ }^{12}$ I greatly appreciate John Hagedoorn's constructive and insightful comments on this study. I would also like to thank John Ettlie and Will Mitchell for their helpful suggestions on earlier versions of the paper, as well as seminar participants at the University of California Berkeley, Maastricht University, ESADE Barcelona, and conference participants at the Tilburg Innovation Conference and the NSF Globalization of Engineering Workshop. I also thank Wim Vanhaverbeke for supporting the data collection via Exnovate.
} 


\section{INTRODUCTION}

Recent research has highlighted the notion of dynamic capabilities (DCs) to address how firms can adapt to volatile environments by renewing their resource base (e.g. Teece, Pisano \& Shuen, 1997). Most of this research focuses on resource creation and reconfiguration within the firm's boundaries (e.g. Zollo \& Winter, 2002; Zahra, Sapienza \& Davidsson, 2006), such as the creation, integration, and retention of internal knowledge assets (Marsh \& Stock, 2006; Cepeda \& Vera, 2007), the reconfiguration of resources between divisions (Galunic \& Eisenhardt, 2001), or the transformation of internal organizational forms and functions (Rindova \& Kotha, 2001). In particular, literature has discussed the role of internal R\&D for creating new product and process innovations that allow firms to create and sustain competitive advantage in innovation in changing market and technology conditions (e.g. Helfat, 1997; Danneels, 2008; Macher \& Mowery, 2009).

However, due to accelerating environmental and technological complexities, it might become problematic for firms to rely too much on internal resource creation as the sole foundation for competitive advantage in innovation. Instead, firms need to rely more on external sources of renewal and innovation in order to stay abreast of rapidly changing environments (Teece, 2007). While alliances and acquisitions constitute two traditional ways of accessing external resources (e.g. Karim \& Mitchell, 2000), recent literature suggests that firms increasingly access more diverse external sources in more flexible ways, including competitors, customers, start-up firms, universities, individual inventors, and other institutions (Fey \& Birkinshaw, 2005; Laursen \& Salter, 2006). These increasing knowledge flows between firms and a variety of other parties have been summarized as the phenomenon of open innovation (Chesbrough, 2003). According to the open innovation model firm boundaries are becoming more permeable, enabling resources to increasingly flow into and out of the firm at various stages of the innovation funnel (Chesbrough, Vanhaverbeke, \& West, 2006). As a consequence of these open innovation processes, apart from internal resource creation and reconfiguration, accessing and leveraging external resources becomes gradually more important.

In light of this shift towards open innovation and external renewal, a crucial question refers to how firms can renew their resource base and create competitive advantage in innovation by tapping into these external sources. So far, external knowledge resources are considered to be 'out there', ready to be exploited by firms, and we have a limited understanding of the capabilities and processes of identifying these resources and sourcing them into firms (Dahlander \& Gann, 2010; Davis \& Eisenhardt, 2011). While existing literature largely unpacks DCs for internal renewal, research on adding, integrating, and recombining external resources is scarcer. Finally, it remains unclear how firms can create a competitive advantage in innovation if resources are becoming more and more externally available and transferable. To address these gaps, this paper examines the process of external 
resource renewal. It aims at enriching our understanding of the DCs required for renewing the firm's resource base via external paths.

To shed light on the process of external resource renewal, two specific objectives will be addressed. First, this study aims at developing the theory of DCs by conceptualizing DCs for accessing, integrating, and reconfiguring external resources. In his seminal contribution, Teece (2007) categorizes DCs into sensing, seizing, and reconfiguring. However, so far, these categories remain broad concepts of thought, enabling a deeper and more systematic development of these constructs in a particular context. In addition, their applicability to external renewal has not been explicitly discussed. To address these gaps, this study aims at developing constructs for external sensing, seizing, and reconfiguring DCs by conceptualizing them in terms of specific underlying organizational processes. Second, this paper aims at developing a more fine-grained understanding of the process of external resource renewal. I use survey data to empirically measure and validate the new constructs of external sensing, seizing, and reconfiguring DCs and to examine the relationships that explain how they lead to competitive advantage in innovation. Specifically, I examine how these external DCs renew and modify a subset of the firm's resource base - the technological resource base - and how this modified technological resource base, in turn, affects competitive advantage in innovation.

The results demonstrate that competitive advantage in innovation rests to a large extent on firms' external DCs. They enable firms to gain external access to new technological resources, seize these resources for developing superior technological capabilities, and reconfigure the externally shaped technological resource base to obtain additional benefits in terms of innovation. The results further show that external resource renewal can be detrimental unless firms deploy specific bundles of processes that put external DCs into use. Therefore, this study adds to an explanation why some firms are better than others in creating value from external resources and becoming effective at open innovation. It contributes to existing literature by conceptualizing external DCs beyond the traditional alliances and acquisitions context and empirically exploring the relationships by which they renew the resource base and lead to competitive advantage in innovation.

\section{CONCEPTUALIZING EXTERNAL DYNAMIC CAPABILITIES}

DCs have been discussed as crucial mechanisms for adding, shedding, and renewing resources and operational capabilities (e.g. Teece, Pisano, \& Shuen, 1997; Eisenhardt \& Martin, 2000; Zahra, Sapienza \& Davidsson, 2006). Resources are stocks of factors or inputs to production that a firm owns, controls or has access to (Amit \& Schoemaker, 1993; Helfat \& Peteraf, 2003), while operational capabilities refer to the deployment of these resources to attain desired goals on a day-to-day basis (Wang \& Ahmed, 2007). Resources and operational capabilities are, however, 
essentially static in nature and are not capable of explaining competitive advantage in changing environments. As a result, DCs fill this gap by emphasizing the firm's pursuit of the renewal of these resources and operational capabilities (Winter, 2003). However, there is still much conceptual ambiguity, little operationalization, and a lack of empirical grounding concerning the concept of DCs and the mechanisms by which they change resources and operational capabilities (Wang \& Ahmed, 2007; Barreto, 2010). So far, specifications of DCs have often remained abstract and vague, thereby impeding their empirical measurement and analysis (Ambrosini \& Bowman, 2009). To address this issue, this section aims at further conceptualizing the notion of DCs in order to generate a better understanding of DCs and to enable their empirical analysis in the context of external renewal.

For conceptualizing external DCs, it first needs to be noted that DCs can serve various purposes (Helfat \& Winter, 2011), such as external corporate venturing (Keil, 2004), changing the organization's form and function (Rindova \& Kotha, 2001), or divesting resources (Moliterno \& Wiersema, 2007). In particular, literature has highlighted the role of DCs for developing new technologies (e.g. Marsh \& Stock, 2006; Macher \& Mowery, 2009) and, ultimately, creating new innovations (Lorenzoni \& Lipparini, 1999; Karim \& Mitchell, 2000). Innovation is a key purpose of resource renewal and, therefore, constitutes an ideal setting for studying DCs (Winter, 2003). Hence, the following discussion of the nature of DCs focuses on innovation as the purpose of resource renewal.

The understanding of DCs can be facilitated by grouping DCs into two different modes of resource renewal - those that use internal resource creation and development paths and those that use external resource acquisition and integration paths (see table 4.1). The left column of table 4.1 portrays a large number of DCs employed to internally renew resources and operational capabilities. For instance, internal entrepreneurial efforts, involving formal and informal coordination mechanisms, can lead to new resource creation (Zahra, Sapienza \& Davidsson, 2006). Helfat (1997) argues that internal R\&D is a DC which helps firms to respond to changes in the market. Moreover, existing internal resources can be integrated and reconfigured, such as between organizational divisions or across time, to develop new innovative products (Marsh \& Stock, 2006; Pavlou \& El Sawy, 2006). Hence, extant literature unpacks many different DCs that use internal mechanisms for changing the firm's resource base.

However, recent literature, particularly in the field of open innovation (e.g. Chesbrough, 2003; Laursen \& Salter, 2006; Garriga, von Krogh, \& Spaeth, 2013), has shown that in today's context it might be insufficient to rely on internal sources of renewal. Resources and operational capabilities that were traditionally developed internally are now increasingly being accessed outside the firm's boundaries 
Table 4.1: Categorization of existing literature into modes of resource renewal and classes of dynamic capabilities

\begin{tabular}{|c|c|c|}
\hline \multirow{2}{*}{$\begin{array}{l}\text { CLASSES } \\
\text { OF DCS }\end{array}$} & \multicolumn{2}{|c|}{ MODES OF RESOURCE RENEWAL } \\
\hline & INTERNAL RENEWAL & EXTERNAL RENEWAL \\
\hline SENSING & $\begin{array}{l}\text { - Generation of new strategies (Augier \& Teece, 2006) } \\
\text { - Defining critical knowledge areas (Cepeda \& Vera, } \\
\text { 2007) } \\
\text { - Internal creative destruction and constructive } \\
\text { conflict (Danneels, 2008) } \\
\text { - Creative search and strategic sense-making (Pandza } \\
\text { \& Thorpe, 2009) } \\
\text { - Entrepreneurial activities (Augier \& Teece, 2006; } \\
\text { Zahra, Sapienza, \& Davidsson, 2006) } \\
\text { - Knowledge creation routines and experiential } \\
\text { action (Eisenhardt \& Martin, 2000) } \\
\text { - Selection of new technologies and business models } \\
\text { (Augier \& Teece, 2006) }\end{array}$ & $\begin{array}{l}\text { - Environmental scanning } \\
\text { (Danneels, 2008) } \\
\text { - Selecting appropriate modes } \\
\text { of capability sourcing (Capron } \\
\text { \& Mitchell, 2009) } \\
\text { - Search and selection of } \\
\text { alliance or acquisition candi- } \\
\text { dates (Capron \& Anand, 2007; } \\
\text { Helfat et al., 2007; Schilke \& } \\
\text { Goerzen, 2010) }\end{array}$ \\
\hline SEIZING & $\begin{array}{l}\text { - Commitment to R\&D (Helfat, 1997) } \\
\text { - Implementation of technologies and business } \\
\text { models (Augier \& Teece, 2006) } \\
\text { - Asset alignment and designing near-decomposable } \\
\text { systems (Augier \& Teece, 2006) } \\
\text { - Multi-functional teams to coordinate and integrate } \\
\text { resources and skills (Eisenhardt \& Martin, 2000; } \\
\text { Ambrosini \& Bowman, 2003; Macher \& Mowery, } \\
\text { 2009) } \\
\text { - Knowledge management infrastructure (Cepeda \& } \\
\text { Vera, 2007; Easterby-Smith \& Prieto, 2008) } \\
\text { - Building new technological or market-related } \\
\text { resources (Danneels, 2008) } \\
\text { - Strategic decision making to pool resources } \\
\text { (Eisenhardt \& Martin, 2000) } \\
\text { - Divestment of assets (Eisenhardt \& Martin, 2000; } \\
\text { Moliterno \& Wiersema, 2007; Danneels, 2010) }\end{array}$ & $\begin{array}{l}\text { - Alliance and acquisition } \\
\text { routines (Eisenhardt \& Martin, } \\
2000 \text {; Danneels, 2010) } \\
\text { - External corporate venturing } \\
\text { (Keil, 2004). } \\
\text { - Inter-firm collaborations to } \\
\text { expand and improve core } \\
\text { competencies (Lorenzoni \& } \\
\text { Lipparini, 1999; Ettlie \& } \\
\text { Pavlou, 2006) } \\
\text { - Alliance manage- } \\
\text { ment/relational capability } \\
\text { (Dyer \& Kale, 2007; Schilke \& } \\
\text { Goerzen, 2010) }\end{array}$ \\
\hline $\begin{array}{l}\text { RECON- } \\
\text { FIGURING }\end{array}$ & $\begin{array}{l}\text { - Reconfiguring core processes to exploit economies } \\
\text { of scale (Ambrosini \& Bowman, 2003) } \\
\text { - Knowledge brokering and resource allocation } \\
\text { routines; co-evolving and patching (Eisenhardt \& } \\
\text { Martin, 2000) } \\
\text { - Re-combining resources and capabilities between } \\
\text { divisions (Galunic \& Eisenhardt, 2001) } \\
\text { - Building, aligning, and adapting co-specialized } \\
\text { assets (Helfat et al., 2007; Teece, 2007) } \\
\text { - Effectuating new combinations (Augier \& Teece, } \\
\text { 2006) } \\
\text { - Retention and intertemporal integration of } \\
\text { knowledge (Marsh \& Stock, 2006) } \\
\text { - Continuous morphing of business models, organiza- } \\
\text { tional forms and processes (Rindova \& Kotha, 2001) } \\
\text { - Recognizing replication opportunities (Ambrosini \& } \\
\text { Bowman, 2003; Danneels, 2010) }\end{array}$ & $\begin{array}{l}\text { - Acquisition reconfiguration } \\
\text { capability (Capron \& Anand, } \\
\text { 2007) } \\
\text { - Acquisition process for } \\
\text { reconfiguring the firm's mix of } \\
\text { resources (Karim \& Mitchell, } \\
2000 \text { ) }\end{array}$ \\
\hline
\end{tabular}


(Dahlander \& Gann, 2010; Foss, Laursen, \& Pederson, 2011). This transition towards open models of innovation enhances the relevance of externally oriented DCs. This external perspective of DCs is portrayed on the right hand side of table 4.1. Several contributions suggest that firms may require different DCs for reaching across their existing boundaries in search of new resources. For instance, Karim and Mitchell (2000) examined the acquisition process as a DC for reconfiguring the firm's mix of resources. Other studies investigate inter-firm alliances for combining resources across firm boundaries (e.g. Lorenzoni \& Lipparini, 1999; Dyer \& Kale, 2007; Schilke \& Goerzen, 2010). These contributions show that firms have to cope with different constraints when dealing with external resource renewal. For instance, firms face different internal social contexts in the external sourcing of new resources, particularly as external resources are often more distant from the firm's existing stock of resources and operational capabilities (Capron \& Mitchell, 2009). Furthermore, external resource renewal requires the rapid diffusion of know-how learned from external sources throughout the firm (Teece, 2007). Hence, although internal and external DCs serve similar resource-renewal objectives, they differ in their implementation as they need to overcome different organizational constraints.

Although I do not claim that the literature selection in table 4.1 is exhaustive, it becomes evident that research on the external mode of DCs is less extensive and mainly restricted to bilateral relationships, such as alliances and acquisitions. Studies of external DCs often examine very specific topics, such as network relationships in a specific industry (Lorenzoni \& Lipparini, 1999), technology-based new product development partnerships (Ettlie \& Pavlou, 2006), or the reconfiguration of acquired business units (e.g. Karim \& Mitchell, 2000; Capron \& Anand, 2007). However, the concept of open innovation suggests that this view needs to be extended to entail much more diverse modes of accessing resources from a wider range of external parties, such as customers, universities, start-up firms, and competitors (Laursen \& Salter, 2006). The increasing importance of these diverse external sources calls for the development of a better understanding of the nature of externally-oriented DCs. A broader picture of these external DCs is required that goes beyond traditional and bilateral alliances and acquisitions.

Besides differentiating between the internal and external mode of renewal, literature has highlighted the multidimensional nature of DCs (Barreto, 2010). For analytical purposes, DCs need to be further disaggregated in order to explain their underlying mechanisms and relationships (Eisenhardt \& Martin, 2000; Wang \& Ahmed, 2007). Therefore, I suggest a second classification mechanism in order to provide further insights into the broad concept of DCs (see table 4.1). Teece (2007) conceptualizes three classes of DCs at the most comprehensive analytical level. First, 'sensing' refers to the identification and assessment of market and technological opportunities. Second, 'seizing' refers to the organizational strategy and infra- 
structure for integrating resources to create and capture value from opportunities. Finally, 'reconfiguring' refers to the continuous transformation and modification of resources. As shown in table 4.1, Teece's (2007) encompassing framework allows the classification of existing literature into these different classes of DCs. Teece's (2007) framework most explicitly acknowledges the dispersion of knowledge by suggesting that sources of renewal might lie external to the firm. Hence, internal as well as external modes of DCs can be categorized with respect to sensing, seizing, and reconfiguring.

Teece (2007) presents an impressive array of organizational activities, procedures, systems and structures that represent microfoundations of different classes of DCs and are necessary for creating and sustaining overall business success and competitive advantage. In order to enable an empirical analysis of DCs, I apply Teece's (2007) broader conceptualization of different classes of DCs to the context of external resource renewal in innovation. As explained above, research on alliances and acquisitions offer some suggestions for these external DCs, enabling a further conceptualization that applies to a wider range of external interactions. Furthermore, with one exception (Kindström, Kowalkowski, and Sandberg, 2012), prior empirical studies have not captured the multidimensional nature of DCs in terms of sensing, seizing, and reconfiguring. Within this background, the conceptualization of sensing, seizing, and reconfiguring DCs can be deepened by discussing how the various microfoundations of DCs in terms of underlying activities, systems, and procedures (Teece, 2007) can be bundled into specific organizational processes that support sensing, seizing, and reconfiguring DCs. Such bundling would contribute to a more parsimonious conceptualization of DCs. Finally, the relationships between these underlying dimensions or processes and the different classes of DCs need to be clarified. Hence, the constructs of sensing, seizing, and reconfiguration DCs, for the context of external resource renewal are, so far, not clearly delineated. In what follows, the nature of these classes of external DCs is further identified.

Due to accelerating globalization and technological complexity, sources of innovation are increasingly distributed and the identification of relevant external knowledge and technology becomes more and more difficult (Pitelis \& Teece, 2010). Furthermore, technological and competitive uncertainties make it difficult to determine which external resources are most likely to support innovative products that fit the firm's strategic orientation and are relevant for existing and emerging markets (Grant, 1996). These external dynamics and complexities combined with inertia in firms' search processes for external resources could result in the selection of sub-optimal external sources with too little diversity (Uzzi, 1997). Hence, firms require external sensing DCs for identifying valuable sources of external resource renewal.

While external sensing DC leads to the identification of external resources, a further challenge refers to the actual incorporation of these resources within the 
organizational context. Once external knowledge sources have been recognized as valuable opportunities for exchange, these opportunities need to be 'seized' in order to optimize their outcomes (Teece, 2007). Firms need to be able to absorb the knowledge contained in the external sources and integrate it into their internal innovative processes (Zahra \& George, 2002; Wang \& Ahmed, 2007). Hence, external seizing DC refers to the capacity to address opportunities for external renewal and incorporate external resources within the organization.

In the literature, it has been discussed how existing resources can be leveraged by putting them into new uses (Marsh \& Stock, 2006; Danneels, 2010). Eisenhardt and Brown (1999), for instance, introduced the concept of 'patching' to describe the ability to reconfigure resources into the right pieces at the right scale to address new opportunities. Similarly, new products can be created by brokering knowledge from previous projects and existing technologies (Hargadon \& Sutton, 1997; Eisenhardt \& Martin, 2000). Such leveraging effects are also relevant in the context of externally generated resources, where external reconfiguring DC can be described as a combinative capability (Kogut \& Zander, 1992) that refers to the novel synthesis of external and internal resources (Galunic \& Rodan, 1998). As such, external reconfiguring DC refers to the capacity to recombine external resources internally in order to achieve novel configurations that serve new purposes.

Having defined and characterized external sensing, seizing, and reconfiguring DCs, the next step refers to further conceptualizing these broad categories. So far, different classes of DCs have remained inside a black box; there is a lack of knowledge about how these DCs are exercised. However, the existence of DCs cannot be assumed without specifying the particular organizational processes that put these capabilities into use (Galunic \& Eisenhardt, 2001; Helfat et al., 2007). I understand organizational processes as sets of actions that repeat over time and allow managers to accomplish some business task (Teece, Pisano, \& Shuen, 1997; Bingham, Eisenhardt, \& Furr, 2007). Processes, in terms of theses repeated sets of actions are crucial for the development and deployment of DCs (Wang \& Ahmed, 2007). Hence, in order to further conceptualize external sensing, seizing, and reconfiguring DCs I move to a deeper analytical level by analyzing and disentangling their underlying processes.

\section{Enabling Processes of External Dynamic Capabilities}

DCs are enabled and driven by identifiable and specific processes (e.g. Helfat et al., 2007; Wang \& Ahmed, 2007; Helfat \& Peteraf, 2009) and these processes have often been subject of empirical research in their own right (Eisenhardt \& Martin, 2000). Drawing on this existing research I identify a set of specific underlying processes that put external DCs into use. In table 4.2, I delineate how external 
sensing, seizing, and reconfiguring DCs can be understood in terms of these processes. The rightmost column of table 4.2 lists a wide range of studies that have discussed various underlying activities, skills, and tools of DCs. Although most of the identified papers discuss aspects of DCs in the context of internal renewal, I argue that some of the delineated activities may, in modified form, also be applicable for external resource renewal. Furthermore, I suggest how related activities, skills, and tools can be bundled and how different labels and meanings can be reconciled and aggregated into categories of processes.

Processes of external sensing DC As portrayed in table 4.2, external sensing DC is proposed to be driven by the underlying processes 'external scanning' and 'strategic selection'. The ability to sense opportunities requires the constant surveillance and monitoring of markets and technologies (Wang \& Ahmed, 2007). These surveillance and monitoring activities can be summarized as the process of external scanning, which refers to the wide-range observation of the firm's environment (Kogut \& Zander, 1992; Galunic \& Rodan, 1998). External scanning processes enable firms to identify and recognize new and emerging markets and technologies (Danneels, 2008) and develop a sense of the future (Brown \& Eisenhardt, 1997). Such market and technology intelligence drives the firm's ability to sense opportunities for external resource renewal.

When such opportunities are first glimpsed, firms need to gather and filter technological, market, and competitive information to figure out implications for action (Cepeda \& Vera, 2007). In particular, firms need to analyze external knowledge sources and conduct strategic selection processes (Capron \& Mitchell, 2009). 'Selection' refers to the organizational activities involved in identifying a preferred alternative for organizational change and renewal (Brown \& Eisenhardt, 1997; Zott, 2003). This selection should occur in accordance with the firm's strategy and internal competencies in order to achieve fit and avoid over-search (Capron \& Anand, 2007). Strategic selection leads to an assessment and decision of what needs to be done internally and what can be in-sourced from the external world and, therefore, facilitates the firm's capacity to sense and shape opportunities for external resource renewal.

Processes of external seizing $D C$ The second row of table 4.2 classifies existing literature to delineate processes that allow firms to seize opportunities for external renewal. As external resources emerge from different thought worlds, they are likely to remain unrecognizable and separate from the organization without conscious intervention (Hargadon \& Sutton, 1997; Marsh \& Stock, 2006). Effective incorporation requires coordination processes which include the assignment of roles and responsibilities, such as brokers and boundary spanners (Brown \& 


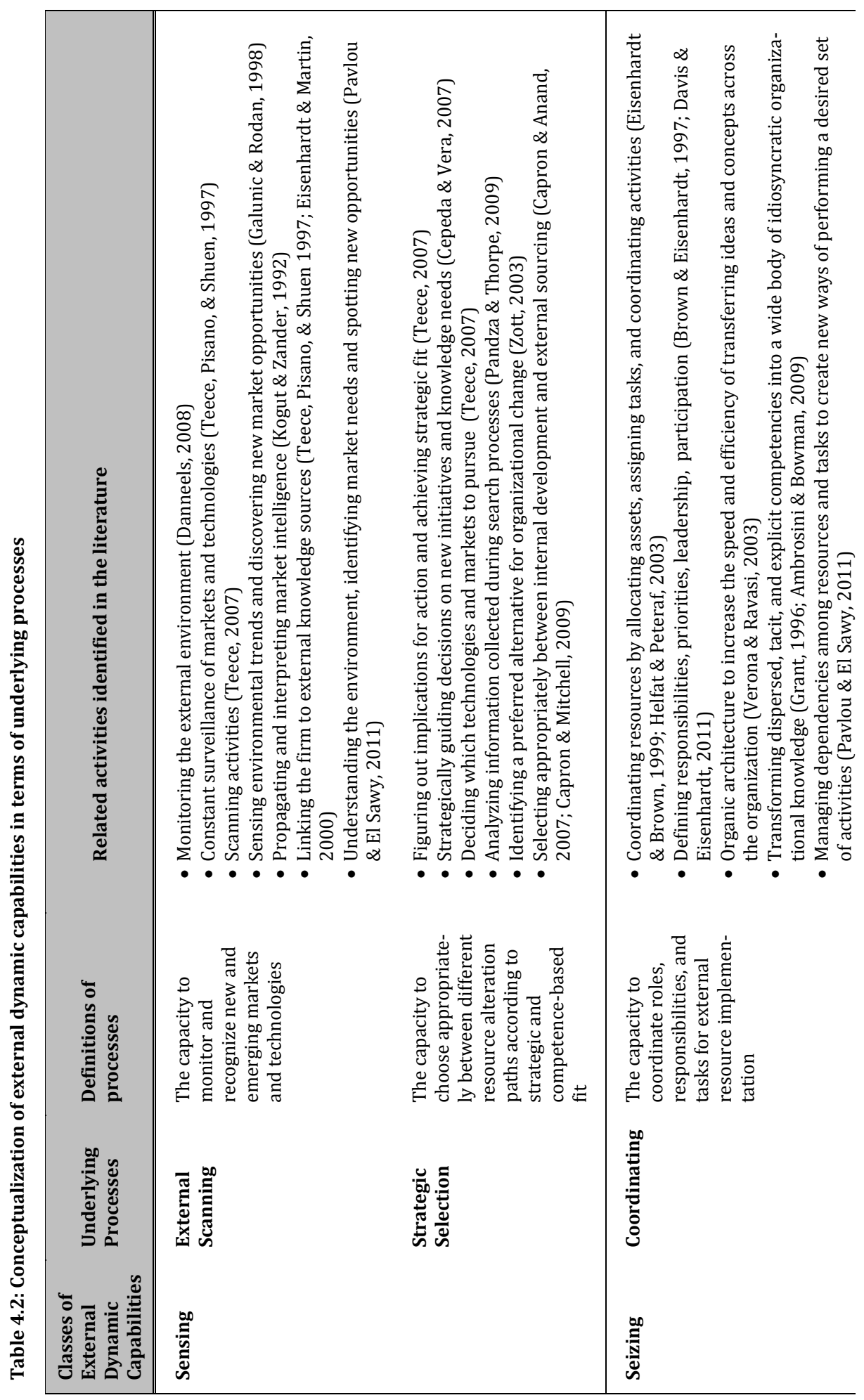



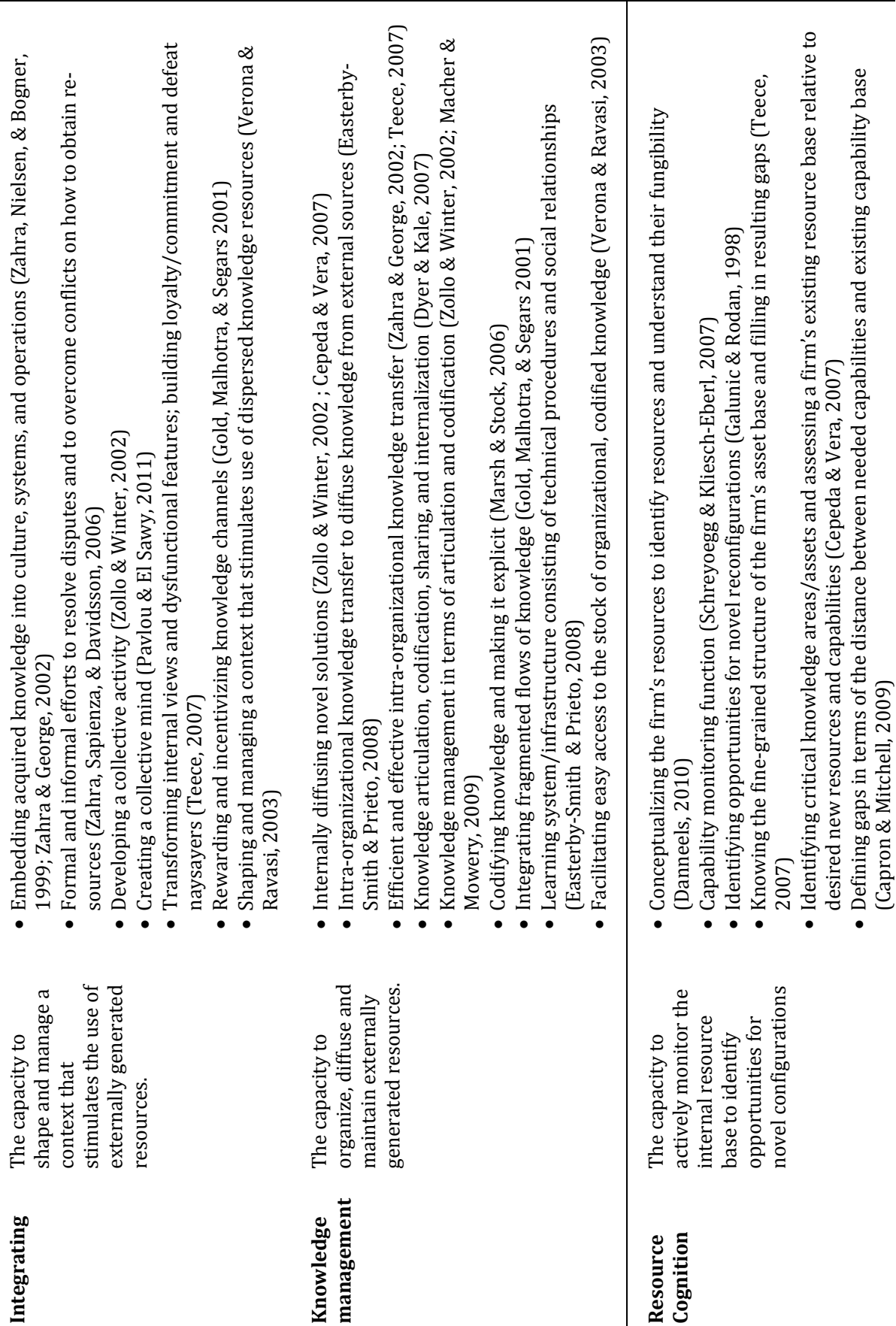


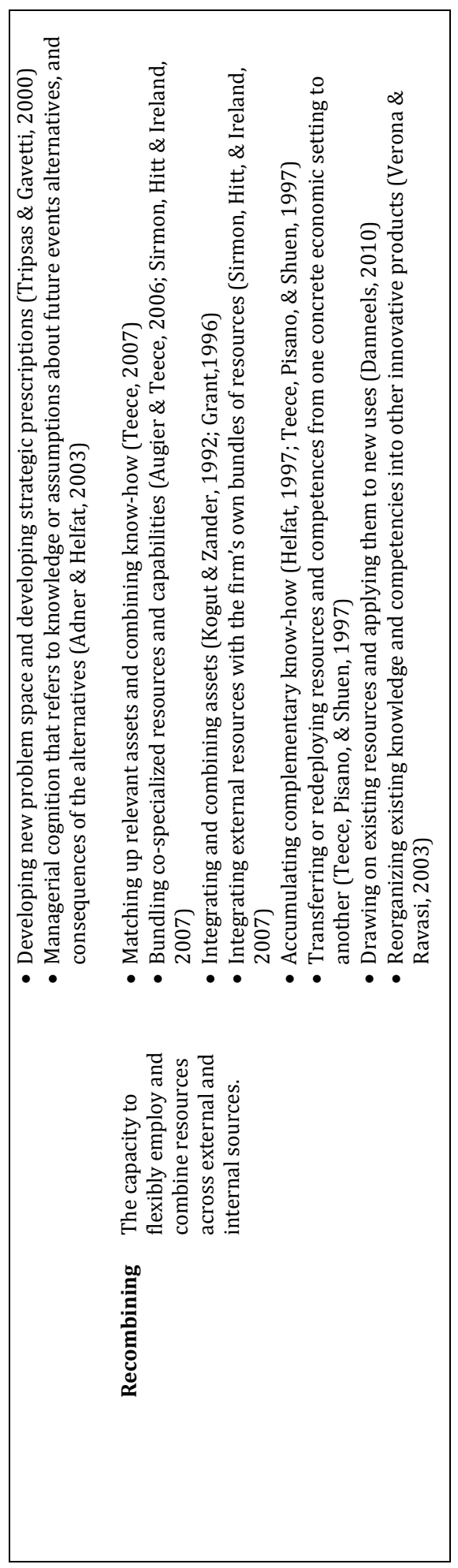


Eisenhardt, 1997; Davis \& Eisenhardt, 2011), and an organic architecture for external knowledge implementation (Eisenhardt \& Brown, 1999; Helfat \& Peteraf, 2003). Coordination processes are essential for preparing external resources for internal use (Ambrosini \& Bowman, 2009). As they have been shown to enhance the speed and efficiency of resource transfer (Verona \& Ravasi, 2003) they are suggested to facilitate external seizing DC.

In addition, effective incorporation of external resources requires their integration into the firm's culture (Zahra, Nielsen \& Bogner, 1999). Employees' resistance to accept external knowledge can lead to implementation stickiness (Szulanski, 2000; Teece, 2007). Hence, conflicts regarding how to obtain and assemble resources need to be overcome (Zahra, Sapienza \& Davidsson, 2006). Corporate values, effective communication, and reward systems help determining the channels and types of knowledge that are tolerated and encouraged (Gold, Malhotra \& Segars, 2001). These activities and tools that stimulate the usage of external resources (Verona \& Ravasi, 2003) can be labeled as integrating processes.

Finally, the firm's knowledge management (KM) infrastructure plays an important role in diffusing external knowledge resources within the organization (Gold, Malhotra \& Segars 2001; Cepeda \& Vera, 2007). An effective KM infrastructure supports the articulation, codification and dissemination of external knowledge resources (Marsh \& Stock, 2006), which have been identified as important mechanisms of DCs (Zollo \& Winter, 2002). KM infrastructure, knowledge codification and dissemination can be summarized as KM processes. These KM processes organize the diffusion of external knowledge within the organization so that it can be assimilated and utilized (Verona, 1999).

Processes of external reconfiguring $D C$ As a final category, table 4.2 portrays the disaggregation of external reconfiguring DC. The capacity to reconfigure external resources is driven by the underlying processes 'resource cognition' and 'recombining'. It has been stressed in the literature that managerial cognition about firm resources is crucial for explaining the deployment of DCs (Danneels, 2010). This cognition refers to the active observation and monitoring of the existing resource base in order to identify opportunities for novel configurations (Galunic \& Rodan, 1998; Schreyoegg \& Kliesch-Eberl, 2007). In order to effectively recombine resources, deep knowledge of the resource base is required (Teece, 2007; Danneels, 2010) and assumptions concerning alternative problem spaces need to be created (Tripsas \& Gavetti, 2000; Adner \& Helfat, 2003). These cognitive activities can be summarized and labeled as resource cognition processes.

Furthermore, the DCs literature has highlighted that value can be created when firms effectively match up assets (Teece, 2007), bundle relevant resources (Sirmon, Hitt \& Ireland, 2007), and recombine relevant know-how (Grant, 1996; Yayavaram \& Ahuja, 2008). Recombination processes reflect a firm's ability to flexibly reorganize external and internal resources and competencies (Verona \& 
Ravasi, 2003). This means that externally acquired resources are transferred from one concrete economic setting to another (Teece, Pisano \& Shuen, 1997; Yayavaram \& Ahuja, 2008). Hence, recombining reflects knowledge brokering (Eisenhardt \& Martin, 2000) from internal and external knowledge resources to address new problems or opportunities. As a consequence it facilitates the capability to reconfigure external knowledge internally to achieve new applications.

In sum, as the existence of DCs cannot be assumed without specifying the particular processes that put them into use, I conceptualize the black box of external DCs by means of a specific set of measurable processes that are grounded in empirical research (see table 4.2). These processes may not exhaust all factors that enable the specified DCs, but they are suggested to reflect existing literature. Having identified the key processes that explain the abstract concepts of external DCs, the next step is to propose a testable model in order to create a more parsimonious picture of DCs and to enable their empirical analysis.

\section{Higher-Order Models of External Dynamic Capabilities and their Enabling Processes}

Since I conceptualize external DCs in terms of specific processes that constitute underlying dimensions of these DCs, higher-order models are an appropriate representation of such constructs (e.g. Law, Wong, \& Mobley, 1998; Edwards, 2001; Wetzels, Odekerken-Schroeder, \& van Oppen, 2009). I propose formative secondorder models, which represent a coherent and parsimonious depiction of the multidimensional nature of external DCs (see figure 4.1). Second-order models are suggested as classes of DCs reside at a higher level of abstraction than their underlying processes (Law \& Wong, 1999; Edwards, 2001). Furthermore, formative modeling is appropriate, as (1) the first-order constructs represent distinct processes that are not interchangeable, (2) the first-order processes are not necessarily correlated (Diamantopolous \& Winklhofer, 2001), and (3) the underlying processes enable the higher-order DCs to occur. This means that the direction of causality runs from the processes to the higher-order constructs, such that different classes of external DCs each represent a combination of several underlying processes into a general concept (Law \& Wong, 1999; Becker, Klein, \& Wetzels, 2012).

By conceptualizing and measuring DCs in terms of their underlying processes I capture the conceptual richness of the constructs, while at the same time making them less vague (Edwards, 2001; Barreto, 2010). The abstract constructs of external DCs can now be reconceptualized in terms of their underlying processes. External sensing DC refers to the ability to scan the external environment and strategically select resource renewal paths. External seizing DC refers to the ability to coordinate resource transfer, integrate external resources within the organizat- 
Figure 4.1: Conceptualization of external dynamic capabilities in terms of second-order models

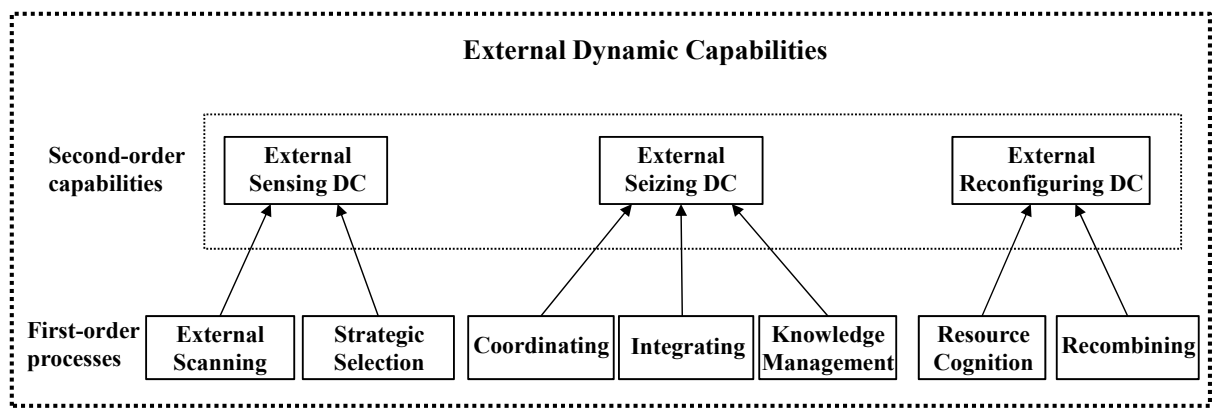

ion and apply systematic KM processes. And finally, external reconfiguring DC refers to the ability to develop resource cognition and recombine external and internal resources in order to achieve novel configurations. While the abstract higher-order constructs are theoretically relevant, the lower order constructs describe specific and observable processes. The relationships between these higher-order external DCs, the firm's resource base and competitive advantage in innovation are discussed next.

\section{STRUCTURAL RELATIONSHIPS: EXTERNAL RESOURCE RENEWAL}

In order to renew its resource base, a firm needs to accumulate new resources as well as build new operational capabilities to be able to deploy these resources (Grant, 1996; Helfat et al., 2007). New resources need to be owned, controlled or accessed on a semi-permanent basis in order to become part of the firm's resource base (Maritan \& Peteraf, 2011). In the context of external renewal, resources lie outside the firm's boundaries and are most likely not independently owned or controlled by the individual firm (Zander \& Zander, 2005). However, firms may use superior access to external resources in order to augment their own resource base. Hence, this study disentangles the resource base into resource access and operational capabilities (Zahra, Sapienza \& Davidsson, 2006) to investigate their respective interactions with different classes of DCs.

Resources and operational capabilities can be manifold, including, for instance, marketing-related, managerial-related, and technology-related resources and operational capabilities. Due to the broad scope of the resource base, the context of the analysis of external renewal is restricted to a certain subset of resources and operational capabilities. More specifically, the analysis of this study focuses on technology-related resources and capabilities, due to their relevance to innovation (Verona, 1999) and external knowledge sourcing (Fey \& Birkinshaw, 2005). On the one hand, technological resources refer to the tangible and intangible inputs for producing technology; they include engineering and manufacturing 
know-how, and technological methods and procedures (Danneels, 2008). On the other hand, technological capabilities refer to a coordinated set of tasks that utilize these resources for desired end results (Helfat \& Peteraf, 2003); they aim at producing, developing, and improving technology, products and processes (McEvily, Eisenhardt, \& Prescott, 2004; Song et al., 2005).

Decisions concerning new technological resources are characterized by uncertainty, complexity, and organizational conflict (Amit \& Schoemaker, 1993). The firm needs to identify external opportunities and anticipate, ex ante, a set of technological assets as grounds for establishing competitive advantage in innovation (Kraaijenbrink, Spender \& Groen, 2010). This challenge is accelerating as the firm's technological asset accumulation is not anymore restricted by its boundaries, but can be augmented to include resources from external sources and networks (Song et al., 2005; Dyer \& Kale, 2007).

External sensing DC enables firms to connect to external sources and networks, leading to privileged access to new technological resources (Zander \& Zander, 2005). As explained in the conceptualization of external sensing DC, systematic processes of external scanning and strategic selection enhance the identification of emerging knowledge and technology sources that fit the firm's strategy. If firms demonstrate strong DCs in sensing these opportunities for external technological renewal, they are more likely to obtain access to relevant technological resources outside their boundaries. Firms may then use this access to draw upon these resources, which they do not independently control, in order to augment their internal technological resource base (Zander \& Zander, 2005). Hence, the more and the better the firm scans the external environment and selects appropriate opportunities, the more access it will obtain to new technological resources. In other words, the processes of external scanning and strategic selection, which constitute a firm's external sensing DC, jointly determine the extent to which firms gain access to new technological resources.

H1: External sensing DC increases the firm's access to new technological resources.

Recently it has been argued in the literature that resources are for most part tradable and are, therefore, unlikely to be a source of competitive advantage (Fey \& Birkinshaw, 2005; Kraaijenbrink, Spender \& Groen, 2010). Value is only created when firms make use of their new technological resources and deploy them appropriately within the firm's context (Sirmon, Hitt \& Ireland, 2007; Ambrosini \& Bowman, 2009). Hence, firms require operational capabilities in the technical realm to deploy newly accessed technological resources for desired end results (e.g. Amit \& Schoemaker, 1993). In general, operational capabilities are activated and shaped by the firm's resources (Song et al., 2005; Wang \& Ahmed, 2007), since the resource portfolio provides the basis for developing operational capabilities (Sirmon, Hitt, \& 
Ireland, 2007). A capability is an ability "to perform a coordinated set of tasks utilizing organizational resources." (Helfat \& Peteraf, 2003, p.999). In other words, the selection, access and accumulation of resources build the foundation for capabilities to perform operational tasks (Kogut \& Zander, 1992; Zahra, Sapienza \& Davidsson, 2006). Therefore, in the more specific case, access to technological resources antecedes the deployment of technological capabilities. Technological capabilities are tangible or intangible processes that are developed over time through complex interactions among the firm's resources (Amit \& Schoemaker, 1993).

The more resources that can be integrated within a certain capability, the greater the difficulty faced by competitors in replicating that capability and the more value that capability can generate (Grant, 1996). Preferential access to a greater variety of resources increases a firm's potential value creation (Sirmon, Hitt, \& Ireland, 2007). In line with this argument Shamsie, Martin and Miller (2009) show that renewal will achieve better returns when the firm has access to a greater breadth of resources. Furthermore, the more resources a firm accumulates, the more flexibly it can respond to future contingencies (Miller, 2002). Applying this to the technical realm, increasing breadth of new technological resources will increase the firm's capacity to quickly adapt technical specifications and optimize technological development according to emerging contingencies. Consequently, it can be expected that the extent to which a firm accesses new external technological resources determines the quality of its technological capabilities. The more preferential access to a greater variety of technological resources firms can obtain, the more superior will be the firm's technological capabilities that bundle and integrate these resources. Hence, the following hypothesis suggests that differences in resource access can at least partially explain capability differences among competitors (Leiblein, 2010).

H2: The more new technological resources the firm accesses, the more superior will be its technological capabilities.

Value-creating operational capabilities do not only derive from access to resources, but are particularly dependent on how resources are integrated and coordinated within the firm (Teece, Pisano \& Shuen, 1997; Ambrosini \& Bowman, 2009). Hence, the quantity or breadth of technological resource access may be a necessary, but insufficient condition for creating superior technological capabilities that outperform those of competitors. Instead, firms also require distinctive capabilities to make better use of these new technological resources, incorporate them into their internal innovation processes (Wang \& Ahmed, 2007) and, thereby, isolate them from competing firms (Kraaijenbrink, Spender \& Groen, 2010). In 
other words, externally accessed technological resources need to be 'seized' in order to optimize their deployment (Teece, 2007).

As argued above, the DC to seize external resources is captured by the underlying processes of coordination, integration, and knowledge management. Jointly, these processes allow firms to make better use of their access to new technological resources by adapting them to the organizational context and facilitating their internal implementation and dissemination. Hence, the more firms coordinate, integrate, and maintain externally sourced technological resources, the more likely it is that they will be assimilated into high-performing technological capabilities. These processes, however, do not only allow firms to make better use of externally accessed resources, but also enable them to integrate and adapt these resources into their own internal innovation processes and, thereby, transform them into firm-specific assets. These firm-specific assets enable firms to develop superior technological capabilities that are isolated from the external world and are thereby, not easily imitated by competitors (Kraaijenbrink, Spender \& Groen, 2010).

External seizing DC is also essentially path dependent. In general, DCs are viewed to be path dependent, as they are contingent on the firm's previous decisions and the stock of resources that it holds (Eisenhardt \& Martin, 2000; Zollo \& Winter, 2002). This means that what firms can seize depends of what kinds of resources they have gained access to. In other words, previously obtained access to new technological resources puts bounds around what kinds of resources can be seized (Teece, Pisano \& Shuen, 1997). Thus, access to new technological resources and the strength of a firm's external seizing DC are expected to interact in shaping the firm's technological capabilities. As a consequence, external seizing DC is suggested to moderate the relationship between new technological resource access and technological capabilities.

H3: External seizing DC positively moderates the relationship between new technological resource access and technological capabilities, such that the relationship is weaker under conditions of low external seizing $D C$ and stronger under conditions of high external seizing $D C$.

In the literature, operational capabilities, particularly those in technological areas, have frequently been stressed as drivers of competitive advantage in innovation (e.g. Amit \& Schoemaker, 1993; Verona, 1999; Protogerou, Caloghirou \& Lioukas, 2011). Superior technological capabilities serve as a platform for competitive advantage in innovation (Song et al., 2005). In particular, strong capabilities for technological operations that outperform those of competitors lead to the development of superior products and services that better meet customer needs, while outdated and inadequate technological capabilities would result in poorer process 
efficiency and product effectiveness (Pavlou \& El Sawy, 2006). Superior technological capabilities enable the firm to transform inputs into outputs in an efficient and effective way and therefore to meet an increasing variety of market expectations without excessive costs or time (Protogerou, Caloghirou \& Lioukas, 2011). Consequently, in line with this literature, I suggest that superior technological capabilities are associated with competitive advantage in innovation.

H4: Superior technological capabilities lead to competitive advantage in innovation.

So far, I have argued that external sensing and seizing DCs lead to the augmentation of technological resources and capabilities. A further key to sustained competitive advantage in innovation is the ability to reconfigure (Bowman \& Ambrosini, 2003). Reconfiguring is particularly relevant in innovation where most new products are inventive recombinations of existing technological resources and capabilities (Henderson \& Clark, 1990; Hargadon \& Sutton, 1997). It is argued here that external reconfiguring DC can contribute to competitive advantage in innovation by drawing on externally shaped technological capabilities and applying them to new uses, such as new product categories.

As argued above, the external DC to reconfigure is driven by resource cognition and recombination processes. Resource cognition refers to the active monitoring of the internal resource base to identify opportunities for new applications, while recombination reflects the reorganization of internal and external assets from one concrete setting to another. Jointly, these processes enable firms to leverage externally assembled technological capabilities by putting them into new uses and unanticipated applications. Managerial cognition and recombination processes help to untangle resource configurations embedded within established technological capabilities and integrate them with other resources in order to create novel applications for innovations (Grant, 1996; Galunic \& Rodan, 1998).

Reconfiguration helps to achieve inimitability, which is crucial for creating and maintaining competitive advantage in innovation (Kraaijenbrink, Spender \& Groen, 2010). Novel combinations that combine both externally and internally shaped technological capabilities are complex and ambiguous and will, therefore, be more difficult to imitate. Externally assembled technological capabilities may further exhibit complementarity in the deployment or application with internal resources; that is, the strategic value of each resource's relative magnitude may increase with an increase in the relative magnitude of other strategic resources (Pitelis \& Teece, 2010). As a consequence, the reconfiguration of externally shaped technological capabilities can lead to new innovations that are not easily imitated by competitors (Verona \& Ravasi, 2003). 
Again, the effect of external reconfiguring DC is expected to be path dependent. The firm's current position in terms of the sum of its technological resources and operational capabilities influences the choices and strategic alternatives available to the firm (Teece, Pisano \& Shuen, 1997; Wang \& Ahmed, 2007). Therefore, it can be assumed that novel applications, achieved via reconfiguration, are contingent on the quality of previously shaped technological capabilities. As a result, external reconfiguring DC is suggested to influence the degree to which technological capabilities lead to competitive advantage in innovation, such that external reconfiguring DC moderates the relationship between technological capabilities and competitive advantage in innovation.

H5: External reconfiguring DC positively moderates the relationship between technological capabilities and competitive advantage in innovation, such that the relationship is weaker under conditions of low external reconfiguring DC and stronger under conditions of high external reconfiguring $D C$.

The previous hypotheses indicate that the different classes of DCs have indirect effects on competitive advantage in innovation, through increased access to new technological resources and superior technological capabilities. Indeed, literature stresses that DCs do not directly lead to competitive advantage (e.g. Zahra, Sapienza \& Davidsson, 2006), but DCs do change the resource base of the firm which, in turn, affects performance outcomes (e.g. Ambrosini \& Bowman, 2009). Zott (2003), for instance, suggests that DCs aim at changing a firm's bundles of resources and operational capabilities, which in turn affect performance outcomes. Similarly, Bowman and Ambrosini (2003) argue that DCs are one step removed from competitive advantage and that, therefore, their impact is indirect. In line with this research, I propose indirect effects of external DCs on competitive advantage in innovation, through the mediating role of the resource base. However, differently from previous research, two separate mediating effects are proposed. As it has been argued above, classes of external DCs operate differently on technological resource access and technological capabilities. This emphasizes the need to disentangle the resource base into technological resource access and technological capabilities and to hypothesize two sequential mediating effects.

H6: New technological resource access mediates the relationship between external sensing DC and technological capabilities.

H7: Technological capabilities mediate the relationship between new technological resource access and competitive advantage in innovation. 


\section{METHODOLOGY}

\section{Data and Sample}

In order to test the hypotheses, primary data was required, which was collected by means of a survey of key informants. The data collection was organized via 'Exnovate', the European Network of Excellence on Open and Collaborative Innovation. Firms enrolled on this platform are active in open innovation and thereby, likely to be engaged in external knowledge sourcing. This makes them theoretically relevant to the research question. Exnovate includes 942 managers from international firms, while a large number of firms are situated in the USA and central Europe. 713 of these firms are multinational corporations, while 229 are small and medium-sized firms. The support of a third-party organization helped to enhance the response rate and to directly address key informants on external knowledge sourcing and innovation. Respondents mostly held positions of Innovation Directors, CTOs, Open Innovation Directors, or R\&D managers. The survey was designed according to Dillman's (2007) tailored design method and implemented in spring 2011. Invitation e-mails were sent, explaining the study's purpose and assuring confidentiality. As an incentive, respondents were offered a customized report of the results of the study. During a period of two months, five rounds of contacts were made, yielding 165 responses, which corresponds to a response rate of 17.5 percent, a rate which is comparable to that of other studies directed at higher-level management (Dennis, 2003; Gruber et al., 2010). Due to missing values and multiple responses per firm, the final sample size amounts to 119 . The majority of respondents were from chemical (31 percent), electronics (11 percent) and other manufacturing (25 percent) industries. The size distribution for firms in the sample reveals that large firms are well-represented. Very large firms $(>10,000$ employees $)$ account for about 60 percent of the sample. About 20 percent of the firms are large (1,000-10,000 employees). Small and medium sized firms $(<1,000$ employees $)$ reach a share of only about 13.5 percent of the sample, while for about 7 percent of the firms, the actual size is unknown. The over-representation of large firms is in line with the size distribution of firms in the initial Exnovate data set.

\section{Measures}

Wherever possible, measurement items were adapted from existing scales. For new measures, standard scale development procedures were used (Churchill, 1979; Dillmann, 2007). Based on extensive literature analyses and interviews with managers in six firms, a large pool of potential items was developed. Face-to-face interviews were conducted with six academics to discuss the appropriateness of these new measurement items. In addition, the survey was pilot-tested with eleven innovation managers. All items are rated on seven-point Likert scales. Table 4.3 lists the complete survey measurement scales used in this study. 
External Sensing $\boldsymbol{D C}$ All first-order constructs of the higher-order representations of external DCs are reflectively measured constructs. Hence, the higherorder external DCs are operationalized in terms of reflective formative type II models (Becker, Klein, \& Wetzels, 2012). External sensing DC is modeled as a formative second-order construct with two reflective dimensions. 'Environmental scanning' is adapted from Danneels (2008) to assess the extent to which the firm's employees access outside information regarding technological and market trends. To capture the process of 'strategic selection', a scale by Capron and Mitchell (2009) is adapted to measure the extent to which firms assess the strategic fit between external resources and internal competences.

External Seizing $\boldsymbol{D C}$ is modeled as a formative second-order construct with three reflective dimensions. To operationalize 'coordination' processes, a new scale was developed to capture processes for allocating roles and responsibilities (Brown \& Eisenhardt, 1997; Eisenhardt \& Brown, 1999; Helfat \& Peteraf, 2003; Verona \& Ravasi, 2003; Davis \& Eisenhardt, 2011). To capture 'integrating' processes, a new scale is based on concepts in Gold, Malhotra and Segars (2001), Cepeda and Vera (2007), Zahra, Nielsen and Bogner (1999), and Sirmon, Hitt and Ireland (2007). Items focus on the extent to which the implementation of externally generated resources is encouraged, valued, and incentivized. To capture 'knowledge management' processes, Cepeda and Vera's (2007) scale of knowledge management infrastructure is adapted to the context of external knowledge sourcing.

External Reconfiguring $\boldsymbol{D C}$ is measured in terms of a formative secondorder construct consisting of two dimensions. For 'resource cognition' processes, items were derived from concepts by Danneels (2010) and Schreyoegg \& KlieschEberl (2007); they focus on the effective recognition of internal knowledge and technology needs and gaps. To capture the firm's ability to 'recombine' external and internal resources, items were derived from theoretical concepts of Pavlou and El Sawy (2011), Sirmon, Hitt and Ireland (2007), Gold, Malhotra and Segars (2001), Zahra, Nielsen and Bogner (1999), and Grant (1996); they focus on the assimilation, interaction, and combination of external and internal resources.

Technological Resource Base Danneels' (2008) resource accumulation measure is adapted for the current study to refer to external access to new technological resources. The questions refer to what extent the company has built access to new external technical resources, skills, or competences. Song et al.'s (2005) scale for technological capabilities is adapted to assess the technology-related subset of operational capabilities. Respondents are asked to rate their technology development and new product development capabilities relative to their main competitors. By asking for a direct comparison with competitors, the superiority of 
Table 4.3: Survey Measurement Scales

\section{External Sensing Dynamic Capability}

External Scanning (7-point Likert scale from 'not at all' to 'extensively')

Please consider to what extent your company conducts the following activities to keep abreast of market and technical trends:

Participating in professional association activities

Attending scientific or professional conferences

Attending trade shows (i.e. industry exhibitions)

Establishing contacts with researchers at universities

Reading specialized journals and magazines

Screening the start-up community

Strategic Selection (7-point Likert scale from 'strongly disagree' to 'strongly agree')

In deciding whether to bring external knowledge into the company, we implement processes / mechanisms for...:

... evaluating its fit with our internal competencies

... verifying its applicability to market segments that we are active in

... assessing its potential strategic benefits for our business

... appointing business lines for unsolicited ideas and knowledge

\section{External Seizing Dynamic Capability}

Knowledge Management (KM) (7-point Likert scale from 'not at all 'to 'to a very great degree')

Please indicate the degree to which the following elements are implemented in your company's external knowledge management system:

A system for the analysis and filtration of external information

Processes to inform employees of stored information and codification tools (i.e. tools to transform knowledge into written guidelines)

Tools to access stored knowledge

Fast and easy internal search tools for external knowledge

Systems for the dissemination/allocation of external knowledge

Coordinating (7-point Likert scale from 'not at all' to 'to a very great extent')

Please consider to what extent are the following elements implemented in your firm:

A clear division of roles and responsibilities to implement external knowledge

Knowledge gatekeepers (i.e. central actors forming an interface between external and in-house employees)

Processes to adapt external knowledge to internal development processes

Integrating (7-point Likert scale from 'strongly disagree' to 'strongly agree')

Please indicate to what extent you would disagree or agree with these statements:

Our management communicates the benefits of using external knowledge throughout the firm

Our employees are encouraged to utilize external knowledge

The usage of external knowledge sources is valued in our company

Our company has standardized reward/incentive systems for using external knowledge

Our employees feel legitimized and empowered to use external knowledge 


\section{External Reconfiguring Dynamic Capability}

Resource Cognition (7-point Likert scale from 'strongly disagree' to 'strongly agree')

Please consider to what extent the following statements apply to your company as a whole. To what extent would you disagree or agree with these statements:

We have a thorough understanding about our firm's technological needs

We have a clear overview of current internal knowledge gaps

We recognize internal innovation problems that may require external knowledge

We have a common/consistent understanding of internal knowledge gaps throughout the firm

Recombining (7-point Likert scale from 'not at all' to 'to a very great extent')

We have processes / mechanisms for...

... creating combinations from external and internal knowledge

... integrating different types and sources of external and internal knowledge

... linking external knowledge with our firm's in-house capabilities

... combining external and internal resources into novel configurations (e.g. R\&D results, products)

\section{Technological Resource Base}

Technological Resource Access (7-point Likert scale from 'not at all' to 'to a very great extent')

By accessing external knowledge sources, to what extent does firm obtain:

... access to technological expertise in new areas

... access to R\&D skills and resources in new technical areas

... access to engineering skills and resources in new technological areas

Technological Capabilities (7-point Likert scale from 'behind competition' to 'ahead of competition') Please evaluate how your company performs the specific capabilities as compared to your competitors:

Technology development capabilities

New product development capabilities

\section{Competitive Advantage in Innovation}

Product Effectiveness (7-point Likert scale from 'far below average' to 'far above average')

Please rate the performance of your company as compared to your competitors in the following aspects of new product development (goods or services):

Improvement in product quality/functionality

Major innovations in products

Creation of new product concepts

Process Efficiency (7-point Likert scale from 'far below average' to 'far above average')

Please rate the performance of your company as compared to your competitors in the following aspects of new product development (goods or services):

Overall development costs

Overall efficiencies of new product development processes

Time to market 


\section{Reflective Indicator Variables}

External Sensing (7-point Likert scale from 'not at all' to 'to a very great extent') Please consider to what extent the following statements apply to your company as a whole:

We track promising ideas, knowledge, or technologies in the external environment

We create opportunities through acquiring knowledge and technologies from external sources

We identify external knowledge that is relevant for our innovation processes

External Seizing DC (7-point Likert scale from 'not at all' to 'to a very great extent')

Please consider to what extent the following statements apply to your company as a whole:

We exploit external knowledge and technology in our company

We translate external knowledge into concrete internal applications (e.g. R\&D results)

External knowledge accelerates our firm's R\&D speed

External Reconfiguring DC (7-point Likert scale from 'not at all' to 'to a very great extent')

Please indicate to what extent:

External knowledge enables the development of innovation products in your firm

Processes are implemented in your company to analyze different applications areas for external knowledge 
functional capabilities can be assessed. Self-report measures that ask respondents to rate their firm's competences relative to competitors have become well accepted in the literature (e.g. DeSarbo et al., 2005; Danneels, 2008). Technology-related capabilities focus on technology development and new product development processes.

Competitive Advantage in Innovation The context of new product development (NPD) is frequently used as an indicator of innovativeness (Verona, 1999; Song et al., 2005) Competitive advantage in innovation can then be assessed by means of the efficiency and effectiveness of the NPD process (Verona, 1999). Scales were adopted from Pavlou and El Sawy (2006). Process efficiency refers to time to market and development costs relative to competitors, and is measured with three items. Product effectiveness refers to product quality and innovativeness compared to competitors, also measured with three items. Competitive advantage is then operationalized as the combination between process efficiency and product effectiveness as a nine-item interaction measure (Pavlou \& El Sawy, 2006). This operationalization has one degree of separation from the self-reported measures and thereby, helps to mitigate potential common method bias (Pavlou \& El Sawy, 2006). ${ }^{13}$ Literature shows that subjective scales are widely used and that there are high correlations between subjective and objective measures (Song et al., 2005).

Indicators and Controls To assess the external validity of the higher-order models, eight items were included to assess the strength of overall external sensing, seizing and reconfiguring DCs, as perceived by the respondents. In addition, several control variables were considered. First, the velocity of the firm's environment may influence the effects of both dynamic and operational capabilities on competitive advantage in innovation (Ettlie \& Pavlou, 2006; Pavlou \& El Sawy, 2006). A threeitem measure is adapted from Jaworski and Kohli (1993) to operationalize technological turbulence. Second, the firm's internal R\&D intensity is measured as yearly R\&D expenditure relative to firm size. In addition, I include firm size (in terms of the logarithm of the number of employees), industry effects (processing, manufacturing, and others), and whether firms are diversified, since these variables may shape firms' degrees of technological capabilities and innovation. Finally, I control for returns on assets, as this provides an indication of the financial resources that firms have available for internal technological development and innovation, which represents an alternative explanation to external sourcing. Information on control variables was collected from secondary data, if available, or requested from respondents.

\footnotetext{
${ }^{13}$ I follow Pavlou and El Sawy's (2005) line of reasoning that such an interaction measure is consistent with the theoretical assumption that firms need to combine process efficiency and product effectiveness and should place similar weight on these two dimensions. While firms may emphasize one aspect, such as cost differentiation, they face the risk of lagging behind competitors that focus on all aspects of product effectiveness and process efficiency. As a robustness check I also analyzed the proposed model with a non-interacted, six-item dependent variable. The findings remain robust and qualitatively similar.
} 


\section{Assessing Potential Method and Sampling Bias}

Several steps helped to reduce potential method and sampling biases. First, procedural remedies, such as improving scale items via interviews and pre-testing, and counterbalancing question order, were employed (Podsakoff, McKenzie \& Podsakoff, 2003). Second, Harman's one-factor test suggests that inter-item correlations are not driven solely by common method variance. Third, multiple responses per firm were collected whenever possible. The average correlation among 12 matched pairs of respondents is positive and significant $(0.46)$ and interrater reliability is acceptable (0.61). Finally, I ensured the validity of the subjective measure of competitive advantage in innovation by triangulating it with secondary objective data that was available for a subset of 79 firms. Using the Gale PROMT database, I collected data on new product announcements and analyzed how firms in the sample compare to their main competitors ${ }^{14}$. I correlated this objective information with the average of the corresponding items reported by respondents; that is how they rate themselves as compared to their main competitors on 'major innovations in products' and 'creation of new product concepts'. The subjective and objective measures show a positive and significant correlation $(0.33, \mathrm{p}<0.05)$, supporting the validity of the subjective measure. Together, this evidence demonstrates that common method bias is not a major concern. Moreover, recent research suggests that even if common method bias is present, this does not usually invalidate theoretical findings (Malhotra, Kim, \& Patil, 2006). To test for nonresponse bias, I compared the first and last 25 percent of respondents on key study variables and demographic characteristics (size, age, relative R\&D expenditure). The analysis indicates that the two groups are statistically similar on all demographic and study variables.

\section{DATA ANALYSIS AND RESULTS}

The hypotheses were tested using partial least squares (PLS), a structural equation modeling technique employing a principal component-based estimation approach (Chin, 1998; Chin, Marcolin \& Newsted, 2003). PLS was selected due to the characteristics of the model and sample. PLS explicitly estimates latent variables and their relationships, it accommodates smaller sample sizes, it does not require any assumptions of data distributions, it overcomes identification problems in modeling

\footnotetext{
${ }^{14}$ In the Gale Group PROMT database, I counted the number of new product announcements from 2010 - 2012 for each firm in my dataset. This generates a number that is not likely to be affected by shortterm economic or cyclical trends. Based on databases that provide investor information (e.g. Hoovers), each firm's three most important competitors were identified for which product announcement data was then also collected. Subsequently, I calculated the respective differences of new product announcements of the firms in the dataset and the average of their main competitors for the specified time period. I adjusted these numbers for the total number of new product announcements made by the focal firm and its respective competitors in order to account for any industry differences. These numbers reveal how the firms in the dataset compare to their main competitors on new product announcements, providing an indication of their competitive advantage in innovation.
} 
formative relationships, and is more suitable in explaining complex relationships (Chin, Marcolin \& Newsted, 2003; Henseler, Ringle, \& Sinkovics, 2009; Wetzels, Odekerken-Schroeder, \& van Oppen, 2009). Since the model at hand is based on a relatively small sample, uses formative higher-order constructs, and entails complex relationships in terms of moderating and mediating effects, PLS is more appropriate than covariance-based approaches, such as LISREL. In the following, I will first provide an evaluation of the measurement model before presenting the results of the structural model.

\section{Measurement Validation}

Reflective measurement models Assessing the reliability and validity of measures is crucial for a meaningful application of structural models (Hulland, 1999). Since the operationalization of the different classes of DCs in terms of underlying processes includes a substantial number of new scales, I first conducted exploratory factor analysis with all items belonging to the underlying processes of DCs. Based on the criterion of eigenvalues greater than one, seven factors are extracted. All items load on their respective constructs with no substantial cross-loadings. Overall, this lends some support for the proposed factor structure of underlying processes of DCs. In a second step, I conducted confirmatory factor analysis as supported by Smart PLS. As shown in table 4.4, composite reliabilities for all reflective constructs are above 0.8 , which exceeds the suggested benchmark of 0.7 (Nunally, 1978). All loadings were above 0.7, supporting the reliability of the indicators. In addition, all items load more highly on their own constructs than on others and none of the cross-loadings exceed 0.7 , thereby demonstrating discriminant validity at the item level. Discriminant validity at the construct level can be confirmed, as the square roots of the average variances extracted (AVE) are greater than the correlations between constructs, meaning that all constructs share more variance with their own measures than with others. (Fornell \& Larcker, 1981). Moreover, as shown in table 4.4, the AVEs of all constructs exceed the recommended cut-off value of 0.5 (Fornell \& Larcker, 1981), thereby demonstrating convergent validity. 


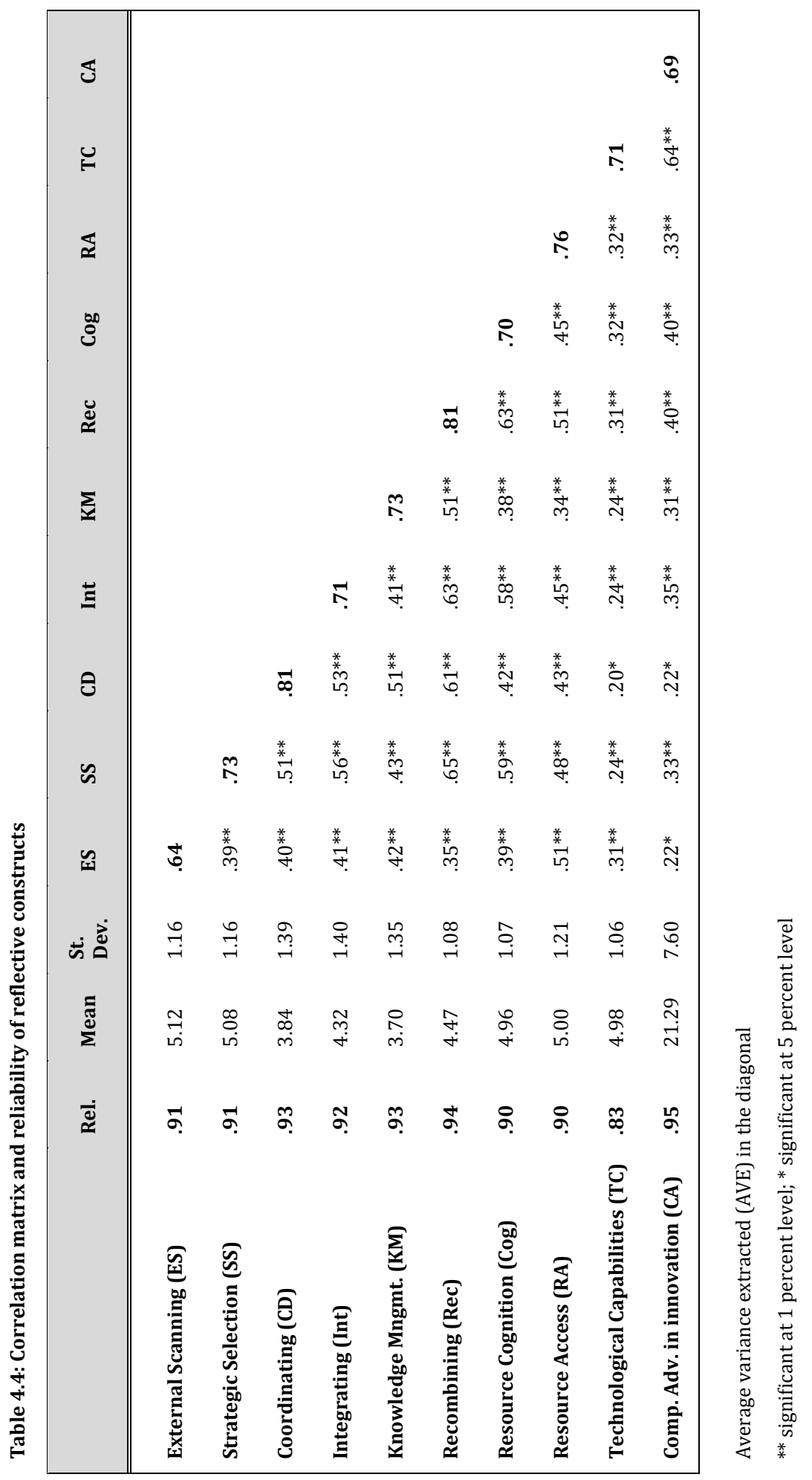


Formative higher-order measurement models Internal consistency and reliability examinations are not appropriate for formative measures (Bagozzi, 1984). Instead, guidelines by Diamantopolous and Winklhofer (2001) were followed to validate the higher-order type II models, including an extensive literature analysis for identifying an exhaustive list of indicators and testing multicollinearity to rule out redundancy (VIFs of all first-order constructs are close to 1.0, suggesting low collinearity). Finally, I assessed the external validity of the formative constructs by testing whether the higher-order constructs are highly correlated with reflective indicators that assess the overall external sensing, seizing and reconfiguring DCs, as perceived by the respondents. ${ }^{15}$ As figure 4.2 reveals, all first-order formative processes demonstrate significant positive relationships with their respective higher-order constructs and the higher-order constructs strongly and positively correlate $(\sim 0.7)$ with their reflective indicators, lending support for the higherorder representation.

\section{Results: Testing the Structural Model}

The proposed research model was tested with Smart PLS (Ringle, Wende \& Will, 2005) and the significance of path coefficients was assessed with 500 bootstrap runs $^{16}$. A two-stage approach was used for integrating the higher-order models into the structural model (Becker, Klein, \& Wetzels, 2012) ${ }^{17}$ First, paths were modeled from the first- to the second-order constructs, using principal component analysis. The weights of the formative constructs are treated as PLS coefficients, and the variance explained in the second-order construct is unity (Wetzels, OdekerkenSchroeder, \& van Oppen, 2009). This is in line with Diamantopolous and Winklhofer's (2001) approach to set the error term to zero to obtain identification in a covariance-based SEM setting. In a second step, I used the latent variable (LV) scores from this analysis to model the formative higher-order constructs, taking the LV scores as indicants for the second-order latent variables in a separate analysis. This approach is most in line with the formative modeling of the first-order constructs (Diamantopolous \& Winklhofer, 2001).

\footnotetext{
15 I used a two-stage approach for modeling these higher-order constructs. The two-stage approach is explained in more detail in the following section.

16 I used the path-weighting scheme and individual-level sign changes.

${ }^{17}$ Alternatives to model second-order constructs include the repeated indicator approach and the hybrid approach (Becker, Klein, \& Wetzels, 2012). According to the repeated indicator approach, a second order factor is directly measured by observed variables for all the first order factors. In the hybrid approach all variables are randomly split so that half are represented on their respective first order construct side and the other half of indicants are represented on the second order construct side. While the hybrid approach has been shown to generate less reliable results (Becker, Klein, \& Wetzles, 2012), the repeated indicator approach represents a suitable alternative to the two-stage approach. Applying the repeated indicator approach to the proposed higher-order structure leads to qualitatively similar results.
} 
Figure 4.2.: Validation of higher order models of external DCs with reflective indicators

\section{Model A: Higher-Order Model of External Sensing DC}

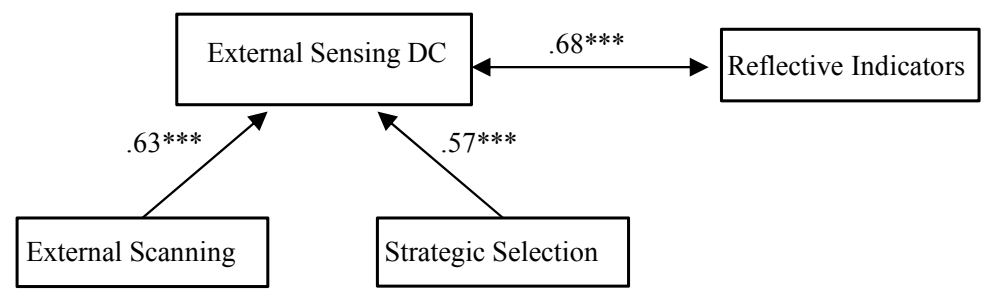

\section{Model B: Higher-Order Model of External Seizing DC}

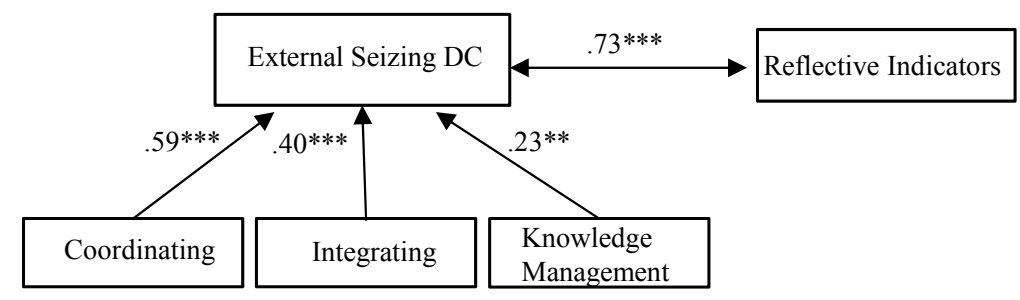

\section{Model C: Higher-Order Model of External Reconfiguring DC}

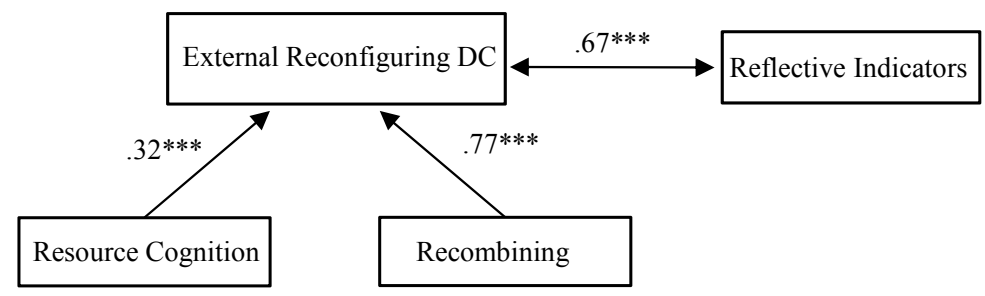

Figure 4.3 reveals the results of the structural model, depicting only significant relationships (and omitting control variables due to parsimony). External sensing DC has a significant positive impact on new technological resource access $(ß=.59$, p-value $<.01)$, thereby supporting $H 1$. The more and the better the firm senses opportunities in the external environment, the more new technological resources it accesses. In other words, external scanning and strategic selection processes, jointly, have a significant positive effect on new technological resources access, explaining 35 percent of its variance (equivalent to a large effect size).

In the context of the complete structural model, new technological resource access has a significant positive impact on technological capabilities $(ß=.33$, p- 


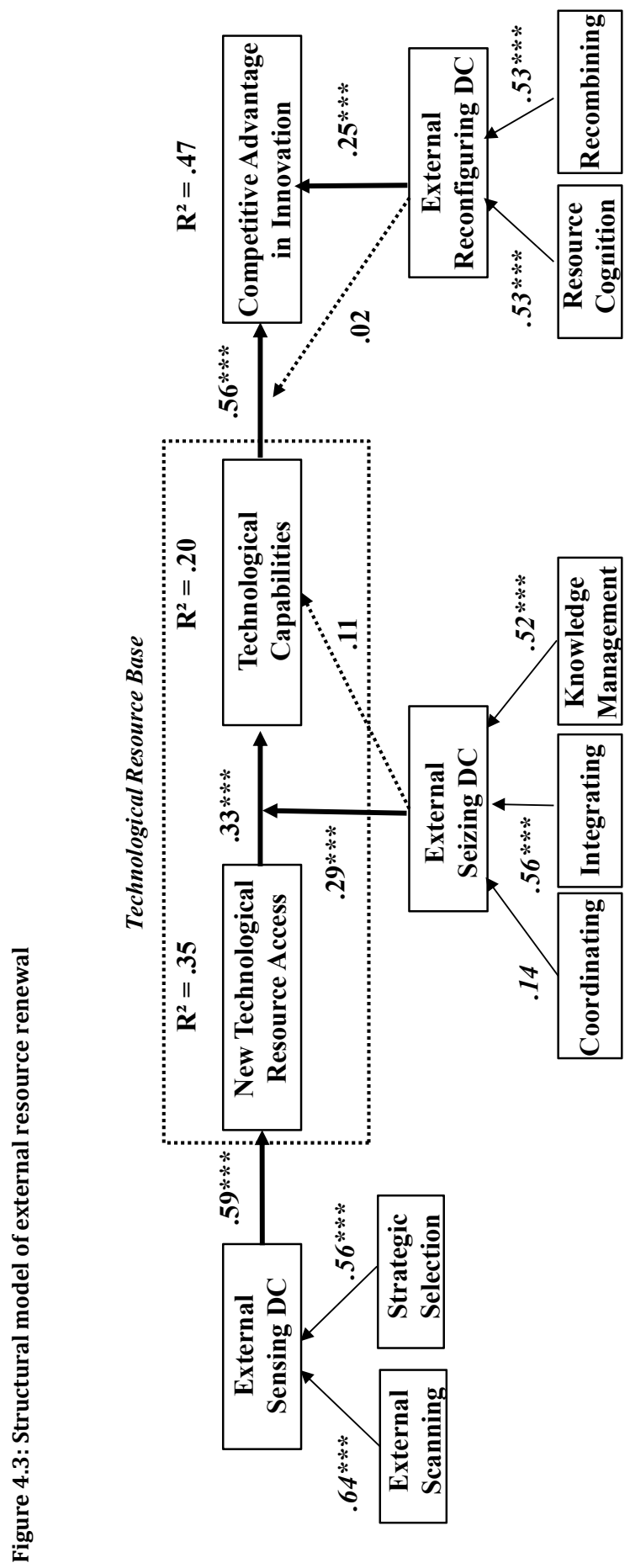

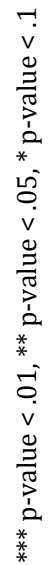


value < .01), providing some support for $\mathrm{H} 2$. However, when evaluating the proposed mediation effect of new technological resource access (H6), it becomes evident that the positive relationship between new technological resource access and technological capabilities can only partially be supported.

Following Baron and Kenny (1986), two criteria for mediation are fulfilled: (1) sensing ( $\mathrm{x}$ ) has a significant positive effect on technological capabilities (y), and (2) the relationship between sensing ( $x$ ) and technological capabilities (y) becomes weaker when including new technological resource access (m). However, the condition that the mediator has a significant effect on the dependent variable cannot be confirmed. New technological resource access (m) does not have a significant impact on technological capabilities (y) when controlling for the direct effect of sensing ( $\mathrm{x}$ ) on technological capabilities (y) and when disregarding the other relationships of the complete structural model.

A possible explanation is that the effect of new technological resource access on technological capabilities is contingent on the level of external seizing DC. H3 hypothesizes that external seizing DC moderates the relationship between new technological resource access and technological capabilities, thereby pointing at moderated mediation. In a next step I evaluated the suggested mediation and moderation effects simultaneously. To test the moderating effects as part of the structural model, I first ran the main effects model in order to obtain estimates for the latent variable scores. The interaction terms are then built up as the elementwise product of the standardized latent variable scores of the predictor and moderator variables. The results show that the impact of new technological resource access on technological capabilities is significantly and positively moderated by external seizing $D C(B=.29$, p-value $<.01)$, thus supporting H3. The f-test comparing the $R^{2}$ between the main and interaction effect (Chin, Marcolin \& Newsted 2003) generates a medium effect size $\left(f^{2}=.15\right)$, providing further support for $\mathrm{H} 3$.

Interestingly, this moderating effect also has an influence on the mediating role of new technological resource access. When including the moderating effect of external seizing DC, the relationship between new technological resource access (m) and technological capabilities (y) becomes significantly positive. At the same time, the direct effect of sensing $(\mathrm{x})$ on technological capabilities (y) becomes insignificant, thereby suggesting full mediation. It is important to note that when including the moderating effect into the structural model, the interpretation of the relationship between new technological resource access and technological capabilities changes. It can now be interpreted as a single effect; it describes the relationship between new technological resource access and technological capabilities at the mean value of external seizing DC. Hence, under the condition that external seizing DC is at least 'average' in strength, the relationship between new technological resource access and technological capabilities is positive and significant. As a 
consequence, the pattern of mediation varies as a function of the moderator 'external seizing DC', thereby providing partial support for $\mathrm{H} 6$.

To further evaluate this effect, I conducted a two group analysis (see figure 4.4). I separately evaluated the mediating effect of new technological resource access for 40 cases that score highest on external seizing DC and for the 40 cases that score lowest on external seizing DC. Figure 4.4 displays divergent results for the two groups. I find the predicted mediating effect of resource access in the high seizing group (group A). New technological resource access fully mediates the relationship between external sensing DC and technological capabilities and there is a strongly positive and significant relationship between technological resource access and technological capabilities $(\beta=.55$, $p$-value $<.01)$. In the low seizing group (group B), however, there is a significant negative relationship between new technological resource access and technologies capabilities $(\beta=-.27$, $p$-value $<.10)$. An adaptation of the t-test for comparing regression coefficients in independent samples (Chin, Marcolin \& Newsted, 2003), confirms that the coefficients of this relationship significantly differ between the two groups. ${ }^{18}$

This means that in cases of weak external seizing DC, externally accessed resources have a negative impact on technological capabilities. These contradicting results in the two-group analysis help to explain why the relationship between new technological resource access and technological capabilities is significant when including the moderating effect, but insignificant when disregarding the role of external seizing DC. It illustrates how the effect of new technological resource access differs with respect to different levels of the moderator variable. As a result, the mediating effect stipulated in $\mathrm{H} 6$ is supported only for average and high levels of external seizing $\mathrm{DC}^{19}$. Furthermore, this shows that $\mathrm{H} 2$ (the more new technological resources the firm accesses, the more superior will be its technological capabilities) is only supported for average and high levels of external seizing DC (when controlling for a direct effect of external sensing DC on technological capabilities).

Proceeding with the evaluation of the complete structural model along figure 4.3, I find that technological capabilities positively influence competitive advantage in innovation, supporting $H 4(\beta=.56$, p-value $<.01)$. Furthermore,

\footnotetext{
${ }^{18} \mathrm{An}$ adaptation of the t-test for comparing regression coefficients in independent samples was conducted, using the equation suggested by Chin (2003), as described and used by Pavlou and El Sawy (2005). A $\mathrm{t}$-value of 39 implies that the coefficients are significantly different from each other.

${ }^{19}$ I tested the significance of the mediation effect by bootstrapping the indirect effect (product terms of the two indirect paths) in the context of the complete structural model. Bootstrapping the path coefficients and calculating their standard errors yields a significant test statistic of 2.6, which lends support for the existence of this mediation effects.
} 
Figure 4.4: Two-group mediation analysis: high versus low external seizing dynamic capabilities

Group A: High External Seizing DCs

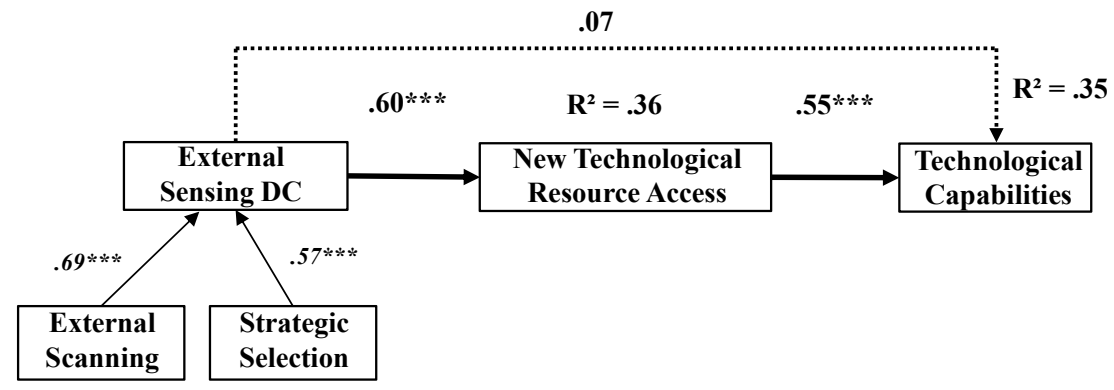

Group B: Low External Seizing DCs

$.40 * * *$

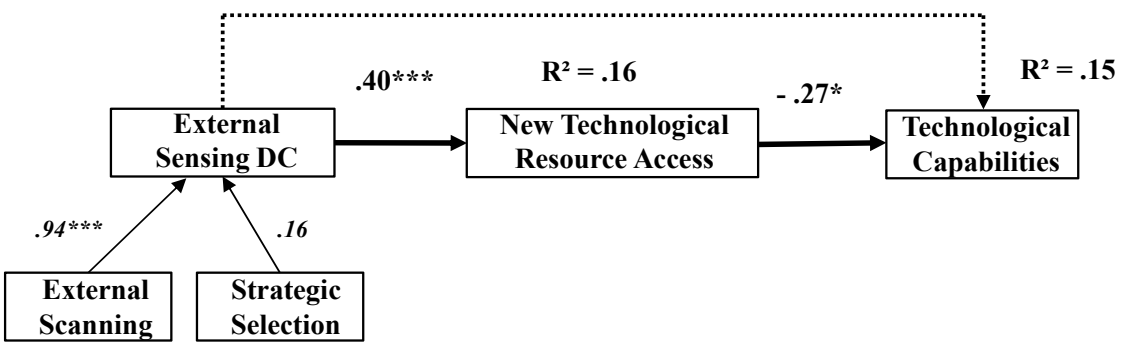

${ }^{* * *}$ p-value $<.01,{ }^{* *}$ p-value $<.05,{ }^{*}$ p-value $<.10$

technological capabilities fully mediate the relationship between new technological resource access and competitive advantage in innovation, supporting H720. To evaluate $\mathrm{H} 5$, I tested the proposed moderating effect of external reconfiguring DC. The moderating effect cannot be supported $(~ \beta=.02$, $p$-value $>.10$ ). Instead, reconfiguring has a positive and significant direct effect on competitive advantage in innovation $(B=.25$, $p$-value $<.01)$ with a medium effect size $\left(f^{2}=.10\right)$.

Control Variables and Robustness 'Technological turbulence' does not reveal any significant effects in the structural model (to preserve the model's clarity, these relationships are not reported). This is in line with Helfat and Winter's (2011) recent assertion that DCs are not restricted to environments of radical change, but are equally important in relatively placid environments. Including firm size, R\&D intensity, diversification, and return on assets in the structural model (with paths modeled to all endogenous variables) does not alter the results and leads to only

${ }^{20}$ Bootstrapping the indirect effect yields a test statistic of 2.8, providing further support for the significant of the mediation effect. 
very small changes in the path coefficients of the variables of interest ${ }^{21}$. To further evaluate potential effects of R\&D intensity, industry effects, and firm size I also conducted multi-group analyses. The main findings remain largely robust across industries, firm sizes, and levels of R\&D intensity (omitted for brevity) ${ }^{22}$. Furthermore, extensive competing model analyses suggest that alternative models are not better in explaining the dependent variables ${ }^{23}$. Also, the Stone-Geisser criteria of the endogenous constructs $\left(Q^{2}=.24, .10\right.$ and .31$)$ suggest high predictive relevance of the structural model. Together this provides some evidence for the robustness of the overall structural model. ${ }^{24}$

\footnotetext{
${ }^{21}$ Interestingly, return on assets has a significantly positive effect on technological capabilities and a negative effect on technological resource access. This may be an indication that firms invest slack resources into the development of capabilities, but are less likely to use them for the sourcing of external resources. Size has a significantly negative effect on technological capabilities, suggesting that large firms are less likely to possess superior technological capabilities. Finally, R\&D intensity has a significantly positive effect on technological capabilities and a negative effect on competitive advantage in innovation. A possible explanation is that internal R\&D does lead to superior technological capabilities and thereby contributes positively to competitive advantage in innovation, but it might be less efficient and more time consuming, thereby demonstrating a negative direct effect on competitive advantage in innovation.

22 In some of the sub-samples (i.e. 'high R\&D intensity', 'small firm size', and 'processing industry') the single effect of 'new technological resource access' on 'technological capabilities' is insignificant. Furthermore, in the 'low R\&D intensity sample' the effect of 'external reconfiguring DC' on 'competitive advantage in innovation' is insignificant. This finding makes intuitive sense, as firms with low R\&D activities have limited opportunities to reconfigure externally shaped resources and capabilities with internally developed resources and capabilities. Finally, in the 'large firms' sample the effect of 'external sensing DC' on 'new technological resource access' becomes insignificant. However it remains to be tested whether these subtle differences between groups are true differences or whether they are artifacts of the small sample sizes that are created by splitting the sample into groups.
}

${ }^{23}$ The first competing model is a reduced direct one, in which direct paths are modeled from external sensing, seizing, and reconfiguring DCs to competitive advantage in innovation. The second model is partially indirect, in which 'technological resource access' is included as a single mediator, and external seizing DC moderates the relationship between 'new technological resource access' and 'competitive advantage in innovation'. Analogously, the third model is partially indirect, including 'technological capabilities' as the single mediator, with external seizing DC moderating the relationship between 'external sensing DC' and 'technological capabilities'. In all three models, less variance is explained in the dependent variable as compared to the suggested research model. Further, in models 2 and 3 , the moderating effects of external seizing DC are insignificant. As a final robustness check, I included paths from external 'sensing', 'seizing', and 'reconfiguring' DCs to all endogenous variables in the model ('technological resource access', 'technological capabilities', and 'competitive advantage in innovation'). The only effect that is marginally significant (at the 10 percent level) is the path from 'reconfiguring' to 'new technological resource access', suggesting some feedback loops that are to be examined in future longitudinal studies. Overall, the competing model analyses corroborate the relationships in figure 4.3.

${ }^{24}$ I also implemented a global goodness-of-fit measure, according to Tenenhaus et al. (2005). This measure is defined as the geometric mean of the average communality (AVE) and average $\mathrm{R}^{2}$ (for endogenous constructs).This yielded a GoF measure of 0.51 , which according to Wetzels, OdekerkenSchroeder, \& van Oppen (2009), represents a large fit value and thereby allows me to conclude that the suggested model performs well. 


\section{DISCUSSION}

Following recent theoretical developments that emphasize the importance of external sources of renewal and the transformation from a closed to a more open innovation model (e.g. Chesbrough, 2003; Fey \& Birkinshaw, 2005; Laursen \& Salter, 2006; Garriga, von Krogh, \& Spaeth, 2013), this study examined the relationships between external DCs and competitive advantage in innovation. While previous literature on DCs has focused mainly on internal resource creation and reconfiguration (e.g. Zahra, Sapienza \& Davidsson, 2006; Cepeda \& Vera, 2007) I emphasize the relevance of external sources of renewal. In doing so, I unpack the concept of external DCs which aim at renewing the resource base by accessing and integrating resources that reside outside the firm's boundaries. The empirical analysis, in the context of technological renewal, reveals that competitive advantage in innovation rests to a large extent on three classes of external DCs, which enable firms to sense opportunities for accessing external technological resources, seize these resources, and reconfigure them internally.

Despite the importance of DCs, there are few empirical studies assessing the content of DCs and testing their relationships (Macher \& Mowery, 2009). Hence, this study provides an empirical contribution by operationalizing the underlying processes of external DCs and validating their measurements in a sample of international firms. In addition to offering more concrete measures of external DCs, this study explicates empirical links between these DCs, components of the technological resource base, and competitive advantage in innovation. This leads to a better understanding of how DCs operate and function in combination (Ambrosini \& Bowman, 2009) and how they lead to important outcomes (Barreto, 2010). The results show that external sensing, seizing, and reconfiguring DCs are part of a more complex chain of relationships that explains how they renew specific components of the resource base and create competitive advantage in innovation.

In particular, the results show that external sensing DC leads to new technological resource access. Firms that have systematic external scanning and strategic selection processes in place gain access to a larger range of new technological resources. At the same time, the analysis demonstrates that external access to new technological resources is not necessarily beneficial. Instead, technological resource access harms the focal firm unless it possesses a strong external DC for seizing these resources. The multi-group analysis reveals that for firms with weak external seizing DC, new technological resource access has a significantly negative effect on their internal technological capabilities. Gaining access to external technological resources without implementing systematic coordination, integration, and knowledge management processes, has detrimental effects on a firm's technological capabilities. A possible interpretation of this result is that these firms invest time and effort to access new external resources. However, these resources do not add any value as they are never coordinated, integrated and diffused within the firm. As 
an alternative to external renewal, these firms might have been better off by creating and shaping their technological capabilities internally. However, if a firm possesses strong external seizing DC, access to new technological resources has a strong and significantly positive effect on technological capabilities. These results highlight the potential benefits and risks of external renewal. In particular, they emphasize the importance for firms to develop systematic coordination, integration, and knowledge management processes in order to be able to seize new technological resource access into superior technological capabilities.

The empirical analysis, in addition, sheds light on the resource base as a mediating factor. While the mediating role of the resource base has been demonstrated in the literature (e.g. Cepeda \& Vera, 2007; Ambrosini \& Bowman, 2009), this study adds to this research by differentiating between resource access and operational capabilities. The structural model shows that new technological resource access influences the firm's technology-related operational capabilities, which in turn lead to competitive advantage in innovation. In addition, the analysis shows how the identified classes of external DCs operate at different components of the resource base. While external sensing DC has a strong and positive direct effect on new technological resource access, external seizing DC positively moderates the relationship between new technological resource access and technological capabilities. This interaction effect is in line with the path dependency logic inherent in the DCs literature (Zollo \& Winter, 2002; Ambrosini \& Bowman, 2009), as the value creation potential of external seizing DC is dependent on previously accessed resources. Overall, the empirical findings of this study support the differentiation of the technological resource base into technological resource access and technological capabilities. It contributes to existing literature by conveying a more detailed picture of the composition of a subset of the resource base and how it is transformed via different classes of DCs (Amit \& Schoemaker, 1993).

Furthermore, this study clarifies the role of external reconfiguring DC which refers to the capacity to monitor and flexibly recombine external and internal elements of the resource base to create novel applications. Rather than finding a moderating effect of external reconfiguring DC, as hypothesized, I find that this class of external DCs has a direct positive impact on competitive advantage in innovation. This suggests that external reconfiguring DC enables new applications of external and internal resources that are not easily imitated by competitors and therefore have a positive effect on competitive advantage in innovation. This finding also implies that the influence of reconfiguring is independent of previously accumulated technological resources and capabilities. Therefore, this class of external DC does not seem to be essentially path dependent, as the quality or superiority of externally shaped technological capabilities does not interrelate with the extent to which firms can effectively reconfigure these capabilities into new innovations. Instead, reconfiguring leads to an additional effect on competitive advantage in innovation (Helfat \& Peteraf, 2009). 
A possible interpretation is that technological capabilities can be superior or inferior in one organizational setting, such as a certain product category or technological field. However, this superior or inferior position does not automatically determine the value creation potential of these technological capabilities in a different setting or application. Even if the firm possesses technological capabilities in a certain field that are inferior to those of their main competitors, it can create a competitive advantage in innovation if it has the capacity to reconfigure these capabilities in novel ways that lead to new innovations (Henderson \& Clark, 1990; Galunic \& Rodan, 1998). Hence, external reconfiguring DC offers an opportunity to escape from unfavorable path dependencies by applying externally shaped technological capabilities into different economic settings that may offer new or even better value creation opportunities. In contrast to most prior work that emphasizes that effects of DCs are always and entirely mediated by the firm's resource base (e.g. Zott, 2003; Zahra, Sapienza \& Davidsson, 2006), this study shows that one specific class of external DCs (i.e., reconfiguring DC) directly contributes to competitive advantage in innovation. This is because reconfiguring DC can alter the externally extended resource base further, leading to an additional direct effect on competitive advantage in innovation.

In addition to these empirical findings, this study develops a stronger theoretical foundation of external DCs, which have been limited to the context of alliances and acquisitions (e.g. Karim \& Mitchell, 2000; Ettlie \& Pavlou, 2006; Dyer \& Kale, 2007; Schilke \& Goerzen, 2010). So far, research has left the processes by which resources and capabilities are externally renewed largely black boxed (Ambrosini \& Bowman, 2009; Kraaijenbrink, Spender \& Groen, 2010). By explicating specific organizational processes which lead to access, deployment, and reconfiguration of external resources, we are able to look inside this black box. First, external sensing DC is conceptualized in terms of external scanning and strategic selection processes. Second, external seizing DC is captured as the processes to coordinate resource transfer, integrate these resources into the firm's culture, and to provide systematic knowledge management. And finally, external reconfiguring DC refers to the processes of monitoring the resource base and recombining external and internal elements to achieve novel configurations.

This conceptualization in terms of underlying processes offers a more complete understanding of what external DCs are and how they are put into use. With few notable exceptions (Pavlou \& El Sawy, 2006; 2011; Schilke \& Goerzen, 2010), most studies have employed a unidimensional approach to DCs and operationalized them through single measures (Helfat, 1997; Macher \& Mowery, 2009) or multi-item measures (Danneels, 2008; McKelvie \& Davidsson, 2009). However, this unidimensional approach ignores the conceptual richness and complexity of DCs (Barreto, 2010). The second-order models, suggested in this study, are theoretically useful, as they provide a holistic representation of a complex phenomenon and allow matching complex predictors (DCs) with complex outcomes, such as 
competitive advantage in innovation (Edwards, 2001). Furthermore, these higherorder DCs are not easily mimicked as they are established through a combination of lower-level processes. As a consequence, their conceptualization is in line with theoretical assertions that DCs are difficult to imitate (Teece, 2007), heterogeneous in detail (Eisenhardt \& Martin, 2000), and a source of competitive advantage (Ambrosini \& Bowman, 2009). The analysis demonstrates significant effects of these bundles of processes, which provides some evidence that DCs are not single processes, but consist of more complex bundles of processes which jointly modify the resource base (Zollo \& Winter, 2002; Barreto, 2010).

A better understanding of these external DCs also contributes to the emerging field of open innovation (e.g. Chesbrough, Vanhaverbeke, \& West, 2006; Laursen \& Salter, 2006; Dahlander \& Gann, 2010; Foss, Laursen, \& Pedersen, 2011). They elucidate the kinds of capabilities firms need to develop and deploy in order to become effective at open innovation. At the same time, the empirical analysis reveals the potential benefits and risks of open innovation, since it showed that access to external resources can improve as well as harm internal operational capabilities. In this context, external seizing DCs were shown to be particularly important for realizing positive effects from open innovation. This study adds to the current understanding of open innovation by developing a capability perspective that helps to explain firm heterogeneity in creating and capturing value from external sources of innovation.

In sum, this study sheds light on the external mode of DCs and how it can contribute to competitive advantage in innovation. It is not external resources per se, but it is the firm-internal DCs and their underlying processes that are a key to competitive advantage in innovation. The more and the better the firm senses opportunities for external renewal, seizes these opportunities by transforming resources into operational capabilities, and leverages the value potential of external resources by reconfiguring them internally, the more effective and efficient will be its innovation process. Hence, the source of competitive advantage in innovation does not lie externally, but moves even deeper inside the firm. While resources are becoming more and more externally available and transferrable, the capacity to orchestrate such externally available resources remains scarce and becomes a key organizational function (Augier \& Teece, 2006). External DCs help to explain why some firms are better than others in creating value from external sources and how firms can create competitive advantage in innovation on the basis of external resources, which are for most part tradable (Kraaijenbrink, Spender \& Groen, 2010).

\section{Limitations and Future Research}

This study has several limitations, which provide opportunities for future research. First, to create higher-order models of DCs, this study uses constructs which have strong theoretical support in the literature. However, these processes are not 
necessarily exhaustive and future research has to develop a more complete picture of the underlying processes that put external sensing, seizing, and reconfiguring DCs into use. Furthermore, literature shows that resources can be obtained from different external sources (Laursen \& Salter, 2006). It would be of interest to see whether external sensing, seizing, and reconfiguring DCs, in combination with their underlying processes, differ for accessing different external sources, such as customers or universities. Furthermore, the empirical analysis of this study focuses on the renewal of technological resources and technologies capabilities. Future studies could extend this research by investigating marketing- or managerial-related resources and capabilities, which are also relevant for a dynamic capability perspective (e.g. Adner \& Helfat, 2003; Bruni \& Verona, 2009).

Second, the cross-sectional design of the survey does not allow us to observe the short- and long-term effects of the different classes of DCs. While I propose sequenced relationships, all constructs are measured at one point in time. Furthermore, the operationalizations do not directly capture dynamic change in 'new technological resource access' and 'technological capabilities'; instead, positive associations between DCs and the resource base are suggested at one point in time. Hence, the results should be treated with caution as causality cannot be inferred with such cross-sectional data. As a consequence, this study could benefit from a more longitudinal approach in order to better establish causality and disentangle temporal and sequential effects. Despite these limitations, by proposing and testing relationships among external DCs, the firm's technological resource base, and competitive advantage in innovation, this article has brought improved understanding to the concept of external resource renewal. 



\section{CHAPTER 5}

\section{Discussion and Conclusion}




\section{INTRODUCTION}

This dissertation was motivated by the observation that firms respond to increased technological complexity, accelerated R\&D costs, shortened product life cycles and improved market institutions by opening up their boundaries and leveraging inflows and outflows of knowledge and technology (e.g. Chesbrough, 2003; Chesbrough, Vanhaverbeke, \& West, 2006; Laursen \& Salter, 2006). Given these developments, the fundamental assumption of this dissertation is that firms increasingly transform from a closed to an open innovation model. The phenomenon of open innovation suggests that the role of the external sources has changed; while it has previously been considered as a supplement to internal $R \& D$, external sources of innovation are increasingly adopting a more equivalent role. This means that the locus of innovation has shifted beyond the firm's boundaries, since open forms of innovating gradually crowd out more traditional internal forms of innovating (Lakhani \& Tushman, 2012). While prior work has developed a first understanding of antecedents and outcomes of open innovation, it has, so far, been less clear how firms create and capture value from open innovation and why they differ in the extent to which they are successful in doing so.

As the theoretical foundations of open innovation are currently being laid out, it was crucial to develop new constructs and relationships, but also to embed the new phenomenon into existing theories and test some theoretical conjectures. In this dissertation I adopted a capability perspective (e.g. Amit \& Schoemaker, 1993; Helfat, 2000; Danneels, 2002; Marsh \& Stock, 2006; Bingham, Eisenhardt \& Furr, 2007), which proved to be a particularly useful approach for developing a better understanding of relevant constructs and relationships for the phenomenon of open innovation. In this context, this dissertation investigated how firms implement open innovation strategies to benefit from external knowledge sources and paths to market and what kinds of capabilities support these strategies.

At the outset of this dissertation, the identification and integration of external sources of innovation were identified as crucial challenges for firms in the management of open innovation. To shed light on how firms can address such challenges, I aimed at developing a better understanding of the organizational capabilities that support firms in identifying valuable opportunities for open innovation and in translating them into positive innovation outcomes. The three empirical studies that build the core of this dissertation were based on the fundamental assumption that the dynamic capabilities view serves as an appropriate theoretical foundation for addressing these issues. Against this background, the aim of this dissertation was to shed light on the following overarching research question:

\section{How and why do dynamic capabilities explain how firms create and capture value} from open innovation? 
Each of the three empirical studies in this dissertation provides unique insights into this research question by addressing various facets of value creation and value capture from open innovation by means of dynamic capabilities. In the following, the main findings of these studies are summarized. Subsequently, the overall theoretical contributions to the open innovation and dynamic capabilities fields are discussed. Additionally, some more practical implications are laid out. Finally, I will highlight some limitations of this work, which also provide directions for future research.

\section{SUMMARY OF MAIN FINDINGS}

\section{Study 1 - The Fuzzy Front End of Open Innovation: How Firms Identify Oppor- tunities for Open Innovation}

Study one investigated dynamic capabilities that support value creation in an open innovation context. Based on an exploratory empirical study of multiple cases, I developed a theoretical framework of the opportunity identification stage of open innovation. This framework provided interesting insights concerning how and why firms identify and continuously transform opportunities for open innovation. One of these insights refers to the identification of two key dimensions that describe how firms search for or identify opportunities for open innovation. One dimension refers to external discovery which includes local scouting of technologies and global exploration of technological trends in the external environment. The other dimension is reflected in an internal creation process that incorporates reactive identification of internal needs and proactive generation of new strategic themes and topics suitable for open innovation. External discovery and internal creation were demonstrated to represent different dimensions of search for open innovation opportunities.

The developed framework further suggested that these dimensions of opportunity identification have direct implications for the implementation of different types of open innovation. Four distinct modes of open innovation were derived that capture some of the variance that exists when firms create and discover opportunities for open innovation. Complementary open innovation refers to clearly defined initiatives that are based on existing needs and aim at improving internal product lines or innovation projects. Entrepreneurial open innovation creates new opportunities via internal entrepreneurial processes in which external partners or knowledge sources are leveraged to support these processes. Exploratory open innovation pursues the objective of learning about new technological trends and needs of external stakeholders, rather than sourcing specific pieces of external technology into the firm. Finally, the strategic mode of open innovation refers to projects within key emerging innovation areas in which firms look for the most suitable external partners and collaborations. The empirical analysis suggested that 
these four modes are not mutually exclusive, but that there may be different open innovation modes within a single organization - hence, firms consider a portfolio of open innovation opportunities.

Finally, this study introduced three dynamic patterns that explain how firms continuously transform their open innovation opportunity set in order to increase external and internal fit. More specifically, the findings suggested that both the dimensions as well as the modes of open innovation opportunities are adapted. First, the dynamic capability of recalibration was shown to transform the internal opportunity creation process. Recalibration addresses risks of strategic lock-in and path-dependency as it continuously redefines internal strategic objectives and needs. Second, the dynamic capability of strategic filtering was identified to transform the external opportunity discovery process. Strategic filtering aims at avoiding over-search and reconsidering repeated patterns in external partner selection. Third, the dynamic capability of reconfiguring deals with the continuous transformation of open innovation opportunities themselves. Reconfiguring open innovation opportunities between different parts of the organization and different modes of interactions enables firms to re-establish fit when internal requirements change and to optimally leverage the open innovation opportunity portfolio.

\section{Study 2 - Conditions of Open Innovation Effectiveness: Internal Integrative Capability and External Environmental Factors}

In study two I proceeded from value creation to the value capture aspect of open innovation. I started from the observation that while firms increasingly access external sources of innovation, they often struggle to translate this openness into positive innovation outcomes, including increased quality and speed of the firm's internal innovation processes. To address this issue, this study examined factors that determine the effectiveness of outside-in open innovation. In this context, I investigated both internal as well as external factors that moderate the relationship between openness in innovation and open innovation performance.

The findings of this study revealed a positive effect of the degree of openness on open innovation performance. This positive effect was shown to be stronger under firm conditions that are characterized by strong integrative capabilities, particularly by the underlying dimensions of knowledge transfer and knowledge translation capability. Interestingly, the results showed that for firms with weak transfer and translation capabilities, increasing degrees of openness do not lead to higher open innovation performance, suggesting that the positive relationship between openness and open innovation performance is absent under these conditions. This finding emphasized the importance of transfer and translation capabilities for capturing value from increasing degrees of openness in innovation. The results further showed that the effects of the different dimensions of internal 
integrative capability on open innovation performance differ; while transfer and translation capability reinforced the relationship between openness and open innovation performance, the effect of transformation capability was of a direct nature and independent of the firm's degree of openness.

In addition to internal integrative capabilities, external environmental contingencies of open innovation were highlighted in this study. The results revealed that the relationship between openness and open innovation performance is stronger under environmental conditions of high technological turbulence. As the rate of technological change accelerates, firms can capture more benefits with increasing degrees of openness in innovation. Competitive dynamics in the external environment, surprisingly, did not significantly influence the effectiveness of open innovation. Nevertheless, in addition to the internal organization, external environmental factors, in terms of technological turbulence, were shown to partly determine to what extent firms can capture value from their openness in innovation.

\section{Study 3 - External Dynamic Capabilities: Creating Competitive Advantage in Innovation via External Resource Renewal}

In study three I examined an integrative perspective of both value creation and value capture in the context of open innovation. Likewise, I adopted a more holistic perspective of dynamic capabilities by simultaneously considering different classes of external dynamic capabilities and their underlying processes. The findings demonstrated that a more complex chain of relationships explains how classes of external dynamic capabilities renew the technological resource base by sensing, seizing, and reconfiguring resources residing outside the firm's boundaries and, thereby, create a competitive advantage in innovation.

This study looked inside the black box of dynamic capabilities, particularly with respect to their application in sensing, seizing, and reconfiguring external resources. These classes of external dynamic capabilities were conceptualized in terms of second-order models, formed by underlying processes. First, external sensing dynamic capability was conceptualized in terms of external scanning and strategic selection processes. Second, external seizing dynamic capability was captured as the processes to coordinate resource transfer, integrate these resources into the firm's culture, and to provide systematic knowledge management. And finally, external reconfiguring dynamic capability was assessed in terms of the processes of monitoring the resource base and recombining external and internal elements to achieve novel configurations.

Concerning the relationships of these classes of dynamic capabilities, the findings revealed that external sensing dynamic capability leads to enhanced new technological resource access. Firms with stronger external sensing dynamic 
capabilities are able to gain access to a larger range of new technological resources in the external environment. At the same time, however, the analysis demonstrated that such external access to technological resources is not necessarily beneficial. Instead, the results showed that technological resource access harms the focal firm unless it possesses a strong external dynamic capability for seizing these resources. In this context, the significant moderating effect of external seizing dynamic capability on the relationship between technological resource access and technological capabilities was highlighted. Technological capabilities, in turn, were shown to lead to competitive advantage in innovation. Finally, external reconfiguring dynamic capability constituted an additional direct mechanism to further increase a firm's competitive advantage in innovation. These results demonstrated that competitive advantage in innovation rests to a large extent on three classes of external dynamic capabilities, which enable firms to sense opportunities for accessing new external technological resources, seize these resources, and reconfigure them internally.

\section{IMPLICATIONS AND CONTRIBUTIONS}

In the following I will present the main theoretical implications of this dissertation in terms of its contributions to research on open innovation and dynamic capabilities.

\section{Contributions to an Emerging Theory of Open Innovation}

This dissertation contributes to an emerging theory of open innovation. The concept of open innovation gets grounded into prior research and informed by related theories, including strategic entrepreneurship theory, the knowledge-based view and, particularly, the dynamic capabilities view. The contributions of this dissertation can be summarized in terms of four main aspects, which are also summarized in table 5.1. First, it develops a more fine-grained understanding of the phenomenon itself, by delineating different forms or types of open innovation. Second, it sheds some light on the origins and generative processes of open innovation. Third, firm capabilities and underlying processes of open innovation are identified and elucidated. And finally, this dissertation develops a more differentiated picture concerning the outcomes of open innovation and some of the conditions that shape these outcomes. In the following, I will discuss these four aspects in some more detail.

So far, open innovation has remained a rather broad concept that came in many forms and tastes (Dahlander \& Gann, 2010; Huizingh, 2011). In prior work it has mainly been conceptualized in terms of various outside-in and inside-out processes (e.g. Gassmann \& Enkel, 2004) or the breadth and depth of firms' 


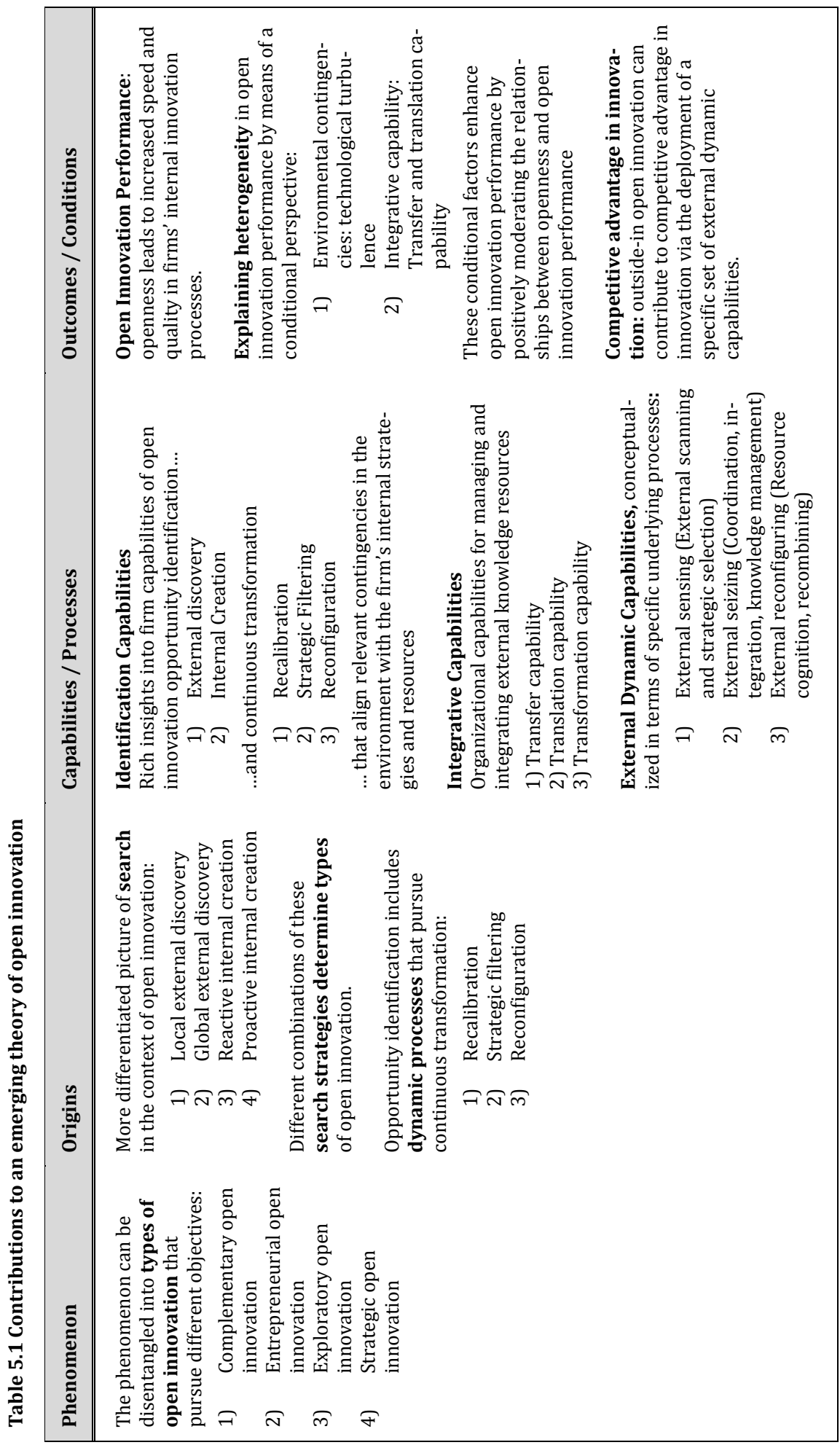


external search strategies (Laursen \& Salter, 2006; Drechsler \& Natter, 2012; Garriga, von Krogh, \& Spaeth, 2013). In this dissertation I contribute to a further conceptualization of the concept of open innovation by disentangling four different types, in terms of complementary, entrepreneurial, exploratory, and strategic open innovation. This contributes to a better understanding and categorization of the diversity of the phenomenon of open innovation. It demonstrates that firms consider a portfolio of different types of open innovation and that each type addresses different objectives, ranging from smaller modifications to existing internal innovation projects to creating new segments and moving into adjacent strategic areas. As a result, this dissertation sheds some light on the complex phenomenon of open innovation and contributes to a better understanding of the different facets of the concept. This conceptualization of open innovation can build the foundation for future studies by providing a means for studying alternative types of open innovation.

A further contribution of this dissertation refers to a better understanding of the generative mechanisms or origins of open innovation (see table 5.1). Combining insights from the strategic entrepreneurship and dynamic capabilities literatures with empirical findings from a multiple case study, I provide a more differentiated picture of search in the context of open innovation. New constructs that describe the identification process of open innovation opportunities were developed. Search for open innovation can now be conceptualized in terms of different combinations of reactive internal creation, proactive internal creation, local external discovery, and global external discovery. These search strategies shed some light on the origins of open innovation, as their combinations were shown to determine different types of open innovation. In addition, dynamic patterns of continuous transformation were identified. These dynamic patterns highlight the importance of aligning an open innovation opportunity portfolio with changing environmental developments and shifting strategic needs. Hence, a primary contribution of this dissertation is the development of an emergent theoretical framework for how firms identify and continuously transform opportunities for open innovation.

The core contribution of this dissertation certainly lies in its insights into firm capabilities for open innovation. As the main focus of this dissertation, I investigated the internal organization of open innovation to provide a better understanding of the capabilities firms require for creating and capturing value from open innovation. Insights gained into capabilities for open innovation are threefold (see table 5.1). First, this dissertation sheds light on capabilities for open innovation opportunity identification and transformation. While external discovery and internal creation were identified as capabilities for opportunity identification, recalibration, strategic filtering, and reconfiguration were delineated as dynamic capabilities that deal with the continuous transformation of the open innovation opportunity set. These capabilities shape different forms of open innovation and 
manage their continuous transformation to enhance external and internal fit. In sum, capabilities for managing a portfolio of open innovation opportunities and, thereby, creating value from open innovation, were identified. This contributes to a better understanding of why firms differ in the extent to which they are able to identify relevant sources of external knowledge and commercialization in an open innovation context.

Second, a better understanding of the integrative capabilities that facilitate value capture from open innovation was developed. Integrative capabilities for open innovation were conceptualized in terms of a set of higher-order organizing principles for external knowledge management, including transfer, translation, and transformation capabilities. These capabilities shed light on how firms develop and deploy external knowledge resources internally in a rent generating manner. It develops a better understanding of the capabilities that determine how efficiently firms can manage knowledge resources across boundaries and how productively these knowledge resources are utilized. These internal integrative capabilities, in terms of transfer, translation, and transformation capability, were shown to represent important factors in determining the effectiveness of open innovation. Hence, they help to explain why firms differ in their abilities to capture value from openness in innovation.

Third, an encompassing set of external dynamic capabilities for renewing the firm's technological resource base and creating competitive advantage in innovation was developed. I showed that a specific set of dynamic capabilities is required for sensing opportunities to access external resources, seizing these external resources in order to enhance internal technological capabilities, and then reconfigure these externally accessed resources internally in order to deliver a positive effect on competitive advantage in innovation. The conceptualization of these dynamic capabilities in terms of underlying processes contributes to a better understanding of how firms can organize internally for open innovation, such that they are able to create and capture value from openness in innovation.

Together, these insights imply that the differences in the existence and strength of these dynamic capabilities for opportunity identification / transformation, integration, and external renewal can be interpreted as a potential source of heterogeneity in open innovation. Dynamic capabilities are not readily available in factor markets and, thus, cannot be obtained via simple market exchanges. Instead, dynamic capabilities are path dependent, embedded into the firm and difficult to imitate (e.g. Teece et al., 1997; Zahra et al., 2006). Hence, this study suggests that firms primarily create and capture value from open innovation not from their control of certain knowledge or technologies, but from the accumulation and implementation of specific dynamic capabilities. This means that rather than outside, the locus of superior outcomes and competitive advantage regarding 
innovation is moving deeper inside the firm, to the superiority in dynamic capabilities.

Finally, this dissertation contributes to existing literature on open innovation by analyzing the variation in open innovation performance across firms in a systematic way. It includes one of the first studies to provide empirical evidence that increasing openness in innovation does indeed lead to enhanced quality and speed in the firms' internal innovation processes. Hence, the potential benefits of open innovation are demonstrated. However, besides these benefits, the potential risks of open innovation are also highlighted. Openness in innovation, in terms of increased access to external knowledge resources, was shown to harm firms' internal capabilities, unless firms deploy capabilities for seizing these resources. These insights draw attention to some of the boundary conditions of open innovation and require a better understanding of the conditions under which firms can successfully draw knowledge from external sources. Addressing this gap, this dissertation developed a more differentiated picture regarding the conditions that make outside-in innovation more effective and thereby, extends our understanding of the performance effects of openness in innovation. In particular, external seizing dynamic capability, integrative capability and technological turbulence were shown to represent conditional factors for capturing value from open innovation. These factors help to explain why some firms benefit more from openness than others (Huizingh, 2011) and lead to a better understanding of the context-dependency of outside-in open innovation (Di Benedetto, 2010). Furthermore, the results demonstrated that we have to look both inside and outside the firm's boundaries to understand the effectiveness of open innovation.

In sum, this dissertation contributes to an emerging theory of open innovation by distinguishing different types of open innovation, developing its origins and generative mechanisms, investigating underlying capabilities and processes that support value creation and value capture from open innovation, and providing a more differentiated picture of outcomes of open innovation and how these outcomes vary under different conditions.

\section{Contributions to the Dynamic Capabilities Field}

This dissertation makes a contribution to the field of dynamic capabilities by conceptualizing and empirically exploring an external perspective of dynamic capabilities. So far, dynamic capabilities and resource- or knowledge-based research have often focused on internal knowledge creation and integration (e.g. Galunic \& Eisenhardt, 2001; Marsh \& Stock, 2006; Zahra, Sapienza, \& Davidsson, 2006; Cepeda \& Vera, 2007). The origin of valuable resources was assumed to mainly lie within the firm itself. However, this study demonstrates that the context of open innovation changes how firms acquire and integrate knowledge and, 
thereby, how they change their resource base. In line with the transition from closed towards open innovation, knowledge resources increasingly originate from outside the firm, implying that external dynamic capabilities for accessing and managing knowledge across inter-organizational boundaries become gradually more important. While prior research on strategic alliances and acquisitions has acknowledged the importance of dynamic capabilities for accessing external resources (e.g. Karim \& Mitchell, 2010; Ettlie \& Pavlou, 2006; Capron \& Anand, 2007; Dyer \& Kale, 2007; Schilke \& Goerzen, 2010), this dissertation adds to this understanding by developing a more encompassing picture of external resources renewal.

Another core contribution of this dissertation is a more fine-grained conceptualization of different classes, dimensions, and underlying processes of external dynamic capabilities. The conceptualization in terms of second-order models that are formed by underlying processes delivers new theoretical insights. By specifying organizational processes that put external dynamic capabilities into use, we can look inside the black box of dynamic capabilities and enrich our understanding of its content. A related contribution refers to a better understanding of the relationships by which the different classes of external dynamic capabilities operate on the technological resource base and lead to competitive advantage in innovation. While sensing was shown to antecede resource access, seizing moderates the relationship between resource access and operational capabilities, whereas reconfiguring directly contributes to competitive advantage in innovation. Hence, a core contribution refers to a more fine-grained analysis of how different classes of dynamic capabilities and components of the resource base interact. This leads to a better understanding of how dynamic capabilities operate and function in combination (Ambrosini \& Bowman, 2009), modify the resource base, and lead to important outcomes (Barreto, 2010).

Despite the importance of dynamic capabilities, there are, so far, few empirical studies assessing the content of dynamic capabilities and testing their relationships (Macher \& Mowery, 2009). Hence, this study provides an empirical contribution to the field of dynamic capabilities by operationalizing underlying processes of external dynamic capabilities and validating their measurements in a sample of international firms. I studied dynamic capabilities in the specific context of open innovation and presented an empirical exploration of their contents and relationships. The conceptualization and empirical analysis of external dynamic capabilities enables a better understanding of the process of external resource renewal and helps to explain how firms leverage resources residing outside their boundaries to renew their internal resource base and create competitive advantage in innovation. 


\section{Managerial implications}

In terms of managerial implications, this dissertation proposes a capability or skills set for open innovation that can be implemented in organizations in terms of specific processes. This set of organizational capabilities is threefold and refers to opportunity identification, external knowledge integration, and reconfiguration, respectively.

A first capability for open innovation refers to the opportunity identification stage. Processes for effective opportunity identification include external monitoring and scanning activities such as actively participating in conferences and tradeshows and building networks with universities and the start-up community. Besides this external orientation, this dissertation reveals that in an open innovation context it is equally important to adopt an internal orientation and develop processes for uncovering and understanding internal gaps and opportunities that can build the grounds for open innovation activities. Combining these external and internal processes, managers can make conscious choices between external sourcing and internal development in terms of strategic selection processes.

A second capability for open innovation focuses on the integration of external knowledge resources into the organizational context. In particular coordination and transfer processes, such as the assignment of new roles and responsibilities, were shown to support effective integration and implementation of open innovation. Second cultural processes support effective integration and can be implemented in terms of corporate values and norms, effective communication, creation of common interests and commitment, and reward and incentive systems that encourage employees to adopt and work with external knowledge resources. A third process relevant for integrative capabilities can be found in the firm's knowledge management infrastructure. Tools, system, and information-processing activities including knowledge storage, processing and retrieval are crucial for capturing value from outside-in open innovation, since they enable the codification and dissemination of external knowledge resources within the organization.

A final capability for the management of open innovation refers to the reconfiguration of open innovation initiatives and the recombination of externally sourced knowledge resources. At this stage, the cognition about existing internal resources and gaps is crucial. For managers this means that they need to observe and monitor the firm's internal resource base, so that additional opportunities for leveraging open innovation initiatives can be recognized. Furthermore, flexible reorganization of external and internal resources can lead to new innovative combinations that are difficult to imitate by competitors and, therefore, contribute to competitive advantage in innovation.

Finally, in addition to the implementation of such internal processes in order to develop capabilities for open innovation, this dissertation showed that 
managers also need to consider the external environment. The results highlight the importance of understanding environmental contingencies, particularly with respect to technological turbulence, that determine the effectiveness of open innovation. If managers take such a capability set and the firm's environmental contingencies into account, then open innovation can lead to enhanced innovative performance and can even contribute to a competitive advantage in innovation.

\section{LIMITATIONS AND SUGGESTIONS FOR FUTURE RESEARCH}

This dissertation is subject to a number of limitations, which also provide directions for future research on the topic at hand. A first problem potentially affecting all studies in this dissertation refers to the lack of longitudinal data. There is likely a substantial time lag between the implementation of firms' open innovation strategies, changes in firms' resource base, and outcome variables such as open innovation performance or competitive advantage in innovation. Since the data in this dissertation are restricted to a cross-sectional nature, any causal implications need to be treated with caution. Hence, future research needs to examine the research questions of this dissertation from a longitudinal perspective in order to draw final conclusions with respect to causal relationships and dynamic aspects of open innovation strategies, changes in resources and capabilities, and performance outcomes.

Another potential limitation relates to the selection of the sample. The survey data that builds the empirical basis for two of the three empirical studies is based on a sampling strategy that contains purposeful elements. Since the data is collected on the basis of Exnovate, which represents a platform for open innovation firms, the sampling is not completely random. Hence, the generalizability of the findings is likely to be limited to firms that have implemented an explicit open innovation strategy which they communicate by means of their memberships in open innovation platforms. In addition, despite significant efforts, the sample size of the survey data remained relatively small. In order to enhance the generalizability of the findings at hand, they would need to be replicated across other samples that are larger and selected according to stricter rule of randomness.

A further potential bias to two of the studies may be found in the details of the collection of the survey data. The survey is largely based on subjective scales that are heavily dependent on self-reports of higher management. Potential biases of self-reported data may be reinforced by the fact that the data relies on single respondents. These elements may potentially lead to a common method bias that may distort the findings of these studies. While I implement various remedies to address such potential bias, it cannot be ruled out completely and further validation with more objective data is required. 
Despite these limitations, which may motivate follow-up empirical studies, this dissertation builds the grounds for some additional and related future research questions. First of all, it cannot be assumed that the consideration in this dissertation of the capabilities for open innovation and their underlying dimensions and processes is comprehensive. There may be additional capabilities and processes relevant for creating and capturing value from open innovation, which need to be disentangled in future research. Furthermore, it would be interesting to investigate to what extent organizational capabilities differ between different types and strategies of open innovation. Different sets of capabilities may be relevant for complementary, entrepreneurial, exploratory, or strategic open innovation. Furthermore, capabilities may differ between different types of partners and external knowledge sources (e.g. customers, competitors, suppliers, universities) or between different mechanisms of sourcing external knowledge (e.g. collaboration, crowdsourcing, licensing, venturing). In addition, it is of interest to investigate capabilities at various levels of the organization, including new product development teams, managers, and other relevant individuals. This might be particularly fruitful, since prior work has shown that antecedents to capabilities and innovation reside at different levels of analysis (Rothaermel \& Hess, 2007; Salvato \& Rerup, 2011). A final stream of future research is a more detailed investigation of insideout open innovation. This dissertation focused heavily on outside-in aspects in terms of accessing, integrating, and leveraging external sources of knowledge. Future studies may adopt a capability perspective to develop a better understanding of how firms create and capture value from inside-out open innovation.

\section{CONCLUSION}

In this dissertation I developed a capability perspective for open innovation. Different sets of dynamic capabilities that help to shed light on how firms create and capture value from open innovation were conceptualized and empirically investigated. The findings of three empirical studies help to explain heterogeneity in the implementation and performance of open innovation strategies. Furthermore, they provide new theoretical insights and an empirical exploration of a specific set of external dynamic capabilities. Overall, this dissertation contributes to an emerging theory of open innovation by providing a better understanding of the phenomenon itself, its origins, underlying capabilities and processes, and open innovation outcomes that are shaped by various conditions. 


\section{REFERENCES}

Adner, R. and C.E. Helfat (2003). Corporate effects and dynamic managerial capabilities. Strategic Management Journal, 24: 1011-1025.

Ahuja, G. and C.M. Lampert (2001). Entrepreneurship in the large corporation: a longitudinal study of how established firms create breakthrough inventions. Strategic Management Journal, 22 (6-7), 521-543.

Aiken, L.S. and S.G. West (1991). Multiple Regression: Testing and Interpreting Interactions. Thousand Oaks: C.A.: Sage.

Almirall, E. and R. Casadesus-Masanell (2010). Open versus closed innovation: a model of discovery and divergence. Academy of Management Review, 35 (1), 27-47.

Alvarez, S.A. and J.B. Barney (2007). Discovery and creation: alternative theories of entrepreneurial action. Strategic Entrepreneurship Journal, 1, 11-26.

Alvarez, S.A., Barney, J.B. and P. Anderson (2013). Forming and exploiting opportunities: The implication of discovery and creation processes for entrepreneurial and organizational research. Organization Science, 24 (1), 301-317.

Ambrosini, V. and C. Bowman (2009). What are dynamic capabilities and are they a useful construct in strategic management? International Journal of Management Reviews, 11 (1), 29-49.

Ambrosini, V., Bowman, C. and N. Collier (2009). Dynamic capabilities: an exploration of how firms renew their resource base. British Journal of Management, 20, S9-S24.

Amit, R. and P.J.H. Schoemaker (1993). Strategic assets and organizational rent. Strategic Management Journal, 14, 33-46.

Ardichvili, A., Cardozo, R. and S. Ray (2003). A theory of entrepreneurial opportunity identification and development. Journal of Business Venturing, 18, 105-123.

Arora, A., Fosfuri, A. and A. Gambardella (2001). Markets for technology and theirimplications for corporate strategy. Industrial and Corporate Change, 10 (2), 419-451.

Arora, A. and A. Nandkumar (2012). Insecure advantage? Markets for technology and the value of resources for entrepreneurial ventures. Strategic Management Journal, 33, 231-251.

Augier, M. and D.J. Teece (2006). Understanding complex organization: the role of know-how, internal structure, and human behavior in the evolution of capabilities. Industrial and Corporate Change, 15 (2), 395-416.

Augier, M. and D.J. Teece (2009). Dynamic capabilities and the role of managers in business strategy and economic performance. Organization Science, 20 (2), 410-421.

Bagozzi, R.P. (1984). A prospectus for theory construction in marketing. Journal of Marketing, 48, 11-29.

Bahemia, H. and B. Squire (2010). A contingent perspective of open innovation in new product development projects. International Journal of Innovation Management, 14 (4), 603-627.

Barney, J.B. (1991). Firm resources and sustained competitive advantage. Journal of Management, 17, 99120.

Baron, R.M. and D.A. Kenny (1986). The moderator - mediator variable distinction in social psychology research: conceptual, strategic, and statistical considerations. Journal of Personality and Social Psychology, 51 (6), 1173-1182.

Barreto, I. (2010). Dynamic Capabilities: A review of past research and an agenda for the future. Journal of Management, 36, 256-280. 
Becker, J.M., Klein, K. and M. Wetzels (2012). Hierarchical latent variable models in PLS-SEM: guidelines for using reflective-formative type models. Long Range Planning, 45, 359-394.

Bianchi, M., Cavaliere, A., Chiaroni, D., Frattini, F. and V. Chiesa (2011). Organisational modes for open innovation in the bio-pharmaceutical industry: an exploratory analysis. Technovation, 31 (1), 22-33.

Bingham, C.B., Eisenhardt, K.M. and N.R. Furr (2007). What makes a process a capability? Heuristics, strategy, and effective capture of opportunities. Strategic Entrepreneurship Journal, 1, 27- 47.

Birkinshaw, J. and F. Monteiro (2007). External knowledge sourcing: Uncovering the technology scouting process. AIM Research Working Paper Series, 1744-0009.

Birkinshaw, J., Bessant, J. and R. Delbridge (2007). Finding, forming, and performing: Creating networks for discontinuous innovation. California Management Review, 49 (3), 67-84.

Bode, C., Wagner, S.M., Petersen, K.J. and L.M. Ellram (2011). Understanding responses to supply chain disruptions: insights from information processing and resource dependence perspectives. Academy of Management Journal, 54 (4), 833-856.

Bogers, M., Afuah, A. and B. Bastian (2010). Users as innovators: A review, critique, and future research directions. Journal of Management, 36 (4), 857-875.

Bowman, C. and V. Ambrosini (1997). Using single respondents in strategy research. British Journal of Management, 8, 119-131.

Bowman, C. and V. Ambrosini (2003). How the resource-based and the dynamic capabilities views of the firm inform corporate-level strategy. British Journal of Management, 14, 289-303.

Brown, S.L. and K.M. Eisenhardt (1997). The art of continuous change: linking complexity theory and time-paced evolution in relentlessly shifting organizations. Administrative Science Quarterly, 42 (1), 1-34.

Brownstone, D. and R. Valletta (2001). The bootstrap and multiple imputations: harnessing increased computing power for improved statistical tests. The Journal of Economic Perspectives, 15 (4), $129-141$

Bruni, D.S. and G. Verona (2009). Dynamic marketing capabilities in science-based firms: an exploratory investigation of the pharmaceutical industry. British Journal of Management, 20, S101-S117.

Bryman, A. (2006). Integrating quantitative and qualitative research: how is it done? Qualitative Research, 6 (1), 97-113.

Capron, L. and J. Anand (2007). Acquisition-based dynamic capabilities. In Helfat, C., Finkelstein, S., Mitchell, W., Peteraf, M., Singh, H., Teece, D. and S. Winter (eds.) Dynamic Capabilities: Understanding Strategic Change in Organizations. Malden M.A: Blackwell.

Capron, L. and W. Mitchell (2009). Selection capability: How capability gaps and internal social frictions affect internal and external strategic renewal. Organization Science, 20 (2), 294-312.

Capron, L., Mitchell, W. and A. Swaminathan (2001). Asset divestiture following horizontal acquisitions: a dynamic view. Strategic Management Journal, 22, 817-844.

Carlile, P.R. (2002). A pragmatic view of knowledge and boundaries: boundary objects in new product development. Organization Science, 13 (4), 442-455.

Carlile, P.R. (2004). Translating and transforming: an integrative framework for managing knowledge across boundaries. Organization Science, 15 (5), 555-568.

Cepeda, G. and D. Vera (2007). Dynamic capabilities and operational capabilities: A knowledge management perspective. Journal of Business Research, 60, 426-437. 
Chesbrough, H.W. (2003). Open Innovation: The new imperative for creating and profiting from technology, Boston, M.A.: Harvard Business School Press.

Chesbrough, H.W. and A.K. Crowther (2006). Beyond high tech: early adopters of openinnovation in other industries. R\&D Management, 36 (3), 229-236.

Chesbrough, H.W., Vanhaverbeke, W. and J. West (2006). Open Innovation: Researching a New Paradigm (pp. 1-12), Oxford: Oxford University Press.

Chesbrough, H.W. (2007). Why companies should have open business models. MIT Sloan Management Review, 48 (2), 21-28.

Chesbrough, H.W. and M.M. Appleyard (2007). Open innovation and strategy. California Management Review, 50, 57-76.

Chiaroni, D., Chiesa,V. and F. Frattini (2011). The open innovation journey: how firms dynamically implement the emerging innovation management paradigm. Technovation, 31 (1), 34-43.

Chin, W.W. (1998). Issues and opinions on structural equation modeling. MIS Quarterly, 22 (1), 7-16.

Chin, W.W., Marcolin, B.L. and P.R. Newsted (2003). A partial least squares latent variable modeling approach for measuring interaction effects: Results from a Monte Carlo simulation study and an electronic-mail emotion/adoption study. Information Systems Research, 14 (2), 189-217.

Churchill, G.A. (1979). A paradigm for developing better measures of marketing constructs. Journal of Marketing Research, 16, 64-73.

Christensen, J.F., Olesen, M.H. and J.S. Kjaer (2005). The industrial dynamics of open innovation evidence from the transformation of consumer electronics. Research Policy, 34, 1533-1549.

Cohen, W.M.. and D.A. Levinthal (1990). Absorptive capacity: a new perspective on learning and innovation. Administrative Science Quarterly, 35, 128-152.

Cohen, J., Cohen, P., West, S.G. and L.S. Aiken (2003). Applied multiple regression / correlation analysis for the behavioral sciences ( $3^{\text {rd }}$ ed.) Mahwah, NJ: Lawrence Erlbaum Associates, Inc.

Collins, K.M.T., Onwuegbuzie, A.J. and Q.G. Jiao (2007). A mixed methods investigation of mixed methods sampling designs in social and health science research. Journal of Mixed Methods Research, 1 (3), 267-294.

Collis, D.J. (1994). How valuable are organizational capabilities? Strategic Management Journal, 15, 143152.

Colquitt, J.A. and C.P. Zapata-Phelan (2007). Trends in theory building and theory testing: A five-decade study of the "Academy of Management Journal". The Academy of Management Journal, 50 (6), 1281-1303.

Dahlander, L. and D.M. Gann (2010). How open is innovation? Research Policy, 39, 699-709.

Danneels, E. (2002). The dynamics of product innovation and firm competences. Strategic Management Journal, 23 (12), 1095-1121.

Danneels, E. (2008). Organizational antecedents of second-order competences. StrategicManagement Journal, 29, 519-543.

Danneels, E. (2010). Trying to become a different type of company: Dynamic capability at Smith Corona. Strategic Management Journal, 32, 1-31.

Davis, J.P. and K. Eisenhardt (2011). Rotating leadership and collaborative innovation: recombination processes in symbiotic relationships. Administrative Science Quarterly, 56 (2), 159-201. 
Dennis, WJ. (2003). Raising response rates in mail surveys of small business owners: results of an experiment. Journal of Small Business Management, 41, 278-295.

DeSarbo, W.S., Di Benedetto, C.A., Song, M. and I. Sinha (2005). Revisiting the Miles and Snow strategic framework: uncovering interrelationships between strategic types, capabilities, environmental uncertainty, and firm performance. Strategic Management Journal, 26, 47-74.

Diamantopolous, A. and H.M. Winklhofer (2001). Index construction with formative indicators: an alternative to scale development. Journal of Marketing Research, 38: 269-277.

Diamantopolous, A. and J.A. Siguaw (2006). Formative versus reflective indicators in organizational measure development: A comparison and empirical illustration. British Journal of Management, $17,263-282$.

Di Benedetto, A. (2010). Comment on 'Is open innovation a field of study or a communication barrier to theory development?'. Technovation, 30, 557.

Di Stefano, G., Peteraf, M. and G. Verona (2010). Dynamic capabilities deconstructed: a bibliographic investigation into the origins, development, and future directions of the research domain. Industrial and Corporate Change, 19 (4), 1187-1204.

Dillmann, D.A. (2007). Mail and Internet Surveys: The Tailored Design Method" (2nd ed.) John Wiley \& Sons: New Jersey.

Dodgson, M., Gann, D. and A. Salter (2006). The role of technology in the shift towards open innovation: the case of Procter \& Gamble. R\&D Management, 36 (3), 333-346.

Drechsler, W. and M. Natter (2012). Understanding a firm's openness decisions in innovation. Journal of Business Research, 65, 438-445.

Dyer, J. and P. Kale (2007). Relational capabilities: Drivers and implications. In Helfat, C., Finkelstein, S., Mitchell, W., Peteraf, M., Singh, H., Teece, D., and Winter, S. (eds.) Dynamic Capabilities: Understanding Strategic Change in Organizations. Malden M.A: Blackwell.

Easterby-Smith, M. and I.M. Prieto (2008). Dynamic capabilities and knowledge management: An integrative role for learning? British Journal of Management, 19, 235-249.

Easterby-Smith, M., Lyles, M.A. and E.W.K. Tsang (2008). Inter-organizational knowledge transfer: current themes and future prospects. Journal of Management Studies, 45 (4), 677-690.

Edmondson, A.C. and S.E. McManus (2007). Methodological fit in management field research. The Academy of Management Review, 32 (4), 1155-1179.

Edwards, J.R. (2001). Multidimensional constructs in organizational behavior research: An integrative analytical framework. Organizational Research Methods, 4 (2), 144-192.

Edwards, J.R. and R.P. Bagozzi (2000). On the nature and direction of relationships between constructs and measures. Psychological Methods, 5 (2), 155-174.

Eisenhardt, K. and S.L. Brown (1999) Patching. Restitching business portfolios in dynamic markets. Harvard Business Review, 77 (3), 72-82.

Eisenhardt, K. and J. Martin (2000). Dynamic capabilities: What are they? StrategicManagement Journal, $21,1105-1121$.

Eisenhardt, K. M. and M.E. Graebner (2007). Theory building from cases: opportunities and challenges. Academy of Management Journal, 50 (1) 25-32.

Elmquist, M., Fredberg, T. and S. Ollila (2009) Exploring the field of open innovation. European Journal of Innovation Management, 32, 1155-1179. 
Ettlie, J.E., and P.A. Pavlou (2006). Technology-based new product development partnerships. Decision Sciences, 37 (2), 117-147.

Fey, C.F. and J. Birkinshaw (2005). External sources of knowledge, governance mode, and R\&D performance. Journal of Management, 31 (4), 597-621.

Fornell, C., and D.F. Larcker (1981). Evaluating structural equation models with unobservable variables and measurement error. Journal of Marketing Research, 18, 39-50.

Foss, N.J., Laursen, K. and T. Pedersen (2011). Linking customer interaction and innovation: the mediating role of new organizational practices. Organization Science, 22 (4), 980-999.

Galunic, D.C. and K. Eisenhardt (2001). Architectural innovation and modular corporate forms. Academy of Management Journal, 44 (6), 1229-1249.

Galunic, D.C. and S. Rodan (1998). Resource recombinations in the firm: knowledge structures, and the potential for Schumpeterian innovation. Strategic Management Journal, 19, 1193-1201.

Garciano, L. and Y. Wu (2012). Knowledge, communication, and organizational capabilities. Organization Science, 23 (5), 1382-1397.

Garriga H., von Krogh, G. and S. Spaeth (2013). How constraints and knowledge impact open innovation. Strategic Management Journal, doi: 10.1002/smj.2049

Gassmann, O. and E. Enkel (2004). Towards a theory of open innovation: Three core process archetypes. Paper presented at R\&D Management conference, Lisbon.

Gibbert, M., Ruigrok, W. and B. Wicki (2008). What passes a rigorous case study? Strategic Management Journal, 29, 1465-1474.

Ginsberg, A. and N. Venkatraman (1985). Contingency perspectives of organizational strategy: a critical review of the empirical research. The Academy of Management Review, 10 (3), 421-434.

Gold, A.H., Malholtra, A. and A.H. Segars (2001). Knowledge management: an organizational capabilities perspective. Journal of Management Information Systems, 18, 185-214.

Grant, R.M. (1996). Prospering in dynamically competitive environments: organizational capability as knowledge integration."Organization Science, 7 (4), 375-387.

Gruber, M., Heinmann, F., Brettel, M. and S. Hungeling (2010). Configurations of resources and capabilities and their performance implications: an exploratory study on technology ventures. Strategic Management Journal, 31, 1337-1356.

Hagedoorn, J. (1993). Understanding the rationale of strategic technology partnering: interorganizational modes of cooperation and sectoral differences. Strategic Management Journal, 14 (5), 371-385.

Hagedoorn, J. and G. Duysters (2002). External sources of innovative capabilities: the preference for strategic alliances or M\&As. Journal of Management Studies, 39, 167-188.

Hair, J.F., Black, W.C., Babin, B.J., Anderson, R.E. and R.L. Tatham (2006). Multivariate Data Analysis (6 edition). Pearson Prentice Hall: New Jersey.

Hargadon, A. and R.I. Sutton (1997). Technology brokering and innovation in a product development firm. Administrative Science Quarterly, 42, 716-749.

Helfat, C.E. (1997) Know-how and asset complementarity and dynamic capability accumulation: the case of R\&D." Strategic Management Journal, 18, 339-360.

Helfat, C.E. (2000). Guest editor's introduction to the special issue: the evolution of firm capabilities. Strategic Management Journal, 21, 955-959. 
Helfat, C.E. and M.A. Peteraf (2003). The dynamic resource-based view: capability lifecycles. Strategic Management Journal, 24, 997-1010.

Helfat, C.E. and M.A. Peteraf (2009). Understanding dynamic capabilities: progress along a developmental path. Strategic Organization, 7, 91-102.

Helfat, C.E., Finkelstein, S., Mitchell, W., Peteraf, M., Singh, H., Teece, D. and S. Winter(2007). Dynamic capabilities: Understanding strategic change in organizations. Malden M.A: Blackwell.

Helfat, C.E. and S.G. Winter (2011). Untangling dynamic and operational capabilities: Strategy for the (n)ever-changing world. Strategic Management Journal, 32, 1243-50.

Henderson, R. and K. Clark (1990). Architectural innovation: the reconfiguration of existing product technologies and the failure of established firms. Administrative Science Quarterly, 35, 9-30.

Henderson, R. and I. Cockburn (1994). Measuring competence? Exploring firm effects in pharmaceutical research. Strategic Management Journal, 15, 63-84.

Henseler, J. Ringle, C.M. and R.R. Sinkovics (2009). The use of partial least squares path modeling in international marketing. In Sinkovics, R.R. and Ghauri, P.N. (eds.) New Challenges to International Marketing (Advances in International Marketing, Volume 20), Emerald Group Publishing Limited, pp.277-319

Herstad, S.J., Bloch, C., Ebersberger, B. and E. Van de Velde (2008). Open innovation andglobalization: Theory, evidence, and implications. Technical Report, VISION ERA-net.

Hitt, M.A., Ireland, R.D., Camp, S.A. and D.L. Sexton (2001). Guest editors' introduction to the special issue strategic entrepreneurship: entrepreneurial strategies for wealth creation. Strategic Management Journal, 22, 479-491.

Huizingh, E.K.R.E. (2011). Open innovation: state of the art and future perspectives. Technovation, 31, 29.

Huang, F., Rice, J. and P. Galvin (2009). Openness, innovation and appropriation strategies: Empirical evidence from Australian businesses. Paper presented at theAnnual Academy of Management Meeting, Chicago 2009.

Hulland, J. (1999). Use of partial least squares (PLS) in strategic management research: A review of four recent studies. Strategic Management Journal, 20 (2), 195-204.

Huston, L. and N. Sakkab (2006). Connect and Develop: Inside Procter \& Gamble's newmodel for innovation. Harvard Business Review, March, 2006.

Iansiti, M. and K.B. Clark (1994). Integration and dynamic capability: evidence from product development in automobiles and mainframe computers. Industrial and Corporate Change, 3 (3), 557 605 .

Ireland, R.D., Hitt, M.A. and D.G. Sirmon (2003). A model of strategic entrepreneurship: The construct and its dimensions. Journal of Management, 29 (6), 963-989.

Ireland, R.D. and J.W. Webb (2007). Strategic entrepreneurship: Creating competitive advantage through streams of innovation. Business Horizons, 50, 49-59.

Jansen, J.J.P., Van den Bosch, F.A.J. and J.W. Volberda (2006). Exploratory innovation, exploitative innovation, and performance: effects of organizational antecedents and environmental moderators. Management Science, 52 (11), 1661-1674.

Jaworski, B. and A. Kohli (1993). Market orientation: antecedents: The construct, research propositions, and managerial implications. Journal of Marketing, 57 (3), 53-70. 
Kale, P. and H. Singh (1999). Building firm capabilities through learning: the role of the alliance learning process in alliance capability and firm-level alliance success. Strategic Management Journal, 28, 981-1000.

Karim, S. and W. Mitchell (2000). Path-dependent and path-breaking change: Reconfiguring business resources following acquisitions in the U.S. medical sector, 1978-1995. Strategic Management Journal, 21, 1061-1081.

Katila, R. and G. Ahuja (2002). Something old, something new: a longitudinal study of search behavior and new product introduction. Academy of Management Journal, 45 (5), 1183-1194.

Katkalo,V.S., Pitelis, C.N. and D.J. Teece (2010). Introduction: on the nature and scope of dynamic capabilities. Industrial and Corporate Change, 19 (4), 1175-1186.

Katz, R. and T.J. Allen (1982). Investigating the Not Invented Here (NIH) syndrome: a look at the performance, tenure and communication patterns of 50 R\&D project groups. R\&D Management, $12(1), 7-19$.

Kay, N.M. (2010). Dynamic capabilities as context: the role of decision, system and structure. Industrial and Corporate Change, 19 (4), 1205-1223.

Keil, T. (2004). Building external corporate venturing capability. Journal of Management Studies, 41 (5), 799-825.

Ketchen, D.J., Ireland, R.D. and C.C. Snow (2007). Strategic entrepreneurship, collaborative innovation, and wealth creation. Strategic Entrepreneurship Journal, 1, 371-385.

Keupp, M.M. and O. Gassmann (2009). Determinants and archetype users of open innovation. $R \& D$ Management, 39 (4), 331-341.

Kindström, D., Kowalkowski, C. and E. Sandberg (2012). Enabling service innovation: A dynamic capabilities approach. Journal of Business Research, doi:10.1016/ j.jbusres.2012.03.003.

Kirschbaum, R. (2005). Open Innovation in Practice. Research Technology Management, July-August, 2005.

Klein, P.G. (2008). Opportunity discovery, entrepreneurial action, and economic organization. Strategic Entrepreneurship Journal, 2, 175-190.

Kline, D. (2003). Sharing the corporate crown jewels. MIT Sloan Management Review, 44, 89-93.

Knudsen, M.P. and T.B. Mortensen (2011). Some immediate - but negative - effects of openness on product development performance. Technovation, 31, 54-64.

Kogut, B. and U. Zander (1992). Knowledge of the firm, combinative capabilities, and the replication of Technology. Organization Science, 3 (3), 383-397.

Kogut, B. and U. Zander (1996). What firms do? Coordination, identity, and learning. Organization Science, 7 (5), 502-518.

Kraaijenbrink, J., Spender, J-C. and A.J. Groen (2011). The Resource-Base View: A review and assessment of its critiques. Journal of Management, 36 (1), 349-372.

Lakhani, K.R. and M.L. Tushman (2012). Open innovation and organizational boundaries: The impact of task decomposition and knowledge distribution on the locus of innovation. Working Paper 12-057, Harvard Business School.

Lambe, C.J. and R.E. Spekman (1997). Alliances, external technology acquisition, and discontinuous technological change. Journal of Product Innovation Management, 14 (2), 102-116. 
Laursen, K. and A. Salter (2006). Open for innovation: The role of openness in explaininginnovation performance among U.K. manufacturing firms. Strategic Management Journal, 27, 131-150.

Lavie, D. (2006). The competitive advantage of interconnected firms: an extension of the resource-based view. Academy of Management Review, 31 (3), 638-658.

Law, K.S. and C.S. Wong (1999). Multidimensional constructs in structural equation analysis: an illustration using the job perception and job satisfaction constructs. Journal of Management, 25 (2), 143-160.

Law, K.S., Wong, C.S. and W.H. Mobley (1998). Toward a taxonomy of multidimensional constructs. The Academy of Management Review, 23 (4), 741-755.

Leiblein, M.J. (2011). What do resource- and capability-based theories propose? Journal of Management, 37 (4), 909-932.

Leiponen, A. and C.E. Helfat (2010). Innovation objectives, knowledge sources, and the benefits of breadth. Strategic Management Journal, 31, 224-236.

Levitt, B. and J.G. March (1988). Organizational learning. Annual Review of Sociology, 14, 319-340.

Lorenzoni, G. and A. Lipparini (1999). The leveraging of interfirm relationships as a distinctive organizational capability: a longitudinal study. Strategic Management Journal, 20, 317-338.

Macher, J.T. and D.C. Mowery (2009). Measuring dynamic capabilities: Practices and performance in semiconductor manufacturing. British Journal of Management, 20, S41-S62.

Malhotra, N.K., Kim, S.S. and A. Patil (2006). Common method variance in IS research: a comparison of alternative approaches and a reanalysis of past research. Management Science, 52 (12), 18651883.

Maritan, C. and M. Peteraf (2011). Invited Editorial: Building a bridge between resource acquisition and resource accumulation. Journal of Management, 37 (5), 1374-1389.

Marsh, S.J. and G. N. Stock (2006). Creating dynamic capability: The role of intertemporal integration, knowledge retention, and interpretation. Journal of Product Innovation Management, 23 (5), 422-426.

McEvily, S.K., Eisenhardt, K.M. and J.E. Prescott (2004). The global acquisition, leverage, and protection of technological competencies. Strategic Management Journal, 25, 713-722.

McKelvie, A. and P. Davidsson (2009). From resource base to dynamic capabilities: an investigation of new firms. British Journal of Management, 20, S63-S80.

Miles, M. and A. Huberman (1994). Qualitative Data Analysis (2nd ed.) Thousand Oaks: C.A.: Sage.

Miller, K.D. (2002). Knowledge inventories and managerial myopia. Strategic Management Journal, 23, 689-706.

Miller, K.D. (2007). Risk and rationality in entrepreneurial processes. Strategic Entrepreneurship Journal, $1,57-74$.

Miller, D. and P.H. Friesen (1983). Strategy-making and environment: the third link. Strategic Management Journal, 4 (3), 221-235.

Moliterno, T.P. and M.F. Wiersema (2007). Firm performance, rent appropriation, and the strategic resource divestment capability. Strategic Management Journal, 28, 1065-87.

Montealegre, R. (2002). A process model of capability development: lessons from the electronic commerce strategy at Bolsa de Valores de Guayaquil. Organization Science, 13 (5), 514-531. 
Mowery, D.C. (1983). The relationship between intrafirm and contractual forms of industrial research in American manufacturing, 1900-1940. Explorations in Economic History, 20 (4), 351-374.

Mowery, D.C., Oxley, J. E. and B.S. Silverman (1996). Strategic alliances and interfirm knowledge transfer. Strategic Management Journal, 17, 77-91.

Nelson, R.R. and S.G. Winter (1982). An evolutionary theory of economic change.Cambridge: Harvard University Press.

Nonaka, I. (1994). A dynamic theory of organizational knowledge creation. Organization Science, 5 (1), 14-37.

Nunally, J. (1978). Psychometric theory. New York: McGraw-Hill.

Pablo, A.L., Reay, T., Dewald, J.R. and A.L. Casebeer (2007). Identifying, enabling and managing dynamic capabilities in the public sector. Journal of Management Studies, 44 (5), 687-708.

Pandza, K. and R. Thorpe (2009). Creative search and strategic sense-making: Missing dimensions in the concept of dynamic capabilities. British Journal of Management, 20, 1, 118-131.

Parida, V., Westerberg, M. and J. Frishammar (2012). Inbound open innovation activities in High-Tech SMEs: The impact on innovation performance. Journal of Small Business Management, 50 (2), 283-309.

Pavlou, P.A. and O.A. El Sawy (2005). Understanding the 'black box' of dynamic capabilities. Working paper, Anderson Graduate School of Management, University of California, Riverside, CA.

Pavlou, P.A. and O.A. El Sawy (2006). From IT leveraging competence to competitive advantage in turbulent environments: The case of new product development. Information Systems Research, 17 (3), 198-227.

Pavlou, P.A. and O.A. El Sawy (2011). Understanding the elusive black box of dynamic capabilities. Decision Sciences, 42 (1), 239-273.

Petroni, G., Venturini, K. and C. Verbano (2012). Open innovation and new issues in R\&D organization and personnel management. The International Journal of Human Resource Management, 23 (1) 147-173.

Pitelis, C.N. and D.J. Teece (2010). Cross-border market co-creation, dynamic capabilities, and the entrepreneurial theory of the multinational enterprise. Industrial and Corporate Change, 19 (4) $1247-1270$.

Podsakoff, P.M., McKenzie, S.B. and N.P. Podsakoff (2003). Common method bias in behavioral research: A critical review of the literature and recommended remedies." Journal of Applied Psychology, 88 (5), 879-903.

Powell, W.W., Kogut, K. and L. Smith-Doerr (1996). Interorganizational collaboration and the locus of innovation: Networks of learning in biotechnology. Administrative Science Quarterly, 41, 116145 .

Protogerou, A., Caloghirou, Y. and S. Lioukas (2011). Dynamic capabilities and their indirect impact on firm performance. Industrial and Corporate Change, 21, 615-647.

Punch, K.F. (2005). Introduction to Social Research - Quantitative and Qualitative Approaches (2nd ed.) Sage Publications: London.

Rindova, V.P. and S. Kotha (2001). Continuous 'morphing': competing through dynamic capabilities, form, and function. Academy of Management Journal, 44 (6), 1263-1280.

Ringle, C.M., Wende, S., and S. Will (2005). SmartPLS 2.0 (M3) Beta, Hamburg, http://www.smartpls.de. 
Rohrbeck, R., Hölzle, K. and H.G. Gemüden (2009). Opening up for competitive advantage- How Deutsche Telekom creates an open innovation ecosystem. R\&D Management, 39 (4), 420-430.

Rosenkopf, L. and A. Nerkar (2001). Beyond local search: boundary-spanning, exploration, and impact in the optical disk industry. Strategic Management Journal, 22 (4), 287-306.

Rothaermel, F.T. and A.M. Hess (2007). Building dynamic capabilities: innovation driven by individual-, firm-, and network-level effects. Organization Science, 18 (6), 898-921.

Salvato, C. (2003). The role of micro-strategies in the engineering of firm evolution. Journal of Management Studies, 40 (1), 83-108.

Salvato, C. and C. Rerup (2011). Beyond collective entities: multilevel research on organizational routines and capabilities. Journal of Management, 37 (2), 468-490.

Sarkar, MB, Aulakh, P.S. and A. Madhok (2009). Process capabilities and value generation in alliance portfolios. Organization Science, 20 (3), 583-600.

Schilke, O. and A. Goerzen (2010). Alliance management capability: An investigation of the construct and its measurement. Journal of Management, 36 (5), 1192-1219.

Schreyoegg, G. and M. Kliesch-Eberl (2007). How dynamic can organizational capabilities be? Towards a dual-process model of capability dynamization. Strategic Management Journal, 28, 913-933.

Shamsie, J., Martin, X. and D. Miller (2009). In with the old, in with the new: capabilities, strategies, and performance among the Hollywood studios. Strategic Management Journal, 30, 1440-1452.

Sieg, J.H., Wallin, M.W. and G. von Krogh (2009). Managerial challenges in openinnovation: A study of innovation intermediation. Paper Presented at the Annual Academy of Management Meeting, Chicago 2009.

Sirmon, D.G., Hitt, M.A. and R.D. Ireland (2007). Managing firm resources in dynamic environments to create value: looking inside the black box. Academy of Management Review, 32 (1), 273-292.

Song, M., Droge, C., Hanvanich, S. and R. Calantone (2005). Marketing and technology resource complementarity: An analysis of their interaction effect in two environmental contexts. Strategic Management Journal, 26, 259-276.

Szulanski, G. (2000). The process of knowledge transfer: A diachronic analysis ofstickiness. Organizational Behavior and Human Decision Processes, 82 (1), 9-27

Teddlie, C. and F. Yu (2007). Mixed methods sampling: A typology with examples. Journal of Mixed Methods Research, 1 (1), 77-100.

Teece, D.J. (1986). Profiting from technological innovation: implications for integration, collaboration, licensing and public policy. Research Policy, 15 (6), 285-305.

Teece, D., Pisano, G. and A. Shuen (1997). Dynamic capabilities and strategic management. Strategic Management Journal, 18, 509-533.

Teece, D.J. (2007). Explicating dynamic capabilities: The nature and microfoundations of sustainable enterprise performance. Strategic Management Journal, 28, 1319-1350.

Teece, D.J. (2012). Dynamic capabilities: Routines versus entrepreneurial action. Journal of Management Studies, 49 (8), 1395-1401.

Tenenhaus, M., Vinzi, V.E., Chatelin, Y.M. and C. Lauro (2005). PLS path modeling. Computational Statistics \& Data Analysis, 48, 159-205.

Tripsas, M. and G. Gavetti (2000). Capabilities, cognition, and inertia: Evidence from digital imaging. Strategic Management Journal, 21, 1147-1161. 
Tushman, M.L. and R. Katz (1980). External communication and project performance: An investigation into the role of gatekeepers. Management Science, 26 (11), 1071-1085.

Uzzi, B. (1997). Social structure and competition in interfirm networks: the paradox of embeddedness. Administrative Science Quarterly, 42 (1), 35-67.

Van De Vrande, V., De Jong, J.P.J. and M. De Rochemont (2009). Open innovation in SMEs: Trends, motives and management challenges. Technovation, 29 (6-7), 423-437.

Venkatraman, N. (1990). Performance implications of strategic coalignment: a methodological perspective. Journal of Management Studies, 27 (1), 19-41.

Verona, G. (1999). A resource-based view of product development. The Academy of Management Review, $24(1), 132-142$.

Verona, G. and D. Ravasi (2003). Unbundling dynamic capabilities: An exploratory study of continuous product innovation. Industrial and Corporate Change, 12 (3), 577-606.

Von Hippel, E. (1976). The dominant role of users in the scientific instrument innovation process. Research Policy, 5 (3), 212-239.

Von Hippel, E. and R. Katz (2002). Shifting innovations to users via toolkits. Management Science, 48 (7), 821-833.

Wallin, M.W. and G. von Krogh (2010). Organizing for open innovation: Focus on the integration of knowledge. Organizational Dynamics, 39 (2), 145-154.

Wang, C. and P. Ahmed (2007). Dynamic capabilities: A review and research agenda. International Journal of Management Reviews, 9 (1), 31-51.

West, J. and M. Bogers (2013). Leveraging external sources of innovation: a review of research on open innovation. Forthcoming in the Journal of Product Innovation Management. Available at SSRN: http://ssrn.com/abstract=2195675

West, J., and S. Gallagher (2006). Patterns of open innovation in open source software. In Chesbrough, H.W., Vanhaverbeke, W., and West, J. (eds), Open Innovation: Researching a New Paradigm (pp. 22-106), Oxford University Press: Oxford.

Wetzels, M., Odekerken-Schroeder, G. and C. van Oppen (2009). Using PLS path modeling for assessing hierarchical construct models: guidelines and empirical illustration. MIS Quarterly, 33 (1), 177 195.

Winter, S.G. (2003). Understanding dynamic capabilities." Strategic Management Journal, 24, 991-995.

Woiceshyn, J. and U. Daellenbach (2005). Integrative capability and technology adoption: evidence from oil firms. Industrial and Corporate Change, 14 (2), 307-342.

Yayavaram, S., and G. Ahuja (2008). Decomposability in knowledge structures and its impact on the usefulness of inventions and knowledge-base malleability. Administrative Science Quarterly, 53, 333-362.

Yin, S. (2009). Case study research: Design and methods (4th ed.) Thousand Oaks, C.A.: Sage.

Zahra, S.A. (1996). Governance, ownership, and corporate entrepreneurship: the moderating impact of industry technological opportunities. The Academy of Management Journal, 39 (6), 1713-1735.

Zahra, S.A. (2008). The virtuous cycle of discovery and creation of entrepreneurial opportunities. Strategic Entrepreneurship Journal, 2, 243-257. 
Zahra, S.A., and W.C. Bogner (2000). Technology strategy and software new ventures' performance: Exploring the moderating effect of the competitive environment. Journal of Business Venturing, 15 (2), 135-173.

Zahra, S.A. and G. George (2002). Absorptive capacity: A review, reconceptualization, and extension. The Academy of Management Review, 27 (2), 185-203.

Zahra, S.A., Nielsen, A.P. and W.C. Bogner (1999). Corporate entrepreneurship, knowledge, and competence development. Entrepreneurship Theory and Practice, 23, 169-189.

Zahra, S.A., Sapienza, H. and P. Davidsson (2006). Entrepreneurship and dynamic capabilities: A review model and research agenda. Journal of Management Studies, 43 (4), 917-955.

Zander, I. and U. Zander (2005). The inside track: On the important (but neglected) role of customers in the resource based view of strategy and firm growth. Journal of Management Studies, 42 (8), 1519-1548.

Zollo, M. and Winter, S. (2002). Deliberate learning and the evolution of dynamic capabilities. Organization Science, 13 (3), 339-351.

Zott, C. (2003). Dynamic capabilities and the emergence of intraindustry differential firm performance: Insights from a simulation study. Strategic Management Journal, 24 (2), 97-125 


\section{SUMMARY}

This dissertation was motivated by the observation that firms respond to increasing technological complexity, accelerating R\&D costs, shortening product life cycles and improving market institutions by opening up their boundaries and leveraging inflows and outflows of knowledge and technology. It set out to address the recent transformation from the traditional closed innovation model to a model of open innovation (OI) that increasingly integrates external sources of innovation and paths to markets. Using dynamic capabilities as a theoretical perspective and building on Teece's conceptualization in terms of sensing, seizing, and reconfiguring dynamic capabilities, I investigate how and why firms create and capture value from OI. In addressing this overarching research question, I present three separate empirical studies that deal with various facets of value creation and value capture from OI by means of dynamic capabilities. In implementing these studies I use both exploratory qualitative research designs as well as confirmatory quantitative research designs. In particular, these studies address the following sub research questions:

1) How and why do firms identify and continuously transform opportunities for OI?

2) What kinds of firm-internal capabilities and environmental factors determine the effectiveness of OI?

3) How can external dynamic capabilities be conceptualized and what are the underlying relationships that renew the firm's resource base and lead to competitive advantage in innovation?

The first chapter deals with antecedents of OI and investigates the generative mechanisms by which firms create OI initiatives and put them into practice. In particular, it explores how firms create and shape opportunities for OI. By marrying the dynamic capabilities and strategic entrepreneurship literatures and implementing a case study research design, this study (1) disentangles patterns of opportunity identification through which firms shape their OI strategies, (2) examines the implications of such opportunity identification patterns for a portfolio of OI activities, and (3) sheds light on how opportunities for OI are continuously transformed. It develops new theoretical constructs of OI opportunity identification (external discovery and internal creation) and the continuous transformation of these opportunities (strategic filtering, recalibrating, reconfiguring). In addition, new relationships are developed that explain how these new constructs of opportunity identification generate different modes of openness (complementary OI, entrepreneurial OI, exploratory OI, and strategic OI). These constructs and relationships describe a theoretical framework that provides interesting insights concerning how and why firms identify and continuously transform opportunities for OI. 
In study two I proceed from value creation to value capture by investigating the conditions under which openness in innovation is most effective. To shed light on why firms differ in their abilities to capture benefits from openness in innovation, this study examines how the effectiveness of $\mathrm{OI}$ is moderated by various internal and external conditions. The main findings reveal that increasing access to external knowledge sources leads to enhanced OI performance, particularly when firms possess strong integrative capabilities - in terms of transfer and translation capabilities - and operate under environmental circumstances of high technological turbulence. Interestingly, the results show that for firms with weak transfer and translation capabilities, the relationship between openness and OI performance is absent. This finding emphasizes the importance of transfer and translation capabilities for capturing value from increasing degrees of openness. In sum, the findings shed some light on why some firms are benefiting more from OI than others.

Study three adopts an integrative perspective of value creation and value capture by examining the process of external resource renewal. I simultaneously consider three classes of dynamic capabilities, including external sensing, external seizing, and external reconfiguring. Compared to studies 1 and 2 that investigate antecedents of openness and moderators of OI performance, this study examines changes in the firm's resource base and investigates competitive advantage in innovation as the main outcome variable of interest. The analysis shows that a more complex chain of relationships explains how these external dynamic capabilities renew specific components of the resource base and create competitive advantage in innovation. It further reveals that competitive advantages rests to a large extent on these three classes of external dynamic capabilities, which enable firms to sense opportunities for accessing new external resources, seize these resources, and reconfigure them internally. Surprisingly, the results demonstrate that external resource renewal is detrimental unless firms deploy external seizing dynamic capabilities. Therefore, this study adds to an explanation why firms differ in creating and capturing value from external resources or, in other words, why some firms are more effective at OI than others.

The contributions of this dissertation to the field of OI can be summarized in terms of four main aspects. First, it develops a more fine-grained understanding of the phenomenon itself by delineating different types of OI. Second, it sheds some light on the origins and generative processes of OI. Third, firm capabilities and underlying processes of OI are identified and elucidated. Fourth, this dissertation develops a more differentiated picture concerning the outcomes of OI and some of the conditions that shape these outcomes. Additionally, this dissertation makes a contribution to the field of dynamic capabilities by conceptualizing and empirically exploring an external perspective of dynamic capabilities. This dissertation demonstrates that the context of OI changes how firms acquire and integrate knowledge and, thereby, how they change their resource base. In line with the transition from closed towards open innovation, knowledge resources increasingly originate from 
outside the firm, implying that external dynamic capabilities for accessing and managing knowledge across organizational boundaries become gradually more important. This dissertation adds to this understanding by developing a more encompassing picture of external resources renewal and a more fine-grained conceptualization of different classes, dimensions, and underlying processes of external dynamic capabilities.

Concluding, in this dissertation I develop a capability perspective for OI. Different sets of dynamic capabilities that help to shed light on how firms create and capture value from OI are conceptualized and empirically investigated. The findings of three empirical studies help to explain heterogeneity in the implementation and performance of OI strategies. Furthermore, they provide new theoretical insights and an empirical exploration of a specific set of external dynamic capabilities. Overall, this dissertation contributes to an emerging theory of OI by providing a better understanding of the phenomenon itself, its origins, underlying capabilities and processes, and OI outcomes that are shaped by various conditions. 


\section{SAMENVATTING}

De aanleiding voor deze dissertatie was de observatie dat bedrijven hun grenzen openbreken en gebruik maken van de in- en uitstroom van kennis en technologie. Dit wordt veroorzaakt door een toenemende technologische complexiteit, stijgende R\&D-uitgaven, de steeds kortere levensduur van producten en verbeterde marktinstituten. De dissertatie is gericht op de recente verandering van het traditionele gesloten innovatiemodel tot een model van open innovatie (OI), waarbij externe bronnen van innovatie en marktpaden steeds meer worden geïntegreerd. Door dynamische vaardigheden als theoretisch perspectief te gebruiken en voort te bouwen op het concept van Teece, wat betreft het 'sensing, seizing en reconfiguring' van dynamische vaardigheden, onderzoek ik hoe en waarom bedrijven vanuit OI waarde creëren en zich toe-eigenen. Bij het beantwoorden van deze overkoepelende onderzoeksvraag, -presenteer ik drie afzonderlijke, empirische onderzoeken die ingaan op verschillende facetten van waardecreatie en waardetoe-eigening door OI, door gebruik te maken van dynamische vaardigheden.In de uitvoering van deze onderzoeken, gebruik ik zowel een verkennende, kwalitatieve onderzoeksopzet als een bevestigende, kwantitatieve onderzoeksopzet. In deze onderzoeken werden met name de volgende deelonderzoeksvragen aan de orde gesteld:

1) Hoe en waarom identificeren bedrijven OI-mogelijkheden en blijven ze deze voortdurend veranderen?

2) Welke vormen van interne bedrijfsvaardigheden en omgevingsfactoren bepalen de effectiviteit van OI?

3) Hoe kan er van externe dynamische vaardigheden een concept worden gevormd en wat zijn de onderliggende relaties die de beschikbare middelen van het bedrijf vernieuwen en tot een competitief voordeel leiden in innovatie?

In het eerste hoofdstuk worden antecedenten van OI beschreven en worden de generatieve mechanismen onderzocht waarmee de bedrijven OI-initiatieven creëren en in de praktijk brengen. Er wordt met name onderzocht hoe bedrijven mogelijkheden voor OI creëren en vormgeven. Door de dynamische vaardigheden en de literatuur over strategisch ondernemerschap te combineren en het onderzoek op te zetten als een casestudy, is het resultaat dat dit onderzoek (1) patronen om mogelijkheden te identificeren ontwart waarmee bedrijven hun OIstrategieën vormgeven, (2) ingaat op de implicaties van dergelijke identificatiepatronen voor een portfolio van OI-activiteiten en (3) een licht werpt op hoe mogelijkheden voor OI voortdurend worden veranderd. In dit onderzoek worden nieuwe theoretische -constructen ontwikkeld voor de identificatie van OI- 
mogelijkheden (externe ontdekking en interne creatie) en de voortdurende verandering van deze mogelijkheden (strategische filtering, recalibratie, reconfiguratie). Bovendien worden nieuwe verbanden gelegd die verklaren hoe deze nieuwe constructen voor de identificatie van OI-mogelijkheden verschillende maten van openheid creëren (aanvullend OI, ondernemend OI, verkennend OI en strategisch OI). Deze constructen en verbanden beschrijven een theoretisch -kader dat een interessant inzicht biedt wat betreft het hoe en waarom deze bedrijven OImogelijkheden identificeren en voortdurend veranderen.

In het tweede onderzoek ga ik vanuit het concept van waardecreatie naar waardetoe-eigening door de omstandigheden te onderzoeken waaronder openheid in innovatie het meest effectief is. Om inzicht te krijgen in deverschillen tussen bedrijven wat betreft hun mogelijkheden om door middel van openheid in innovatie voordeel te behalen, gaat dit onderzoek in op hoe de effectiviteit van OI bepaald wordt door verscheidene interne en externe omstandigheden. De hoofdbevinding is dat een betere toegang tot externe kennisbronnen tot verhoogde OI-prestaties leidt, vooral wanneer bedrijven sterke integratieve vaardigheden bezitten - op het punt van transfer- en omzettingsvaardigheden - en wanneer ze in een turbulente hoogtechnologische omgeving werken. Interessant genoeg laten de resultaten zien dat er bij bedrijven met zwakker transfer- en omzettingsvaardigheden geen relatie is tussen openheid en OI-prestatie. Deze bevinding benadrukt dat transfer- en omzettingsvaardigheden belangrijk zijn om waarde te kunnen toe-eigenen vanuit toenemende mate van openheid. Bij elkaar opgeteld bieden de bevindingen inzicht in de vraag waarom sommige bedrijven meer van $\mathrm{OI}$ profiteren dan andere.

In onderzoek drie bied ik een integratief perspectief op waarde-creatie en waardetoe-eigening door het proces te onderzoeken waarbij externe middelen worden vernieuwd. Ik kijk tegelijkertijd naar drie klassen van dynamische vaardigheden, waaronder extern sensing, seizing en reconfiguring. In vergelijking met onderzoeken 1 en 2, die ingaan op de antecedenten van openheid en de moderators van OI-prestatie, is dit onderzoek gericht op de veranderingen in de beschikbare middelen van het bedrijf en het competitieve voordeel in innovatie als de belangrijkste uitkomstvariabele. De analyse laat zien dat een complexer web van relaties verklaart hoe deze externe dynamische vaardigheden specifieke componenten van de beschikbare middelen vernieuwen en competitief voordeel creëren in innovatie. Verder onthult het onderzoek dat competitieve voordelen grotendeels op deze drie klassen van externe dynamische vaardigheden rusten, die bedrijven in staat stellen om mogelijkheden te detecteren (sensing) om toegang te krijgen tot nieuwe externe middelen, om zich deze middelen eigen te maken (seizing) en om ze intern aan te passen (reconfiguring). Verrassend genoeg laten de resultaten zien dat externe vernieuwing van de middelen nadelig is, tenzij bedrijven externe dynamische vaardigheden inzetten om zich deze middelen eigen te maken. Daarom verklaart onderzoek waarom bedrijven onderling verschillen in 
de creatie en toe-eigening van waarde vanuit externe middelen of, in andere woorden, waarom sommige bedrijven effectiever zijn in OI dan andere.

De toegevoegde waarde van deze dissertatie aan het veld van OI kunnen worden samengevat in vier hoofdaspecten. Ten eerste ontwikkelt het onderzoek een verfijnder begrip van het fenomeen OI zelf door verschillende vormen af te bakenen. Ten tweede werpt het een licht op de oorsprong en de generatieve processen van OI. Ten derde worden bedrijfsvaardigheden en de onderliggende processen van OI geïdentificeerd en nader toegelicht. Ten slotte biedt deze dissertatie een meer gedifferentieerd beeld wat betreft de uitkomst van OI en sommige voorwaarden die deze uitkomsten vormgeven. Deze dissertatie levert ook een bijdrage aan het onderzoeksveld van dynamische vaardigheden door een extern perspectief op dynamische vaardigheden te conceptualiseren en empirische te verkennen. Deze dissertatie laat zien dat de context van OI de manier verandert waarop bedrijven kennis vergaren en integreren en, daarmee, hoe ze hun beschikbare middelen veranderen. Net zoals bij de overgang van gesloten tot open innovatie komen kennisbronnen steeds meer van buiten het bedrijf, wat impliceert dat externe dynamische vaardigheden geleidelijk aan steeds belangrijker worden voor de toegang tot en het beheer van kennis buiten de grenzen van organisaties. Deze dissertatie draagt bij aan dit begrip door een meer omvattend beeld te ontwikkelen hoe externe middelen worden vernieuwd en door een verfijnder beeld te vormen van verschillende klassen, dimensies en onderliggende processen van externe dynamische vaardigheden.

Tot slot ontwikkel ik in deze dissertatie een vaardigheidsperspectief voor OI. Verschillende sets van dynamische vaardigheden die helpen om een licht te werpen op hoe bedrijven vanuit OI waarde creëren en zich toe-eigenen, zijn in beeld gebracht en empirisch onderzocht. De bevindingen van drie empirische onderzoeken helpen de heterogeniteit te verklaren in de implementatie en prestatie van OI-strategieën. Verder bieden zij nieuwe theoretische inzichten en een empirische verkenning van een specifieke set van externe dynamische vaardigheden. In het geheel draagt deze dissertatie bij aan een opkomende theorie van OI door een beter begrip te bieden van het fenomeen zelf, de oorsprong ervan, onderliggende vaardigheden en processen, en OI-uitkomsten die gevormd worden door verscheidene omstandigheden. 


\section{ACKNOWLEDGMENTS}

First of all, I would like to thank my supervisor and promoter Professor John Hagedoorn. I greatly appreciate that he has always been a very supportive minister of the interior - granting me academic freedom while providing valuable advice and helpful suggestions on my dissertation - as well as an excellent foreign minister sending me to various international conferences, enabling my visiting researcher position at UC Berkeley, and encouraging me to apply for a postdoctoral researcher position at UC Berkeley. I would also like to express my gratitude to Professor Henry Chesbrough, who sponsored my visiting scholarship at UC Berkeley, accepted to be a member of my dissertation committee, and gave me the opportunity to continue my career as a postdoctoral researcher at the Institute for Business Innovation at UC Berkeley. Furthermore, I would like to thank Professor Martin Wetzels and Professor Pierre Mohnen for their efforts as members of my assessment committee. I greatly appreciate their prompt evaluation and approval of my dissertation. I would like to thank Professor Wim Vanhaverbeke for providing me with the opportunity to collect survey data via Exnovate. Many thanks go to John Hagedoorn and Boris Lokshin for their co-authorship. I have and still am enjoying our collaboration in terms of joint research projects and appreciate the opportunity to learn from their expertise and experience. Many thanks go to Adela Buttolo, Anita Weijzen and Mieke van Zutphen for their support on administrative issues in Maastricht. I would like to thank my PhD fellows Nico, Anna, Kathi, Tom, Roy, Darja, Karen, Harold, Martijn, Maarten, and Sjir with whom I have always shared a pleasant atmosphere, both work-related as well as socially. Special thanks go to Gabri and Bart and, of course, to Désirée and Katja - my paranymphs - for their friendship that will surely last beyond this PhD project.

Und mit mir freuen sich Tammo, Hans-Gerd, Annemarie, Felix, Bea, Baby Gabby, Lutz, Kathrin, Theo, Jacqueline. Danke!

Berkeley, Ann-Kristin Zobel

October, 2013 


\section{BIOGRAPHICAL SKETCH}

Ann-Kristin Zobel was born April 14th 1987 in Herdecke, Germany. She received her Bachelor degree in 'International Business' at Maastricht University in 2008. During her studies she was a visiting undergraduate student at Simon Frasier University, Vancouver (Canada). She proceeded with her studies in 'Business Research' at Maastricht University and graduated with a M.Sc. (cum laude) in 2010.

Subsequently, she started her dissertation research at the Department of Organization and Strategy at the School of Business and Economics, Maastricht University. In 2012 she was a visiting doctorate researcher at the Institute of Business Innovation of the Haas School of Business, University of California, and Berkeley (USA).

She presented her doctoral research on various occasions, including the 2013 AOM Annual Meeting in Orlando (USA), the Innovation Seminar of the Haas School of Business at UC Berkeley (USA), the $2^{\text {nd }}$ Tilburg Conference on Innovation (The Netherlands), the National Science Foundation Engineering Globalization Workshop in Washington DC (USA), the PhD in Management Science Seminar 'Open Innovation \& Open Business Models' at ESADE in Barcelona (Spain), the PDMA-UIC Doctoral Consortium / Innovation Conference 2011 in Chicago (USA), the DRUIDDIME Academy Winter Conference 2011 in Aalborg (Denmark), and the KUL-UMADICE-ZEW PhD Workshop in Mannheim (Germany).

As of July 2013, Ann-Kristin works as a postdocorate researcher at the Institute for Business Innovation of the Haas School of Business, University of California, Berkeley. 